\title{
Trade, Development and Resilience: An Archaeology of Contemporary Livelihoods in Turkana, Northern Kenya
}

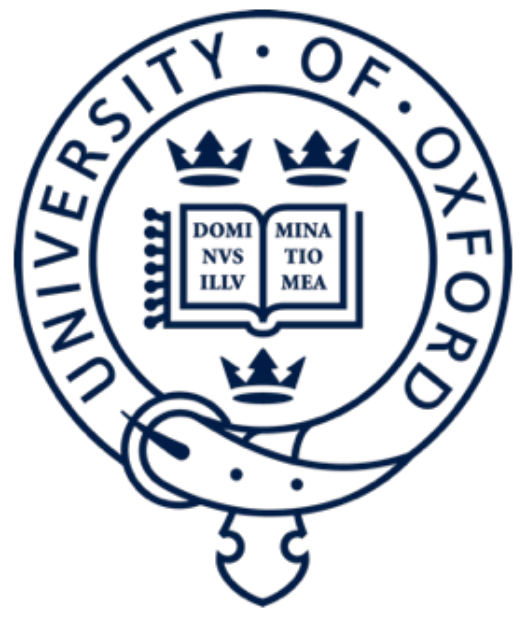

Samuel F. Derbyshire

The Queen's College

University of Oxford

A thesis submitted for the degree of

Doctor of Philosophy 


\begin{abstract}
The recent history of the Turkana of northern Kenya has rarely been explored in detail, a fact that corresponds with, and to a large extent facilitates, their regular portrayal in the popular press as passive, unchanging and therefore vulnerable in the face of ongoing and ensuing socio-economic transformations. Such visions of the Turkana and the region in which they live have, via their manifestation in the policies and practices of development-orientated interventions, actively inhibited (although never fully arrested) the fulfilment of various local desires and aspirations over the years. In addressing these topics, this thesis provides some hitherto largely unexplored and unrecognised historical context to the many socio-economic and political issues surrounding Turkana's ongoing development. It discusses interdisciplinary research which combined archaeological and ethnographic techniques and was undertaken amongst communities engaged in the most prominent livelihoods that have historically underlain the Turkana pastoral economy: fishing (akichem), cultivation (akitare), herding (akiyok) and raiding (aremor). In doing so, it draws attention to some of the ways in which these communities have actively and dynamically negotiated broad economic, environmental and political transformations over the last century and beyond, thereby providing a picture of social change and long-term continuity that might serve as a means for a more critical assessment of regional development over the coming years.
\end{abstract}

By weaving together a series of historical narratives that emerge from a consideration of the changing production, use and exchange of material culture, the thesis builds an understanding of Turkana's history that diverges from more standard, implicitly accepted notions of recent change in such regions of the world that envisage globalisation purely as a process of convergence or homogenisation. Its central argument, which it demonstrates using various examples, is that seemingly disruptive transformations in daily practices, social institutions, livelihoods and systems of livelihood interaction can be envisaged as articulations of longerterm continuities, emerging from a set of durable yet open-ended dispositions within Turkana society and culture. Moreover, rather than being built on a stable, passive repertoire of cultural knowledge, the thesis shows that this capacity for change is established upon a dynamic generative process where value systems and institutions are reconfigured to the same extent as daily practices and skills, as knowledge is continually reconstituted and recast in relation to the shifting constraints and possibilities of daily life. It thus characterises this process as a form of resilience that is deeply rooted in and determinant of the Turkana pastoral economy. 


\section{Acknowledgements}

My initial thanks must go to the government of Kenya, particularly the National Commission for Science Technology and Innovation, for granting me the permits necessary to carry out this research (NACOSTI/P/14/5212/833 and NACOSTI/P/16/5212/13492). I would also like to thank the numerous MCAs, chiefs and administrators in the Turkana County Government who supported and facilitated my fieldwork throughout 2014 and 2015. For my institutional affiliation, I would like to thank the National Museums of Kenya and the British Institute in Eastern Africa. The research behind this thesis was carried out with a grant from the Frederick Soddy Trust administered by the Royal Geographical Society, two grants from the British Institute in Eastern Africa and a grant from the Meyerstein Fund (Institute of Archaeology, University of Oxford). For all of these grants, and for the extensive time and stability they allowed me in the field, I am grateful.

I would also like to thank my supervisors, Peter Mitchell and Dan Hicks, both of whom have been indispensable to the formulation of this thesis over the past four years. I am greatly indebted to Peter Mitchell for his tireless reviews of my work, his indefatigable attention to detail and the advice, support and warmth he has so regularly provided. I am grateful to Dan Hicks for his unwavering faith in my research and for the many challenging and stimulating conversations I have had with him, both during my DPhil and my master's beforehand, it is from these conversations that I have drawn some of my most central interests and ideas. My sincerest thanks also to Chris Morton for his extensive commentary on various parts of this thesis in its early stages, and for his assistance and guidance regarding my use of the Pitt Rivers Museum photographic collections in the field. Likewise, thanks to Phillip Grover and Madeleine Ding for their support during my initial investigations of the Pitt Rivers' Turkanarelated photograph and object collections. Joost Fontein and all staff at the BIEA (past and present) have been extremely helpful over the course of this project, particularly by inviting me to participate in numerous workshops, seminars, exhibitions and other events, which have all allowed me to engage in critical conversations about my developing arguments and to explore new ideas. Joost Fontein's advice and insight have greatly shaped this thesis and my research interests more broadly, I am extremely thankful for them.

I am equally indebted to the staff at the Turkana Basin Institute for their assistance and professionalism over my many visits there, and to Richard and Meave Leakey for their encouragement, good humour and generosity both in Kenya and in New York. Thank you to Richard Ambani for his facilitation of my research in the Kenyan National Archives, and to Matt Davies, Michael Lokuruka, Fr James Good, Per Ditlef Fredriksen, Greg Akall, Neil Carrier, Robert Vigar, Neo Musangi and Nicky Boivin, whose perspectives and knowledge, shared freely, have had a substantial impact on this work. I would also like to thank John and Sam Arum, Daniel Nyamawi Ndegwa, Gabriel Mutunga Musyoka, Willie Mbithi and Fr Joseph Kengah, to whom I have turned for help on innumerable occasions over the last decade. I hope they know how much I appreciate them

I was never entitled to the information contained in these pages, and it is only through the patience and good nature of hundreds of interviewees and participants in Turkana that I have accrued it. It is not possible for me to thank all of these individuals by name but I owe them each a great deal of gratitude. It has been my great privilege to hear their stories and I hope I have done them justice here. For their kindness and regular counsel, I would like to thank Marko Ekeno, Francais Tangarae, Benjamin Epodo and Mosis Eriamun. Likewise, I am grateful to Assistant Chief Vincent Kamais and his family for the hospitality they so regularly 
showed me on my trips to Kerio. Above all, however, I would like to convey my sincerest gratitude to the Lowasa family of Nakurio, and particularly to Lucas, Emeri, Eliza, Aipa, Namoe, Ekitela, Eriamun, Lokwicha and Lokure. What each of you have taught me is impossible to repay. It should go without saying — but I do not think it can be said too often - that my deepest debt of all is owed to Lucas Lowasa, it is not possible to express the extent of my gratitude to him, for everything. Ejokanoi sana ikoku a apa kang.

Finally, I would like to thank my family - Kevin, Liz, Mark and Ellen — for the humour, the critical debate, the constant support and, above all, for the faith you have put in me for so long. Whilst my interests and ambitions have often led me far away, you have all remained with me. Suffice to say that the difficulties faced during the completion of this work, and throughout my research in eastern Africa more broadly, would have been entirely impossible to overcome without you all.To the Leakeys in Nakuru - Nigel, Janey, Harry and Elliot thank you for the warmth and gracious hospitality you have offered me so often over the past few years, and for the encouragement and inspiration I have drawn from you on so many occasions. To Acacia, who has contributed so much to this work and to my life in general, words could not articulate my immense appreciation for all that you have done, and for your confidence in me through thick and thin.

Whilst many have contributed to its formation, this thesis, and consequently any of its errors, are entirely my own work. 


\section{Contents}

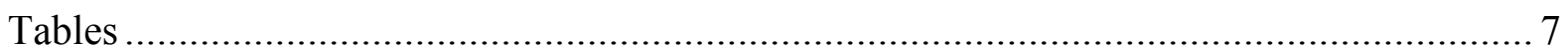

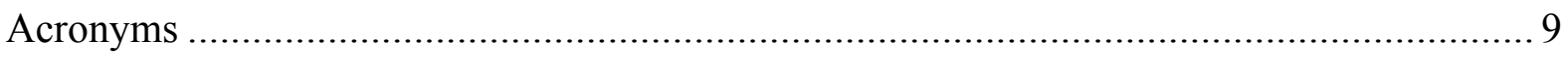

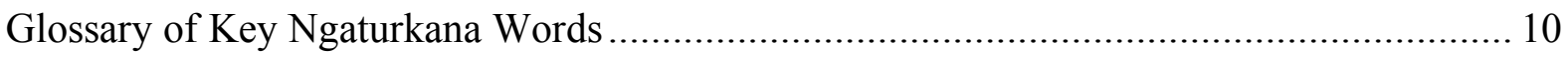

Chapter 1: Introduction and Theoretical Framework ............................................. 14

1.1. Time

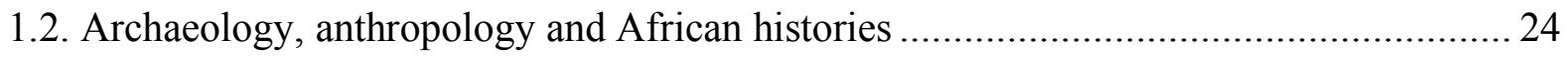

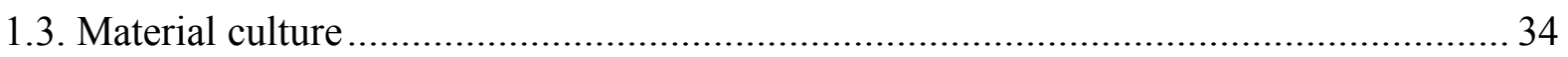

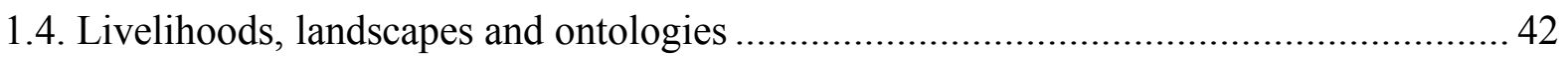

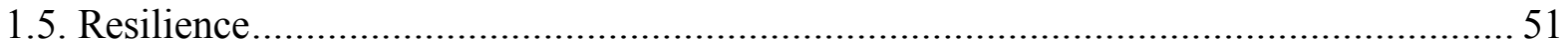

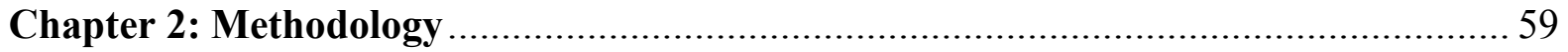

2.1. Participant observation, interviews, market inventories and archival research.............. 61

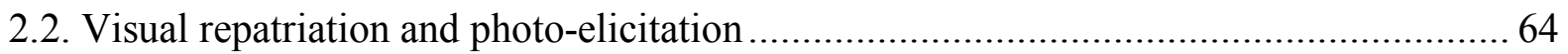

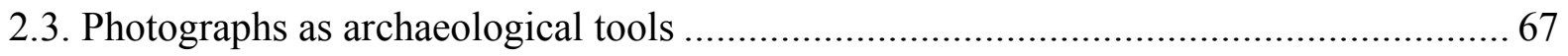

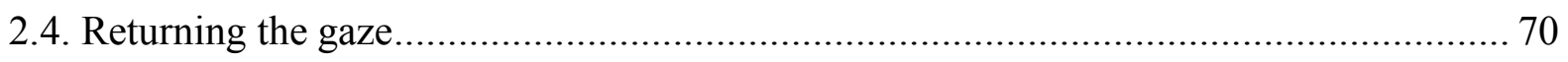

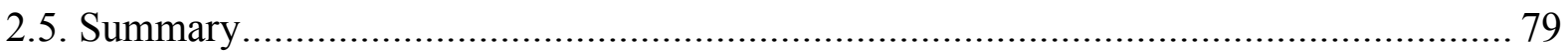

Chapter 3: Turkana in historical and ethnographic perspective ............................... 82

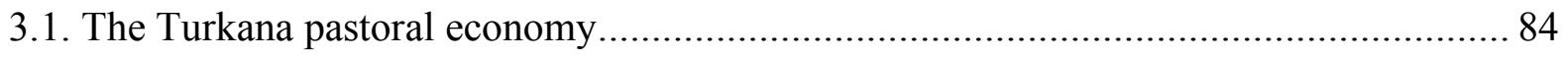

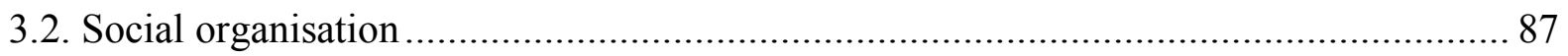

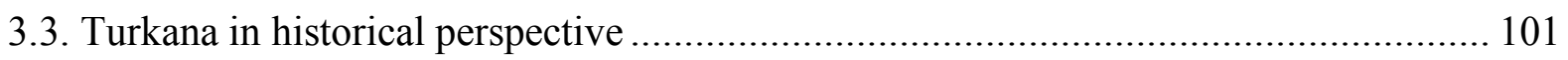

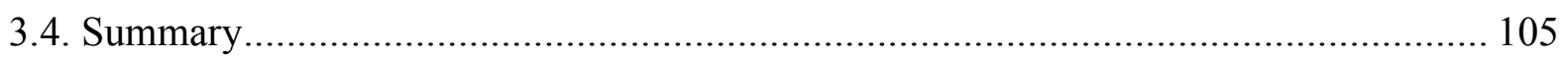

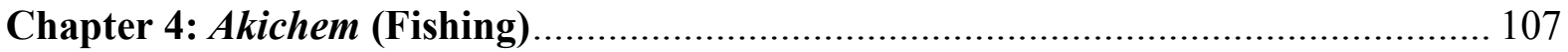

4.1. Introduction and overview of Turkana's fishing communities................................. 107

4.2. Hippopotamus hide shoes, colonial taxes and cotton blankets ................................ 116

4.3. Fishing nets, fibreglass boats and the NORAD scheme........................................ 127

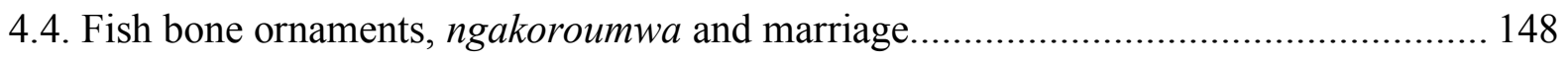

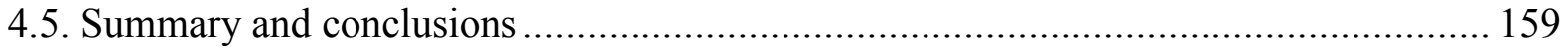

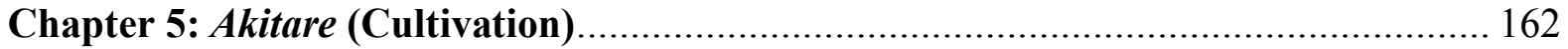

5.1. Introduction and overview of Turkana's cultivating communities .............................. 162 
5.2. The changing hydrology and ecology of the Kerio and the Turkwel

5.3. Mobility, seasonal exchange and atap: cultivation before Ekaru a Atchaka Ekipul (the Year of the Lost Padlock).

5.4. Cars, relief food and irrigation canals: the 1980-1982 famine and the Turkana

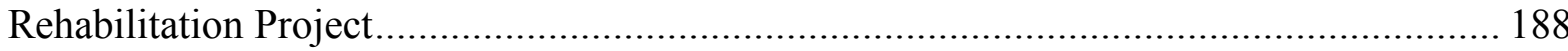

5.5. Sugar sacks, maize flour and the establishment of commercial markets .................... 199

5.6. Palm mats, charcoal and the changing nature of trade ............................................ 217

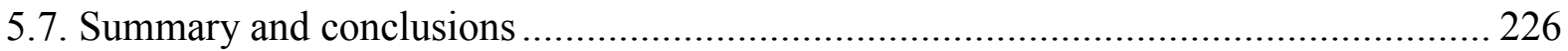

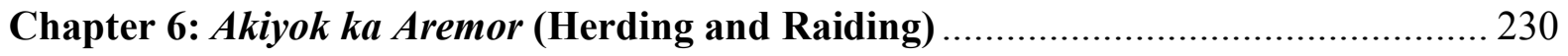

6.1. Introduction and overview of herding and raiding in Turkana ................................. 230

6.2. Livestock, divination and the era of the abuzibuzi headdress ................................... 237

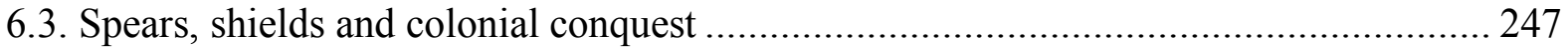

6.4 Guns, cloth ngapukoto and Ekaru a Ngatuk a Nakirionok (the Year of Black Cows) ... 259

6.5. Synthetic fibre hats, plastic spoons and ngoroko: herding and raiding in the years after

Ekaru Asur (the Fleeing Year)..................................................................................... 277

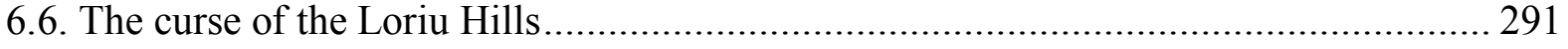

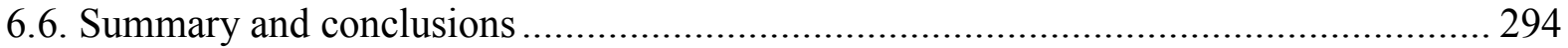

Chapter 7: Summary, Implications and Conclusions .............................................. 298

7.1. Aid, development and intervention in Turkana: past, present and future .................... 299

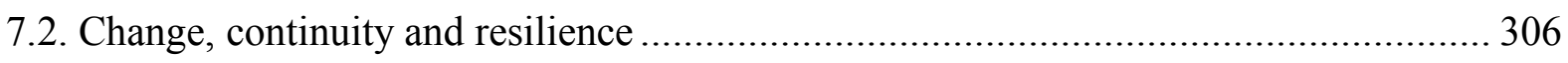

7.3. Methodological considerations and avenues for future research.............................. 311

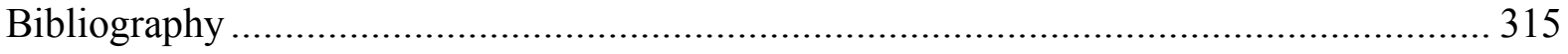

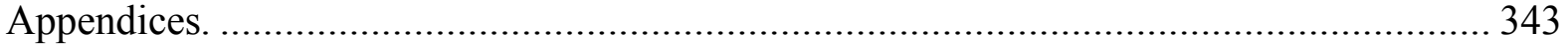

\section{Figures}

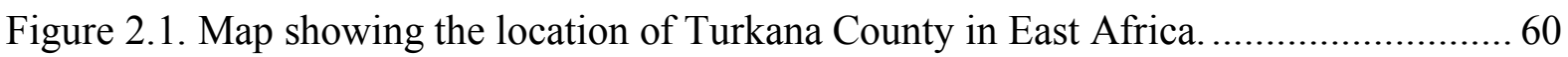

Figure 2.2. Photograph of two young Turkana women taken by Ernest Emley.................... 71

Figure 2.3. Photograph of a prominent leader and emuron (diviner/seer) taken by Wilfred

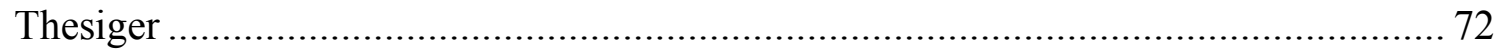

Figure 2.4. Emeri Lowasa discussing one of Thesiger's photographs................................ 76

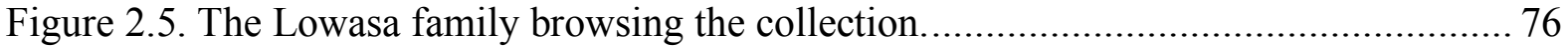




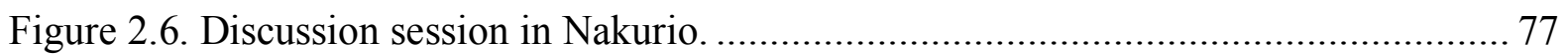

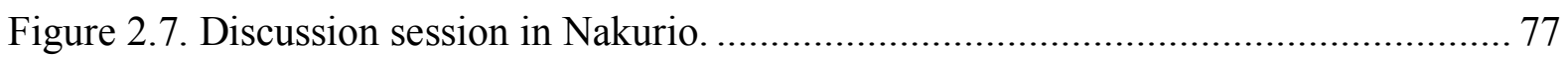

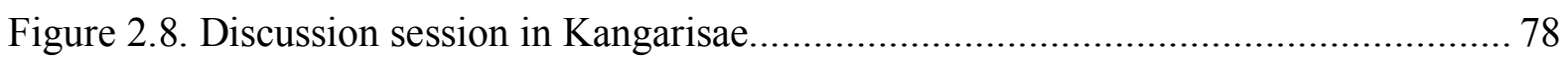

Figure 2.9. Discussion session in Nakoret on market day .............................................. 78

Figure 2.10. A man from Nakoret holds up a photograph of his grandfather. ...................... 81

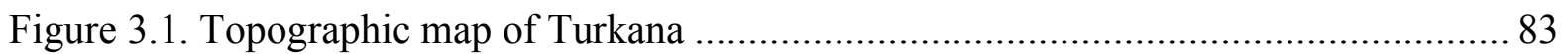

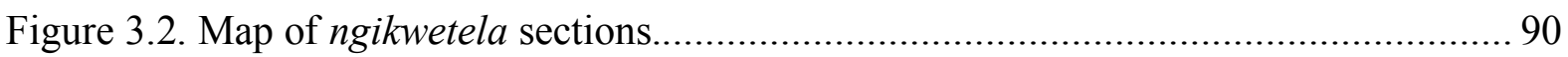

Figure 3.3. Diagram of the akiriket ritual feast. ......................................................... 100

Figure 4.1. Map of Lake Turkana showing key locations on the western shore................ 109

Figure 4.2. Map showing villages in which fieldwork was undertaken............................. 114

Figure 4.3. View of Merier — a typical Turkana fishing village................................... 115

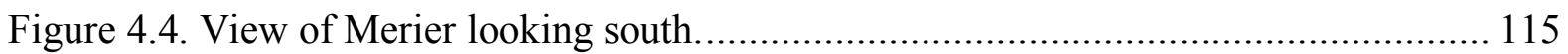

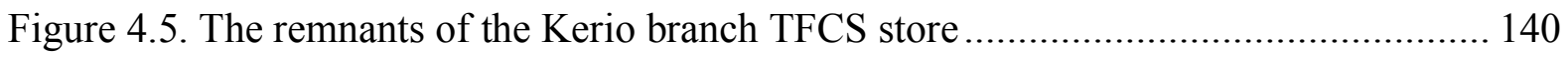

Figure 4.6. The remnants of the Kerio branch TFCS store........................................... 140

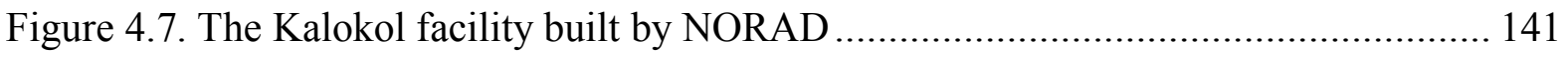

Figure 4.8. Internal main courtyard of the Kalokol facility.......................................... 141

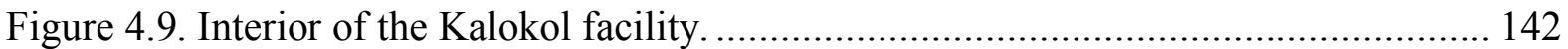

Figure 4.10. Industrial freezers inside the Kalokol facility ............................................ 142

Figure 4.11. Map illustrating the early animal skin trade ............................................. 145

Figure 4.12. Map illustrating the lake animal skin trade in the late colonial and early

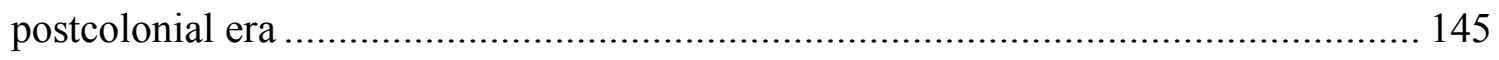

Figure 4.13. Map illustrating trade during the NORAD commercial fishing scheme.......... 146

Figure 4.14. Map illustrating the post-NORAD fish trade............................................. 146

Figure 4.15. Dried fish in Merier awaiting transportation to Kalokol............................... 147

Figure 4.16. A fibreglass boat in operation at Merier.................................................... 147

Figure 4.17. A woman in Nakoret wearing ngakoroumwa in a typical fashion.................. 151

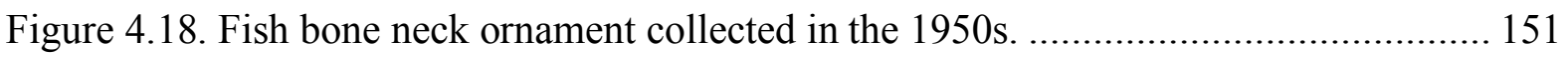

Figure 5.1. Map showing the locations of the villages in which research was undertaken and

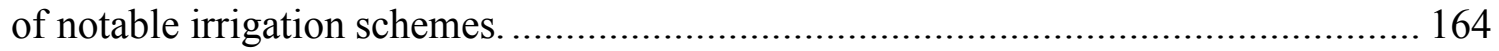

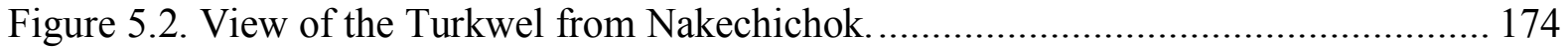

Figure 5.3. View of the Kerio's dry riverbed from Nakurio ............................................. 174 
Figure 5.4. The Turkana calendar.

Figure 5.5. View of the division between two cultivation plots on the bank of the Kerio near

to Nakurio.

Figure 5.6. A cleared cultivation plot on the Kerio.

Figure 5.7. Map showing the locations of the markets at which inventories were collected.209

Figure 5.8. View of a market day at Nakurio. 215

Figure 5.9. A market trader at Nakurio selling plastic bowls and other items. 215

Figure 5.10. Palm mats on sale at a market day in Nakurio. 216

Figure 5.11. A woman from a Kerio cultivating family posing in front of mats 216

Figure 5.12. Charcoal production in a riverside cultivation plot. 224

Figure 5.13. Charcoal mounds along the roadside in southern Turkana. 224

Figure 5.14. A lorry loading charcoal from the roadside 225

Figure 5.15. Sacks of charcoal propped up along the roadside awaiting sale. 225

Figure 6.1. Photograph taken by Thesiger of a young man wearing a typical apukot headdress. 246

Figure 6.2. Photograph taken by Thesiger of a young man applying his colleague's apukot headdress. 246

Figure 6.3. Turkana shield collected in 1928. 258

Figure 6.4. Nkumo Lodio displaying his cloth apukot 275

Figure 6.5. A woman wearing a ngimusio seed ornament amongst her ngakoroumwa. ...... 276 Figure 6.6. A man posing with his rifle 289

Figure 6.7. A man acting out a gun battle with a wooden staff at a wedding dance 289

Figure 6.8. A man wearing a synthetic fibre hat as an apukot as he leads a dance at a wedding ceremony. 290

Figure 6.9. Elders wearing a variety of hat styles as ngapukoto during an akiriket ritual feast at an asapan (initiation) ceremony..... 290

\section{Tables}

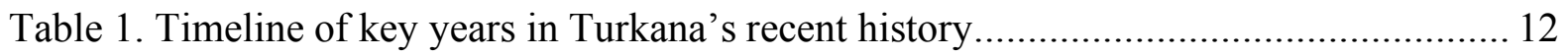

Table 3.1. Catalogue of ngimacharin with contextual information.................................... 93

Table 5.1. Major irrigation schemes undertaken in Turkana........................................... 189 
Table 5.2. Kerio market inventories, Dec 2014-March 2015 ........................................... 204

Table 5.3. Nakoret market inventories, January 2014-March 2015 ............................... 206

Table 5.4. Nakurio market inventories, Jan 2015-March 2015 ...................................... 208

Table 6.1. Timeline of the British conquest of Turkana. ............................................... 257 


\section{Acronyms}

$\begin{array}{ll}\text { AIC } & \text { Africa Inland Church } \\ \text { ASAL } & \text { Arid and Semi-Arid Land Program } \\ \text { DFID } & \text { Department for International Development } \\ \text { FAO } & \text { Food and Agriculture Organisation } \\ \text { MCA } & \text { Member of the County Assembly } \\ \text { MOA } & \text { Ministry of Agriculture } \\ \text { NGO } & \text { Non-Government Organisation } \\ \text { NORAD } & \text { Norwegian Agency for Development } \\ \text { ODI } & \text { Overseas Development Institute } \\ \text { OXFAM } & \text { Oxford Committee for Famine Relief } \\ \text { RCEA } & \text { Reformed Church of East Africa } \\ \text { TRDP } & \text { Turkana Rural Development Program } \\ \text { TRP } & \text { Turkana Rehabilitation Project } \\ \text { WCMD } & \text { Wildlife Conservation and Management Department } \\ \text { UN } & \text { United Nations } \\ \text { UNDP } & \text { United Nations Development Program } \\ \text { USAID } & \text { United States Agency for International Development }\end{array}$




\section{Glossary of Key Ngaturkana Words}

\begin{tabular}{|c|c|}
\hline Abarait (ngabara) & Circular wrist knife \\
\hline Aberu & Married woman \\
\hline Abuzibuzi & Headdress \\
\hline Adakar (plural ngidakarin) & Large settlement \\
\hline Agulu (plural ngagului) & Clay pot \\
\hline Akaluat & Animal skin worn on shoulders \\
\hline Akamu & Dry season \\
\hline Akichem & Fishing \\
\hline Akilam (ngilam) & Curse \\
\hline Akinyonyo & Initiation (female) \\
\hline Akiporo & Rainy season \\
\hline Akiriket & Ritual feast \\
\hline Akitare & Cultivation \\
\hline Akiyok & Herding \\
\hline Akaloboch (plural ngakalobocho) & Wooden spoon \\
\hline$A k u j$ & God \\
\hline Akurum (plural ngakuruma) & Milk gourd \\
\hline Akutom (plural ngakutoma) & Wooden and leather container \\
\hline Akutwa (plural ngakutwae) & Hoe \\
\hline Akwara (plural ngakwara) & Spear, harpoon \\
\hline Amukat (plural ngamuk) & Shoe \\
\hline Amurunot & Magic \\
\hline Apa & Father \\
\hline Apese & Unmarried girl \\
\hline Apukot (plural ngapukoto) & Headdress \\
\hline Aremor & Raiding \\
\hline Asapan & Initiation (males) \\
\hline Atap & Porridge \\
\hline Atubwa (plural ngatubwae) & Rectangular wooden bowl \\
\hline Aupwal (plural ngaupwala) & Shield \\
\hline$A w i$ & Homestead \\
\hline Awi apolon & Cluster of homesteads \\
\hline
\end{tabular}


Ebur (plural ngiburin)

Echwee (ngichweei)

Edengo

Ekaru

Ekichielong

Ekitela (plural nikwetela)

Elepit (ngilepito)

Eleu (plural ngileui)

Emachar (plural ngimacharin)

Emuron (plural ngimurok)

Epute (plural ngipute)

Erokode (plural ngirokode)

Etirae

Eturkan

Kotitan

Moru

Mumwa

Ngakoroumwa

Ngalaso

Ngigeche

Ngikebotok

Ngimoru

Ngimusio

Ngipen

Ngirisae

Ngitalio

Ngoroko
Wooden and leather container

Large goatskin bag

Leather waist cloth

Year

Wooden stool

Territorial section

Fresh milk container

Smoothed goatskin

Clan/ brand, spearhead

Diviner/seer

Conical basket fish trap

Woven palm line with hook

Prosopis juliflora

Turkanaland

Tax

Mountain

Sorghum

Neck ornamentation

Clan subdivision

Vertebrae

Those of have nothing/ those who have no animals

Those of the mountain (generation set)

Seed ornament

Ancestors

Those of the leopard (generation set)

Rituals

Dangerous raiders 
Table 1. Timeline of key years in Turkana's recent history roughly correlated with years in the Gregorian calendar. Where a date range is given in the left-hand column, the Turkana year fell at some point within the range rather than spanning it entirely.

\begin{tabular}{|c|c|c|}
\hline 1910-1915 & $\begin{array}{l}\text { Ekaru a Pumpum } \\
\text { 'The Year of Gunfire' }\end{array}$ & $\begin{array}{l}\text { A year characterised by British 'punitive } \\
\text { patrols', sweeping livestock confiscations } \\
\text { and regular gunfire. } \\
\text { pumpum - gunfire. }\end{array}$ \\
\hline 1950 & $\begin{array}{l}\text { Ekaru Epetapus } \\
\text { 'The Year of Mist' }\end{array}$ & $\begin{array}{l}\text { A year characterised by gentle calm rain that } \\
\text { persisted for a significant period of time and } \\
\text { created a lot of mist. } \\
\text { epetapus - mist. }\end{array}$ \\
\hline 1950-1960 & $\begin{array}{l}\text { Ekaru a lo Turdai } \\
\text { 'The Year of the Disease' }\end{array}$ & $\begin{array}{l}\text { A year characterised by a widespread } \\
\text { livestock disease, most probably rinderpest. } \\
\text { turdai — a livestock disease. }\end{array}$ \\
\hline 1960 & $\begin{array}{l}\text { Ekaru a Namotor } \\
\text { 'The Thin Year' }\end{array}$ & $\begin{array}{l}\text { A year characterised by widespread hunger } \\
\text { experienced by both people and livestock. } \\
\text { The summer of this year was termed } \\
\text { 'namotor' because of the scarcity of grass } \\
\text { and bush. } \\
\text { namotor - thin. }\end{array}$ \\
\hline 1960-1964 & $\begin{array}{l}\text { Ekaru a Ngatuk Nakirionok } \\
\text { 'The Year of Black Cows' }\end{array}$ & $\begin{array}{l}\text { A year characterised by the successful raid } \\
\text { of Borana livestock led by the warrior } \\
\text { Etangan. Etangan's raiding party brought an } \\
\text { abundance of livestock to Turkana from the } \\
\text { eastern side of Lake Turkana, many of these } \\
\text { livestock were black cows. } \\
\text { ngatuk - cows. } \\
\text { nakirionok - black. }\end{array}$ \\
\hline 1964 & $\begin{array}{l}\text { Ekaru Etop Ekosim } \\
\text { 'The Year of Star Tail' }\end{array}$ & $\begin{array}{l}\text { A year characterised by the occurrence of a } \\
\text { large shooting star which left a tail behind it } \\
\text { that stayed in the sky for several minutes. } \\
\text { etop - star. } \\
\text { ekosim - tail. }\end{array}$ \\
\hline 1965-1970 & $\begin{array}{l}\text { Ekaru a Atchaka Ekipul } \\
\text { 'The Year of the Lost Padlock' }\end{array}$ & $\begin{array}{l}\text { A year characterised by extremely heavy } \\
\text { rains which lasted without respite for four } \\
\text { days - it seemed as though the heavens had } \\
\text { 'lost their padlock'. This year is particularly } \\
\text { well remembered within riverside } \\
\text { cultivating communities as a substantial } \\
\text { flood ensued. }\end{array}$ \\
\hline
\end{tabular}


atchaka - lost.

ekipul — padlock.

1970

Ekaru Kaiu

A year characterised by an abundance of food for both livestock and people following

'The Saving Year' or 'The a time of drought and hunger.

Year of Being Saved'

kaiu - to save.

1971-1973 Ekaru ka ata Anayanae

'The Year of Ayanae'

A year characterised by the arrival of a nonTurkana, possibly non-human, woman known as Ayanae, who travelled alone through several villages before departing forever.

$1973 \quad$ Ekaru a Aribokin (1) A year characterised by a solar eclipse.

'The Year of the Solar Eclipse'

$1974 \quad$ Ekaru a Aribokin (2) A year characterised by another solar eclipse, unlike the one in the previous year

'The Year of the Solar Eclipse' this one was preceded by a substantial earthquake.

\begin{tabular}{|c|c|c|}
\hline 1981 & $\begin{array}{l}\text { Ekaru Asur } \\
\text { 'The Fleeing Year' or 'The } \\
\text { Year of Fleeing' }\end{array}$ & $\begin{array}{l}\text { A year characterised by a mass northward } \\
\text { migration of people escaping heavy raiding } \\
\text { from the Pokot in the south. } \\
\text { asur - escape or flee. }\end{array}$ \\
\hline 1987 & $\begin{array}{l}\text { Ekaru a Nawokodou } \\
\text { 'The Year of Clouds' }\end{array}$ & $\begin{array}{l}\text { A year characterised by the regular } \\
\text { manifestation of clouds and yet little rain. } \\
e d u \text { - cloud. }\end{array}$ \\
\hline 1990-1995 & $\begin{array}{l}\text { Ekaru a Eumbi } \\
\text { 'The Year of Millet' }\end{array}$ & $\begin{array}{l}\text { A year characterised by the widespread } \\
\text { arrival of millet, which was distributed by a } \\
\text { range of government and non-government } \\
\text { organisations. Prior to this time, millet had } \\
\text { not widely been eaten in Turkana } \\
\text { eumbi - millet. }\end{array}$ \\
\hline $2000-2001$ & $\begin{array}{l}\text { Ekaru a Lomoo } \\
\text { 'The Year of Bowed Heads/ } \\
\text { Writhing' }\end{array}$ & $\begin{array}{l}\text { A year characterised by a widespread } \\
\text { infectious livestock disease that caused } \\
\text { animals to bow their heads and curl up. } \\
\text { lomoo - to bow one's head/ writhe. }\end{array}$ \\
\hline
\end{tabular}




\section{Chapter 1: Introduction and Theoretical Framework}

Pastoralist peoples have, throughout recent history, been some of the most socially, politically and economically marginalised communities on the African continent (Spencer 1983; Galaty and Bonte 1991; Doornbos 1993; Hughes 2006), and indeed have faced similar obstacles across the globe (Ying et al. 2002; Gooch 2009; Nusrat 2011; Ojeda et al. 2012). The Turkana people of northern Kenya are no exception, and can trace many of the contemporary challenges that they face back through a long history of state violence, neglect and political exclusion spanning both colonial and postcolonial times. What is perhaps even more troubling than this though is their associated persistent portrayal, both within eastern Africa and the wider world, as an ahistorical or primordial society - 'the last vestiges of a bygone era that will not survive the next one or two generations' (McCabe 2004: 3). Such essentialist views are not merely an unfortunate echo of Turkana's fraught past. Rather, they articulate an enduring inadequately nuanced understanding of Turkana culture, society and history that, via its manifestation in the policies and practices of various developmentorientated interventions, has actively inhibited, although never fully arrested, the fulfilment of various local desires and aspirations.

This is troubling enough in its own right. However, it presents itself as a particularly pressing issue when one considers the recent discovery (in 2012) and ongoing exploration of major oil reserves in the Lokichar Basin, southern Turkana - Kenya's first significant oil discovery (see Agade 2014; Johannes et al. 2015). The homeland of one of East Africa's most marginalised populations - one of Kenya's poorest and most under-developed regions — is now poised to become a momentous new East African oil-producing province and a critical economic pillar within Kenya's unfolding future. On top of this, Lake Turkana, Kenya's 
largest lake and a crucial resource within numerous mixed pastoral economies (including that of the Turkana), has recently come under significant threat from the newly constructed Gibe III hydroelectric dam and associated sugarcane plantations on southern Ethiopia's Omo River. The Omo River alone provides roughly $90 \%$ of Lake Turkana's inflow and, whilst predictions regarding the long-term impacts of Gibe III vary, it seems likely that in the ensuing years the lake will undergo a significant reduction in its water levels and a rapid deterioration of its fisheries and general biodiversity (Avery 2012; Velpuri and Senay 2012; Carr 2017). Large-scale socio-economic and environmental transformation is thus irrevocably on the agenda even if the manner in which it will be enacted and mediated over the long term, by the numerous policy makers and organisations involved, remains undefined. It is, of course, susceptible to the influence of prevalent misunderstandings regarding the dynamism of Turkana society and culture, but is also open (perhaps now more than ever before) to local participation, community action and regional leadership.

The aim of this thesis is not to explore the many socio-economic and political issues surrounding Turkana's ongoing development. Rather, it seeks to provide some hitherto largely unexplored and unrecognised historical context to it. I aim to draw attention to some of the ways in which Turkana communities have negotiated broad economic, environmental and political transformations over the recent past and to provide a picture of social change and long-term continuity that might serve as a means for a more critical assessment of regional development over the coming years. In so doing I focus on the most prominent livelihoods that have historically underlain the Turkana pastoral economy: fishing (akichem), cultivating (akitare) and herding/raiding (akiyok ka aremor) - Chapters 4, 5 and 6 respectively. I explore the histories of these livelihoods amongst a selection of communities 
in southern Turkana, building up narratives that extend over the last century and into the present day.

My central argument is that each of the socio-ecological systems that encompass these diverse strategies of subsistence procurement has, throughout recent history, developed by means of an inherent adaptiveness and ingenuity that has allowed it to be continually reworked and reconfigured in relation to a shifting array of socio-economic, environmental and political factors. Various recent works have challenged the often-implicitly held notion that East Africa was, prior to and during the colonial period, a periphery where broad social change was predominantly derived from external metropolitan centres and encountered only passively (Prestholdt 2004, 2008; Pallaver 2008; Desai 2010; Lane 2010). I build on these works to argue that both during and after the colonial period determinative socio-economic changes in Turkana have been actively community-led and crafted by means of gradually accumulating local knowledge and experience. I demonstrate, using various examples, that seemingly disruptive transformations in daily practices, social institutions, livelihoods and systems of livelihood interaction can be envisaged as articulations of longer-term continuities, emerging from a set of durable yet open-ended dispositions within Turkana society and culture. Rather than being built on a stable, passive repertoire of cultural knowledge, I show that this capacity for change is established upon a dynamic generative process where value systems and institutions are reconfigured to the same extent as daily practices and skills, as knowledge is continually reconstituted and recast in relation to changing daily needs and aspirations. I characterise this process as a form of resilience that is deeply rooted in and determinant of the Turkana pastoral economy. 
In explicating this argument, my approach is both conceptually and methodologically interdisciplinary. I draw most prominently on data collected over fourteen months of ethnographic fieldwork undertaken between 2014 and 2015, and several shorter visits to southern Turkana undertaken either side of this stretch (in 2012, 2013 and 2016). I also utilise information collected during in-depth archival research in both the British and Kenyan national archives. My fieldwork, whilst clearly anthropological in nature, was framed by a distinctly archaeological interest in the correlation between material culture change and broader societal transformations over the longue durée.

Much like my focus on livelihoods, my interest in material culture was by reason of its close implication in grounded daily practices and its propensity for revealing narratives of change that are rooted in the more quotidian side of life (Deetz 1977; Schiffer 1991; Schmidt and Walz 2007). This material culture-centeredness manifested itself in my fieldwork largely by means of the visual repatriation of materials collected in Turkana by various individuals over the last century and stored in the Pitt Rivers Museum, Oxford. Prints of historical photographs, along with my own photographs of items from the museum's ethnographic object collections, framed many of my interviews and focus groups, serving to embed discussions in the changing production, use and exchange of everyday objects. In demonstrating this approach, a subplot to this thesis' primary agenda is to contribute methodologically to the growing number of archaeological studies that have engaged with very recent African histories (e.g. Stahl 2001; González-Ruibal 2006, 2013; González-Ruibal et al. 2008; Giblin 2012, 2014; Davies et al. 2014; King et al. 2014; Davies and Moore 2016). 
In this first chapter, I outline the key theoretical issues with which my analysis engages and summarise the major bodies of literature that underpin my argument. In doing so, I begin by considering Turkana's complex relationship with time, and examine both the causes and consequences of a prevailing disregard for the history of its contemporary population. I then discuss anthropological and archaeological approaches to African histories, situating my investigation amidst post-structuralist anthropological approaches to history and postcolonial African archaeologies. Moving on, I explore critical concepts in material culture studies, in relation to which I sketch out my own conceptualisation of material culture change in Turkana and its entanglement in continually transforming social institutions and practices. I then set out the theoretical rationale behind my focus on Turkana livelihoods, tracing its connections with studies of landscape and the ontological turn in anthropology. I conclude by outlining in detail my understanding of the concept of resilience and distinguishing this from other approaches to the study of resilience in the social and environmental sciences.

\subsection{Time}

Turkana's international renown as the location of some of the oldest human fossils ever discovered (Leakey and Lewin 1979; Wood and Leakey 2011), and more recently the oldest known stone tools (Harmand et al. 2015), stands in stark contrast to the pervasive indifference and disregard with which its more recent history is habitually addressed. I do not disagree that a strong case can be made for the economic and political advantages that might be wrought by local communities through the enduring prominence of Turkana's deeper history, and the general emphasis that is placed on the region's significance as an origin point for all human life. However, the local benefits of this dominant and overarching past have 
arguably so far paled in comparison to the roles it has played in obscuring the history and heritage of the region's contemporary population.

Whilst the general obfuscation of this more recent past is without doubt negative in its own right (in terms of academic understandings of Turkana history), even more troubling are its social, economic and political ramifications. Turkana's prominent place at the beginning of a globally orientated story of human evolution and expansion (a story that evokes a sense of belonging in many foreign visitors to the region) seems to have coalesced with a range of tendencies and proclivities in broader understandings of rural, non-industrialised (and particularly pastoralist) African societies. These co-functioning circumstances have served to silence local accounts of time and change, in many cases suppressing the claims of autochthony and belonging that they articulate and the visions of the unfolding future that they disclose.

The fraught relationship between Turkana's deep past and the history of its contemporary population is symptomatic of an even more fundamental tension between the different forms of time that are currently at play within its boundaries. Indeed, the dichotomy of measured time vs. experienced time, what Gosden (1994: 2) refers to as 'a basic antinomy in views of time', seems particularly implacable in Turkana. In many ways the former, the abstract time of sequence and chronology encapsulated by archaeology's 'totalizing narrative' (Lucas 2005: 14), serves to engulf the experiential time of its contemporary population. The particular ways of structuring past, present and future that both inhere in and arise from Turkana communities' involvement with the world around them are more readily circumvented in the shadow of the abstract chronological calendar manufactured by palaeoanthropological and archaeological research. An ostensibly 'traditional' present is 
more easily assimilated with an unchanging past (a stage in Turkana's measured chronology) than it is explained as a product of its own time and history (Stahl 2001). This is certainly the case with representations that arise in the popular press (McCabe 2004) — the visual and rhetorical tropes that beleaguer East African pastoralist communities (Lane 2015) seem particularly dogmatic and incontestable in Turkana.

One key objective of this thesis, therefore, is to pay attention to the forms and qualities of time that emerge from Turkana ways of being in and interacting with the world, and to consider how these might serve to disrupt and challenge abiding visions of historical change in rural African societies. In so doing it draws greatly on phenomenological concepts of time, which have, building on Durkheim's (1915: 11) basic premise of 'social time', sought to examine time's subjectivity and its recursive relationship with society. Husserl's (1964) model of internal time-consciousness, which stands at the root of phenomenological approaches to time in the $20^{\text {th }}$ century, envisioned consciousness as being inherently directed by intention. He argued that time was actively shaped by intention through a process of retention and protention (which he called zeitigung) and that this process of construction was continually ongoing and continually changing rather than simply being comprised of replacement or repetition (Gell 1992). As Morton (2002: 23) outlines, Husserl explicated a 'dynamic rather than a linear notion of causality'. Whilst Husserl's arguments were critical in numerous ways, it was Heidegger who developed them beyond a concentration on perception to explore time as a bodily involvement with the world rather than simply as a mental construct. Heidegger's $(1962,1971,1977)$ concept of dasein ('being there') rooted human knowledge in everyday practice and explored it as something that was 'developed primarily in the process of coping with everyday life' (Gosden 1994: 113). 
Heidegger's turn to practice and his interest in ontological rather than simply epistemological questions (Dreyfus 1991) have been foundational to numerous subsequent accounts of time and temporality, including Ingold's (2000) landscape-based understanding of the human temporal relationship with the physical world and Bourdieu's (1977) practice theory, both of which are important to this thesis as I discuss further on. On a basic level, though, one key question that arises from considering the relationship between practice and time in Turkana is how the temporalities of Turkana livelihoods interact with those that structure the world of development planning and practice. Indeed, development schemes ranging in focus from riverside irrigation to commercial fishing have been influential throughout the last half century in Turkana; they are therefore unavoidably central themes of discussion in this thesis (particularly in Chapters 4 and 5). In considering these past interventions, I suggest that their regular and catastrophic failures can, in large part, be tied to the unwillingness of development planners to acknowledge the temporalities of the livelihoods in which their schemes were situated. Such failures have, however, rarely been conclusive. On numerous occasions the physical residues of development projects have been incorporated into daily life by surrounding communities following their collapse, materials and equipment have often ended up taking part in processes and trajectories of change that were ongoing prior to their initial arrival (Derbyshire and Lowasa forthcoming).

In exploring these stories of assimilation and reconfiguration, this thesis uncovers a temporal relationship that underlies and contradicts the abovementioned inequity between Turkana's measured and experiential time. In many ways, the various large-scale development schemes that have punctuated Turkana's recent past have encompassed and represented the kinds of prevalent ideas that monopolise accounts of the region in the mass media, implicitly envisioning the Turkana as an atemporal or ahistorical people. Indeed, African development 
interventions in general have often been shown to rest on profound misconceptions of local socio-ecological systems, assuming from the outset that they are static and passive rather than dynamic, fluid and adaptive (Kipkorir 1983; Adams and Grove 1984; Adams and Anderson 1988; Ferguson 1994a; Davies et al. 2014; Lane 2015; Davies and Moore 2016). Yet, the use of time on which such assumptions hinge is regularly disrupted in Turkana. Rather than engulfing and suppressing local temporalities, development schemes have routinely been absorbed into them. The material residues of these interventions have come to feature in locally constituted accounts of time and history that directly contradict the imaginaries in which they were initially rooted and the timescales that they once articulated.

This idea is further illuminated by considering Gosden's (1994: 137) account of 'habitual' vs. 'public' time. The former, which draws parallels with Bourdieu's (1977) habitus, emanates from the long-term swathes of unconscious recursive change that comprise community life, whereas the latter entails the conscious manipulation of both practice and time and the invocation of broader narratives. These forms of time are entangled with each other in complex ways and are mutually informative through their co-manifestation in the moment of bodily performance, which itself is therefore the 'conjuncture of structure and agency' (Robb 2002: 154). In considering the arenas of public time that once organised activities at the famine camps, irrigation schemes and fish-processing facilities discussed in this thesis, one cannot help but identify a deeply problematic manipulation of daily life and the routine exertion of power through the deployment of particular social and political narratives. However, it is also clear more broadly that these formal programmes did not ultimately encompass the destruction or disintegration of the ongoing processes of recursive transformation articulated in the daily practices of their participant communities. To the contrary, public times came to be interrupted and reshaped (often following the withdrawal of 
finances and personnel) by means of these pre-existing manners and processes of change the habitual times of participating communities. As Gosden (1994: 130) points out, 'the clash between habit and public time can... change the nature of habit, but it can also bring the structure of public time into question'.

Either way, it seems clear that the politics of time in Turkana do not only play out in the region's representation to, and conceptualisation in, external populations. The silences and mentions that arise from the production of (largely unhistorical and temporally skewed) information, ranging from development planning reports to news articles and advertisements, have recurrently crafted approaches to Turkana's infrastructural and economic development over the years. Moreover, whilst development-orientated organisations in Turkana and throughout Africa have more recently begun to emphasise the value of 'indigenous knowledge' and 'participatory' schemes (Brokensha et al. 1980; Bicker et al. 2004; Sillitoe 2007), these approaches continue to rest on notions of indigenous knowledge as an anchored product of inert practices and livelihoods, or at best very limited and passive social change. Projects are (perhaps largely as a consequence of these assumptions) usually neither designed nor implemented by participating communities (cf. Davies 2008; Lane 2015). In this sense, the enduringly 'high-modernist' (Scott 1998; cf. Fontein 2015) and technocratic form of development in Africa in general, and the roles it continues to play in stifling the political agency and identities of non-industrialised peoples (Abbink 2012), appear to be closely interwoven with time's capacity to serve as a 'medium of hierarchic power and governance' (Munn 1992: 109; see also Foucault 1979; Anderson 1983; Comaroff 1991; Lansing 1991).

Such a characterisation would certainly be applicable to ongoing oil exploration and extraction activities in Turkana, which I discuss in more detail in Chapter 7. However, it is 
also significant to point out that the rhetoric surrounding the responses to these activities by various international organisations, advocacy groups and activists is equally fraught. ${ }^{1}$ Oil company and charity alike invoke similar images of Turkana as a realm of perpetual stasis and equilibrium, inherently at risk of being impacted by the outside world. In doing so, they acquiesce in the view that the future must either entail inevitable and comprehensive disjuncture and the erosion of past ways of life, or the active protection of these ways of life from outside influence. In this sense, whilst their objectives and projections may diverge, both seem rooted in similar notions of 'pessimism and loss', which Moore (2011: 5) considers to be chief amongst the various presuppositions currently adhering to the idea of globalisation. They are both reactions to an enduring understanding of globalisation as an inherently culturally destructive and homogenising process, an understanding that is most concerning in its proscription of any counter-narratives that might foresee entirely different futures.

\subsection{Archaeology, anthropology and African histories}

Engaging with Turkana notions of time and change, and exploring the historical narratives that emerge from them, is not a straightforward task from any disciplinary perspective. Indeed, many have pointed to the roles that the histories of both archaeology and anthropology continue to play in shaping intellectual inquiry today. Numerous authors have addressed the lingering epistemological repercussions, within both disciplines, of colonialism and early theories of progressive social evolution. These have manifested themselves in a range of contexts, from uses of time and analogy (Gould and Watson 1982; Wylie 1982; Fabian 1983; Gosden 1999) to predispositions in the demarcation and delimitation of units

\footnotetext{
${ }^{1}$ www.internationalrivers.org; www.survivalinternational.org.
} 
chosen for study (Stahl 2001; Ardener 2007). Moreover, many authors have also pointed to the inherently preclusive nature of empirical theories of time, history and change rooted in Western philosophy and orientated toward Western perspectives (Mudimbe 1988; Gosden 2001; Reid and Lane 2004; Schmidt and Walz 2007; Lane 2011; Gosden 2012; Nyamnjoh 2012; Wynne-Jones and Fleisher 2015). 'Refracted visions of Africa's past' (Stahl 2001: 1) generate distorted images of its contemporary peoples. With specific reference to research on pastoralist societies, Galaty and Bonte (1991: 4) have highlighted the role that scholarship has played in sustaining common misconceptions by failing to disentangle itself from generalisations that constitute a 'romantically archaic pastiche' and continuing to describe African pastoralists 'in univocal terms, not so much wrong as inadequately nuanced'.

The methodological and conceptual approaches of this thesis, and its ensuing interpretations of Turkana society and culture past and present, must all be recognised as at least partly crafted by the disciplinary histories of both anthropology and archaeology. This is more selfevident in some facets of the work than in others. However, whilst recognising its inherent limitations, one of my major objectives is nevertheless to offer some interpretative development beyond the picture so far rendered by previous more synchronic and general accounts of the Turkana pastoral economy, many of which correspond with Galaty and Bonte's (1991: 4) description. In doing so, my argument converges with a distinctly poststructuralist anthropological interest in the processes and ramifications of capitalist expansion and globalisation (Stahl 2001), which has culminated in the production of ethnographic works that have focused in on dynamic local-level negotiations of change emanating from global processes (e.g. Moore 1986, 2011; Wilmsen 1989; Ortner 1990; Wolf 1994; Catley et al. 2013; Galaty 2013). 
These approaches have been deeply influential in the formulation of this thesis because of their critique and interrogation of the abovementioned prevalent ideas regarding the local effects of globalisation, i.e. its often-presumed correlation with cultural erosion and loss. I draw greatly on their emphases on political economies and their movement away from conceptualisations of recent socio-cultural change in non-industrialised African populations as entirely externally derived (rather than community-driven) and inherently disruptive. Indeed, it is with the aim of following suit that the central discussions - Chapters 4,5 and 6 - examine various recent and ongoing social and economic transformations (such as largescale development interventions, the rise of commercial markets and conflict-related constrictions in cross-border mobility) within longer-term livelihood histories. They thus outline some of the ways in which large-scale transformations have been co-opted and domesticated in Turkana through local value-systems, practices and skill-sets, serving as a means for re-articulating and re-configuring these elements via new material and social possibilities rather than their outright disintegration.

However, the diachronic approach to livelihoods and systems of livelihood interaction outlined here is not envisioned purely as a way of re-contextualising contemporary movements, practices and social interactions by generating a more detailed account of the past. Rather, it seeks to pay attention to the particular ways in which Turkana communities creatively interact with and use their pasts (as comprised by accumulated knowledge and experience of landscapes, places and objects) to organise daily life and respond to shifting economic, political and environmental factors. As I outlined above, this necessitates a consideration of Turkana notions of time and causality, the ontologies through which pasts are imagined, and the ways in which local historical arguments and theories of change have structured daily activities previously, and continue to do so in the present day. 
It is with the intention of pursuing these questions that the historical narratives I outline in Chapters 4, 5 and 6 are not explicitly organised around the numbered years of the Gregorian calendar, but rather in terms of sequences of key regionally specific past events (see Table 1). ${ }^{2}$ Always preceded with the prefix Ekaru a (the year of), such events (which range from successful raids of neighbouring groups to periods of heavy rainfall) are commonly used in Turkana to label calendrical years that occurred within living memory and, more rarely, also appear in oral histories passed down from previous generations. Sequences of events interweave and imbricate between different livelihoods, villages and regions, and constitute the meshwork upon which both personal biographies and community histories are draped. These biographies and histories are also entangled with and conceptualised through other cyclical notions of time, such as the cultivation cycle I describe in Chapter 5 (cf. EvansPritchard 1939; Shanks and Tilley 1987; Dietler and Herbich 1993; Davies and Moore 2016). This process of relating numerous different timescales is not merely a component of telling stories about the past and narrating history (although it is integral to these activities, as is clear from the numerous interview extracts I consider), but also both emerges through and organises everyday livelihood practices in Turkana, the 'taskscape' according to Ingold (2000: 189), which I discuss in more detail below.

In its concern for exploring the longer-term patterns of change and continuity articulated through and constituted by daily social interactions and practices, this thesis also builds on recent developments in postcolonial historical African archaeologies, which have moved away from previous implicitly made correlations between history and European encounter or

\footnotetext{
${ }^{2}$ These past events are roughly correlated with Gregorian calendar dates throughout for the sake of clarity. Attaining these correlations was the result of many months of clarification and comparison in Turkana, using birth dates and events of national significance as key benchmarks.
} 
occupation (and thus textual records). Many archaeologists dealing with African pasts have come to approach history instead as a kind of community memory, transmitted across generations in numerous conscious and unconscious ways (e.g. Lane 2004; Pikirayi 2004; Schmidt and Walz 2007; Schmidt 2009; Straight et al. 2016). Postcolonial approaches to African archaeology have, to a large extent, developed alongside historical approaches in African studies that have reacted to previous debates about the colonial 'invention' of African traditions and ethnicities (Hobsbawm and Ranger 1983; cf. Spear 2003; Nugent 2008), turning with renewed interest to precolonial and oral histories (Fontein 2015). Indeed, Fontein (2015: 7) perceives a 'remarkable consensus about the need to refocus attention on precolonial African histories, and the enduring social, cultural and political continuities through which the ruptures of colonialism and postcolonialism gain traction and make sense' (cf. Fontein 2017).

Like Fontein, I consider this interest in moving beyond accounts of the past that are organised primarily around ruptures and discontinuities to unveil longer-term strands of continuity to currently be one of the most significant of the many common grounds between the archaeology, anthropology and history of Africa. It is certainly one of the major connecting themes that underpins this thesis, most prominently, perhaps, in Chapter 6 where I explore the changing dynamics of herding and raiding (akiyok ka aremor) from the precolonial establishment of Eturkan (Turkanaland), through colonial conquest and government and into the post-independence years of automatic weapons and commercial cross-border livestock trading.

Moreover, I would argue that archaeology's predilection for quotidian artefacts — 'the materialities of everyday life' (Schmidt and Walz 2007: 142) and the 'small things forgotten' 
(Deetz 1977) — renders it uniquely applicable to such an endeavour. Indeed, its methodological and theoretical facility for exploring social life and historical change through everyday things imbues it with a distinctive capacity for generating multi-vocal and heterogeneous accounts of the past that can effectively contravene, or at least recast and reassess, colonial-era texts (cf. Gosden and Knowles 2001; Harrison and Williamson 2004). This was certainly one of the central ideas behind the visual repatriation of photographic and other archival sources from the Pitt Rivers Museum that underpinned much of my fieldwork. Whilst I discuss these methods in more detail in Chapter 2 (along with their correlation with visual anthropology), it is worth noting that my use of gradually accumulated museum archives in Turkana (in photographic form) was motivated in large part by archaeological approaches to the lived past that have specifically focused on material culture change as a means of drawing out both broader and more personal historical narratives.

Perhaps the most noteworthy of such approaches is Schiffer's (1991) exploration of the portable radio in American life throughout the $20^{\text {th }}$ century, which embeds a rich chronicle of everyday life in their many changing facets, from production to form and function. Of equal significance, however, are biographical approaches to objects (Appadurai 1986; Kopytoff 1986; Gosden and Marshall 1999; Thomas 1999) that have unveiled numerous avenues of inquiry through the idea that objects might be understood to either have, articulate/perform or correspond with biographies. In a straightforward sense, these kinds of archaeologically informed material culture analyses seem to harbour significant and hitherto largely untapped potential for research in Africa, particularly for those seeking to engage with remembered histories in regions where contemporary populations have had a materially ephemeral impact on the landscapes in which they dwell and yet a substantial impact on various object and photographic archives worldwide. 
It must, of course, be both conceded and emphasised that collections of ethnographic photographs and other objects are often products of colonial and Western visions of rural/small-scale African societies as much as they are avenues into the pasts of such peoples. Indeed, this has made them useful foci for analyses of the colonial societies, cultures and collectors behind their amalgamation in museums (e.g. Edwards 2001, 2010; Gosden and Knowles 2001). However, whilst I do not refute the influence and significance of the changing social context behind its consolidation, my use of the Pitt Rivers Museum collection was not primarily concerned with exploring the colonial visions of Turkana or Africa that it embodies. I was not concerned with reading the history it contained, so to speak, but rather with using it as a tool in the field (in the form of prints of historical photographs and photographs of historical objects) to unlock new ways of talking and thinking about the past and elicit memories and stories (not necessarily tied to individual photographs) of everyday change that would otherwise be extremely difficult to ascertain.

As I describe in Chapter 2, the collection facilitated this in two key ways. Firstly, and perhaps most obviously, it did so through its multi-temporal nature and its encapsulation of broad socio-economic, political and environmental changes over the last century or so. Of equal importance, however, was the 'rawness' and ambiguity of the photographs (Edwards 2001), their openness to being inserted into and used to tell numerous versions of the past in a range of diverse settings and in relation to many different themes. I consider this use of object and photographic collections as archaeological tools to elicit and record new historical narratives in Africa to be a particularly successful means of disrupting and subverting the enduring legacies of the colonial gaze that they outwardly represent. In a straightforward sense, returning gradually accumulated collections (in one form or another) to places, like Turkana, 
that continue to be implicitly portrayed as ahistorical to the wider world, and exploring accounts of time and change that controvert the timelessness implied by albums, assemblages and documents within such collections, is a politically and symbolically significant act.

In this regard and others, my research has developed in close co-ordination with, and response to, recent arguments for the necessity of constructive archaeological engagement with contemporary political issues, and active participation in local research contexts (Dawdy 2009; Meskell 2009). As Giblin (2012: 126) points out, such arguments, which have emerged from the distinctly post-processual realisation that archaeology is not, and never has been, an apolitical objective inquiry (Shanks and Tilley 1987), are in many contexts also a response to the 'structural and epistemological decolonial challenge that concerns all forms of knowledge production' identified by the postcolonial critique (cf. Mudimbe 1985; Appiah 1992; Mbembe 2001; Smith and Wobst 2005; Shepherd and Haber 2011). This decolonial challenge has been debated and embraced in numerous forms and contexts by archaeologists worldwide, but has been a particularly fundamental concern within the emerging theories and methods of 'indigenous archaeology', a multi-seeded and multiform sub-discipline orientated towards research undertaken 'by, for and with indigenous communities' (ColwellChanthaphonh et al. 2010: 228, see also Silliman 2008).

Indigenous archaeology has grown to maturity in Australia (Harrison and Williamson 2004), New Zealand (Rika-Heke 2010) and North America (Nicholas 1997; Nicholas and Andrews 1997; Watkins 2000, 2003) where there are currently numerous innovative projects and lively ongoing debates. However, in sub-Saharan Africa, despite the development and expansion of postcolonial historical archaeologies in more recent years, it has not yet convincingly taken root (Lane 2011). This is not to suggest that there is a dearth of archaeological research that 
involves close collaboration and involvement with various local communities (e.g. Chirikure and Pwiti 2008; Denbow et al. 2009; Davies et al. 2014; Schmidt and Pikirayi 2016). Rather, these projects have chosen not to explicitly designate their approaches as 'indigenous archaeology' for a number of reasons. One is perhaps the inadvertent essentialisation of the cultures and practices of participating communities that might emerge from structuring research activities around the term 'indigenous'. This term, as Lane (2011) points out, does not hold the same significance in African contexts as it does in countries and continents where self-identifying indigenous groups are often marginalised, and indigeneity correlates with a sense of 'firstness' or 'nativeness' in relation to the descendant populations of settlers of European descent (South Africa is a notable exception to this; see also Yeh 2007). Even more substantial though, is the point that the implied dichotomy between 'indigenous' and 'scientific' archaeological approaches reproduces colonial thought paradigms by envisioning indigenous knowledge and theories as the consequences of ahistorical 'pristine' epistemologies that contrast with the dynamism of modern scientific thought (cf. Lane 2011; Giblin 2012).

Nevertheless, the objectives, methods and practices of much of the archaeological research in Africa that is positioned as 'postcolonial' and involves close collaboration with local populations, converge strongly with those of indigenous archaeologies elsewhere. Giblin (2012: 136) makes the shrewd argument that:

'if African indigeneity is released from its essentialist and racist colonial baggage and associated ideas of being pristine, original, ancient and ahistorical, or non-scientific, indigenous African epistemologies might be constructed as "of the place" epistemologies, which would depolarize "indigenous" and "scientific" as each archaeology is performed, constructed and understood as a new "of the place" hybrid knowledge system'.

Whilst I am not entirely convinced of the possibility that African indigeneity could ever be released from its colonial baggage within or by means of the context of archaeological 
research (and am more persuaded by the argument for rejecting the term 'indigenous' in African research contexts altogether), my approach to the research I discuss here has been deeply influenced by Giblin's call to construct African epistemologies as 'of the place epistemologies'. Aside from its movement beyond the polarisation of the terms 'indigenous' and 'scientific', such an act of reconfiguring concurrently implies the need for the inherently collaborative nature of all social research to be acknowledged and enhanced, and for purposeful co-operation at the point of interpretation in the field to be a core objective of any investigation into the African past.

Having said this, whilst the fieldwork I undertook in Turkana and its outcomes (primarily this thesis) were purposefully and actively rooted in and constructed through-in relation to Turkana epistemologies and ontologies, I do not presume that conducting this research has necessarily brought any tangible benefits to the various communities and individuals who participated along the way (which is often a primary objective of indigenous archaeology), aside from the opportunities it afforded people to engage in some vigorous conversations and to observe and discuss resources that are not locally available. Moreover, I must concede that both the strategy I deployed in the field and the selection and organisation of the photographic collection that was visually repatriated were my own doing, rather than that of the various communities who participated in the research. In this sense, both the research methodology and many of the questions it sought to address were not constructed collaboratively, but were rather manifestations of my own interests. These factors perhaps correlate with the broader point that the primary significance of this research has been its facility to produce narratives that may contest enduring and widely held problematic suppositions regarding social change and historicity in Turkana which, as I outlined above, still influence development planning and practice, rather than its applicability or engagement 
with immediate local needs or aspirations. This is not to say, however, that the former might not benefit the latter in the longer term.

\subsection{Material culture}

A critical concept around which almost all recent approaches to the study of material culture have come to be woven, and which has moulded debates about the sociality of things and the 'thingness' of sociality alike, is that of objectification (Tilley 2006; see also Miller 1987, 2005, 2010). This concept, which first surfaced in Hegel's (1977) Phenomenology of the Spirit, was the tool that facilitated the initial deconstruction of the perhaps otherwise implicitly assumed division between humanity and materiality. Hegel's process of objectification - the embodiment or materialisation of ideas - envisaged human subjects as being crafted by means of the image created and reflected by the very act of producing material forms. Or, as Miller (2005: 08) summarises, 'we cannot know who we are, or become what we are, except by looking in a material mirror'.

In the last few decades, the development of Hegel's original idea through explorations within both archaeology and anthropology of the link between the process of objectification and material culture, broadly under the banner of 'material culture studies', have elucidated numerous examples of the ways in which social identities, institutions and practices do not simply serve to produce objects, but are rather themselves constituted by the production, use, exchange and consumption of material things (e.g. Hodder 1982; Moore 1986; Miller 1987, 1998; Tilley 1990; Tilley et al. 2006). To many of those occupied by this endeavour, and certainly to Miller (2005: 6), Bourdieu's $(1977,1984,1990)$ theory of practice has been a key source of ideas. Indeed, it was Bourdieu, building on Lévi-Strauss' structuralism and 
transforming it through its immersion in everyday practice (Miller 2005), who argued that human socialisation - our learning of habitual ways of being in the world - occurs by means of our entanglements in the relationships that exist between and constitute material things.

The 'material-cultural turn' (Hicks 2010) has thus been predominantly concerned with demonstrating the diverse ways in which humanity does not precede the creation of form, but rather both human consciousness and material things — subjects and objects — are produced 'in the wake' (Miller 2005: 10) of the fundamental process of objectification. This notion that the subject-object dichotomy is illusory or superficial, a mere distraction from a more significant underlying process, has also been central to works that have sought to move beyond a simplistic distinction between things and people altogether, turning instead to map the dynamic patterns and networks of interaction between them. Gell (1998) achieved this by conceptualising objects, specifically art, as the distributed agency of subjects throughout society, their effects engendered by means of their attribution to a prior human agency. Latour (2005), on the other hand, sees human agency as itself largely crafted by that of nonhumans within transient meaning-producing networks of relations comprised by bundles of equally significant humans and non-humans.

Latour's work seems to parallel a recent dissatisfaction in the archaeological world with the reinforcement, in many of the analyses undertaken in the name of material culture studies, of pre-existing unquestioned conceptualisations of objects purely as extensions of the social. Indeed, Hicks (2010: 69) laments the fact that 'the complexities of materials and their change over time are not accounted for' in much of this work (see also Knappett 2012). The growing archaeological insistence on materiality as 'the physicality of matter' (Boivin 2008: 129) has 
perhaps also been stoked in part by Ingold's (2007: 1) assertion that form is not necessarily imposed upon things from without, but rather 'continually generated and dissolved within the fluxes of materials across the interface between substances and the medium that surrounds them' (cf. Knappett 2007; Tilley 2007). Ingold's emphasis on the materials that constitute everyday things leads to the argument that such things are not imbued with agency from human subjects in a simplistic sense, but are instead active by means of their particular entanglements in the 'currents of the lifeworld'. Focusing on the materiality of things, Ingold (2007: 14) argues, serves to engulf and stifle the properties of materials, forcing us to fall back on the timeworn dualisms of nature and culture, mind and matter, ideas and things.

Whilst I am generally in agreement with Ingold's (2007: 14) notion that we should 'take materials seriously', and indeed am largely concerned in this thesis with looking beyond the mutual and recursive constitution of what are often reductively conveyed as prior forms to the habits and rhythms of life that both take part in and flow by means of inherently openended processes of objectification (cf. Rowlands 2005), my interests seem to co-ordinate much less with many of the responses to materiality that have come from the world of archaeology. In archaeology, the abovementioned discontent with the notion that materiality is merely constructed by humans (cf. Webmoor and Witmore 1998: 55; Knappett 2012), and indeed with studies that approach things primarily from the side of people (rather than vice versa), has manifested itself in research that has sought to 'use abandonment to reveal materiality’ (Knappett 2012: 193), divorcing humans from the situation altogether.

These approaches, broadly positioned as 'archaeologies of the contemporary past' have, amongst many other things, comprised explorations of materials such as the debris of war and ‘supermodernity’ (González-Ruibal 2006, 2008), the architectural ruins of failed development schemes and abandoned council houses (Buchli and Lucas 2001), farms and 
industrial towns (Olsen 2010). Whilst these kinds of investigation have shown themselves to have a set of unique capabilities (at the very least their ability to deconstruct both the practice of archaeology itself and the period widely referred to as 'modernity'), in so doing they have, as Harrison (2013: 44) argues, come to be deeply interwoven with the idea of 'a past which is buried and hidden' (in a figurative rather than a literal sense) as opposed to one which is alive, imminent and actively constituted and re-constituted by its participation in daily life.

Perhaps by extension, they often seem to be implicitly juxtaposed with studies that are more overtly aligned with a social constructivist approach (cf. Knappett 2012), a tendency that has persuaded me not to model my research in Turkana in their image. To me, just as materiality need not necessarily be envisioned as a manifestation purely of the social, so too should an archaeological thing-centeredness not automatically be predicated upon the avoidance of the socially constructed meanings of objects and places. Nor must it instinctively, for that matter, circumvent in-depth ethnographic encounter and observation. Indeed, in using everyday material culture to explore Turkana notions of time, history and change, as this thesis seeks to do, it is necessary to approach objects, at least in part, from their place within the fluctuating processes of life that constitute them socially.

Just as Miller (2005: 15) reasons that anthropology must (if it is to find relevance) climb down from the lofty philosophical realms where the subject-object separation can be collapsed, and where humanity can be revealed as an epiphenomenon, to concern itself instead with 'ethnographic empathy and ordinary language', so too should archaeology be able to reach further than a materiality that is awoken only in stillness and silence to one that takes part in and is recursively informed by social institutions, livelihoods and daily practices and movements. Such a principle is perhaps what González-Ruibal (2015: 44) envisages by 
suggesting that archaeologies in and of contemporary societies must be reorientated to become less about the contemporary past per se and more about 'a creative engagement with the present'. It is arguably also a precept upon which renditions of the kind of politically engaged and locally orientated archaeology needed to confront the ongoing decolonial challenge in African research (Giblin 2012) might be developed.

Either way, being based primarily upon material culture change, the exploration of recent Turkana history outlined here inevitably takes form through and draws its inferences from an attention to the objectification processes that structure daily life throughout the region. In doing so it does not focus solely on the production of everyday things, but rather considers objectification as a process in which things take part 'throughout their lifecycles, in moments of exchange, appropriation and consumption' (Tilley 2006: 60-61; cf. Miller 1987). I suggest that one of the key values of such a stance, especially with regard to research focused on recent African histories, is the faculty it affords for thinking through the superficial disjunctures and discontinuities that otherwise seem to be indexed by the changing materiality of everyday things, particularly in relation to the escalating process of globalisation.

In other words, by starting out from the fundamental notion that all things used in Turkana take part in, and are both pragmatically and symbolically constituted by means of, Turkana ontologies - regardless of the materials used in their construction and whether they were created locally or in external production zones (such as a Chinese factory) — it is easier to avoid falling back on the stubborn and misleading antinomy between 'tradition' and 'modernity'. In particular, it is more feasible to eschew a view of history that implicitly envisions social change as the erosion of the former in correlation with, or indeed because of, 
the establishment of the latter. It can be shown that the temporal distinctions between the widespread use of spears and that of guns (which I explore in Chapter 6), for example, or that between the wearing of animal skins and of cloth blankets (which I explore in Chapter 4), are by no means inherently indicative of fundamental changes within the social institutions or daily practices that such objects are used to perform.

In demonstrating this point, and in exploring the changing ways in which everyday things from near and far have been caught up in uniquely Turkana ways of being in the world, I draw greatly on so-called 'biographical' approaches to objects. As I noted above, these have arguably been some of the most fruitful routes of analysis within material culture studies in recent years, as well as a particularly fertile canopy for interdisciplinary inquiry between anthropology and archaeology. Building largely on Appadurai's (1986) The Social Life of Things (and Kopytoff's contribution to that volume), explorations of socio-material relations via the theme of biography have also tied in with a view of objectification that de-emphasises production to explore objects as things that can both create and be created (and recreated) socially, pragmatically, ideologically and symbolically at different points throughout their lives by means of their successive re-contextualisation (cf. Gosden and Marshall 1999). Indeed, Hoskins (2006: 74) characterises these approaches with the general summary that "things can be said to have "biographies" as they go through a series of transformations from gift to commodity to inalienable possessions, and persons can also be said to invest aspects of their own biographies on things'. In this thesis, I explore Turkana history from both these angles, at times approaching human biographies through a focus on things and at others outlining the biographies of different kinds of object by drawing together the past experiences and memories of various individuals and communities. 
It is important to clarify that, in relation to the latter of these undertakings, I am not concerned with tracing the biographies of specific objects as they 'repeatedly move between people' (Gosden and Marshall 1999: 174), but rather with outlining aspects of the biographies of various object categories or 'types' over several decades of socio-economic, ecological and political change. As I mentioned above, such an approach is perhaps most comparable to Schiffer's (1991) exploration of portable American radios. In doing this, I examine how histories of production, use and exchange, and the gradually transforming social institutions in which these have been entangled over the years, are imminent and critical forces within always-ongoing and habitually rooted objectification processes. I trace, in the series of examples interspersed throughout this thesis, how memory, experience and historical knowledge serve to enmesh everyday objects from near and far with a historicity that is neither wholly contingent on their overall form nor established purely through the materials used in their construction, but rather one that is continually emerging and becoming through "the ensemble of phenomenal and material properties of "things"' (Coupaye and Douny 2009: 24) and their performance in daily life. This approach is, on one level, aimed at moving beyond what Keane (2005: 183) perceives as a frequent and frustrating separation of things from ideas in social analyses, to explore their mutual entanglement and constitution in daily livelihood practices and to attain a 'better understanding of the historicity inherent to signs in their very materiality' (cf. Tilley 2006).

In following this line of enquiry, I envisage everyday things both as materialisations of historical experience and knowledge (a grounds for the past to be rearticulated by means of an array of shifting socio-economic circumstances and, in so doing, to exert influence over those circumstances) and as a domain for the recasting of the past, for its reconfiguration and redescription in light of a changing set of daily needs and aspirations. In this sense, I am not 
only interested in the social life of things per se, but also in their social potential and 'futurity' (Keane 2005, 2006). In other words, I am not concerned with assessing how new objects either destroy or reinforce supposedly stable or inert socio-cultural meanings, an endeavour rooted in the Saussurean idea that signs are merely the costume of a deeper set of impalpable or intangible meanings (Saussure 1959: 102-22). Indeed, I set my arguments up in opposition to this idea and instead seek to examine how things take part in the continual production of new contexts where meanings might be invoked precisely by means of their paradoxical implication in both locally rooted histories and deviations from such histories (see Thomas 1999: 18). Things are embedded in change and continuity in equal measure in Turkana, serving (in both directions) as the means to direct one by means of the other.

I explore these points from numerous angles throughout this thesis using a series of examples that feature in various different arguments, but I do so most explicitly in Chapter 6. This chapter, which examines herding and raiding over the last century and beyond, regularly returns to various key objects, the most prominent of which is the male apukot headdress (and its predecessor the abuzibuzi). It considers the various social and material transformations in which this style of head ornamentation has been implicated over the years, and the complex ways in which it has been reformulated, reconstituted and yet also reiterated in relation to numerous shifting economic and political factors. This process ultimately reveals the fact that the apukot, although longstanding, cannot be reduced to one particular form or set of materials but, like the broader social institutions and practices in which it performs, has instead been a continual act of negotiation, construction and reconstruction. 


\subsection{Livelihoods, landscapes and ontologies}

The idea that everyday things in Turkana are always in the process of being created and recreated, both in terms of long-term trajectories of socio-material interaction over many generations and in the sense that a single object is open to meaning different things at different times of day, week, month or year as it is successively re-contextualised, ties in with a similar but much broader and all-encompassing perspective of the worlds in which Turkana objects perform. What I mean by this is that envisioning material culture as inherently 'open' and fundamentally entangled with humans in a fluid and dynamic process of meaning production inevitably leads one to infer that Turkana society itself is not founded on a set of deep-seated guiding principles or ideas that are intangible and determinant — a stable knowledge encoded onto things, places, landscapes or practices. Rather, it is something that is learned and enacted precisely by means of an individual's interactions with, and existence within, the world around them. This is not to suggest that historical knowledge and experience have no role to play in structuring society or informing its gradual transformation through the generations. Rather, it is to submit that such knowledge and experience do not passively underlie daily life, but instead are passed on and learned through collaborative interactions with and participation in things, places, landscapes and practices. Such knowledge, like material culture, is therefore always in the process of being reconstituted as it emerges by means of, and finds relevance within, a changing set of daily challenges, needs and aspirations.

To me, exploring a livelihood history is an act of tracing how a community's fundamental orientation toward the world, as constituted by their activities of subsistence procurement, has emerged through, and, in the process, determined shifting environmental, political, 
economic and social factors through the years. In other words, it is a way of analysing historical change in any given location specifically by means of a group's changing physical engagements with the world around them. In adopting this approach, however, I do not disregard the ways in which places and landscapes in Turkana are imaginatively socially constructed, attending instead purely to the technological or practical aspects of subsistence, but rather root my arguments in Ingold's (2000: 9) view of livelihood as an avenue of inquiry that might allow us to move beyond the "division between naturalistic and "culturalogical" accounts' altogether. Ways of acting in the world are, Ingold (2000: 25) argues, at the same time ways of perceiving it, of constructing it socially, and in this sense the ritual and the mundane are not articulations of different kinds of knowledge or logic (one cultural, the other practical) but rather, like all other aspects of daily life, mutually constitute each other by means of their entanglements in the same 'poetics of dwelling'.

In setting out this view, Ingold (2000: 13-26) envisions what he terms an 'ecology of life' by drawing on previous arguments made by Bateson (1972) for an 'ecology of mind'. Bateson's understanding, which Ingold sets up against Lévi Strauss' (1972) writing on structuralism and ecology, pictures the world as something that comes into existence in the mind by means of movement and interaction. In this sense, mind and world should not be envisaged as separate fixed realms between which information passes across a definable interface, as Lévi-Strauss would have it, but rather as deeply interfused and without obvious boundary. Building on this concept, Ingold (2000: 20) proposes that humans and their environments should not be understood as opposed or even separate, as is often implied, but rather as elements within one 'indivisible totality'. This totality, he argues, is not static or stable but instead open-ended and constantly under construction. Knowledge of it:

'is a knowledge not of a formal, authorised kind, transmissible in contexts outside those of practical application. On the contrary, it is based in feeling, consisting in the 
skills, sensitivities and orientations that have developed through long experience of conducting one's life in a particular environment' (Ingold 2000: 25).

Thinking about Turkana livelihoods as indivisible totalities or 'sentient ecologies' — a term referred to by Ingold but developed initially by Anderson (2000) — is a useful framework for organising and analysing the distinct clusters of historical narratives that they both generate and are organised through. They have, after all, emerged from the very different long-term experiences of communities dispersed amongst Turkana's diverse environments, ranging from riverine gallery forest to the exposed lake shore, and from mountainous scrubland to vast semi-arid plains. This very multiplicity, both in terms of perspectives of the historical past and the ensuing organisation of contemporary life, is something that is rarely accounted for in much of the social research undertaken in and on Turkana. The tendency to envisage Turkana pastoralism purely (or even primarily) as the herding of livestock, rather than as an activity intricately socially and economically interwoven with a set of other subsistence strategies and modes of life in a complex and dynamically changing pastoral economy, has often led to over-simplified and generalised accounts of Turkana society and culture (i.e. those critiqued by Galaty and Bonte 1991). I seek to address this shortfall with the accounts I offer in this thesis but must clarify here, as I do at numerous other points throughout the rest of the work, that neither fishing, herding nor cultivation have ever been closed socioecological systems organised around fixed populations. Rather, they have all fluctuated both spatially and temporally as individuals, families and entire communities have moved between them making a living amidst an ever-changing array of influences, challenges and desires.

Equally significant and appealing about adopting an Ingoldian conception of livelihoods, however, is its stark contrast with the ideas that have structured the often livelihoodorientated development that has taken place in Turkana over the past half century or so. 
Indeed, critiquing this history of development was another key objective behind my decision to organise my fieldwork around different livelihoods. As is clear in Chapters 4 and 5, Ingold's notion that knowledge and skill are dynamically learned through interaction with the world, and largely intuitive could not contrast more profoundly with the attitude that has characterised Turkana's major development interventions over the recent past. By situating two of these - NORAD's attempted development of a large-scale fishing industry in the 1970s and 1980s (Chapter 4), and the Turkana Rehabilitation Project irrigation schemes instigated following a famine in the early 1980s (Chapter 5) — within the long-term histories of dynamic human-environment interaction that they both overlooked, I hope to emphasise some of the practical consequences of the of marginalisation of Turkana's historical past. I also seek to draw attention to related presumptions regarding the passivity and restrictiveness of 'indigenous knowledge' that have fed into 'development myth making' (Ferguson 1990: 178; cf. Lane 2015) in Turkana over the years.

Ingold's attribution of cultural knowledge to intuition, and the arguments he puts forward with his 'dwelling perspective' — 'a perspective that treats the immersion of the organismperson in an environment or lifeworld as an inescapable condition of existence' (Ingold 2000: 153) - connects his work with the ideas of Pierre Bourdieu. Bourdieu's (1977) practice theory, which I have already mentioned, is another key perspective on which this thesis draws. Like both Ingold and Heidegger, whose writing on practice is the foundation of Ingold's dwelling perspective, one of Bourdieu's key contentions is that knowledge primarily arises through practice (Gosden 1993). Bourdieu's notion of habitus, derived in large part from Marx, envisions social action as engendered by means of the unconscious recursive transmission of lasting cultural dispositions. In a well-known and often quoted statement, he encapsulates habitus as: 
'systems of durable, transposable dispositions, structured structures predisposed to function as structuring structures, that is, as principles which generate and organise practices and representations that can be objectively adapted to their outcomes without presupposing a conscious aiming at ends or an express mastery of the operations necessary to obtain them' (Bourdieu 1977: 72).

Practice theory can perhaps be understood as a development of Husserl's notion of internal time consciousness - social action as emanating from the retention of past actions in combination with the protention of future outcomes — by means of its interfusion with a Heideggerian view of temporality as rooted in practice, a product of being-in-the-world (Morton 2002). Its resulting characterisation of everyday practices as articulations of a fundamental orientation toward the world, activities that continually emerge through a set of durable dispositions constituted by the recursive and intuitive recollection of past experiences by means of changing daily contexts, is a core component of my understanding of sociocultural change and continuity in Turkana in relation to the various broad-scale transformations that have occurred over the recent past. It is by drawing on Bourdieu that I envisage such socio-economic or environmental transformations not as inherently disruptive, but rather as processes that have been negotiated by means of durable dispositions within the worlds of fishing, cultivating, herding and raiding. I argue that fundamental changes within the context of social action (e.g. faunal extinction, infrastructural development or political overhaul) have been mediated, largely unconsciously, through dynamic habitual practices, and have in turn served ultimately as a means for the re-articulation of certain underlying orientations toward the world rather than for their destruction or dramatic alteration.

As I outline below, this notion of continuity as a process continually and dynamically emerging within communities' daily practices by means of, rather than in spite of, significant transformations in northern Kenya's infrastructure, environment, economy and political organisation equates to what I consider to be a resilience deeply rooted in Turkana society 
and culture. However, before discussing this overarching motif of the thesis in more detail, it is worth noting some of the other key correlations between a focus on daily practices and livelihoods and the theoretical stances I have outlined above.

Perhaps most notably, I would suggest that thinking about the temporality of practice in terms of habit, intuition and unconscious recursiveness ties in closely with Miller's (1987) early writing on objectification and material culture (which, as I noted above, itself draws heavily on Bourdieu's practice theory). Of particular significance in this work is Miller's (1987) concept of the 'humility of things', the idea that their social importance and meaning are in most cases not patently obvious. Rather, the more they are taken for granted and camouflaged in the activities of daily life, the 'more powerfully they determine our expectations' (Miller 2005: 5). This capacity of objects to 'fade out of focus and remain peripheral to our vision and yet determinant of our behaviour and identity' (Miller 2005: 5) underlies much of the analysis in this thesis. It is primarily by considering objects' inconspicuous entanglements in, and yet decisive perpetuation of, the more mundane, quotidian currents and rhythms of daily life that I seek to use them to explore the dynamics of change that have governed the practices central to cultivation, fishing, herding and raiding in Turkana over the years. It is, in this sense, perhaps the humility of things that renders them uniquely capable of uncovering the everyday histories that rarely find their way into written records (cf. Deetz 1977).

A focus on the temporality of practice also links back to the comments I made in Section 1.1 regarding the conflicting views of time that currently lie in uneasy tension within the Turkana landscape. Landscape is a key theme in Ingold's (2000) writing on the perception of the environment, which might be seen on one level as a step beyond a consideration of the temporality of practice, such as that offered by Bourdieu, toward an understanding of its 
inculcation in the physical world. Building on the ideas of Husserl, Heidegger and Gell, amongst others, Ingold (2000: 196) contends that the landscape is not a sterile back drop for human action, but rather an entity through which the world opens up as the present 'gathers the past and future into itself, like refractions in a crystal ball'. In this view, it is not simply constituted as an accumulation of the residues of past events, but is rather constantly coming into being by means of its participation in the patterns of dwelling activities that constitute what Ingold (2000: 190) terms 'taskscapes'.

Envisaging landscape as inextricably entangled in and temporally constituted by daily practices in an interactive process where time and space both produce and get produced by social action (Giddens 1984; see also Gosden and Head 1994) has particularly significant connotations for a place like Turkana. It rouses the possibility that Turkana's famously barren landscape, as envisaged and constructed in archaeology, palaeoanthropology and the popular press alike, has perhaps itself served as the most conclusive invalidation of recent history. What I mean by this is that its unquestioned, indeed seemingly matter-of-fact, synonymy with distant geological eras - its popular contemplation as a place 'twisted and rendered by the cataclysmic convulsions of a long-ago past' (Brown 1989: 16) — has perhaps concealed, to the outside world, its changing historical interactions with the communities who have dwelt within it over the last half millennium and the temporalities that it comprises as a result. This thesis seeks to depart from such common conceptualisations of the Turkana landscape as a neutral backdrop for evolutionary history, or a 'cradle of mankind' (Amin 1981), and instead explore the histories of dwelling activities that it invokes in daily life amongst those who pursue their livelihoods by means of its varied features and resources. 
In this respect, my approach ties in closely with the interests of studies encompassed by the paradigm of 'historical ecology', which have generally utilised landscape as their key unit of study in explorations of human interactions with the environment over the long term (e.g. Crumley 1994; Balée 1998; Balée and Erickson 2006; Lane 2010; Stump 2010, 2013; Davies 2012; Marchant and Lane 2013). Like the research presented in this thesis, approaches to historical ecology are in most cases both conceptually and methodologically interdisciplinary, drawing together perspectives from (among other disciplines) anthropology, archaeology and history (Lane 2010). Moreover, their fundamentally holistic view of human-environment relations as a 'total phenomenon' (Balée 2006: 76) seems in many ways to parallel Ingold's (2000) abovementioned conceptualisation of livelihoods as 'ecologies of life'. Having said this, unlike the large majority of studies in historical ecology my focus in this thesis is not landscape formation. Nor do I specifically use landscape as an overarching connecting theme for the various periods and processes of change that I consider. For this reason, more than any other, whilst there are clear comparisons and overlaps I would be wary of explicitly designating my research as an historical ecology approach to Turkana livelihoods.

Before concluding this section and outlining how I seek to build on these various bodies of theory using the concept of resilience, one further corpus of work demands consideration, namely the so-called 'ontological turn' in anthropology. Associated primarily with the works of de Castro (1998, 2014), Descola (2005), Latour (2005) and Kohn (2013), although manifested in the thinking and writing of many others, the ontological turn has generated much debate in anthropology over the last few years. Broadly speaking, it can be characterised as a reaction to the 'writing culture' trend in postmodern anthropology which concerned itself with the study of cultural representations of reality (Clifford and Marcus 1986). In constituting itself largely through differentiation, the ontological approach has 
argued against the notion of anthropology as the study of various distinct views of one underlying 'real world', advocating instead a view that acknowledges the existence of multiple different worlds or realities all existing and overlapping together. In its underlying ambition to 'take difference — alterity — seriously as the starting point for social analysis' (Henare et al. 2007: 12) it is a project in relation to which the arguments I present in this thesis might perhaps gain some traction. Indeed, the idea that research might be aimed at exploring other ways of being as activities that emanate from and are organised by other worlds (ontologies), rather than simply other world views (epistemologies) is a stimulating one regardless of the theoretical and methodological complexities that it provokes. Heywood (2012: 146), for instance, makes the point that taking other worlds seriously entails a sort of tacit meta-ontology of its own, in which a multiplicity of worlds can exist (cf. Pederson 2012).

Unlike Heywood, who perhaps envisages an ontological approach purely as a fixed theoretical framework for social analysis, this thesis' correlation with an ontological perspective is only along the lines of its function as a heuristic analytical device (Holbraad 2012; Pederson 2012). In this regard, my exploration of the disparities between the strategies of development planners/practitioners and local fishing and cultivating communities in the large-scale development interventions I discuss in Chapters 4 and 5 is rooted in the underlying principle that such situations comprise radically different ontologies existing together in fraught tension. I consider these dramatically dissimilar ways of being in the world, perceiving history and organising daily life to be part and parcel of separate 'ecologies of humans and non-humans inextricably woven in the same existential sphere' (GonzálezRuibal et al. 2011: 2) which are mutually entangled in uneasy cooperation. The same might also be said of the colonial conquest of Turkana, which I discuss in Chapter 6, when a drawn- 
out conflict between the British and the Turkana reverberated through different ontologies with profoundly different perceptual outcomes. The livestock confiscation policy that the British enacted continues to be made sense of amongst herding communities in the present day in terms of livestock's role in authority construction, with the British envisaged as vociferous raiders amidst a milieu of inter-ethnic livestock theft.

Whilst it is perhaps not entirely clear in these examples where ontology gives way to epistemology (Fontein 2015), the key point is that things make sense in different ways depending on the ontology from which — or in relation to which — one attempts to view them. Thus, whilst I do not seek in this thesis to contribute to debates over the relative merits, disadvantages and possibilities of ontological reasoning (cf. Henare et al. 2007; Carrithers et al. 2010) I do, on a basic level, seek to tie my arguments about various broad socioeconomic, political and environmental transformations that have taken place over the last century in Turkana to perspectives that arise from the particular ways of being that constitute the worlds of cultivation, fishing and herding. In doing so I do not claim to be able to fully comprehend, explicate or represent these perspectives, having not myself come from any of the worlds where they originate. Instead I present them in partial form, using interview extracts and vignettes, to guide my arguments and reasoning throughout.

\subsection{Resilience}

It should be clear by now that the research I discuss in this thesis finds its theoretical foothold in the interplay between several distinct bodies of literature, themselves dispersed in varying degrees amongst the disciplines of anthropology, history and archaeology. In employing these varied approaches and theoretical stances, however, my overall objective is much less 
nebulous. The arguments I present in the three central chapters of this thesis - Chapters 4,5 and 6 - are each concerned with outlining aspects of what I perceive to be a form of resilience that has characterised socio-economic and cultural change amongst Turkana's diverse communities over the last century and beyond. However, my understanding of this resilience as a characteristic of dynamically negotiated and enacted change not only within grounded livelihood practices and accompanying skillsets but also in social institutions, cultural values and the political organisation of daily life diverges somewhat from the perspectives of many existing studies that are framed by an interest in resilience. Therefore, before briefly outlining the overall structure of this thesis, I explore in this section current approaches to resilience and outline where I situate my own arguments in relation to them.

Resilience is a term that has come to be defined and utilised in analytically diverse ways across the social and environmental sciences (Widlok et al. 2012). In studies focused on natural resource management, for example (particularly those that approach farming landscapes as socio-ecological systems), it has come to be understood by many as a feature of complex and dynamically adapting structures of human-environment interaction, often based on the enduring prominence of local knowledge and the resistance of substantial outside influence (e.g. Berkes and Folke 1998; Tengö and Hammer 2003: 133; Plieninger and Bieling 2012; Widlok et al. 2012; Davies et al. 2014). In the case of the Iraqw'ar Da/aw of the Mbulu highlands in Tanzania, for example, Tengö and Hammer (2003: 133) argue that their farming system endures through a 'multitude of management practices based on local ecological knowledge' which are embedded in a 'nested set of institutions' (see also Widgren 2012). Similar arguments have also been made in case studies focused on pastoralist communities, where resilience is often understood as a trait written into dynamic and responsive pastoralist strategies, allowing various communities to weather stress induced by environmental 
degradation, drought, disease epidemics or livestock theft (Fratkin 1986; Robinson and Berkes 2010; Watson et al. 2016).

Indeed, considerations of the ways in which pastoralist communities cope in often highly volatile environments have, since the 1980s, propped up debates over whether pastoralist systems should be envisaged as 'equilibrial' (essentially stable and made unstable by issues such as overstocking or overgrazing) or 'nonequilibrial' (inherently unstable but nevertheless 'persistent') in nature (Ellis and Swift 1988; Sullivan and Rhode 2002; Vetter 2005). McCabe's $(1987,1990,2004)$ work on Turkana pastoralism and raiding makes a compelling argument for the former as a nonequilibrial system, comprising a highly variable and opportunistic management of livestock, occasional dependence on external resources and highly dynamic mobility patterns.

Whilst on one level I wholeheartedly agree with McCabe's characterisation of Turkana pastoralism, and draw greatly on studies that emphasise spatial and temporal dynamism and adaptiveness in socio-ecological systems, I am less convinced by the underlying assumptions that are commonly made about the local knowledge, and manners of knowledge attainment, on which such resilient systems are based. Indeed, I would argue that the resilience of various livelihoods and systems of livelihood interaction, particularly in rural African contexts, seems often to be implicitly attributed to a notion of culturally specific knowledge that is inadequately expanded or defined. Perhaps because of this, while the overall systems of subsistence procurement that structure various non-industrialised African societies no longer tend, for the most part, to be interpreted as predominantly passive or inert, ${ }^{3}$ the knowledge

\footnotetext{
${ }^{3}$ Particularly following the arguments of Adams and Grove (1984), Adams and Anderson (1988) and Adams $(1989,2003)$, which I consider in more detail in Chapter 5.
} 
repertoires and 'nested' socio-cultural institutions that govern them do often appear (perhaps unintendedly) as rigid, stable and immutable. This is, to an extent, an overly generalised argument, however it does seem particularly applicable to the rhetoric that runs through development- and policy-orientated discussions of 'environmental sustainability' in the context of pastoralist societies (as argued by Lane 2015). Either way, one of the most dissatisfying ideas that often emerges from many practice-rooted, socio-ecological systemsbased examinations of resilience is that, even if not based on balance or stasis, given that it is considered to be enacted by means of fixed methods and expertise and (to a certain extent) reliant on certain environmental conditions (i.e. access to land and resources), resilience seems inherently susceptible to erosion and deterioration if not protected.

On the other side of the coin, various recent ethnographic studies have sought to pursue analyses of forms of 'cultural resilience', diverting scrutiny toward the ways in which various cultural traits survive in often marginalised communities despite the burden of change. Fortier (2009), for example, explores the cultural resilience of Himalayan hunter-gatherers in her work Kings of the Forest, outlining how the Raute people have retained certain traditions and practices in a rapidly changing world. To Fortier (2009: 2), cultural resilience is 'the ability to hold on to traditional beliefs and practices in the face of constant pressures to assimilate exerted by a dominant society'. A similar argument is made by Galaty (2013) in his discussion of the 'indigenisation of pastoral modernity', to which I return in Chapter 6. Whilst he does not specifically frame his argument in terms of resilience, Galaty's (2013: 474) contention that many pastoralist societies have used 'time-tried techniques' and 'customary institutions' to accommodate and capitalise on the 'modern world' seems to parallel many other investigations of cultural resilience (e.g. Thomas 1999; Hadler 2008). 
Such investigations have uncovered a range of compelling case studies, and are perhaps most significant in their struggle to engender a shift away from the persistent melancholia of the rhetoric surrounding marginalised communities in the 'developing world' (cf. Moore 2011). However, theorising culture purely in distinction to broader 'assimilative forces', or envisioning it as a repertoire that might be deployed to either deflect or mediate intractable change, arguably does little to dismantle familiar and narrow impressions of cultural values, institutions and knowledge as somehow detached from being in the world — as intangible and perpetual prior to their expression in practice. In other words, resilience seems still to find its conceptual footing in a range of tired dichotomies such as tradition-modernity, nature-culture, thing-idea, rather than being envisaged as an ontological disposition that is articulated in the 'excessive potentiality of material substance' (Fontein 2015: 71).

My objective in this thesis, then, is to explore socio-cultural resilience in Turkana livelihoods not as something that emerges in spite of broader economic, environmental or political changes by means of an underlying culturally entrenched knowledge, but rather through them as an inherently open-ended orientation toward the world that might be recognised as a particular manner of change and illustrated over the long-term. In other words, I envision the knowledge that abides in various Turkana socio-cultural institutions and value systems not merely as the guiding compulsion behind various daily practices, but rather as itself inherently entangled in, actively constituted by and dynamically accumulated through changing interactions with the world in a process of continual reconfiguration. Like the habitus, this process comprises 'an endless capacity to engender products — thoughts, perceptions, expressions, actions — whose limits are set by the historically and socially situated conditions of its production', meaning that it is never reduced to 'the creation of unpredictable novelty' (Bourdieu 1977: 95). 
It is as a result of the generative and productive (rather than restrictive) propensity of this process that such institutions and systems are themselves inherently open-ended and perpetually under construction. Like the material culture categories that I use as my tools of enquiry, they are durable because they are impossible to define unequivocally, from the perspective of the longue durée, in terms of their form, function and constitutive materials. The notion that ties my arguments together, therefore, is that culture, or culturally entrenched knowledge, does not merely engender the dynamism and adaptability of broader socioecological systems, but is rather itself equally dynamic and open-ended, continually taking part in and being reconstituted through the production of new contexts for social action.

This thesis progresses through seven chapters:

Chapter 2 outlines the methodology behind my research. It discusses my engagement in participant observation, my collection of semi-structured interviews and market inventories and my regular convention of focus group discussions - exercises that constituted the backbone of my fieldwork. It then explores in detail my use of historical photographs and photographs of ethnographic object collections, considering the theoretical and methodological significance of this approach in relation to recent developments both in postcolonial historical archaeology and visual anthropology. Chapter 3 provides historical and ethnographic context for the central discussions of the thesis. It first outlines the Turkana pastoral economy, identifying the key debates concerning its characteristics and mode of operation. It then considers the principal features of Turkana social organisation, describing 
the configuration of and relationship between territorial sections, clans, generation sets and settlements. It concludes by providing a broad historical timeline of the Turkana from their initial split from the broader Ateker cluster to their establishment in the Turkana Basin and their ensuing interactions with the colonial and postcolonial Kenyan states.

Chapter 4 constitutes the first of the thesis' three central discussions and explores the history of fishing — akichem - along the western shore of Lake Turkana. I outline some of the key transformations experienced by fishing communities during the $20^{\text {th }}$ century, including the establishment of Lodwar and Kalokol as trading centres and the construction and rapid demise of the NORAD fishing scheme in the 1970s, to argue that a clear sense of continuity can be apprehended within both the configuration of this livelihood and the broader relationship between the lacustrine and inland herding populations. Rather than being the articulation of stability or rigidity within daily practices, exchange systems or the institutions that govern daily life, this continuity is engendered through the resilient manner in which lakeside communities interact with and capitalise on their shifting circumstances to continually reshape and re-establish their identity. Building on this argument, Chapter 5 explores the recent history of cultivation - akitare — and the changing interactions between farming and herding communities in relation to recent substantial environmental and economic changes. It draws on fieldwork conducted amongst two key riverside communities to discuss their different responses to the changing hydrology of Turkana's major rivers, the changing seasonality of cultivation, the implementation of large-scale irrigation projects during the 1980s and the more recent establishment of market centres in several riverside locations. I argue that, like the fishing communities, Turkana's cultivating population have negotiated these changes to adapt their livelihood on their own terms, whilst at the same time 
reshaping and restating their position within the broader economy and their relationship to the herding sector.

Chapter 6 discusses herding and raiding — akiyok ka aremor — exploring resilience as a paradigm that explains the changing configuration of social institutions, value systems, cosmology, the political organisation of daily life and the construction of identity within and around these closely related occupations. It traces the changing nature of conflict and warfare, and associated transformations in the socio-political roles of ngimurok (diviners/seers), livestock, warriors and government officials, considering how a set of fundamental characteristics have continually found expression in the shifting and converging possibilities and constraints of the $20^{\text {th }}$ and $21^{\text {st }}$ centuries. Chapter 7 returns to the departure points set out above. It revisits the central arguments of the thesis to discuss their implications both for Turkana's ensuing socio-economic transformations and for the key ongoing debates, set out in Chapter 3, regarding pastoralism both in Turkana and Africa more broadly. It concludes by discussing the methodological contribution made by this thesis to the growing corpus of archaeological research that focuses on the recent African past and by highlighting some key lines of inquiry for future research. 


\section{Chapter 2: Methodology}

As noted in Chapter 1, my fieldwork in Turkana was framed by a focus on material culture and, to a large extent, organised around an extensive collection of historical photographs from the Pitt Rivers Museum, Oxford, which I visually repatriated to Turkana in June 2014 and used for over a year in the field. This mobile collection was supplemented with copies of a range of other published photographs taken in Turkana throughout the $20^{\text {th }}$ century, along with my own photographs of objects in the Pitt Rivers' ethnographic object collections and various other collections at museums and institutions worldwide. ${ }^{4}$ In this chapter I outline the methodological and theoretical motivations behind and the implications of this approach, tracing its links both with recent developments in the sphere of visual anthropology and with archaeological approaches to the recent past. However, whilst my use of photographs was integral to much of my fieldwork, I also conducted a large portion of my interviews and focus group discussions without them. Moreover, of equal significance to my collection of interviews and my convention of group discussions (both with and without photographs) was my engagement in long-term participant observation, my regular inventorying of local markets and a range of other methods. Therefore, before discussing visual repatriation and photo-elicitation, I first summarise (in section 2.1) the elements of my research methodology that were less contingent on Turkana-related historical collections.

At this juncture I must also point out that, whilst my research methodology was both decidedly interdisciplinary and reasonably rewarding in its generation of a range of hitherto largely undocumented historical narratives, a great deal of additional and/or alternative

\footnotetext{
${ }^{4}$ Most extensively the collections at the American Museum of Natural History, New York, and the Kenyan National Archives, Nairobi.
} 
fieldwork could have been done to improve the depth and breadth of discussion in this thesis. My research area, for example, was primarily limited to the southeastern quarter of Turkana County (see Figure 2.1). Whilst this area is extremely broad in its own right (Turkana County encompasses some $68,680 \mathrm{~km}^{2}$ ), its histories do not necessarily correspond with the whole of Eturkan (Turkanaland) and its people. Indeed, there are a great many territorial sections and clans whose stories, memories and experiences are not present in the account of $20^{\text {th }}$-century Turkana history that I outline here, particularly those from the far north. This is a pressing cause for further research in the years to come. Furthermore, whilst my focus on livelihoods has not been unproductive, this was by no means the only or indeed the best way of structuring the fieldwork. There are many avenues of inquiry and topics of analysis that I have not been able to cover by means of this connecting theme, and thus a great deal of potential for further explorations of Turkana's recent past. I return to these in Chapter 7.

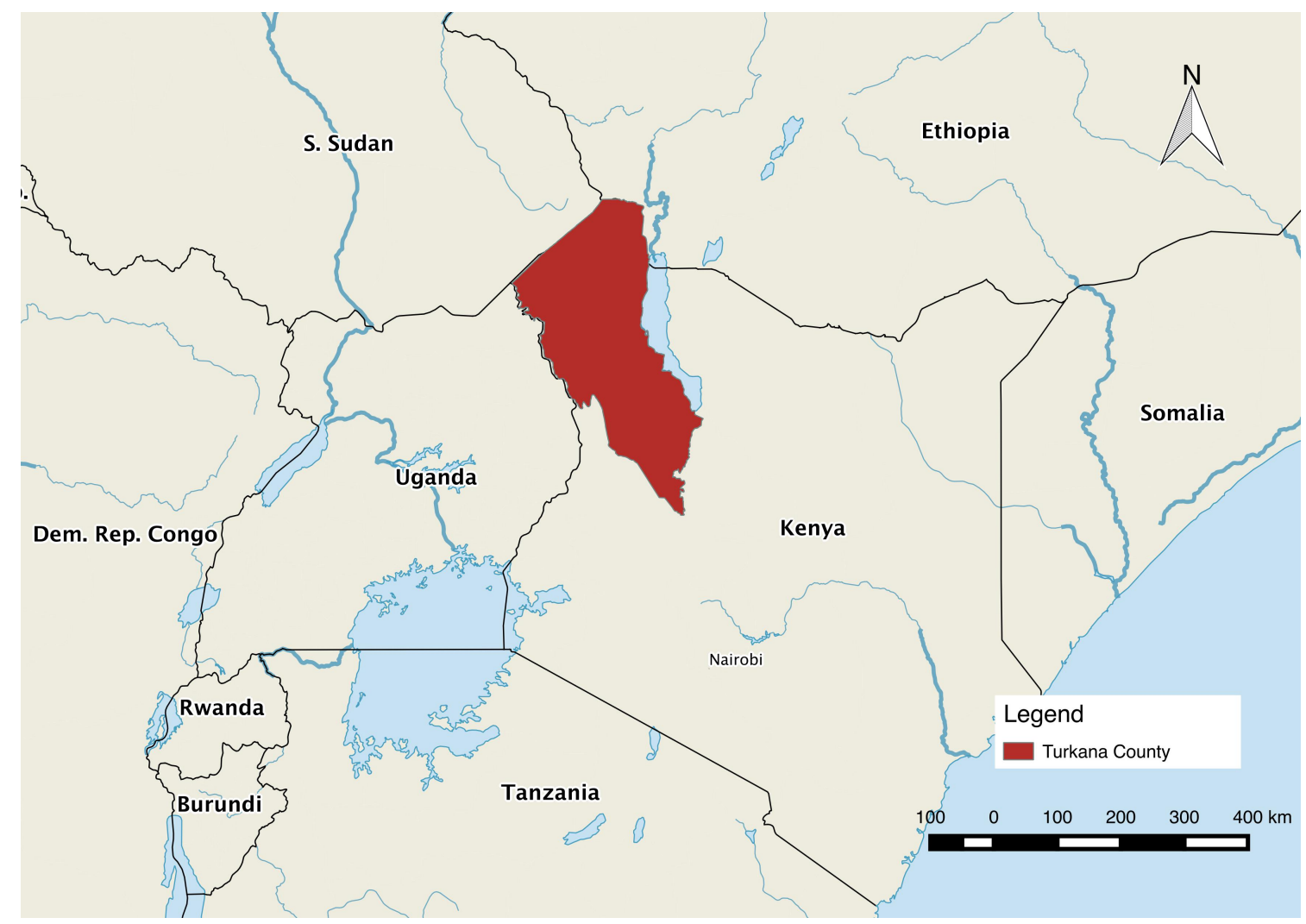

Figure 2.1. Map showing the location of Turkana County in East Africa. 


\subsection{Participant observation, interviews, market inventories and archival research}

A critical concept since the emergence of so-called 'interpretive archaeologies' has been the assertion that archaeologists are, no matter the age or depth of their focus of study, engaged in an investigation that is both of and in the present (Meskell 2002; Ucko 2005). This idea has, over the last few decades, come to engender a diversity of conceptual and methodological responses, ranging from heritage-based research that is actively and consciously politically engaged (i.e. postcolonial, public, community and indigenous archaeologies; Harrison and Williamson 2004; Gosden 2012; Schmidt and Pikirayi 2016) to research that shifts the emphasis altogether from 'deeper' history to the lived or contemporary past (e.g. Buchli and Lucas 2002; Harrison and Schofield 2010; Graves-Brown et al. 2013). Whilst to a certain extent, as I outlined in Chapter 1, all these responses to the post-processual emphasis on subjectivity have influenced this thesis in one way or another, my fieldwork was also largely informed by its inverse implications. What I mean by this is that my research did not primarily revolve around an interest in the 'presentness' of the past, so to speak, but rather in the intricate historicity of the activities undertaken in the present. As Geissler and Lachenal (2016: 15) have recently summarised, in the same way that archaeological artefacts are not just from the past:

'The present faced by the anthropologist is also always the presence of multiple pasts. What exists is a remainder, carrying traces of past actions, thought or relations. Hence, ethnographic fieldwork is always a labour of synchronisation, of making and sharing, disentangling and interweaving discreet and sometimes contradicting temporalities, rather than a synchronic undertaking premised upon "coevalness" in a shared present.'

It is such a view of ethnography as the making sense of the heterogeneous pasts that both manifest themselves in and come to be reinterpreted through contemporary social action that is most applicable to my fieldwork in northern Kenya. This is, as I discuss further Chapter 6, 
perhaps also comparable to Fontein's (2015: 5) interest in what he terms 'the immanence of the past' in the cultural and political dimensions of land reform in southern Zimbabwe. Either way, in undertaking participant observation amongst communities involved in fishing, cultivation, herding and raiding throughout my research in Turkana, my central objective was to build on my gradually accumulating understanding of these livelihoods' temporalities (as ascertained through interviews and focus group discussions) by encountering them as they wove their way through daily activities. Ultimately, this understanding of the diverse ways in which pasts come to gain traction and find expression in everyday practices, objects and landscapes in the present has been critical in my interpretations not only of contemporary issues, but also of all the different historical eras and processes that I discuss in this thesis. Therefore, whilst the arguments set out in Chapters 4, 5 and 6 are correlated in a straightforward sense with various interview extracts, of equal significance to the formulation of these arguments (and indeed to my particular uses of the various extracts) has been my continual reference to the contextual field notes that I kept on a daily basis in Turkana.

Alongside participant observation, I undertook both interviews and focus group discussions on a regular basis whilst in the field. As I outline below, many of these were orientated around the photographic collection that I maintained throughout the research, however a large number also took place without reference to this collection. In both circumstances, interviews took on numerous different forms, at times comprising in-depth biographies or life histories, and at others being focused on specific times, themes or objects. Some interviews were conducted to clarify issues that had emerged through other observations and informal conversations or to obtain information about a certain period or person of interest, such as the interviews undertaken with prominent ngimurok (diviners/ seers) to which I refer throughout Chapter 6, whilst other interviews had no prior objective and developed intuitively in relation 
to their circumstances. All of these different forms of interview have been equally important to my overall analysis.

I also convened focus group discussions in a wide variety of locations at various points throughout the research, at times as an exploratory exercise to develop an understanding of issues that would be carried forward in one-on-one interviews, and at others as a clarificatory exercise to draw together and summarise concepts, narratives or questions that had emerged after prolonged inquiry into a particular theme. In most cases interviews and group sessions were conducted in Swahili, a language in which I am fluent, however they were also often undertaken in Ngaturkana. In these latter instances, I relied upon the intermittent clarifications and translations of research assistants. ${ }^{5}$

A further key source of data was my regular surveying of small markets in a range of locations throughout southern Turkana. I collected inventories of the commodities being sold by each of the traders in attendance at these markets on a monthly basis, gathering contextual information through conversations with them and general observations made on market days. I discuss these inventories in most detail in Chapter 5, where I suggest that the markets' emergence in the last few decades has served to articulate pre-existing exchange dynamics between cultivating and herding communities. However, the inventories were also key points of reference during the formulation of many of the other arguments I set out in this thesis, serving to stimulate numerous critical lines of inquiry and points of discussion throughout my fieldwork. Along with a wide range of significant villages, towns and other locations, I mapped these markets using a handheld GPS device. GPS mapping, which I undertook

\footnotetext{
${ }^{5}$ Whilst I began learning Ngaturkana in 2012, and continued to do so particularly intensively throughout 2014 and 2015, I depended upon research assistants for help during the kinds of in-depth and conceptually intricate interviews that I required for my research.
} 
regularly throughout the research, not only facilitated the production of the various maps presented in Chapters 4, 5 and 6, but was also an activity that could be undertaken in conjunction with interviews and informal conversations, rooting them in the spatial and topographic dimensions of the landscapes to which they referred.

In developing my field notes post-fieldwork, and building up the key arguments that I outline in this thesis, I remained in close contact with a range of individuals in Turkana, regularly discussing emerging ideas and hypotheses and making several shorter trips back to Turkana from Nairobi to hold informal discussions and to clarify various details. I also regularly consulted documents in the Kenyan National Archives, Nairobi, and made use of a range of reports and communications stored in the National Archives, Kew, over several visits. This archival research is perhaps most evident in Chapter 6, where I deploy it alongside various interview extracts in my exploration of early relations between the Turkana and the British during the initial conquest of northwestern Kenya. However, it likewise feeds into a range of other discussions throughout the thesis. As I have noted previously, archives also formed the basis of much of my fieldwork through my visual repatriation of a collection of historical photographs and my utilisation of this collection in a range of photo-elicitation exercises. I discuss this side of my fieldwork methodology in the remaining sections of this chapter.

\subsection{Visual repatriation and photo-elicitation}

It is no secret that the last few decades have seen a monumental shift in the ways museums containing historical ethnographic collections are envisioned, engaged with and utilised in the contemporary world, a development that Peers and Brown (2003: 1) see as 'one of the most important... in the history of museums'. Often-uncomfortable bodies of everyday objects, 
photographs, films and other materials have ascended to an unlikely position at the vanguard of much anthropological outreach and research. This has taken place not in denial, but rather in direct confrontation of various institutions' earlier entanglements with the colonial project, their complicity in the production and representation to Western audiences of visions of primitiveness and otherness and their accompanying roles (in conjunction with early ethnographer partners and contributors) in disseminating and incubating 'literary and theoretical savages' (MacDougal 1997: 279) in popular culture.

Indeed, this troubled heritage, and its enduring legacies in more recent displays, representations and outreach/partnership policies, was the subject of much critique in the 1990s (e.g. Clifford 1991, 1997; Coombes 1994; Harlan 1995; Barringer and Flyn 1998). From these debates, Clifford's (1997: 192-3) conceptualisation of museums as 'contact zones' - spaces where different cultures, worldviews, interests and stakeholders encounter each other and contest the past in an ongoing 'historical, political, [and] moral relationship' — has perhaps been the most influential. The point that these meetings and conversations are ongoing, unfinished and open to the incorporation of heterogeneous pasts and multi-vocal accounts has become critical in numerous research and outreach projects that have taken part in transforming the one-way relationship that had previously existed between museums and their source communities (Peers and Brown 2003; Crooke 2008; Marstine 2006). Museum collections are no longer seen as dead places, lifeless vestiges of colonialism and imperialism, but rather as opportunities to open up new ways of thinking and talking about both past and present — tools that might help to subvert the colonial gaze (and its legacies) and find new values, histories and meanings in its remains. 
In no other museum-based medium is this open-endedness and lack of fixity more profound and valuable than in historical ethnographic photographs, things that Edwards (2003: 83) considers to be 'the most potent of museum objects'. Their very stillness and mutability, the traits that often made them such persuasive indicators of the timelessness and pristineness of societies living at the margins of empire, also imbue them with a powerful potential to express counter-narratives and articulate a diversity of new versions of the times, histories and transformations that they depict (Poignant 1994; Edwards 2001, 2003). Their place in museum collections has, in many cases, been unveiled as inconclusive and temporary, a singular stage in a still-unfolding biography (Bell 2003). Visual repatriation, and the oftenaccompanying field method of photo-elicitation (Collier and Collier 1986), have seen these objects take part in, and become tools that are used to tell, neglected and supressed histories in the locales to which they pertain, rather than simply remaining as enclosed visions of the past that are read in silence and obscurity. Whilst the act of returning such photographs to source communities and using them to gather new information is not without theoretical and ethical implications (e.g. Niessen 1991; Thomas 1997), it has nevertheless provided many museums with a much-required means of building relationships with peoples who are geographically remote from their facilities. In the process, many communities across the globe have embroiled collections of historical photographs in local knowledge systems, inscribing personal experiences of past places, people, events and objects on to them and using them to address ongoing social, economic and political issues (e.g. Bell 2003, 2008, 2010; Binney and Chaplin 2003; Carrier and Quaintance 2012).

Meanwhile, as discussed in Chapter 1, archaeology has been undergoing a parallel and similar transformation. In conjunction with its move away from previously made correlations between history and European encounter or occupation, historical archaeologies that are 
broadly positioned as postcolonial have become less about merely collecting the past for interpretation and presentation elsewhere and more about public engagement and community collaboration (Greer et al. 2002; Harrison and Williamson 2004; Davies et al. 2014; Schmidt and Pikirayi 2016), the exploration of indigenous historical narratives, the retrieval of pasts that are valuable or 'useable' (Lane 2011; Stump 2013) in the contemporary world and connected local and global political issues. In much the same way as visual anthropology has done by means of museum collections, archaeology has, in such contexts, come to serve as a vehicle for the construction of narratives that might controvert and disrupt the lingering repercussions of older interpretative models based on the notion of progressive social evolution.

This divergence and yet mutual significance of postcolonial historical archaeologies and recent developments in visual and museum anthropology struck me when I was surveying the extensive ethnographic objects and photographs from Turkana in the archives of the Pitt Rivers Museum in 2013. Both enterprises seemed to me to be grappling with the same objectives, confronting similar troubled disciplinary pasts and finding new ways of inserting themselves into non-Western epistemologies and narratives that the broader disciplines of archaeology and anthropology could, in turn, be influenced by and perhaps even re-imagined through. In doing so, however, they were forging new methodological paths that drew close but did not fully converge.

\subsection{Photographs as archaeological tools}

What made this recognition particularly pertinent was the fact that numerous features of the collection from Turkana that lay before me argued for its relevance to archaeological analysis 
and interpretation. Albums of ethnographic photographs and accompanying artefacts are, after all, the deposits made by various interventions into Turkana through the years, 'the cumulative remains of multiple past processes' (Lucas 2004: 38) existing as a kind of palimpsest many miles away from the initial sphere of their enactment. Indeed, it so happens that the Pitt Rivers Museum contains a uniquely expansive collection from Turkana, with the earliest objects and images dating to the years of colonial conquest at the dawn of the $20^{\text {th }}$ century and the latest donated in the 1990s. These gradually accumulated residues document subtle changes in the production, use and exchange of a range of everyday objects throughout the various social, economic and political transformations that have manifested themselves in northern Kenya over the last century. As is the case in numerous archaeological sites, this has largely been the result of accident rather than purposeful preservation. The changing materiality of everyday life is thus not necessarily patently discernible in the collection, but can rather be located in backgrounds and subtle details — the presence or absence of shells in female neck ornamentation, for example, or the shift from leopard and baboon skins to large cotton blankets in male clothing.

It also became apparent to me during my early encounters with the collection that by accidentally apprehending these details it had served to undermine the vision of Turkana that many of the individual albums and photographs were initially designed to portray. Images of a romantic 'vanishing race' had, over time, accumulated into a much larger and more detailed picture of a dynamically changing population, a cluster of communities who have continuously incorporated new materials into a changing socio-material universe, reimagining various practices, institutions and objects along the way. The colonial gaze had been collapsed by the passage of time, by the very materiality of the "colonial visual economy' and its physical endurance beneath a slew of later deposits. To a place like 
Turkana — still shadowed by the legacies of its colonial past and regularly represented through various visual tropes in the popular press as a timeless and purely traditional world — the counter-narratives captured in the Pitt Rivers Museum collection could not be more significant, more urgent.

It was the recognition, however, that these narratives (of which I could only catch quiet and vague glimpses) were dormant and unable to surface away from the memories, knowledge, experiences and voices that might fully disclose them that led me to formulate a visual repatriation project. I imagined that such a project could perhaps 'convey a past that had not died in individual memories, but which had been suppressed in the European-recorded historiography' (Binney and Chaplin 2003: 100), as was the case with the early $20^{\text {th }}$-century collection of photographs of Maori elders visually repatriated by Binney and Chaplin. However, unlike this and many other like-minded projects, I wanted to find out what might emerge from a fuller temporal range of photographs and a focus on changing material culture. It was with these intentions that I amalgamated an assortment of historical ethnographic photograph collections into a single chronicle, which I augmented with my own photographs of various Turkana artefacts from the Pitt Rivers Museum and other collections and brought to southern Turkana in June 2014. Edwards (2003: 90) maintains that people do not merely talk about historical photographs but rather 'talk with them and weep over them', their ambiguity and silence serving to transform them into tools that can be used to tell numerous divergent accounts of the past. I wondered what they might do as archaeological tools. 


\subsection{Returning the gaze}

The collection that I brought to Turkana in June 2014 comprised over 150 photographs. Within it, the early colonial era was represented by Ernest Emley's images from the 1920s, one of which is shown in Figure 2.2, followed by a selection of shots dating to the 1930s and 1940s which feature in Nigel Pavitt's (2008: 218-219) photographic account of the formation of Britain's Kenya colony. Photographs taken by the explorer and travel writer Sir Wilfred Thesiger on his first visit to Turkana in the early 1960s, such as that shown in Figure 2.3, portrayed scenes from the middle years of the $20^{\text {th }}$ century and were followed by images from his last visit in the 1980s. More recent decades were represented by photographs from a range of anthropological and ethnohistorical research publications. High quality versions of all images were printed and brought into the field as a chronologically ordered catalogue, the images used were selected to represent a wide range of places, people and objects. The collection was moved around southern Turkana to a wide variety of villages, towns, marketplaces and homesteads. The photographs were passed around in numerous contexts, from large-scale discussion sessions comprising groups of over 50 people, to more focused one-on-one interviews (Figures 2.4-2.10). 


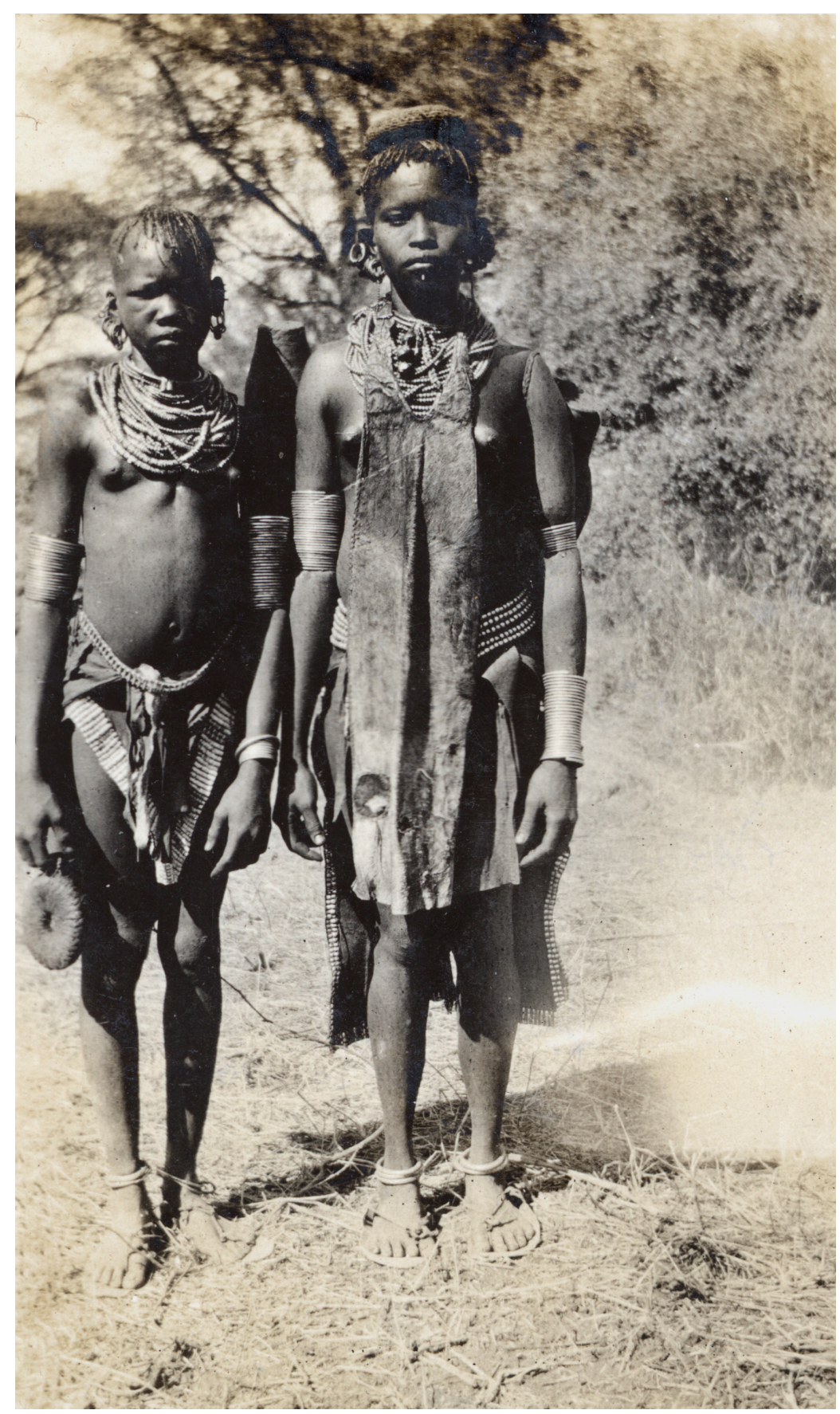

Figure 2.2. A photograph of two young Turkana women taken by Ernest Emley in the early 1920s. Emley's intention with this image was most probably to portray two distinct styles of dress and body adornment - those of unmarried and married Turkana women. The girl to the left of the photograph, being unmarried, is wearing a short triangular leather apron, whilst the girl to the right is wearing skins of a longer length and extensive ostrich eggshell beads.

Like much of his writing on Turkana, Emley produced such photographs to simplify and generalise aspects of daily life, organising them into categories that might be more easily understood by Western audiences. His photographs and accompanying descriptions, if taken at face value, work to disguise variation across both space and time. Accession no. 2003.132.3.8. Pitt Rivers Museum, University of Oxford. 


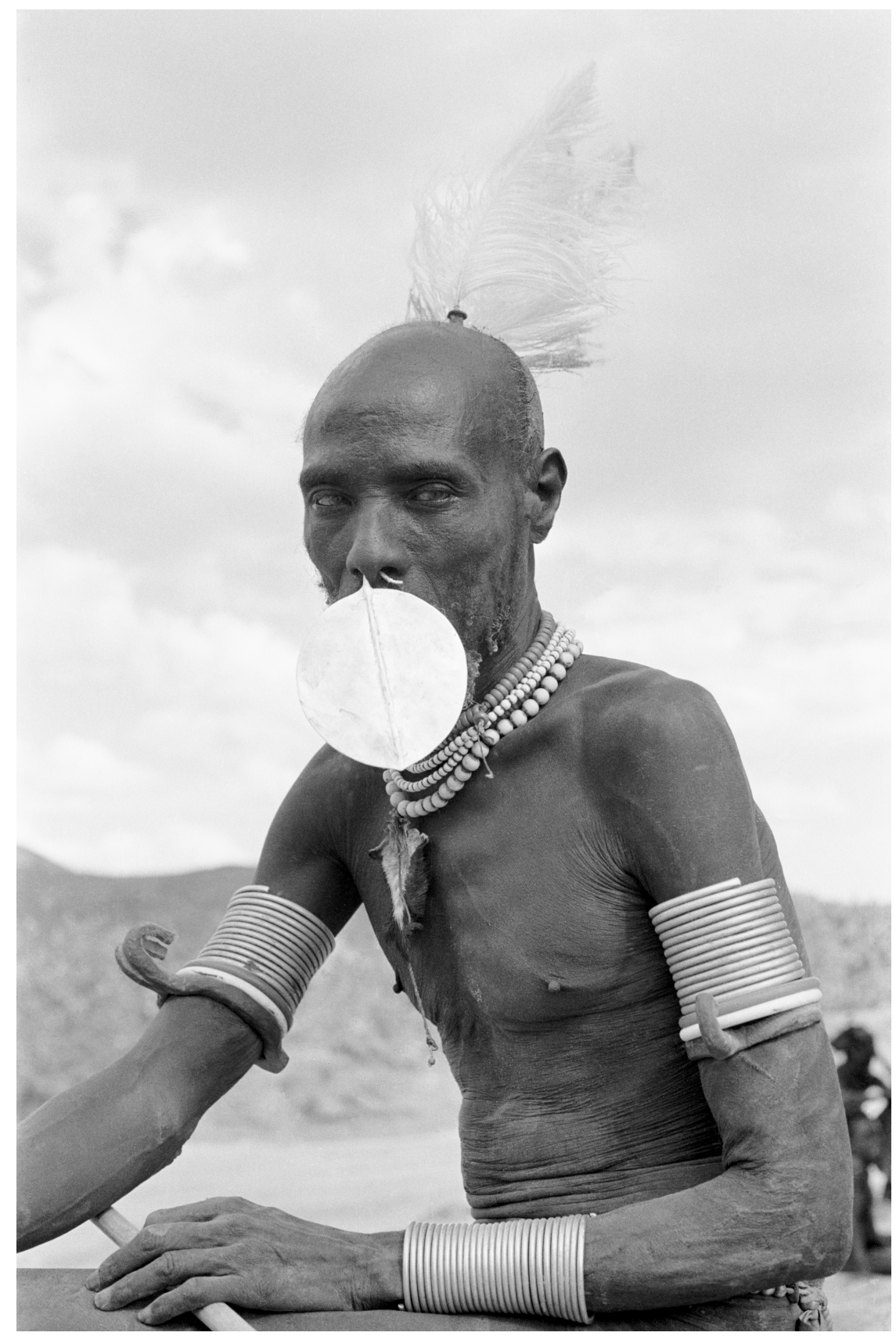

Figure 2.3. Towards the end of the colonial era and into the decades following Kenya's independence (1963), photographers who reached Turkana began to opt for more romantic and idealistic representations of the region and its people, a trait that has, to a large extent, endured into the present day. One of the earliest and most significant bodies of Turkana images to comprise these characteristics is the work of Wilfred Thesiger, who first visited the region in the early 1960s. Thesiger's photographs from this time have been described by Edwards (2010: 106) as 'markers of time and simultaneously a projection into timelessness'. His romantic engagement with the landscape, careful framing and use of light, Edwards argues, work together to endow his numerous subjects with a sense of ancient nobility. Such aesthetic qualities can be recognised in this photograph, which was taken by Thesiger in 1961. The heavily adorned subject, a prominent leader and emuron (diviner/seer), is shot from a low angle. He looks down to the lens in a regal pose that is framed only by muted clouds and a soft and low-set horizon. Accession no. 2004.130.30279.1. Pitt Rivers Museum, University of Oxford 
As I noted above, despite the nature of their fabrication and their inventive vision of Turkana, the photographs in the collection nevertheless inevitably, and usually unintentionally or inadvertently, captured various everyday and mundane aspects of the changing Turkana socio-material universe. It was with the objective of emphasising these features that I crosscompared them with object collections at a range of institutions prior to my fieldwork, and interspersed my own photographs of these objects throughout the larger collection. Using material culture to draw out broader socio-economic, political or environmental changes over long periods of time is, of course, a manner of inquiry that is central to archaeological research undertaken in numerous contexts. Archaeology, as Schiffer (1991: 4) points out, is not only by necessity orientated around everyday things, 'but it aims at extracting as much detail as possible about the people who made and used those things found in the ground'. This archaeological predisposition to focus on the detail that inheres in quotidian materialities, however, also aligns with recent trends in the reading of historical photographs in the world of visual anthropology. In particular, Edwards (2001: 2) points out that 'a concentration on content alone, ethnographic appearance — the obvious characteristics of a photograph - is easy, but will reveal only the obvious. Instead one should concentrate on the detail'.

During the photo-elicitation sessions that I undertook in Turkana, this focus on material culture, both in terms of the inclusion of my own photographs of ethnographic object collections and the particular questions I pursued, constituted one of the most significant influences that I had on the narratives that emerged. This is not to say that people did not use the photographs for a range of other purposes and to tell a wide variety of other stories less concerned with quotidian material histories. To the contrary, many used the collection to name certain deceased individuals or to trace their own genealogies. Figure 2.10, for 
example, depicts a scene from a meeting in Nakoret, in which a prominent diviner holds a photograph of his own grandfather, known as Lodip, who had been photographed by Thesiger 54 years previously in a nearby location. The inquiries that I contributed were influenced by all of these other narratives and by the ways people came to interact with and use the photographs. My interest in changing material culture, although prominent and influential during many exchanges, was thus not passive, but rather crafted collaboratively over the months. It was reinterpreted constantly by those who responded to my questions in diverse ways, at times answering with their own questions and at others amending and reorganising my initial question before replying, but always reforming and remaking the knowledge that slowly accumulated.

Another key influence in the shifting conversations was the form of the collection itself. The affectivity of the photographs did not emerge from their 'volume, opacity, tactility and a physical presence' (Batchen, 1997: 2) in a straightforward sense, but rather these qualities seemed to be tightly bound up in the images' representation of many different times and places. In other words, the presentational form of the collection — the chronologically ordered catalogue — was made deeply consequential through the changing styles and colours of visual representation that it comprised. This became clear to me on many occasions, as I observed how individuals made sense of various stylistic transitions, sometimes sorting the images into piles according to the qualities and colours of the photographs and often remarking on the superiority of the more recent images. It was clear that the changing toning and surface effects of the photographs were powerful indicators of the temporal distance between the different albums and of the passage of time that the overall collection reflected (cf. Edwards 2002). I would argue that all of these qualities led the collection to evoke 
accounts of the past that were structured around longer-term narratives of incremental change as opposed to the dichotomy of 'past vs. present' or 'then vs. now'.

Moreover, despite their arrangement into chronological order and their depiction of consecutive eras, the photographs did not work to evoke a singular narrative of change over the last century. Instead, those who spent time with the images used them to tell stories that not only related to many different times, but also to many different rates and scales of change. Whilst some used them to explore specific memories of objects and locations, or events in which these had been implicated, others opted to narrate much broader changes to society, exchange relations and the environment that have unfolded over several generations. To some, the photographs presented an opportunity to recount their life-story, and yet to others they were a means of outlining the ways in which an entire community had transformed for better or for worse. 


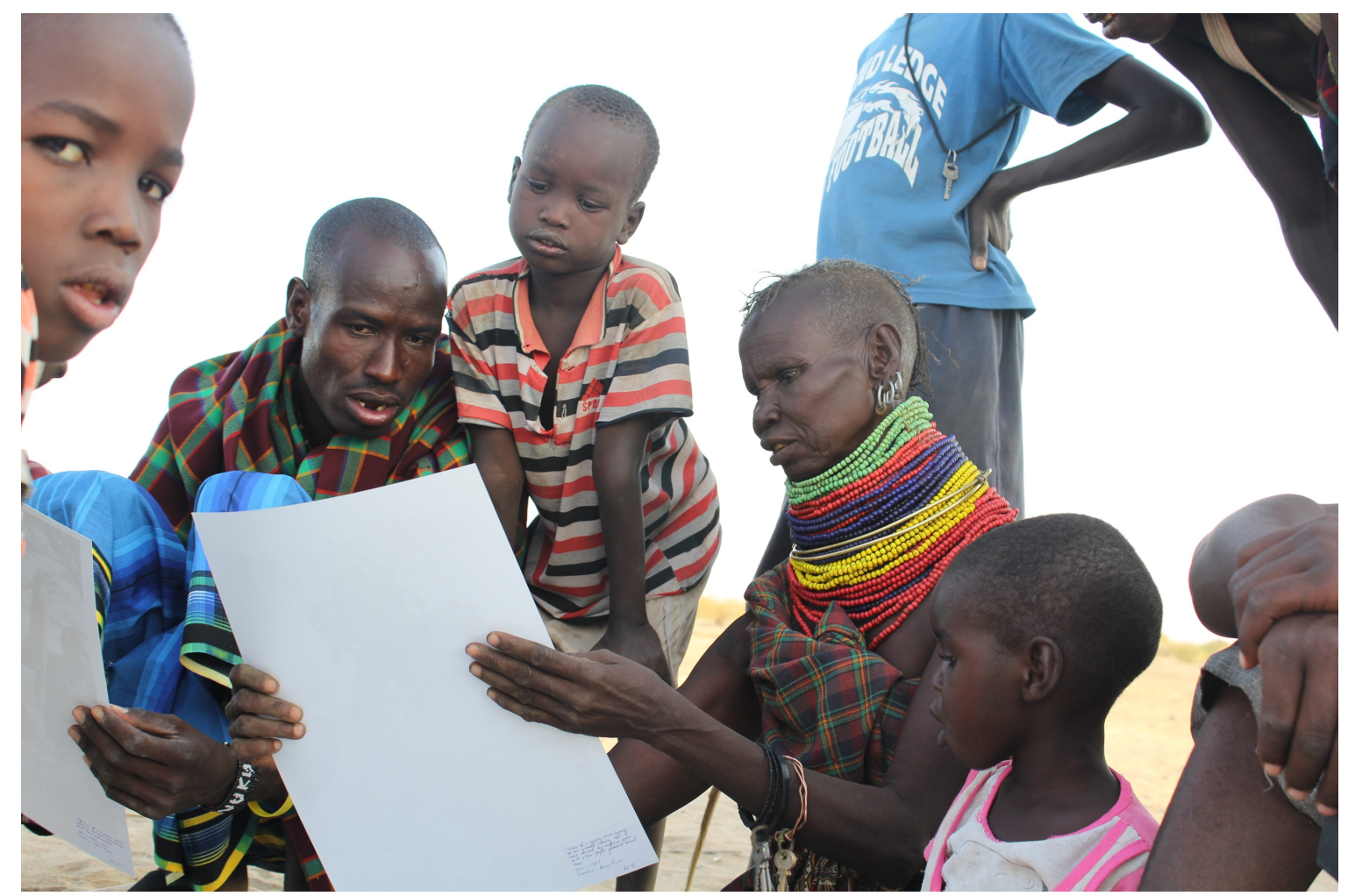

Figure 2.4. Emeri Lowasa discussing one of Thesiger's photographs with her son, Namoe, as other family members look on.

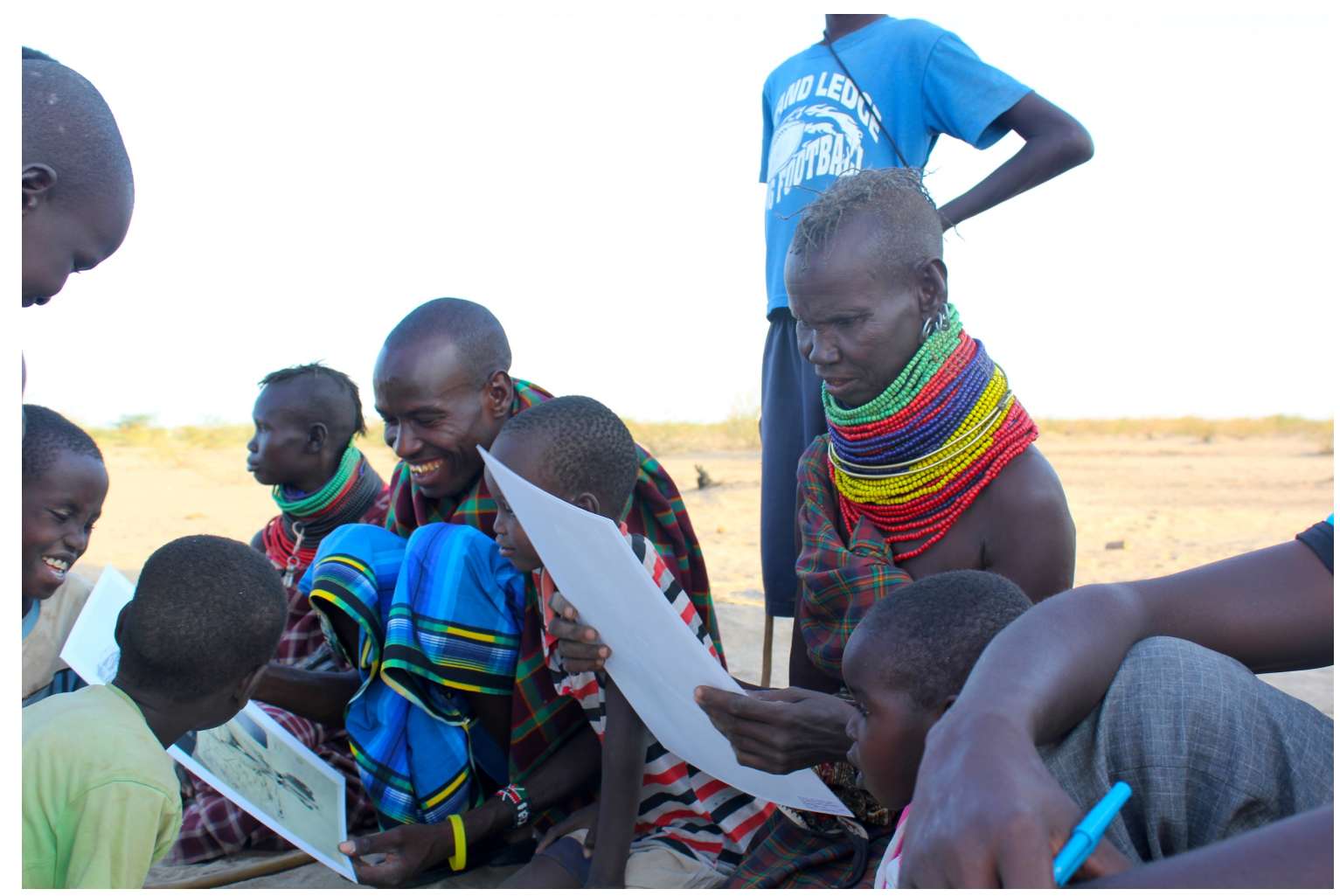

Figure 2.5. The Lowasa family browsing the collection. 


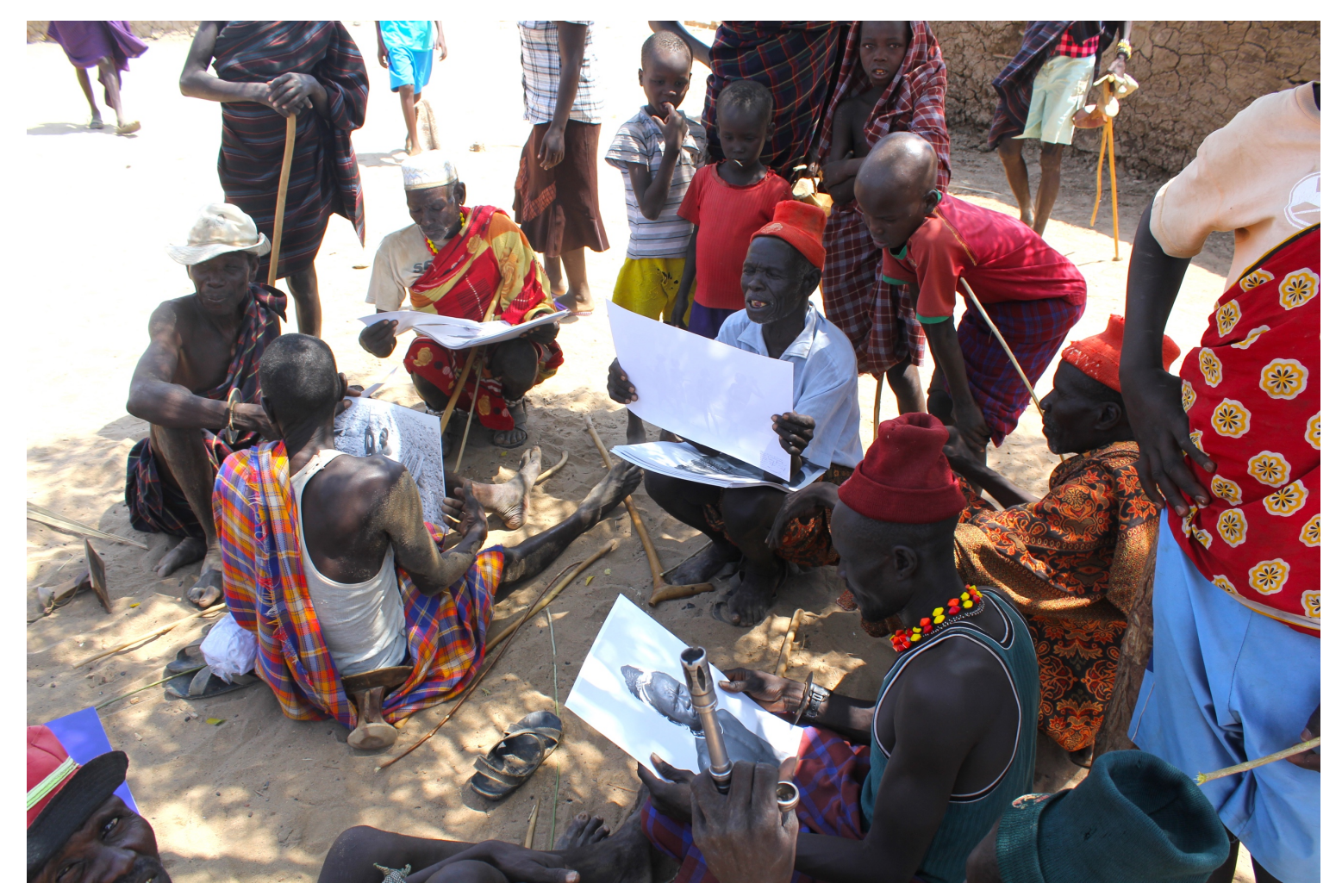

Figure 2.6. The collection is passed around by a group of men at a discussion session in Nakurio.

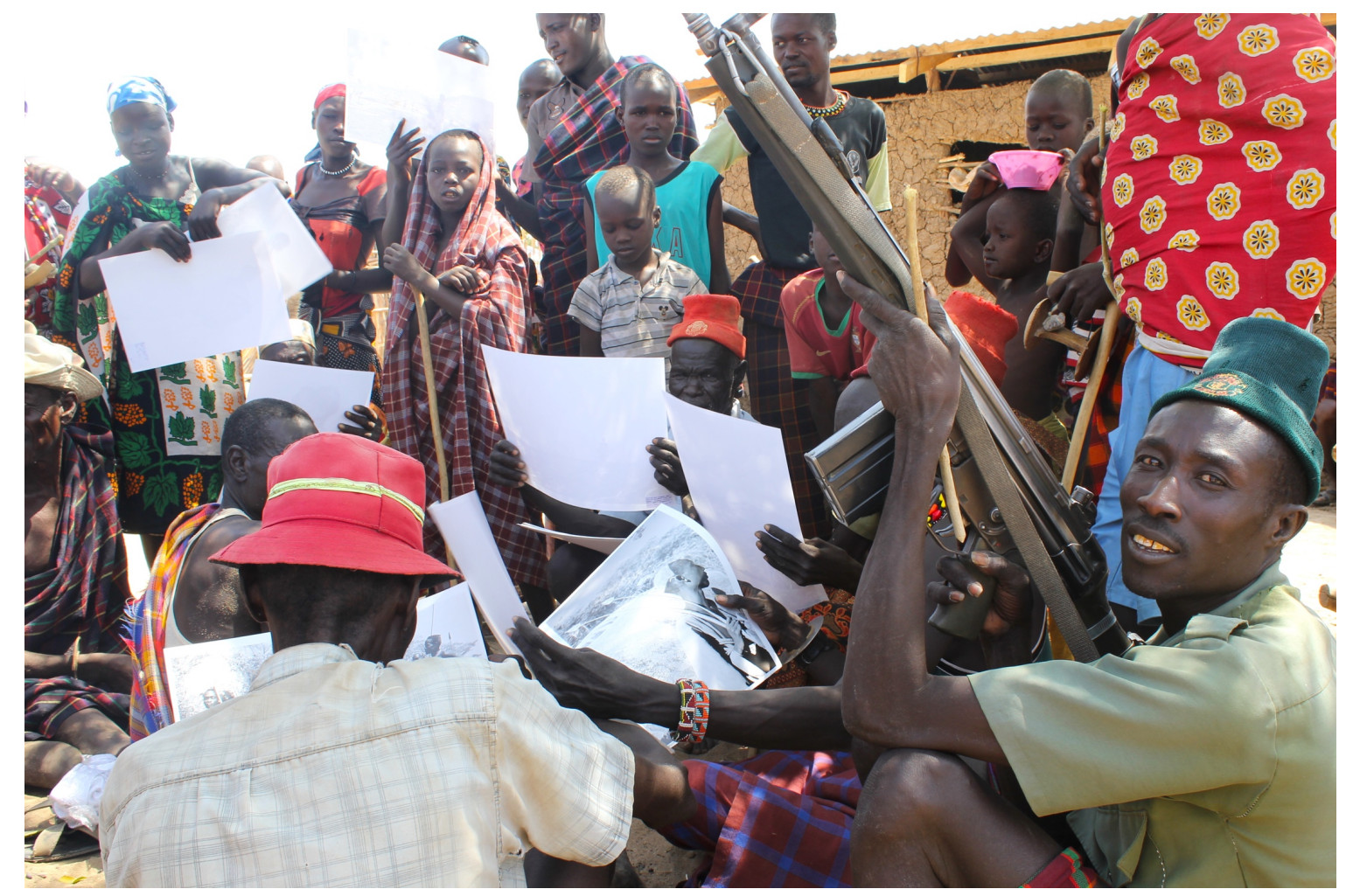

Figure 2.7. At the Nakurio discussion session, a man poses with his rifle for a photograph in response to seeing images of men posing with their spears. 


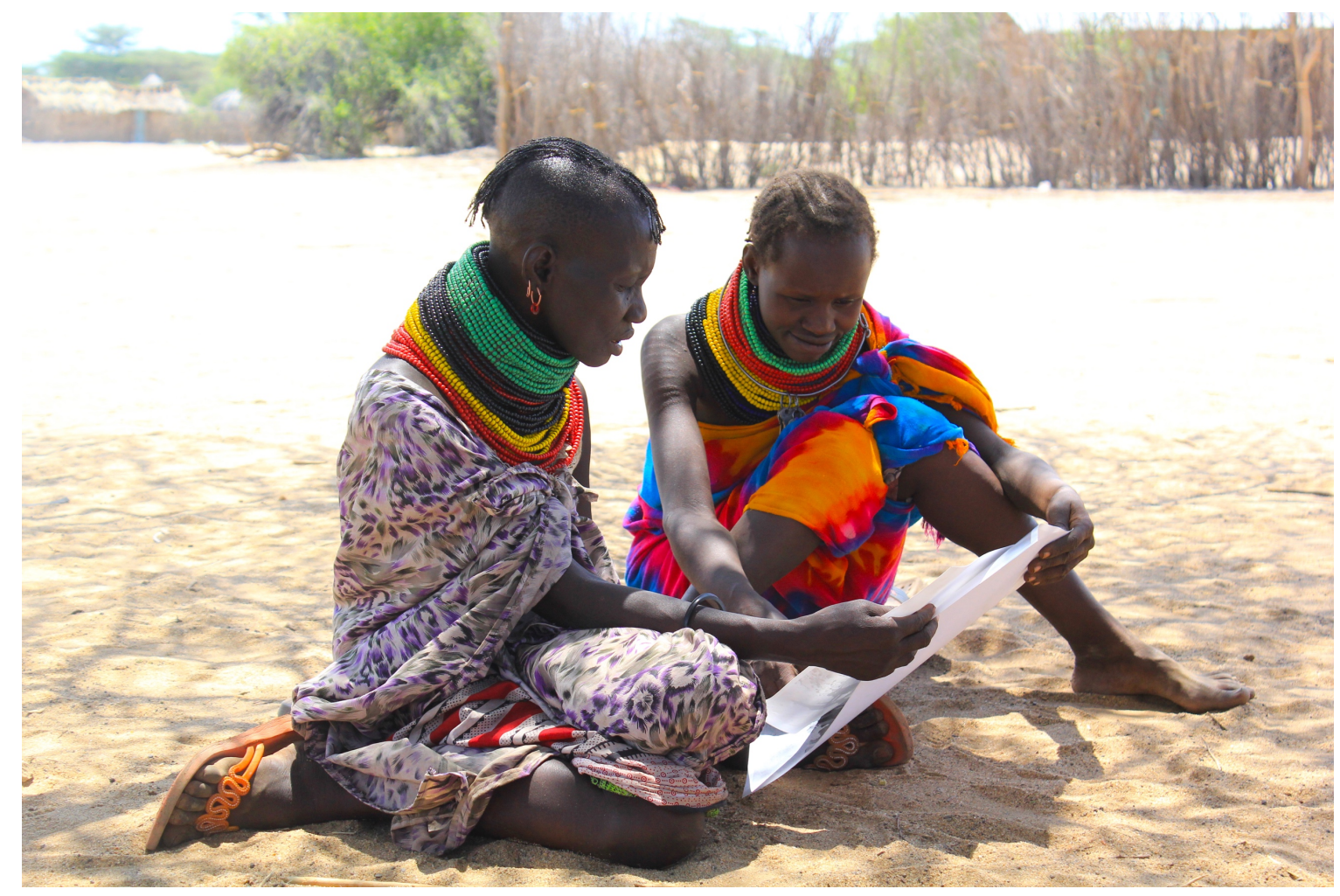

Figure 2.8. Two young women discussing a photograph at a group discussion session in Kangarisae.

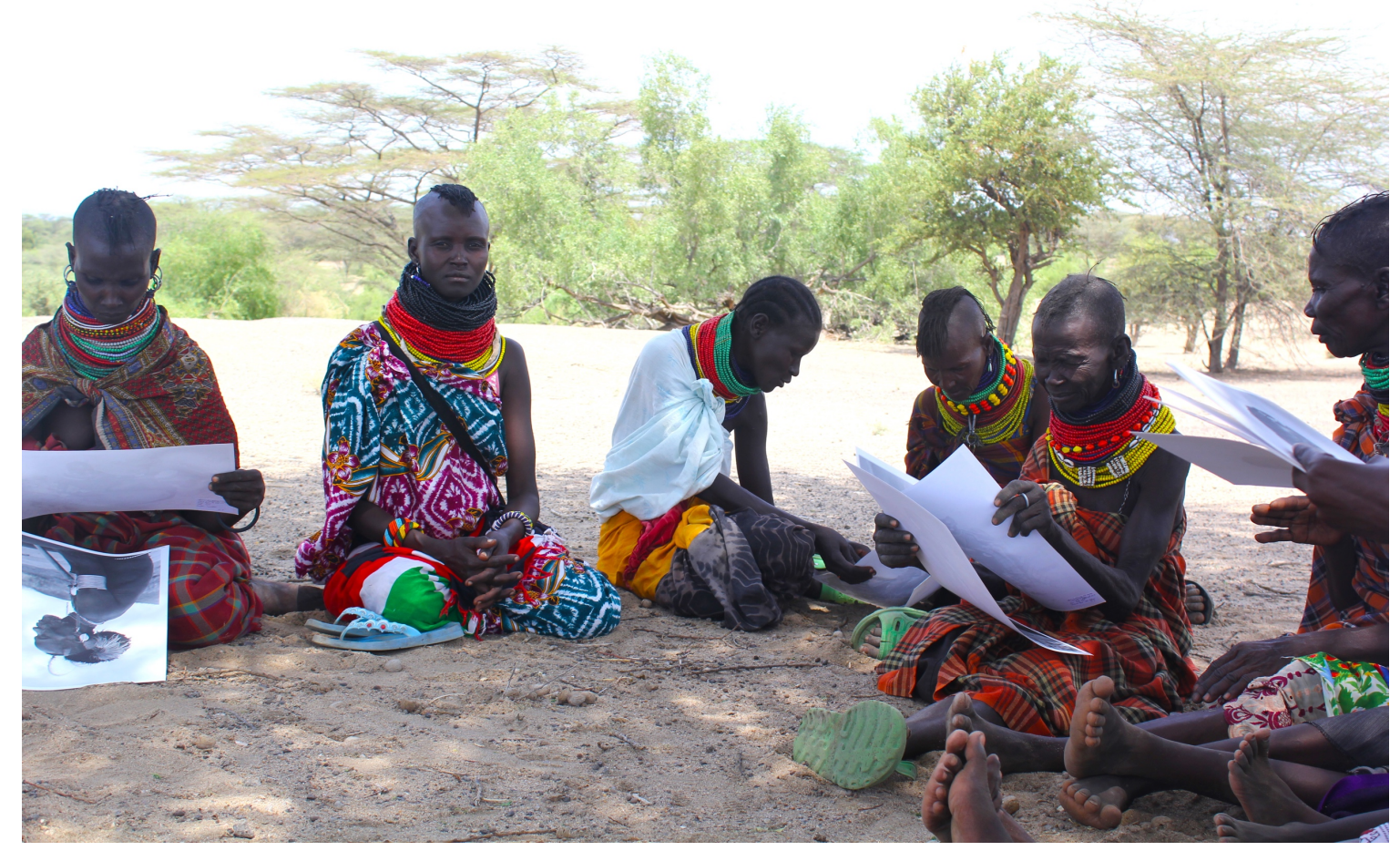

Figure 2.9. A group of women exploring the collection during a discussion session in Nakoret on market day. 


\subsection{Summary}

As I suggested in Chapter 1, the idea that an archaeological approach to ethnographic photographs might provide historical narratives that actively subvert and contradict the very vision that both archaeology and photography have historically co-functioned to reinforce is, on one level, politically significant. It at least has the potential to be so in the future as the project to decolonise archaeological theory and practice continues (cf. Ogundiran 2015; Schmidt and Pikirayi 2016) and various museum collections become ever more accessible to source communities across the globe. As both these processes continue to gather pace, the point that historical photographs tend to become 'symbolic of peoples' desires to control their own histories and their own destinies' (Edwards 2003: 84) might perhaps instil deeper methodological and theoretical connections between postcolonial African archaeologies and visual anthropology. Indeed, whilst the approach I have taken in this thesis is just one possible example, and largely experimental and exploratory in nature, I suggest that it makes a strong case for the advantages that similar collections of historical ethnographic photographs might bring to archaeological research seeking to engage with African histories.

Perhaps it is true that 'the master's tools will never dismantle the master's house' (Lorde 1984: 113). Yet, as Colwell-Chanthaphonh (2012) argues, dismantling the house altogether is perhaps not essential to the task of decolonising archaeology. We might instead attempt to 'reimagine and remake contemporary archaeology... constructing more rooms for more people, new rooms for new views' (Colwell-Chanthaphonh 2012: 282). Such an act of reimagining and remaking will surely only be possible in the house of theory if it also takes place within the very toolset at an archaeologist's disposal, and it is to this latter task that the possibility of historical photographs as archaeological tools is most pertinent. To provide 
some critical context for the arguments that arise from my use of historical photographs as archaeological tools, the following chapter discusses Turkana in historical and ethnographic perspective. 


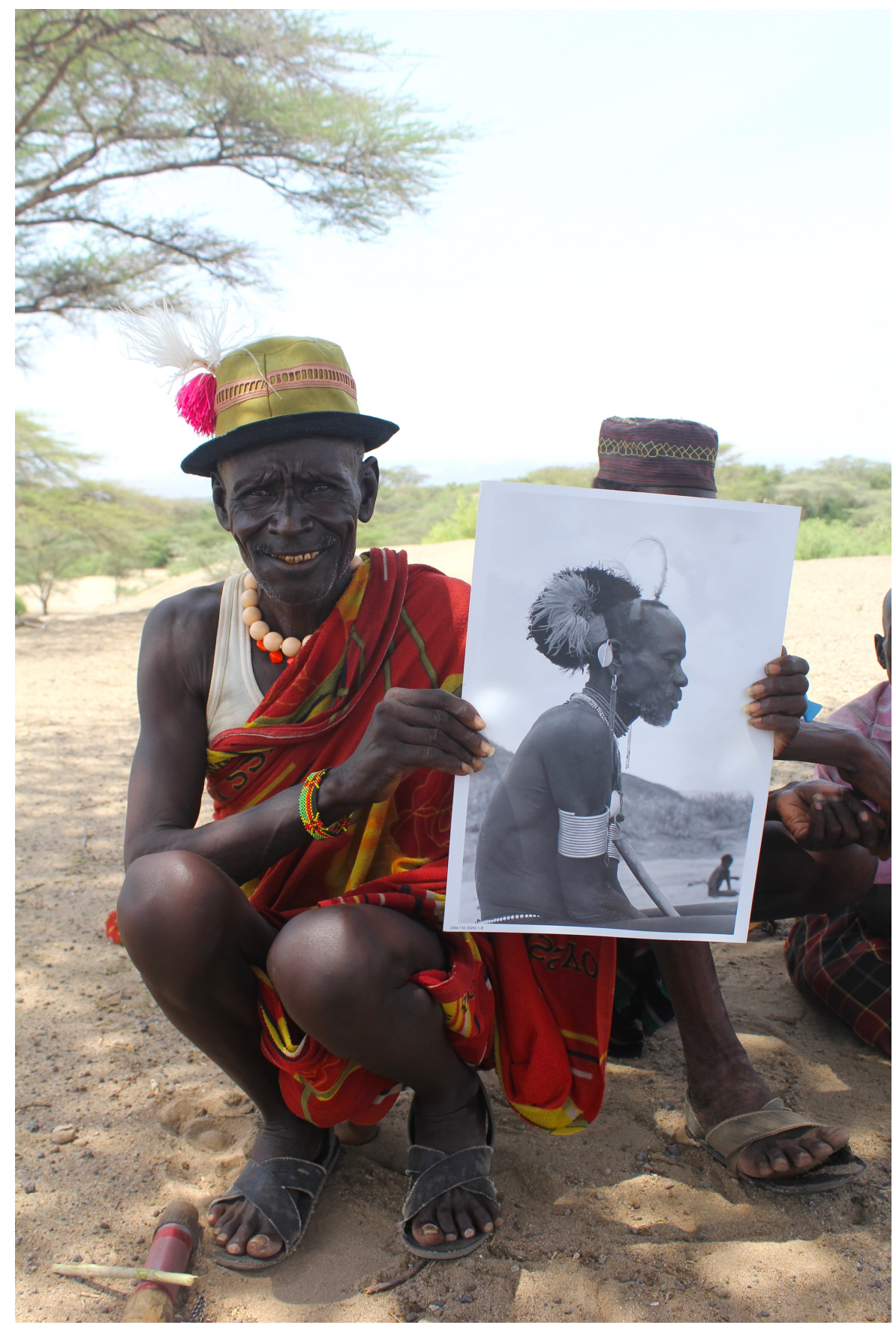

Figure 2.10. A man from Nakoret holds up a photograph of his grandfather, which was discovered during an examination of the collection. The photograph was taken 54 years previously by Thesiger in a nearby location. 


\section{Chapter 3: Turkana in historical and ethnographic perspective}

I noted in Chapter 2 that the Turkana region encompasses over $68,000 \mathrm{~km}^{2}$. This expansive area is situated almost exclusively within the bounds of the Gregory Rift (the eastern branch of the East African Rift fracture system) and is enfolded by Ethiopia to the northeast, South Sudan to the north and Uganda to the west, the southern border of Turkana County being the only one that connects it to the rest of Kenya. Turkana's topography predominantly consists of low-lying arid and semi-arid plains, broken intermittently by a series of significantly less arid hill and mountain ranges (15 in total; Figure 3.1). Rainfall is extremely low and intensely variable (Ellis et al. 1993), with severe droughts occurring on a relatively regular basis. Various annual grasses emerge following periods of substantial rain and are crucial to those maintaining large herds of cattle. Otherwise, the dominant vegetation consists of mixed shrubs and acacia trees, with denser and more varied woodlands (encompassing various palm species) occurring on the banks of major rivers. To the east of Turkana County lies the closed-basin semi-saline Lake Turkana, the fourth largest of the African Great Lakes (Yuretich and Cerling 1983; Kolding 1992). Lake Turkana covers an area of $7560 \mathrm{~km}^{2}$ (Kolding 1992), although this has already begun to reduce following the construction of the Gibe III Dam on the Omo River, the lake's primary water source.

In this chapter, I provide some necessary contextual information to frame the analyses and discussions I present in Chapters 4, 5 and 6. I illustrate some major aspects of Turkana's social geography, clarifying how its population is dispersed across this unique landscape and some of the ways in which its diverse communities engage with and prosper by means of a considerably volatile environment. Section 3.1 discusses the dynamics of the Turkana pastoral economy, referring to the key literature in the process. Section 3.2 gives a broad 
account of the basic features of Turkana social organisation and Section 3.3 a brief historical overview of the region, succinctly delineating the origins of the Turkana, their expansion into their current territory, their colonial conquest and their post-independence interactions with various development interventions.

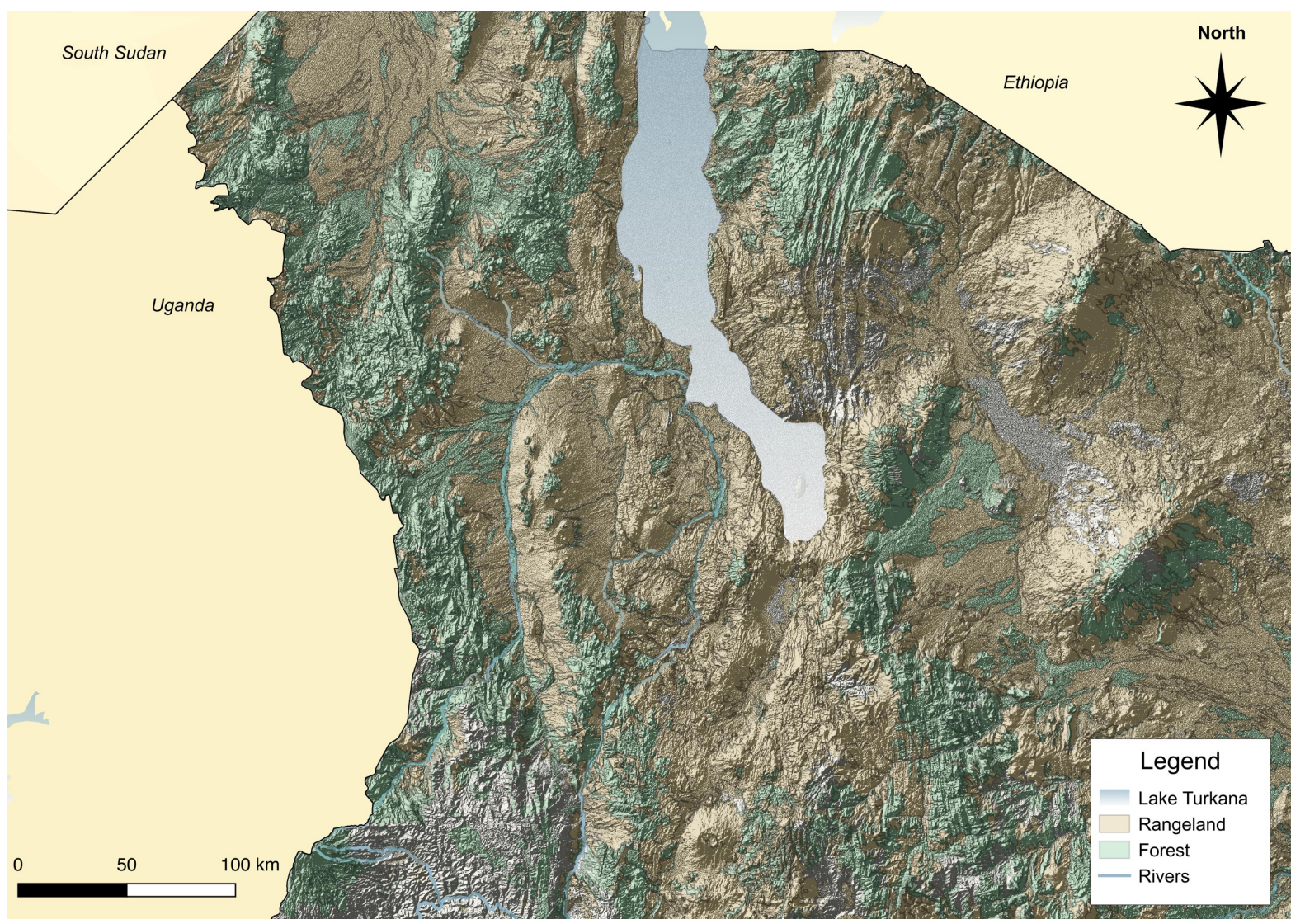

Figure 3.1. Topographic map of Turkana showing the rough distribution of forest and rangeland. 


\subsection{The Turkana pastoral economy}

Turkana's population is, according to a Kenyan national census undertaken in 2009, currently above 855,000 , although this should be viewed as a rough approximation and includes over 150,000 refugees (mostly from the civil war in South Sudan) settled in the Kakuma refugee camp (KNBS 2009). The majority of this population, roughly two-thirds according to McCabe (2004: 39), are directly engaged in pastoralism on a permanent basis, raising and herding five core species of livestock: camels, cattle, sheep, goats and donkeys. The hot, arid and extremely unpredictable environment of northern Kenya is negotiated by these herders via a programme of intense mobility, with mixed herds being divided, scattered and reunified on a regular basis relative to the individual watering, grazing and browsing needs of constituent livestock, the capabilities of leading herders, the availability of water, pasture and forage, the threat of raiding from enemy groups and disease. Turkana pastoralism is thus a fundamentally complex and strategic occupation, requiring immense skill and successful only by means of an adequate depth of knowledge and experience. It is also inherently fluid, an individual's daily decisions being made in relation to an intricate and continually shifting web of known and estimated socio-economic, political and environmental factors (cf. Scoones 1996).

As I noted above, the Turkana region is subject to regular and often severe droughts. These have, on numerous occasions throughout the last century, engendered a critical short-term reduction in natural resource availability and widespread livestock decimation (Hogg 1982, 1987; Ellis et al. 1987). In such instances, large portions of the herding sector have, following extensive livestock losses, generally been driven to settle in cultivating or fishing populations for short-term relief where they rely on any remaining herds of small livestock (sheep and 
goats) and fish/agricultural produce (Broch-Due 1999). Over the last few decades, 'famine camps' and relief food (which are constructed/delivered by various government and nongovernment development organisations) have also come to be incorporated into this drought response strategy, a point I discuss in more detail in Chapter 5. In these times of emergency, the impacted population tends to remain static for a period of several months or years until environmental conditions improve and herds can be accrued once again. However, it should also be pointed out that on top of seeking refuge in farming/fishing communities and famine camps, some segments of the herding sector are inclined, during such times, either to move into hill ranges or to migrate deep into the territories of neighbouring pastoralist groups in order to conserve dwindling herds. The territory of the Karamojong in northeastern Uganda is by far the most common of these drought-time destinations. In more recent years Karamojong-Turkana relations have been relatively peaceful, ${ }^{6}$ but having said this, drought inevitably substantially increases conflict in all of Turkana's border regions, with outlying rangelands and hilly areas usually becoming arenas of intense violence and livestock theft.

As I noted in Chapter 1, the fundamental adaptability and dynamism of Turkana pastoralism has recently been the subject of works that have, as part of a broader movement in studies of pastoralism, sought to demonstrate its 'nonequilibrial' or 'disequilibrial' nature. This has largely been in distinction to previous characterisations of pastoral ecosystems as generally 'equilibrial' (Hardin 1968; Brown 1971; Lamprey 1983) that were deeply influential to the formation of colonial and postcolonial development policies regarding pastoralist rangelands. In seeking to discredit views of pastoralism as an anachronistic lifestyle incompatible with 'sustainable development' as ecological carrying capacities are surpassed, what Ellis and

\footnotetext{
${ }^{6}$ Such a migration occurred very recently when, due to a lack of substantial rains over much of Turkana during 2016-2017, several large groups of Turkana herders moved across the border into northeastern Uganda in search of pasture.
} 
Swift (1988) call the 'pastoral paradigm', many studies of African pastoralist communities undertaken over the last few decades have argued that the 'boom and bust cycle of livestockbased economies .... [should] be understood as a normal and expected outcome of the system's unstable dynamics' (McCabe 2004: 37). In other words, pastoral economies situated in arid and semi-arid regions of Africa are inherently unstable but nevertheless durable. They are able to weather regular and sometimes drastic environmental fluctuations, and other catastrophes, by means of an innate flexibility that comprises a series of coping strategies during times of stress and rapid livestock reproduction during times of abundance (Ellis and Swift 1988; Westoby et al. 1989; Benhke and Scoones 1993; McCabe 2004).

This disequilibrial characterisation of Turkana pastoralism has significant connotations with regard to development planning and practice. Indeed, it is now a well-established argument that encouraging herd reduction, the privatisation of communal rangelands and alternative economic pursuits in Turkana is not only unnecessary, but also detrimental to a large portion of the population (Swift 1977; Hogg 1987; Monbiot 1994). It has been suggested on many occasions that development organisations should instead support the flexibility of pastoralism by protecting rangelands and herds and safeguarding pastoralist institutions and coping strategies (McCabe 1987, 1990, 2004; Ellis et al. 1991, 1993). ${ }^{7}$ The various case studies I explore in this thesis certainly serve as evidence to support these arguments. They underline some of the catastrophic developmental consequences of unsophisticated and unquestioned interpretations of the Turkana pastoral economy, and stress the need for development interventions, if they are to take place at all, to be aimed at supporting its existing dynamics

\footnotetext{
${ }^{7}$ McCabe (2004) also makes the point that enduring visions of East African rangelands as under threat from pastoralist societies who have an irrational and unquenchable fixation on the accrual of extensive livestock herds can be traced back to prominent colonial era ideas. In particular, Herskovits' (1926) article describing what he perceived to be a 'cattle complex' in pastoralist peoples was both influenced by, and extremely persuasive in advancing, such widely held assumptions.
} 
rather than engendering systemic replacement or overhaul. I discuss these points in more detail in Chapter 7.

Chapters 4 and 5 focus on fishing and cultivating communities in southern Turkana, populations that have, as I previously noted, historically provided refuge for destitute pastoralists during times of stress. These communities comprise a significant portion of the region's overall population, possess long histories of habitation in river and lakeside environments and continue to utilise these resources with expert skill. Whilst their numbers are known to swell during times of stress as members of the herding sector seek sanctuary, they do not merely comprise stock-less pastoralists. Indeed, these communities' indispensability to the wider population is by no means confined to the last resort they offer during droughts and famines. Rather, by means of their changing roles in dynamic regional exchange systems, they have served as integral components in the broader economy on a year-round basis since beyond living memory.

\subsection{Social organisation}

The Turkana pastoral economy thus comprises a diverse array of subsistence procurement strategies, which interact by means of spatially and temporally varied systems of mobility, co-operation and exchange and in so doing are broadly oriented around the central occupation of raising and maintaining large mixed livestock herds. The complexity of this economic structure is mirrored in, and largely engendered by means of, the equally complex organisation of Turkana society. Describing Turkana social organisation in any kind of comprehensive manner would probably not even be possible in an entire thesis, let alone a single chapter. Moreover, like the broader economy that they underpin, the various units that 
comprise Turkana society are continually transforming, dissolving and emerging in relation to each other, they are thus always at risk of being construed collectively by means of overlygeneralised statements. Nevertheless, in this section I briefly summarise some of the core elements, features and institutions of Turkana social structure in order to provide an interpretative framework for the rest of this thesis.

\section{Ngikwetela}

The ekitela (plural ngikwetela) is a territorially specific section into which all Turkana are born. There are some 18 or 19 ngikwetela dispersed throughout Turkanaland, the boundaries between them generally delineated by various topographic features (Gulliver 1955; Soper 1985; McCabe 2004; Figure 3.2). Within an individual's ekitela, he and his livestock are guaranteed access to forage and open sources of water such as rivers, streams and shallow pools. It should be noted, however, that some water sources are governed by rules of access that are not contingent on the ekitela. Small wells, for example, are not open for all to use, but are managed by a single individual (usually the person who dug them) and his stock associates, friends and extended family. In southern Turkana, ngikwetela tend to serve as grazing enclaves that are guarded from ubiquitous use, their boundaries enforced by councils of elders whose permission must be sought from members of external ngikwetela before access is granted (Dyson-Hudson and McCabe 1985; McCabe 2004: 54). In the north, however, Gulliver (1951) and Lamphear (1992) have argued that boundaries between territorial sections are enforced to a much lesser extent, with herders passing relatively freely between them and crossing several ngikwetela during the dry season. 
Due to their geographical specificity, Turkana's fishing communities are not dispersed throughout the ngikwetela, but are contained within the small number of sections that encompass segments of Lake Turkana's shore. These are the Ngisiger, the Ngibocheros and the Ngiesetou. ${ }^{8}$ Cultivation is, in a similar way, limited to ngikwetela that comprise significant portions of Turkana's major rivers, however these are far more numerous than those that abut the lake. Barrow (1990) has emphasised the critical role that river-dwelling communities within these territorial sections play in governing access to riverine forests during the dry season, when they become a crucial source of forage for members of the herding sector. Physical movement between ngikwetela territories is in no way restricted or controlled, save for the grazing-related management of the southern sections mentioned above. Moreover, wider social and familial networks are rarely confined to single sections, but are instead commonly dispersed across several, with social ties and stock associations (formed either on the basis of clan membership, as I outline below, or through institutions such as marriage and initiation) serving as the foundation upon which a single family unit is able to access a diverse array of resources contained within various ngikwetela throughout the year.

\footnotetext{
${ }^{8}$ It is important to clarify that these are not the only Turkana communities involved in fishing on the lake. There are also several Turkana communities settled along its eastern shore in Marsabit County, but their affiliation remains unclear.
} 


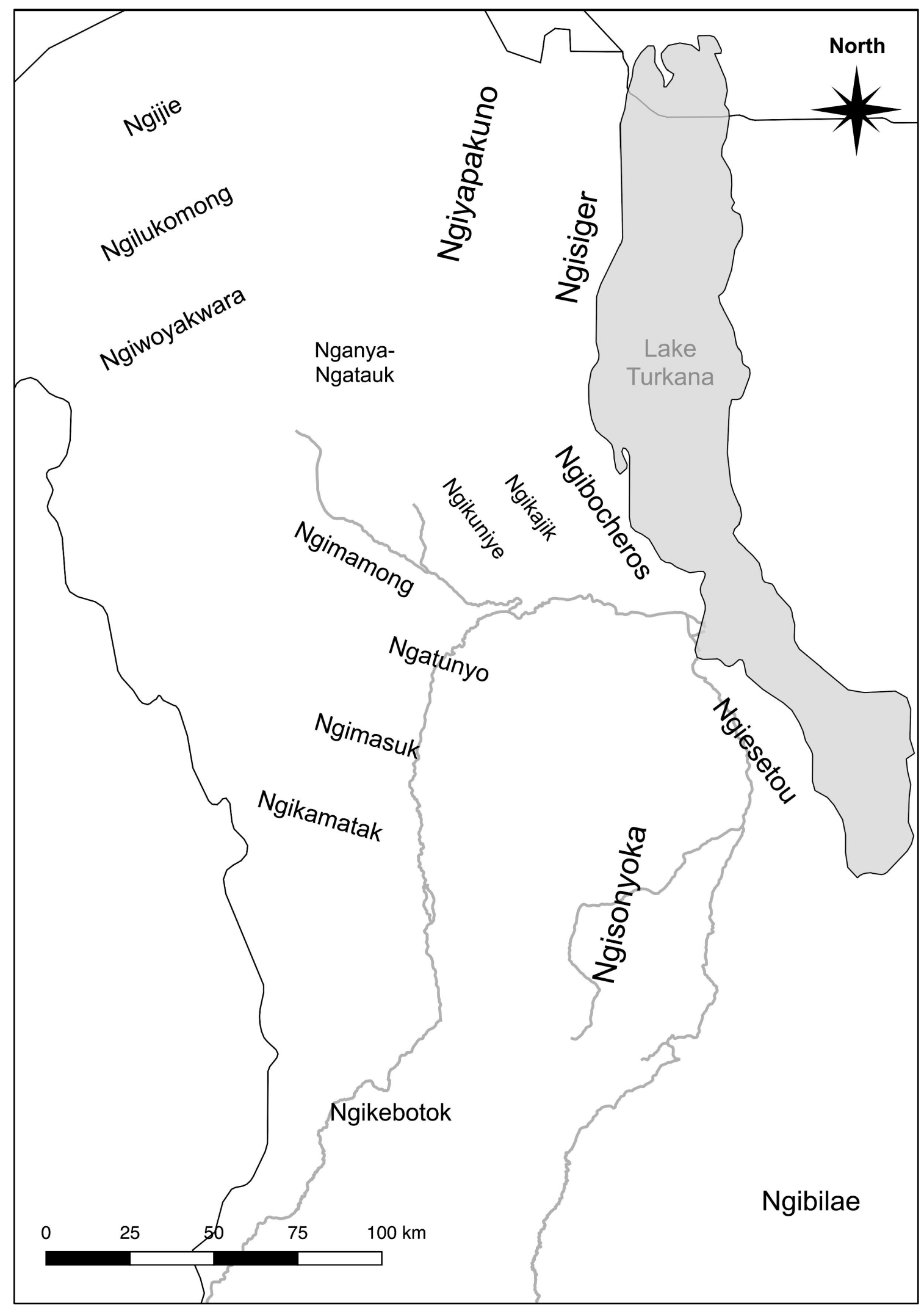

Figure 3.2. Map illustrating the layout and rough extent of ngikwetela sections. 


\section{Ngimacharin}

The emachar (plural ngimacharin) is a geographically non-specific social stratum that is, broadly speaking, organised around and articulated through the differentiation of methods and styles of livestock branding. These divisions, generally referred to in the literature as 'clans', are exogamous, marriage throughout Turkana thus being a process whereby women are seen to depart from the customs and rituals (ngitalio) of their natal clans to adopt those of their husbands. This process of initiation is ritualised in the ceremony of akinyonyo, which occurs when a woman reaches her marital home. Indeed, whilst livestock brands (and stock associations) are the core underlying organising principle of ngimacharin, their heterogeneity is also articulated through and constituted by an extremely diverse and intricate variety of styles of body adornment, scarification, ornamentation, dress and daily ritual and ceremonial activities. These features tend to be ascribed to various clan-specific historical narratives and genealogies (see Table 3.1).

Ngimacharin are both numerous (numbering roughly 29) and flexible, a new emachar generally being said to emerge when certain members of a single generation 'reject' the customs and rituals of their parents', for one reason or another, and form a new branding system (Barrett 1998). Indeed, some of the clans that are currently in existence are known to have emerged during the early years of the $20^{\text {th }}$ century. This process of divergence, however, is perhaps significantly more drawn-out and convoluted than it appears in many of the origin stories that are recounted today. The majority of the ngimacharin currently in existence comprise several subdivisions (ngalaso) which all maintain characteristics that are subtly unique from, and yet closely related to, their broader clan delimitation. In this regard, a critical avenue of enquiry for future research remains the question of how the Turkana clan 
system responded to the formation of the Kenyan state during the colonial era and how it has developed in relation to the continuing postcolonial rigidifcation of district (and more recently county) boundaries.

Clan membership is generally dispersed throughout Turkana amongst the broader territorial sections, with one ekitela often comprising a large variety of different ngimacharin. That being said, some of the smaller ngimacharin are argued to be restricted to certain northern or southern sections (Gulliver 1951; McCabe 2004). As I noted above, ngimacharin constitute a critical social mechanism in the establishment of the stock associations that are fundamental to a pastoralist's career, the visibility of clan-specific livestock brands being a key component of this. However, these ties are also made in a variety of other ways, including through marriage, raiding, initiation and exchange. All ngimacharin are listed in Table 3.1. 
Table 3.1. Catalogue of ngimacharin with contextual information (Soper 1985; Lamphear 1993; Barret 1998).

\begin{tabular}{|c|c|}
\hline $\begin{array}{l}\text { Clan } \\
\quad-\quad \text { Subdivision (ngalaso) }\end{array}$ & Additional information \\
\hline $\begin{array}{l}\text { Ngidocha } \\
\text { - Ngidocha lu ngakup } \\
\text { - Ndidocha lu emunyen }\end{array}$ & $\begin{array}{l}\text { Stemming from the word adokachin — to } \\
\text { scuffle. This is in reference to a ceremonial } \\
\text { dance. } \\
\text { Ngidocha are said to have been founded by } \\
\text { a man called Lokadoket following a raid } \\
\text { that penetrated as far as the eastern side of } \\
\text { Lake Turkana. } \\
\text { Ngidocha lu ngakup — 'the Ngidocha of the } \\
\text { black soil' } \\
\text { Ngidocha lu emunyen — 'the Ngidocha of } \\
\text { the red ochre'. }\end{array}$ \\
\hline Ngiduya & $\begin{array}{l}\text { Stemming from the word } a d u i \text { - hole or } \\
\text { depression. }\end{array}$ \\
\hline Ngikadanya & $\begin{array}{l}\text { 'Those of the silver studs' } \\
\text { Stemming from the word ngidany - silver } \\
\text { studs. This is in reference to the patterns of } \\
\text { silver studs worn in married Ngikidanya } \\
\text { women's ngadwelin. }\end{array}$ \\
\hline Ngikaleeso & $\begin{array}{l}\text { Stemming from the word ekalees - ostrich. } \\
\text { The Ngikaleeso are suggested to have been } \\
\text { founded by the son of a woman from the } \\
\text { Nyangatom people who was captured } \\
\text { during a raid. This founder's name was } \\
\text { Ekoriongor. }\end{array}$ \\
\hline Ngikarewok & \\
\hline Ngikatap & $\begin{array}{l}\text { Stemming from the word atap - a kind of } \\
\text { porridge made from sorghum and milk } \\
\text { following harvests when herders come in } \\
\text { from the plains to trade with cultivating } \\
\text { communities. }\end{array}$ \\
\hline
\end{tabular}




\begin{tabular}{|c|c|}
\hline Ngikatekok & $\begin{array}{l}\text { 'Those who see' } \\
\text { Stemming from the word akitere - to see. } \\
\text { This is in relation to the clan's incorporation } \\
\text { of numerous powerful ngimurok (diviners- } \\
\text { seers). }\end{array}$ \\
\hline $\begin{array}{l}\text { Ngikinom } \\
\begin{array}{l}\text { - Ngikinom lu itechekete ngaberu } \\
\text { kech ngakes }\end{array} \\
\text { - Ngikinom lu ebanyete ngakes }\end{array}$ & $\begin{array}{l}\text { 'Those who burn' } \\
\text { Stemming from the word akinom - to } \\
\text { burn. Fire/burning is a central theme in } \\
\text { many of the rituals and ceremonies carried } \\
\text { out amongst Ngikinom families. Including, } \\
\text { for example, immediately post-birth when a } \\
\text { burning coal is passed over the new born } \\
\text { baby several times. } \\
\text { Ngikinom lu itechekete ngaberu kech ngakes } \\
\text { - 'the Ngikinom who shave but do not cut } \\
\text { the hair of women' } \\
\text { Ngikinom lu ebanyete ngakes - 'the } \\
\text { Ngikinom who do not shave the hair of } \\
\text { women' } \\
\text { Clan suggested to have been founded by a } \\
\text { man called Asike. }\end{array}$ \\
\hline Ngikomesoroko & 'Those of the spear point' \\
\hline Ngikurerr & $\begin{array}{l}\text { Stemming from the word akurerr - a kind } \\
\text { of bush. }\end{array}$ \\
\hline Ngikurruk & Stemming from the word akurruk - crow. \\
\hline Ngilelet & $\begin{array}{l}\text { Said to have been founded by a man called } \\
\text { Akol from the foot of the Loima Hills. }\end{array}$ \\
\hline $\begin{array}{l}\text { Ngilobol } \\
\quad \text { - Ngibolol lu aaruna }\end{array}$ & 'Those of the red antelope' \\
\hline
\end{tabular}




\begin{tabular}{|c|c|}
\hline $\begin{array}{l}\text { - Ngibolol lu apol } \\
\text { - } \quad \text { Ngibolol lu egete }\end{array}$ & $\begin{array}{l}\text { Stemming from the word akolobae - red } \\
\text { antelope. This is in relation to the unique } \\
\text { antelope skins worn by early Ngilobol when } \\
\text { they broke away from their ancestral clan, } \\
\text { the Ngimeturuana. }\end{array}$ \\
\hline \multicolumn{2}{|l|}{ Ngimacharmukata } \\
\hline Ngimedeo & $\begin{array}{l}\text { Stemming from the word akimed — 'to } \\
\text { choke'. } \\
\text { This is possibly in reference to a popular } \\
\text { story of a woman who went into the bush to } \\
\text { collect wild fruit following the birth of her } \\
\text { child. She began to choke on a berry and } \\
\text { was saved by passing hunters. }\end{array}$ \\
\hline \multicolumn{2}{|l|}{ Ngimerpur } \\
\hline Ngimeturuana & $\begin{array}{l}\text { 'Those of the grain chaff' } \\
\text { Stemming from the word ngameturuan - } \\
\text { grain chaff. } \\
\text { Founded by Epetapus, the father of the well- } \\
\text { known Lokerio. Lokerio was a military } \\
\text { leader and powerful diviner during the mid- } \\
19^{\text {th }} \text { century, who oversaw the Turkana's } \\
\text { expansion into the full extent of their } \\
\text { current territory. } \\
\text { Ngimeturuana have a reputation for } \\
\text { originating powerful diviners. }\end{array}$ \\
\hline $\begin{array}{l}\text { Ngingolereto } \\
\begin{array}{l}\text { - } \\
\text { Engoloretoit lo ikale } \\
\text { - Engoloretoit lo sigerit }\end{array}\end{array}$ & $\begin{array}{l}\text { Stemming from the word engoleana- } \\
\text { 'variegated' or 'patterned'. } \\
\text { This is in reference to the patterned } \\
\text { sheepskin that women wear during } \\
\text { marriage. } \\
\text { Clan argued to have been started by a man } \\
\text { called Lomear - the son of a Samburu } \\
\text { woman who was captured during a raid. }\end{array}$ \\
\hline
\end{tabular}




\begin{tabular}{|c|c|}
\hline $\begin{array}{l}\text { Ngiponga } \\
\begin{array}{l}\text { - Ngiponga lu egete } \\
\text { - Ngiponga lu akine } \\
\text { - Ngiponga lu emunyen }\end{array}\end{array}$ & $\begin{array}{l}\text { Stemming from the word aponga - a kind } \\
\text { of bush with well known medicinal } \\
\text { properties. } \\
\text { The founder of the Ngiponga is argued to } \\
\text { have been a man called Kiyapus, from } \\
\text { Lorugumu. }\end{array}$ \\
\hline $\begin{array}{l}\text { Ngipucho } \\
\begin{array}{l}\text { - } \\
\text { - Ngipucho lu e epiding } \\
\text { - Ngipucho lu e egec } \\
\text { Ngipucho a apurukuch }\end{array}\end{array}$ & $\begin{array}{l}\text { Stemming from the word epucho - a kind } \\
\text { of bush. }\end{array}$ \\
\hline Ngirarak & $\begin{array}{l}\text { Stemming from the word arara- } \\
\text { 'cheetah', apparently in reference to the fact } \\
\text { that the skins (ngadwelin) historically worn } \\
\text { by married Ngirarak women were spotted in } \\
\text { a similar fashion to a cheetah's skin. } \\
\text { Founded by Aletile Lomongin, originally } \\
\text { from Samburu, who is said to have been } \\
\text { killed by colonial soldiers in the early } 20^{\text {th }} \\
\text { century. } \\
\text { The shape and pattern of the Ngirarak brand } \\
\text { is said to represent this event. }\end{array}$ \\
\hline Ngiriamar & \\
\hline Ngisalika & $\begin{array}{l}\text { Stemming from the word asalakait - a fine } \\
\text { cut of meat given to a woman after she } \\
\text { delivers a child. }\end{array}$ \\
\hline $\begin{array}{l}\text { Ngisiger } \\
\begin{array}{l}\text { - } \\
\text { - }\end{array} \text { Ngimanyang lu a ngitoroi } \\
\text { - Ngisiger lu a a akuriebok } \\
\text { - Ngisiger lu a lokadabong }\end{array}$ & $\begin{array}{l}\text { 'Those of the ereges stick' } \\
\text { Stemming from the word ereges - a ritual } \\
\text { stick. This stick is carried by women during } \\
\text { wedding dances; the hooked end is referred } \\
\text { to as eseger. } \\
\text { Ngisiger refers to both a territorial section } \\
\text { and a brand. }\end{array}$ \\
\hline
\end{tabular}




\begin{tabular}{|l|l|}
\hline Ngitarapokolong & $\begin{array}{l}\text { 'Those who cover up against the sun' } \\
\text { Stemming from the words akirap - cover } \\
\text { and akolong - sun. } \\
\text { Many Ngitarapokolong ritual and } \\
\text { ceremonial activities are orientated around } \\
\text { the sun. }\end{array}$ \\
\hline $\begin{array}{l}\text { Ngitengor } \\
\text { Ngiteso } \\
-\quad \text { Ngiteso lu e ekitoe alokiryon }\end{array}$ & \\
\hline Ngitholika & \\
\hline Ngiwana & \\
\hline
\end{tabular}

Note. This catalogue also draws on various interviews and conversations I had in the field. It is incomplete, with many subdivisions absent. Moreover, much of the contextual information is unverified and unverifiable, clan origin stories are relatively diverse and open to numerous interpretations. The ones included here are some of the most commonly articulated in the present day but should by no means be understood as exclusive.

\section{Asapanu}

Some have argued that a formal progressive age-grade system existed in Turkana in the past, particularly during the era of resistance to colonial conquest in the early $20^{\text {th }}$ century when warriorship became an even more acutely important component of the Turkana social hierarchy (Lamphear 1976, 1992). Whilst this is not impossible, and many of the communities that were ancestral to the Turkana in the Ateker cluster still comprise formal age-grade systems (Gulliver 1951; Muller 1989; McCabe 2004), there is nothing in Turkana's contemporary social organisation to indicate that such a system ever existed. I remain unconvinced of such a formal system's widespread actuality at any point in the $20^{\text {th }}$ century, having never heard description of it in any of my interviews, conversations or group 
discussions, and it certainly does not exist anywhere in Turkana in the present. That being said, it is perhaps plausible that an age-grade scheme either endured or re-emerged sporadically throughout the region in the late $19^{\text {th }}$ and early $20^{\text {th }}$ centuries, perhaps only in certain ngikwetela or ngimacharin. Either way, historical narratives, at least those that are disclosed and discussed in southern Turkana, are never structured around such a system. As I noted in Chapter 1, and as will become clear throughout Chapters 4, 5 and 6, they are instead related to sequences of key past events.

Almost all male Turkana individuals are, however, implicated by birth in a system of alternating generation sets (аsapanu) which is organised around two core bodies: the ngimoru (those of the mountain) and the ngirisae (those of the leopard). In being born, a male is automatically established as a member of the set that is opposed to his father's, and throughout his life will reiterate this fact in a range of contexts. During akiriket — ritual feasting — for example, ngimoru and ngirisae occupy opposite wings of a crescent-shaped sitting arrangement. On each side of the crescent, individuals are organised in order of their initiation year (from most recent on the outside to oldest on the inside) around a roasting animal. Meat from this animal is given first to the earliest initiated in each set before being passed down along each wing, and is usually thrown haphazardly behind the crescent to the uninitiated men who form a band at the rear. Asapan — the initiation ceremony — is therefore a critical moment in an individual's life whereby he becomes a recognised senior member of the generation set into which he was born by default. This ceremony, by extension, denotes an individual's status as an adult and his capacity to marry. ${ }^{9}$ Akiriket feasts

\footnotetext{
${ }^{9}$ This is a very generalised account of the asapan ceremony. Whilst asapan remains a critical juncture in the lives of many Turkana males, it is worth noting that in some areas it has come to be undertaken much later in life (following marriage) and with much smaller groups of initiates. Asapan has also, despite changing very little as a ceremony over the recent past, come to take on a range of different significances in relation to Turkanaland's changing socio-political geography.
} 
form a core component of numerous crucial ceremonies, ranging from initiation to marriage, but are also often held without explicit purpose.

Along with the asapan ceremony, and akiriket feasts more generally, asapanu are emphasised in a range of other daily contexts. As I explore in Chapter 4, they corresponded historically with different styles of male ceremonial dress, with ngirisae generally wearing leopard skins and ngimoru baboon skins over their shoulders. Whilst such skins are no longer worn, it remains common for the wives of initiated men to wear a ring around their neck on top of their bundles of ngakoroumwa beads (see Chapter 4) that correlates with the colour of their husband's generation set. In such instances, the wife of a ngirisae wears a light silver ring and the wife of a ngimoru a black one. McCabe (2004: 59) also recalls asapanu being used to divide labour during a period of increased insecurity amongst the Ngisonyoka section close to the southern border of Turkana in the 1990s, during which time one group remained on the plains to protect women and children and the other went into the hills in search of enemy raiders. 


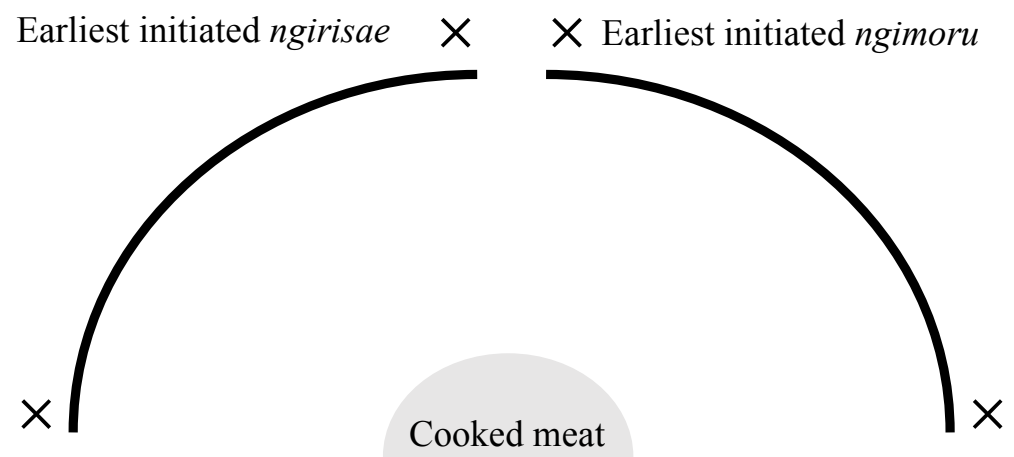

Most recently initiated ngirisae

Most recently initiated ngimoru

Fire/ roasting meat

Figure 3.3. Diagram showing the organisation of the akiriket ritual feast.

\section{Adakar, awi apolon ka awi}

Communities throughout Turkana are generally divided into small single family homesteads (the awi). These units tend to comprise a man, his wives and children and any other dependent individuals who are cared for by the family. They also contain various kraals 
which hold a portion of the family's livestock, although herds are often divided and sent off in different directions to be herded by young men. A single awi is usually connected to a cluster of other homesteads (generally those of close family members); this organisation is referred to as an awi apolon. These clusters are often only temporary, particularly for those engaged in herding on a year-round basis and will be abandoned and rebuilt several times each year. In the pastoralist sector, large groups will often converge upon a particular location during the rainy season. In these instances, impermanent settlements called ngidakarin (singular adakar) form, tending to comprise several hundred families (thousands of individuals).

However, the term adakar is also sometimes applied to various small permanent settlements, or villages, which have emerged over the last few decades close to stable water sources and tracks that lead to larger urban centres. In these settlements, small populations live together on a year-round basis as their relatives migrate with the family herds, returning several times each year. Similarly, cultivating and fishing communities usually occupy single locations on a permanent basis, although often in more remote locations. Fishing communities, who tend to have either very limited or no livestock, construct small semi-permanent settlements on the lake shore where an entire community will live together dispersed throughout individual houses (rather than larger clusters of homesteads).

\subsection{Turkana in historical perspective}

The remaining chapters of this thesis encompass discussions of various key aspects of Turkana's $20^{\text {th }}$-century history. The summary of the Turkana pastoral economy and the description of some of the core elements of Turkana's social geography presented above will 
hopefully help to contextualise these discussions as they unfold. However, it is also worthwhile at this juncture to provide a broad historical overview that can frame the narratives that emerge within a longer-term timeline.

A commonly recounted origin story in Turkana today refers to a woman called Nayeche, who is encountered by a group of young herders in search of a lost grey bull. In this story, the herders have departed from their homeland and ventured for the first time into what is today known as Turkana. On encountering Nayeche, an elderly mother who had reached the area before them, they find their lost bull living with her. She welcomes them to the new region, explains that she had come from the same place as them to gather wild fruits, makes a fire and invites them to rest. The young herders are so impressed with the abundant plains and forests in the new region that they return to their homeland to fetch their livestock, wives, families and friends. They return to Turkana to settle permanently, thus becoming the first Turkana. Lamphear (1988: 28) underlines several similarities connecting this story to the oral histories of various other East African pastoralist groups, but also points out that it succinctly characterises the initial process of incursion into the Turkana Basin 'by which Ateker foraging expeditions and cattle camps gradually began to exploit the upper Tarash [sic] region from their bases in eastern Karamoja' (see also Lamphear 1976).

This process, which saw the Turkana split from the Jie community in present-day northeastern Uganda, was part of a broad course of 'frequent splitting and fusing of ethnic groups' (McCabe 2004: 48) that took place between 500 and 200 years ago amongst a larger linguistic cluster of pastoralist and agro-pastoralist communities referred to as the 'Ateker' (comprising the Karamojong, the Jie, the Turkana, the Dodoth, the Toposa and the Nyangatom). Archaeological, ethnolinguistic and oral historical evidence places communities 
ancestral to the Ateker cluster in South Sudan prior to around 500 years ago (Lamphear 1976, 1988; Ehret and Posnansky 1982; Muller 1989; Ehret 2001). By the early part of the $18^{\text {th }}$ century, communities of Turkana had emerged as a distinct component within the Ateker, establishing themselves close to the headwaters of the Tarach River in present-day northern Kenya. ${ }^{10}$ Over the next 200 years (and particularly during the mid- $19^{\text {th }}$ century), their territory expanded significantly to encompass vast stretches of north-western Kenya's arid and semi-arid plains. Before the colonial period began, Turkanaland (Eturkan) had emerged as one of the largest pastoralist territories in eastern Africa. I discuss this process of territorial expansion in more detail in Chapter 6, outlining its correlation with the solidification of Turkana corporate identity. However, it is perhaps worth noting here that, as part of it, several neighbouring ethnic groups (particularly in the south) engaged in livelihoods ranging from hunting/gathering to agro-pastoralism gradually came to be incorporated into the Turkana, bringing with them various practices and traditions of their own (Lamphear 1988).

During the late $19^{\text {th }}$ century early European expeditions began to reach Turkana, ${ }^{11}$ the first of them (in 1886-1888) being a convoy led by the Hungarian aristocrat Count Samuel Teleki who named the region's vast lake 'Lake Rudolf' after his patron, Prince Rudolf of Austria (the son of Emperor Francis Joseph II; see von Höhnel 1894; Brown 1989). Following Teleki's expedition, which he undertook with Austrian naval lieutenant Ludwig von Höhnel, several subsequent journeys were made to the region by numerous individuals including the American William Chanler (from 1892-1894), the Italian Vittorio Bottego (from 1895-1897) and the Englishman Herbert Austin (in 1901). It was not until the early years of the $20^{\text {th }}$

\footnotetext{
${ }^{10}$ At the headwaters of the Tarach lies a mountain named Moru a Nayache, meaning 'Nayeche's mountain' or 'mountain of Nayeche'. Oral histories dictate that the earliest Turkana lived in caves surrounding Moru a Nayeche before spreading out into the wider region, hence the name Ngiturkana - 'people of the caves'.

${ }^{11}$ Although these were preceded by Swahili caravans in search of ivory (McCabe 2004; Håkansson 2007).
} 
century, however, that British administration was established in Turkana. In the years that ensued, relations between the British forces (the King's African Rifles) and the Turkana were particularly violent, with armed skirmishes taking place on a regular basis. During this time, the British mounted several 'punitive expeditions' aimed at exerting British authority and dominion through the confiscation of livestock. Largely in response to these heavy livestock losses (which crippled their pastoral economy), the Turkana put up a powerful military resistance that lasted until the early 1920s, primarily led by an individual called Ebei who is still widely known and revered in the present day. Again, these events are explored in detail in Chapter 6, where a timeline of the British conquest of Turkana is provided (Table 6.1).

Following Ebei's death the colonial civil administration was reintroduced and by 1928 tax began to be collected from the Turkana on a regular basis. However, throughout the first half of the $20^{\text {th }}$ century Turkana remained an acutely marginal district in colonial Kenya, seen to comprise no valuable natural resources (which is somewhat ironic when one considers the recent discovery of expansive oil reserves) and to be of consequence only as a buffer against expansion from Italian-occupied Abyssinia. Infrastructural development was practically nonexistent throughout Turkana both during and immediately after colonialism, and McCabe (2004) points out that the region was declared a 'closed district' in the final decades of the colonial era, meaning civilian movement in and out was restricted. By 1960 'only two primary schools and one mission had been established' (McCabe 2004: 52). In the decades following Kenyan independence Turkana captured the attention of a range of development organisations and, particularly during the 1970s and 1980s, saw a series of large-scale interventions. Perhaps the most extensive were the fishing industry (and associated infrastructure) that was developed on Lake Turkana by the Norwegian Agency for Development (NORAD) in the late 1970s and the large-scale irrigation schemes implemented 
by the Turkana Rehabilitation Project (TRP) along the Turkwel and Kerio Rivers in the early 1980s. I consider both these development interventions in detail in Chapters 4 and 5 respectively.

Following a relative slump in development activity in the 1990s and early 2000s (Broch-Due 1999), the discovery of large oil reserves in the Lokichar Basin was announced by Africa Oil Corporation and their partner exploration firm Tullow Oil plc in 2012. This discovery came two years after Kenya's adoption of a new constitution (in April 2010) that set in place the devolution of power from national to local governments, following which Turkana District was rebranded Turkana County. The discovery of oil was greeted with both optimism and uncertainty by international organisations and civil society groups. Many of these were quick to caution against the pitfalls of 'the resource curse', citing examples of other oil-producing countries in Africa (e.g. Nigeria, Angola, Equatorial Guinea) where host communities have failed to benefit satisfactorily from resource extraction (e.g. Vasquez 2013). Debate over guidelines for the nascent petroleum sector continues.

\subsection{Summary}

In any consideration of Turkana social organisation, livelihood systems or long-term history (let alone all of these collectively) it is difficult not to recognise an underlying sense of fluidity. Over the last few hundred years, Turkana society and identity have emerged by means of a sequence of significant migrations, divergences, incorporations and adaptions. Understanding this process of iterative transformation over the long-term should be a critical aspect of any interpretation of the social and economic structures that govern daily life throughout the region in the present day. However, fluidity is not only a defining 
characteristic of Turkana over the longue durée, it also clearly characterises the regular workings of the regional pastoral economy. Everything from broader livelihood practices and systems of livelihood interaction down to the strategies of individual families and units are all open to transform in rapid response to the shifting circumstances of their context. The social mechanisms, economic strategies and personal skills that work to co-produce and facilitate the endurance of this complex economic system are both diverse and sophisticated. The following chapter explores how a wide assortment of them have been deployed by fishing communities along the western shore of lake Turkana to accommodate and capitalise on a series of substantial transformations over the past century, setting out the first of three central discussions that illustrate the core argument of this thesis. 


\section{Chapter 4: Akichem (Fishing)}

'It is said that a long time ago the whole of Turkana was abundant with grass and wild animals, but then there was a huge drought and many of the animals died...People were starving... One day, during this drought there was a man walking by the lake edge. He saw a dead fish that had been washed up on the shore, he picked it up and began to eat it...to see if it was edible - before this time Turkana people had never eaten fish. When he saw [that the fish was edible] he went to tell the other Ngiesetou that there were animals in the water that could provide for them when the animals on the land were unable to survive. He convinced them that they should try and make a living by fishing in this lake. These people became known as ngikebotok, meaning that they were very poor, or that they had nothing. Over time many other people came to join in with this lifestyle, today there are very many of us.'

- The story of the emergence of fishing in Turkana as told by Echarai Lokote Longorok, a fisherman in Merrier Village. ${ }^{12}$

\subsection{Introduction and overview of Turkana's fishing communities}

There are currently over 8000 people actively involved in fishing on the shores of Lake Turkana (Yongo et al. 2010). ${ }^{13}$ Along the western side of the lake (the east of Turkana County) this community is arranged into clusters of villages that stretch over $200 \mathrm{~km}$ from Mugur in the south to Todonyang in the north, immediately below the Omo Delta and the boundaries of South Sudan and Ethiopia (see Figure 4.1). As Longorok's story indicates, fishing in Turkana is widely regarded by lakeside communities to have been a pastoralist response or adaptation to severe drought and livestock decimation when it first emerged. As

\footnotetext{
${ }^{12}$ (Interview with Echarai Longorok, Merier, 04/03/2015). Variations of this folktale are recounted frequently amongst the fishing communities along the western shore of Lake Turkana; this version was chosen to be included here for its completeness. Broch-Due (1999: 59-60) also describes a version of this origin story specifically relating to the Ngibocheros.

${ }^{13}$ Yongo et al.'s (2010: 28) estimation of 8,160 is very conservative, there are probably a lot more. Avery's (2014: 14) report suggests there are 56,000 people living 'on or close to the western shore', although a large number of these are probably engaged in pastoralism.
} 
I noted in Chapter 3, three territorial sections are generally recognised as the earliest to settle permanently along the western shores of the lake and engage in lacustrine activities: the Ngisiger, the Ngibocheros and the Ngiesetou (Kolding 1989).

The conceptualisation of fishing in Lake Turkana as the pursuit of the 'destitute' endures in oral histories, but also emerges consistently in academic contexts. This is due in large part to the fact that throughout the 1960s and 1970s large-scale international development schemes envisioned a commercial fishing industry as a principal solution to various economic problems faced throughout the Turkana region (caused by droughts in 1960-61 and the early 1970s), and recruited waves of people from inland herding communities who had been settled into 'famine camps' (Hogg 1982; Broch-Due 1986; Kolding 1989). These newcomers were provided with training and equipment and integrated into an emerging complex network of internationally funded community based fishing co-operatives that lasted until the mid-1980s (Henriksen 1974; Bayley 1982a: 351). On top of this, core fishing communities have, over the years, tended to be recurrently augmented by members of the pastoralist population during times of drought and economic hardship. ${ }^{14}$

\footnotetext{
${ }^{14}$ Kolding (1989) points out that population numbers in lakeside Turkana villages are known to swell in times of drought, and to reduce during times of ecological stability. Sobania (1988) describes a very similar situation on the eastern side of the lake between the Dies and El Molo communities and their pastoralist neighbours, the Rendille and Samburu.
} 


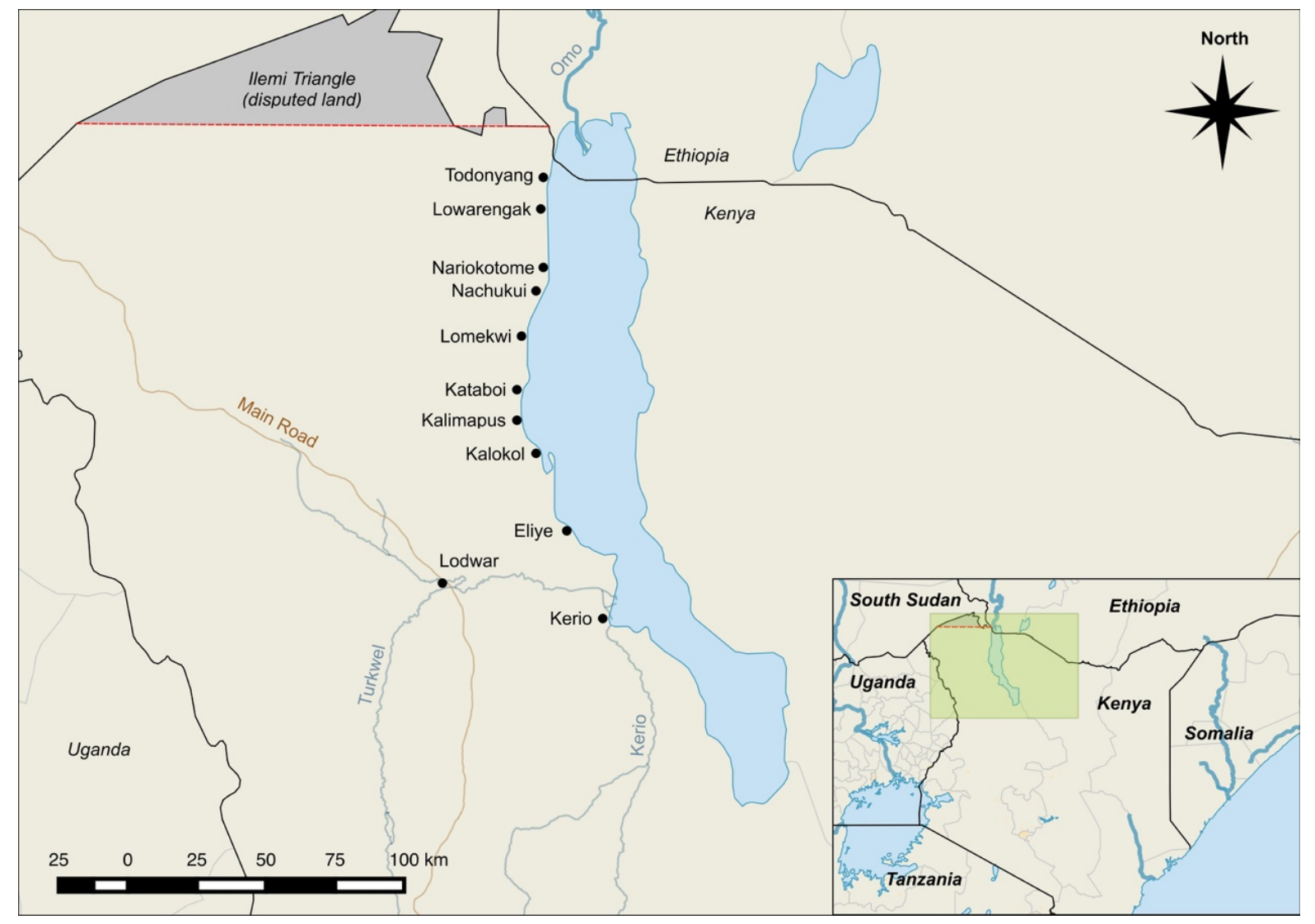

Figure 4.1. Map of Lake Turkana showing key locations on the western shore.

In these contexts, studies undertaken in Turkana fishing villages have generally been concerned with the emergency or survival-orientated characteristics of fishing systems rather than the autochthony or 'belonging' of the core communities engaged in them. ${ }^{15}$ The novelty of fishing set against prevalent pastoralism, and the associated awareness that it arose in response to hardship faced in the pastoralist sector (and does so recurrently), has seemingly overshadowed the potential for viewing it as a longstanding connected livelihood with its own distinct historical narrative. Significantly, core communities of Ngisiger, Ngibocheros and Ngiesetou Turkana have exploited the lake's resources continually for well over a hundred years. One of the earliest textual references to fishing in Turkana is Ernest Emley's

\footnotetext{
${ }^{15}$ These have generally been ethnoarchaeological, relating to the early Holocene exploitation of Lake Turkana (for example Stewart 1991; Barthelme 1997; Robbins 2006), or social anthropological studies concerned with economic development and food security (for example Hogg 1982; Bailey and Jentoft 1990; Yongo et al. 2010).
} 
(1927: 20-21) description of permanent villages 'on the shores of Lake Rudolf' in an account written in his time as an administrative officer, although many life histories collected during my recent fieldwork amongst the fishing communities in the southern portion of the lake attest to an origin far beyond living memory. ${ }^{16}$ Moreover, Broch-Due and Sanders (1999: 42) point out that groups of cattle-less Turkana (presumably including fishermen) were involved in ivory hunting during the early European expeditions to northern Kenya in the late $19^{\text {th }}$ and early $20^{\text {th }}$ centuries, and 'have probably existed for centuries' (see also Rayne: 1923). Over several generations these groups have frequently interacted with, been augmented by, and merged with populations from inland territorial sections.

Many of the studies undertaken in or focused on fishing communities in Turkana have not engaged with this history (although for exceptions see Broch-Due1996; 1999), a result of their immediate connections with applied economic development projects or, in the case of ethno-archaeological research, their synchronic outlooks. However, it is also noteworthy that earlier ethnographic studies undertaken in the broader region have focused almost exclusively on mobile herding communities, a fact that has rendered fishing villages and their historical transitions difficult to discern in the contextual literature. Most notably, Ernest Emley's (1927) account, mentioned above, stops short of any description of the lakeside villages and the livelihoods in which they were engaged. Similarly, Gulliver's $(1950,1955,1958)$ ethnographic accounts, the earliest comprehensive academic research focused on the Turkana people, make no mention whatsoever of the fishing communities along the lake edge. To echo Wilmsen's (1989: xv) description of San peoples in southern

\footnotetext{
${ }^{16}$ Emley (1927: 53-54) also includes a brief description of woven fishing traps or ngwelya used by communities who have 'no other form of food, except the mukoma palm fruit, and possess no stock,' but only describes their use in rivers.
} 
Africa, Turkana's fishing populations have been forgotten by 'ethnographers who [were] not looking for them'.

The marginalisation of Turkana's lake dwelling communities from early anthropological research probably originally developed out of the perception that fishing was not a 'traditional' Turkana livelihood. This is a view that has perhaps also been interwoven with the fact that throughout history a strong 'cultural stigma' (Sobania 1988; Lokuruka 2006) was frequently assigned to fishing, horticultural, and hunting-gathering communities by pastoralist Turkana sections, especially during times of environmental stability when few herding groups were forced to rely on alternative economic means. Indeed, the term 'ngikebotok' (which features in Longorok's story above) is a broad economic category, applied to any peripheral group who do not possess livestock. As a classificatory term it is undoubtedly longstanding and significant. However, subscribing to such a broad delineation of factions within Turkana society also carries the danger of subsuming all non-pastoralist 'poor' Turkana groups into one homogenous section and neglecting the particularity of various identities and economic strategies within. Broch-Due (1999: 57) specifically points out that the term 'sets up a distinction between dominant livelihoods based on livestock versus grain, fish and game' in what she terms the 'dominant pastoralist discourse'.

In recent decades this 'dominant pastoralist discourse' has continued to attract scholarly attention in Turkana. Anthropological research has continued to concentrate on herding practices, with Turkana communities featuring frequently in critical anthropological discussions of pastoralism, mobility and human ecology (as discussed in Chapter 3). Whilst this is unsurprising considering the omnipresence and centrality of herding to the vast majority of Turkana communities, pastoralism's authority in anthropological and 
archaeological literature relating to the region has perhaps overshadowed and even excluded historical research with a particular focus on alternative livelihoods within the pastoralist economy. This is, paradoxically, to the detriment of general historical understandings of pastoralist Turkana groups, who in many cases have developed through time via an entanglement and engagement with the fishing communities along the lake. The story of the interaction and interrelationship between these two quite distinct livelihoods over the last century remains opaque to scholarly understandings of the region.

Conversely, the important relationship between fishing communities and early East African food-producing communities (agriculturalists and pastoralists) in prehistory is well recognised (especially in the works of Sutton 1974; Phillipson 1977; Oliver 1982; Robertshaw 1987). Moreover, discussions of the origins of contemporary East African pastoralist societies frequently reflect on the extremely ethnically and economically fluid precolonial character of the region. This was a time when communities were 'continuously re-shaped as individuals and groups moved, according to their economic status at any given time, between the subsistence modes of pastoralism, agriculture and hunting-gathering and fishing' (Sobania 1988: 43). The complete termination of this fluidity in colonial times is brought into question by studies that point out the enduring economic diversity of pastoralist systems in the postcolonial world and their common, though not necessarily obligatory, interdependence with neighbouring livelihoods (e.g. Berntsen 1976; Anderson 1988), and Sobania (1988: 41) describes the 'dynamic role of ...[fishing] communities as a component of the pastoralist ecosystem' on the eastern side of Lake Turkana.

Whilst Turkana fishing communities are not ethnically distinct from their inland counterparts, they are undeniably profoundly dissimilar in terms of both their social and economic 
organisation and their modes of life. Therefore, rather than approaching fishing as a continually peripheral 'emergency' or 'survival-based' occupation, this chapter explores its history as a distinct and 'genuine' Turkana livelihood, with its own unique record of transformation and continuity. The fluidity of movement between different economic sections of Turkana society is not repudiated, both in terms of the frequent recurrence of droughtstimulated incorporations of pastoralist groups into sedentary fishing villages, and of the departure of individuals and families from lake edge settlements once they have accrued adequate livestock to return to or adopt a pastoralist career. Rather, these aspects are considered as components within a set of intertwined and congruous historical narratives recounted and deployed in numerous manners and contexts within contemporary fishing communities.

It is important to note that, whilst fishing almost certainly first originated amongst Turkana pastoralists as an emergency subsistence strategy following serious drought and starvation (as indicated in Longorok's story), over the last few decades it has developed into a relatively successful commercial industry (Amuka et al. 1985; Yongo et al. 2010). Communities of fishermen and women have, over several generations, undergone drastic economic transformations. Fishing has gone from being purely subsistence based to becoming an avenue into broader trade networks, paid labour and education. This economic story is enmeshed within a context of equally significant social and political change. Indeed, Longorok's story is framed by his knowledge of several generations of lived transformation, and in this context his allusion to the destitution faced during the emergence of fishing and the continued use of the term ngikebotok take on various more nuanced significances. 
The fieldwork on which this chapter draws was undertaken in 28 villages stretching along the southwestern shore of Lake Turkana, between Kalokol in the centre and Mugur in the south. Most of this research was focused on the Ngiesetou villages surrounding and beneath the Kerio Delta - Merier, Achukut, Elelea, Nawoierangan, Mugur, and Nanyangakipi (see Figures 4.2-4.4) - simply because these villages occupied the portion of the lake closest to my research base at Nakurio Village (Which is situated inland from Lake Turkana along the Kerio River). As such, the narratives depicted in this chapter are unmistakeably regional and do not reflect a singular and definitive history of Turkana fishing as a whole, but rather represent a framework of historical knowledge and experience focused on a distinct cluster of fishing villages. There is doubtless a great deal of variation with regard to the historical development of fishing along the west coast of Lake Turkana, and a lot of research yet to accomplish.

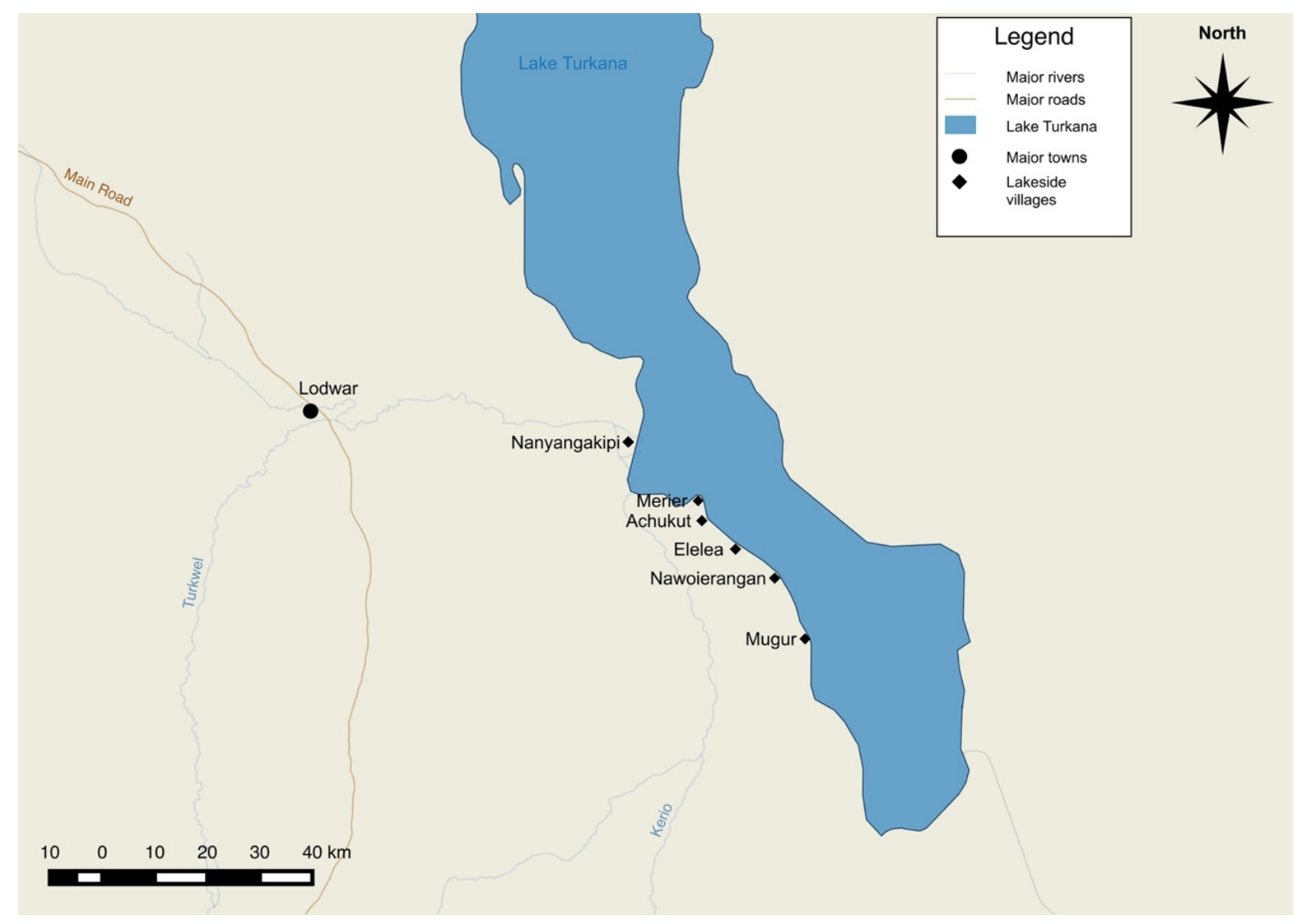

Figure 4.2. Map of the southern portion of Lake Turkana showing villages in which fieldwork was undertaken. 


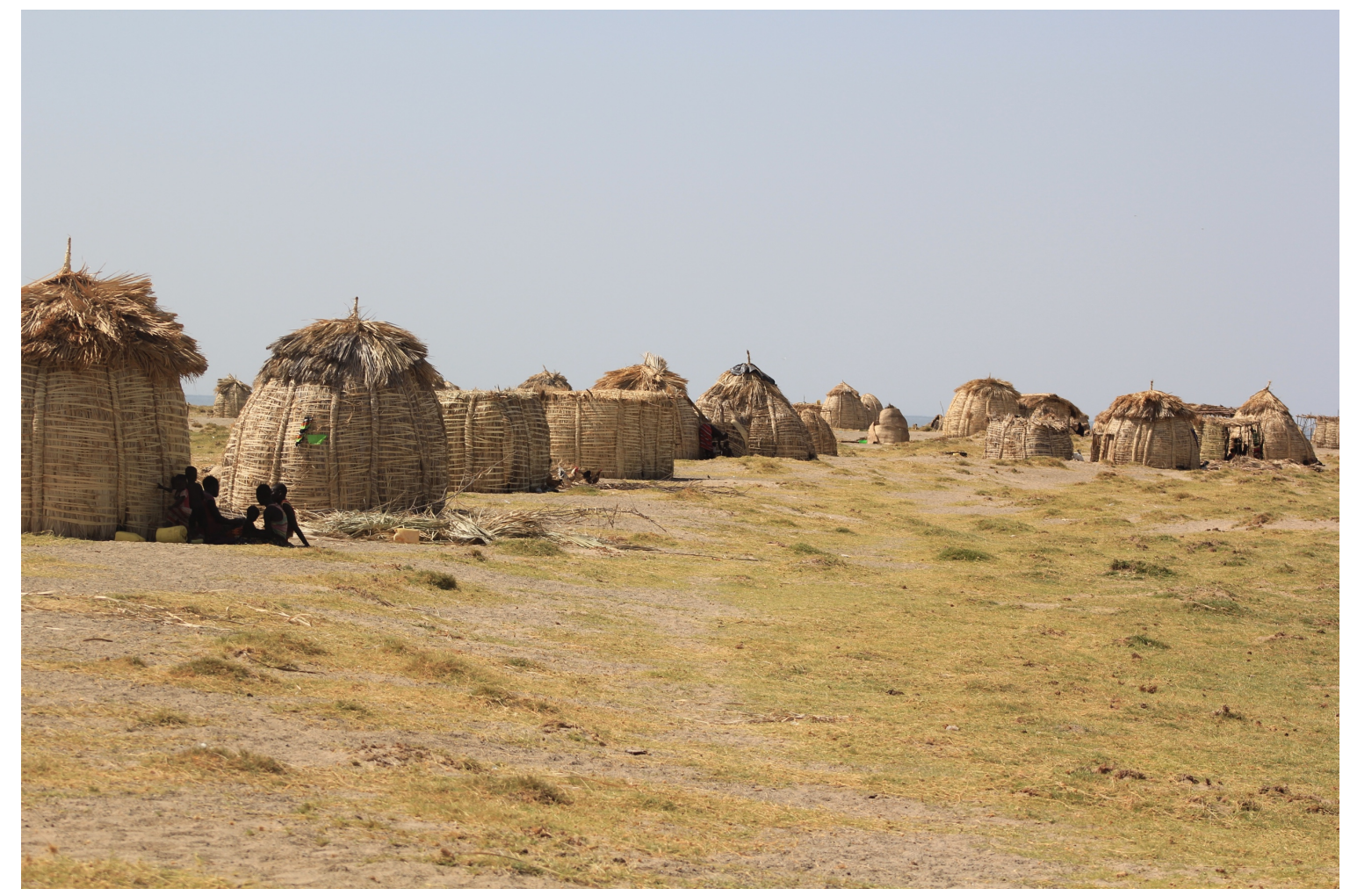

Figure 4.3. View of Merier - a typical Turkana fishing village.

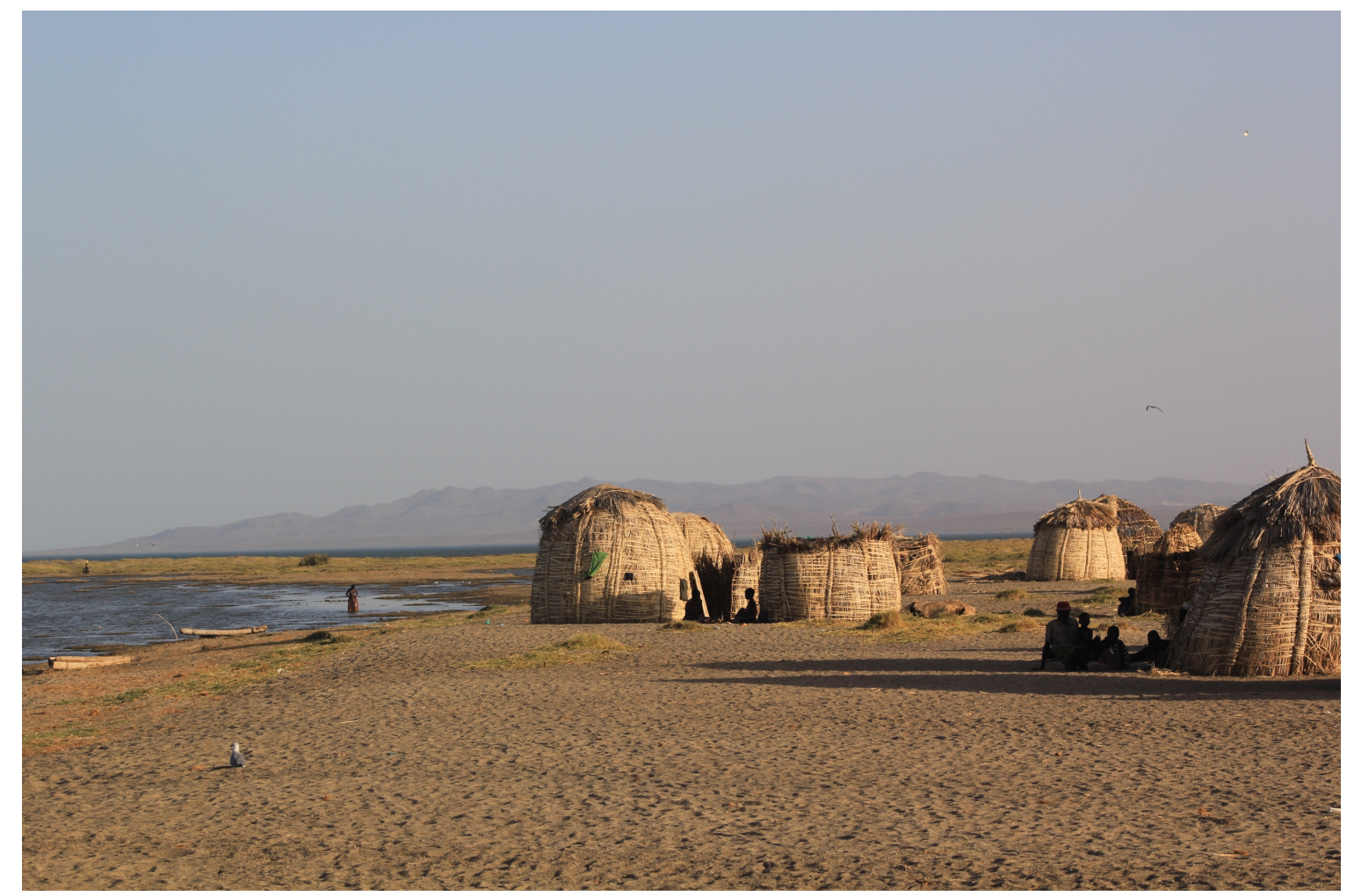

Figure 4.4. View of Merier looking south. 


\subsection{Hippopotamus hide shoes, colonial taxes and cotton blankets}

It is difficult to determine a precise date for the emergence of fishing amongst the Turkana. It is known that the lake's resources were exploited as far back as the early Holocene (Stewart 1991; Barthelme 1997; Robbins 2006), however these prehistoric communities were not direct antecedents to the current occupants of the region, who, as I outlined in Chapter 3, migrated into the Turkana Basin between 300 and 400 years ago as part of the Ateker migration of Eastern Nilotic speakers. Life histories I collected along the western shore of the lake put the origin of today's fishing villages at well over a hundred years ago. ${ }^{17}$ This is corroborated by an interview recorded by Broch-Due (1999: 59), which describes how 'The Ngibosheros have been fishing... at the lake for a very long time. They have been fishing for generations: at least from the time of our grandfathers and perhaps before.'

What is also clear from several variations of the origin story included at the beginning of this chapter is that the earliest Turkana fishing communities are considered to have comprised very poor people. The term ngikebotok, meaning 'those who have nothing', directly refers to an absence of livestock. The first Turkana fishing communities surfaced in an exclusively pastoralist context, and were descended from inland nomadic herding units. They therefore consisted of people who had either lost, or were unable to maintain, herds of domesticated animals, and it was almost certainly in this context that the term ngikebotok arose. Marked similarities can be noted with the Dasenech term dies applied to fishing communities in the northern part of Lake Turkana which also means 'poor' and is specifically entwined with the

\footnotetext{
${ }^{17}$ For example, in an interview with Joseph Ekiru Epakan (50 years old) at Merier Village he states 'I know that the parents of my grandparents were born in Merier Village, and I think their parents were also from here' $(04 / 03 / 15)$.
} 
notion of being without animals. In an interview collected by Sobania (1988: 47) on the eastern side of the lake this is explained as follows:

'Dies are Dasenech. Like those people we call Elmolo (Hereny), we call those who are Dasenech, Dies. [They are] people without animals... those Dasenech who don't have animals are Dies... A person whose animals we can't see [does not have stock], next he goes to the lakeshore. A person whose animals aren't many, he has his animals [is not a Dies].'

It is uncertain whether the catastrophic event depicted in the origin story (in Longorok's case a 'huge drought') was a singular trigger event, or refers to the general context through which fishing was first adopted over several years. ${ }^{18}$ In either case, it is possible that it first happened at some point within the time frame of the epizootics and smallpox outbreak that devastated pastoralist communities across East Africa in the late $19^{\text {th }}$ century. Significantly, the spread of bovine pleuro-pneumonia and rinderpest at this time is known to have caused large populations of Samburu herders to seek refuge with El Molo fishing communities on the east side of Lake Turkana. ${ }^{19}$ Lamphear (1992) and McCabe (2004: 50, 265) both suggest that most Turkana communities were spared from these outbreaks as a result of the isolation of their livestock on remote mountain pastures. However, it seems plausible that at least some Turkana groups were affected, particularly those furthest south. Lamphear's (1976: 229) oral histories describe 'severe droughts in the Kerio and Turkwell areas in the late $19^{\text {th }}$ century' which could also be considered as the root causes of settlement along the lake if it was indeed purely an environmental response.

Considering the enduringly fluid nature of large portions of the populations in most Turkana fishing villages it seems likely that the earliest groups settled along the lakes sporadically and

\footnotetext{
${ }^{18}$ It was clear in 2014-2015 that many people are divided on this issue, and various individuals and villages attested to starkly different versions of the origin story.

${ }^{19}$ Moreover, much like Longorok's attribution of the emergence of fishing to a drought, an E1 Molo interview that Sobania (1988: 50) presents in his ethnohistorical account of the east side of the lake describes this as a time when 'there was a great drought and a famine spread all across the people'.
} 
as a result of multiple converging factors. A time of prolonged instability and numerous causes would also explain why the earliest groups (presumably Ngisiger, Ngibocheros and Ngiesetou) were not purely transitory emergency camps housing whole ex-pastoralist communities for short periods of time before dissolution, but rather permanent settlements, which nevertheless saw frequently fluctuating populations. It is equally plausible that this period of instability occurred long before the late $19^{\text {th }}$ century, and that during the late $1800 \mathrm{~s}$ groups were seeking refuge in pre-existing fishing communities along the lake edge (much like many Samburu did in El Molo villages on the eastern side of the lake). Today most of the villages maintain a fluid character, with individuals regularly departing to herd livestock that have been acquired via marriage, raiding, or other means (although, importantly, a core community remains and has done so in the past).

Several large group discussions that I convened in villages between Kalokol and Mugur (Elelea, Merier, Mugur and Nanyangakipi) focused on the material culture of the precolonial and early colonial eras via an examination of the photographic collection I maintained in the field. These discussions produced a clear image of the late $19^{\text {th }}$ and early $20^{\text {th }}$ centuries, a time when fishing was small-scale and purely subsistence based, predominantly occurring in the shallow waters near to the lakeshore. Significantly, during this time the lacustrine communities' mode and means of production were not orientated toward large landings. Fish were either caught with an erokode (plural ngirokode; a woven palm line with bone hook), an akwara (plural ngakwara; a spear or harpoon) or an epute (plural ngiputei; a conical basket with a hole at the base used for trapping and extracting fish in shallow waters). Ngiputei are still frequently used today, although more commonly in shallow rivers than in the lake. Tilapia (Oreochromis niloticus) were frequently netted close to the shoreline, along with the occasional soft shell turtle (Trionyx triunguis). Those who ventured out into deeper waters 
would do so using rafts made from the trunks of doum palm trees (Hyphaene compressa), a practice that also remains common today, and further away from the shore it was possible to spear large Nile perch (Lates niloticus).

Throughout these early years the fishing communities also frequently hunted crocodiles and hippopotami. ${ }^{20}$ This was pointed out several times during conversations with individuals from the oldest Ngisiger, Ngibocheros, and Ngiesetou generations, and later explored in a series of focus group discussions that centred on photographs from the early colonial era. ${ }^{21} \mathrm{At}$ some point early on in the $20^{\text {th }}$ century the skins of these animals came both to facilitate and to dominate trade between the lake communities and wider groups of Turkana herders. Both crocodile and hippopotamus skins were highly desired by inland communities, who used them to make shields (nagupwala) and shoes (ngamuk). Older members of herding communities across southern and central Turkana frequently remember buying hippopotamus hide shoes from lakeside villages during the first half of the $20^{\text {th }}$ century, and some elders still retain pairs that have lasted several decades. ${ }^{22}$

\footnotetext{
${ }^{20}$ This was a widespread activity for many communities around Lake Turkana throughout the first half of the $20^{\text {th }}$ century. The El Molo, who were at that time living on the islands in the middle of the lake, frequently hunted crocodile and hippopotami (as ascertained through interviews and discussions conducted in El Molo villages north of Loiyangalani between 14/06/2014-21/06/2014). The Dasenech in the north also partook in frequent lake game hunts. Many communities continue to hunt these animals, including the Turkana. However, this primarily occurs at night and is highly secretive as hunting all wild animals is now illegal.

${ }^{21}$ Most prominently images included in Pavitt's (2008) photographic account of Kenya during the early colonial period, and a range of Emley's photographs.

${ }^{22}$ It came to light on several occasions that men being interviewed were wearing hippopotamus hide shoes bought from the lake edge villages before independence. Members of lakeside communities tended to have only had hippopotamus skin shoes in the past, while members of inland communities had shoes made from a range of wild animal skins including giraffe, rhinoceros, and buffalo. Having said this, hippopotamus skins were widely accepted to have been the best quality and the most expensive throughout lakeside and inland communities.
} 
During this time, some members of the lake communities were able to trade enough skins to accrue quite significant herds of livestock, and ultimately to depart the villages altogether. This was pointed out during an interview with David Ekuam, a fisherman from the region south of the Kerio Delta:

'In those days, long before independence, before Kenyatta, people from the lake acquired goats with crocodile skins and hippopotamus skin shoes, but mostly hippopotamus skin shoes... This is the [only]... way people could buy anything in those days, and the young men would spend every day looking for [hippopotami] to kill. Killing a hippopotamus was very dangerous, and removing its skin was a lot of work, our communities were very skilled' (interview with David Ekuam, Merier, 09/03/2015). ${ }^{23}$

Two pairs of hippopotamus shoes and a crocodile skin shield collected in 1948 are held by The Smithsonian Institution in its assemblage of Turkana objects at the American Museum of Natural History, New York. ${ }^{24}$

This trade in skins was initially wholly contained within communities of Turkana, and was implicated in the development of a unique pastoral-lacustrine exchange relationship. Fishing communities offered hippopotamus skin shoes and crocodile skin shields in return for livestock, but also animal products such as goat and cow skins (which, unlike hippopotamus skins, were suitable for clothing) and a range of domestic items made from materials only available in hillside scrubland and riverine forests. These included wooden and leather fat containers called akutom (plural ngakutoma) and ebur (plural ngiburin), milk gourds called akurum (plural ngakurumo), wooden spoons called akaloboch (plural ngakalobocho), wooden bowls called atubwa (plural ngatubwae) and clay pots called agulu (plural ngagului). The trade was predominantly facilitated through a system of strong fictive kinship ties between members of fishing communities and inland herders, connections that were

\footnotetext{
${ }^{23}$ Jomo Kenyatta, the first president of Kenya, $1964-1978$.

${ }^{24}$ Hippopotamus skin shoes: catalogue nos. 90.1/8388 AB and 90.1/8389 AB. Crocodile skin shield: catalogue no. $90.1 / 8255$. N.B. these items show considerable use wear and were almost certainly fairly old at the time of their collection.
} 
significant not only as a means for fishermen to depart the villages after accruing enough animals, but also as avenues back into the lakeside villages during times of hardship faced by the herding groups. In this sense, hippopotamus skin shoes (and to a lesser extent crocodile skin shields) were integral elements in the expanding and contracting nature of the early lakeside settlements. $^{25}$

However, the consanguinity of the two livelihoods was strained when the trade in lakederived animal hides eventually became considerable enough to be integrated into the colonial tax system. The British had sought innovative ways to extract taxes from the start of their relations with Turkana communities in 1906 and they ultimately came to be collected on a routine basis in the form of livestock via local individuals who had been appointed by the government on account of their social standing. In a report from 1948 compiled for Lord Hailey by the Colonial Research Council the situation is explained as follows:

'Hitherto a number of headmen (chiefs) and sub-headmen have been recognised by government and given powers under Native Authority Ordinance of 1937. These authorities have been "appointed" by the administrator, though they have for the more part been chosen from persons having local prestige for various reasons... the "chiefs" and headmen have begun to collect the poll tax introduced some years ago... but the system requires improvement' (Lord Hailey papers 1948: 1). ${ }^{26}$

Some years previously, Ernest Emley had remarked that during initial relations 'Tax collection amongst a raw nomadic tribe was... found to be a most difficult task, and very little tax was obtained' (Emley 1927: 1). What Emley and other colonial officials portrayed as scant reward for a protracted and tedious collection process was actually momentous for

\footnotetext{
${ }^{25}$ The importance of hippopotamus hide shoes and the trade relationships between fishing communities and pastoralist groups in which they were implicated was also picked up in Sobania's (1988) ethnohistorical research conducted amongst Daasanach, Samburu and El Molo communities on the eastern side of Lake Turkana, he describes the 'eagerly sought hide shoes which they [the El Molo] exchanged for spears.' (Sobania 1998: 48).

${ }^{26}$ Report on the Northern Frontier Province and Turkana, Colonial Office: Lord Hailey Papers $\mathrm{UKNA} / \mathrm{CO} / 1018 / 24$.
} 
the Turkana population, who were profoundly affected by livestock confiscations as I explore in Chapter 6.

For the people of the lake, who had little to no livestock, some appointed chiefs and headmen began to seize animal skins as tax payments, Ekuam continues: ${ }^{27}$

'When the white men were in power they had their own chosen chiefs. There was a man well known... [to this community] and the others to the south, his name was Epeot and the white men paid him from Lodwar... Epeot came here to take hippo skins as taxes, he took goats from the herding families and he took skins from my parents and the other fishermen. This went on for many years, and Epeot became very corrupt, he took too much. People began to refuse paying any taxes to him. The whites sent their askaris, and when they arrived at these villages they saw that we had nothing. They did not demand anything, and they said that we would no longer pay any taxes' (interview with David Ekuam, Merier, 09/03/2015). ${ }^{28}$

Although it was eventually stopped, Epeot's taxation scheme doubtless served to connect the fishing villages in his administrative zone (close to the Kerio Delta) to the colonial regime very early on. His system arose in the late 1920 s or early 1930 s, when colonial taxes were reinstated following several years of conflict between the Turkana and the British. The earliest form of tax had been the 'hut tax', which served as one of the primary mechanisms for British subjugation of the Turkana in the early decades of the $20^{\text {th }}$ century (but almost certainly did not affect the lakeside communities), I discuss this in more detail in Chapter 6. The universal poll tax described in the above extract from the Lord Hailey Papers was introduced to the whole of Turkana by 1928, but had been collected annually in southern Turkana for several years by this time. ${ }^{29}$ In relation to this later tax, its innovative application to the hide trade by a number of headmen, combined with the static nature of the lakeside groups, conceivably led to a far heavier and more regular taxation than was experienced by

\footnotetext{
${ }^{27}$ During the early colonial period designated headmen or 'chiefs', paid by the colonial authorities were key in attempts to govern the Turkana region (Lamphear 1976, 1992).

${ }^{28}$ Askari - Swahili term for 'soldier'

${ }^{29}$ This is outlined in a Handing Over Report (from R.W Baker-Beall to W.A Perreau) - KNA/PRBDC/Turk/3/2.
} 
many of the other mobile communities, who could migrate north or west in order to avoid taxation. In this sense, the presence of colonialism as experienced via colonial era chiefs after the initial resistance movement, was perhaps far more immediate to these communities than it was to mobile ones in terms of its hegemonic position in day-to-day life.

It also seems clear that by the time it was terminated Epeot's scheme had made many of the fishing communities sharply cognisant of the economic value of their hippopotamus hide shoes and other skins in a broader context, and the potential benefits of shifting their trade to Lodwar (the regional centre and colonial headquarters). People soon began transporting skins for exchange in Lodwar themselves, and before Ekaru Epetapus (roughly 1950) a robust trade system had emerged. ${ }^{30}$ This system connected the lakeside communities with members of the wider Turkana population who travelled to Lodwar to trade livestock, and traders from non-Turkana communities further south who brought with them various commodities from larger centres nearer to Nairobi (along with their own regional produce, including pottery and tobacco). It began during the colonial era alongside taxation, but continued until well after independence. ${ }^{31}$ John Peikai, a fisherman from Nanyangakipi Village, remembered it as follows:

'When I was young, it was the time people in the south were just beginning to wear the thick blankets from Lodwar. People were carrying hippopotamus and crocodile skins to Lodwar on donkeys, and trading them there for blankets. They were expensive; we would pay ten pairs of hippopotamus skin shoes to buy one single blanket. Not everyone was able to buy them, and many people still wore edengo and akaluat, which were cheaper and could be bought nearby from people with animals, or made for free if there were livestock around. People in fishing villages had mostly stopped wearing edengo and akaluat and instead wore blankets by Ekaru a Aribokin and Ekaru ka ata Anayanae' (interview with John Peikai, Merier, $09 / 03 / 2015) .^{32}$

\footnotetext{
${ }^{30}$ Ekaru Epetapus literally means 'The Year of the Mist'. It was the year of a slow calm rain that lasted a long time and created a lot of mist.

${ }^{31}$ A burgeoning trade in animal hides is mentioned in the North Turkana and Turkana District Annual Report from 1926 - KNA/TDAR-DC/Turk/1/1.

${ }^{32}$ Ekaru a Aribokin 'The Year of the Solar Eclipse' and Ekaru ka ata Anayanae 'The Year of Anayanae' (a foreign woman who travelled through the fishing villages alone) were two years that occurred close to each other in the early 1970s (1971-73).
} 
Numerous interviews and life histories both from along the lake edge and from further inland, confirm that the transition in clothing mentioned by Peikai was experienced throughout Turkana in the middle years of the $20^{\text {th }}$ century. Edengo (leather waistcloths made from the hides of domesticated animals) and akaluat (the hides of leopards or baboons, depending on one's generation-set, worn about the shoulders) were once widespread throughout Turkana. ${ }^{33}$ Towards the end of the colonial era (1963) these were gradually replaced with large cotton wraps, which had been made accessible to communities in the north of Kenya via improving national infrastructure and trade networks. ${ }^{34}$

What is significant is that the fishing communities managed to incorporate these new cotton blankets into their own lives via their monopoly on the trade in wild animal skins (particularly hippopotamus skins) in lieu of livestock ownership. As Peikai observes, most men in the community had attained large blankets by the years Ekaru a Aribokin and Ekaru ka ata Anayanae (the early 1970s). This was before any substantial commercial development of Turkana's fishing industry, and during a time when very few of the fishing communities were selling the fish they caught. Thus, although these communities were undoubtedly considered to be very poor both by the colonial administration (who had eventually refused to tax them) and their nomadic counterparts (who had large herds of animals), they clearly maintained an economic leverage that facilitated their negotiation of the various material

\footnotetext{
${ }^{33}$ One of the earliest images depicting initiated Turkana men in akaluat shoulder robes was taken in 1931 during a speech by Governor Byrne. It is featured in Pavitt's $(2008,280)$ collection. Furthermore, the American Museum of Natural History holds a Ngimoru generation-set baboon skin akaluat collected in 1948 in its collection of Turkana ethnographic objects, catalogue no. 90.1/8401. ${ }^{34}$ This trend was also regularly picked up in photograph-based discussion sessions away from the lake edge. Emley's photographs from the early years of the $20^{\text {th }}$ century reflect the widespread use of edengo and akaluat skins, as does a selection of images dating to the 1930s published in Pavitt's (2008) collection. Thesiger's photographs from the early 1960s depict a general mix of attire, with many individuals still wearing edengo waistcloths, but a predominance of large cotton blankets.
} 
changes brought during the colonial era and the early years of Kenyan independence.

Moreover, many individuals exploited the trade in skins and remained within their lakeside communities, instead of accruing livestock and departing the villages altogether to pursue a pastoralist career. This implies that, on top of sustaining their economic independence, the fishing communities' trade in skins correspondingly provided enough security to mean that many were uninterested in an alternative lifestyle.

The shifting focus of this lake-animal skin trade from local village boundaries to Lodwar town also reflected a transformation, or augmentation, of its fundamental character, vis-à-vis its development from being primarily a system of gift exchange between local consociates to becoming a larger commodity exchange network. It is relevant to note that during this time many individuals from the general ngikebotok grouping were also becoming involved in various Lodwar-based colonial labour projects (more so than individuals from mobile herding groups who were economically tied to livestock), the cash from which probably also facilitated the acquisition of cotton wraps. Broch-Due and Sanders (1999: 47) point out that 'It was the historically cattle-less Turkana who were keen to take advantage of alternative subsistence strategies, a fact the administration... recognized and regretted'. However, these labour projects are not remembered in many fishing villages today, and were probably more significant to those who chose to settle permanently in Lodwar than they were to those who remained at the lake edge and travelled to Lodwar purely to exploit the market.

Considering the immense success of their flourishing trade it is unsurprising that the communities were angered when, in 1977, the Kenyan government introduced legislation that made the hunting of all wild animals illegal. A man named Lokinei Ewoi was the first wildlife officer to be posted to Turkana in 1976; he was from a fishing village by birth and as 
such was selected to oversee the administration of the new wildlife laws amongst those who were making a living by contravening them. Ewoi passed through Nakurio Village in April 2015, during which time we discussed his career at length.

'I was from Naturur Village, I went on foot to Maralal in 1964, [where] I was trained as a wildlife officer. I did not return to Turkana until 1976, I had spent ten years in Mount Elgon. When I came back my objectives were to stop people hunting wild animals... [and to] protect people and their livestock from wild animals. I was the first and only wildlife warden. When I began, my job was very difficult. No one was convinced by the new rules; we had meetings with local chiefs... At that time people were selling hippopotamus skins, and people were still making shields from crocodile skins. There was a very successful trade in Lodwar, and many herders were buying skins from ngikebotok. During our meetings we told the people that if they continued to hunt hippos and crocodiles they would go to prison for over twenty years.... This helped to prevent them... I worked in that position until 1999 and in that time numbers of crocodiles and hippos have stabilised' (interview with Lokinei Ewoi, Nakurio, 10/04/2015).

The year Ewoi returned to Turkana marked the time of the consolidation of the Game Department and the National Parks Service into one single department — the Wildlife Conservation and Management Department (WCMD). It was the responsibility of the newly formed WCMD to enforce the ban on hunting across the nation and protect Kenya's wildlife resources for the maintenance of wildlife-based tourism. Whilst the inhabitants of the fishing villages were clearly not implicated in any kind of tourist trade, and did not reap any financial benefits from the protection of these animals, they were nevertheless required to accept and abide by the new nationwide law.

Despite the emergence of an alternative trade in fish (which I consider in the following section) the new law had profound consequences for the lacustrine communities. Most significantly, it severed their involvement in enduring local and regional exchange networks, deeply affecting the dynamics of their relationship with other territorial sections. On a local scale the illegalisation of hunting caused the termination of the socially prescribed personal trade relationships that had existed between members of the fishing communities and visiting pastoralists, who had continued to trade with the lakeside villages throughout the middle 
years of the $20^{\text {th }}$ century. This disconnection rapidly altered the material culture corpus of many of the lakeside villages, gourds, fat containers, bowls and pots no longer filtered into the villages from the surrounding area. Instead, the communities found themselves increasingly reliant on containers and cooking appliances sold in Kalokol, ${ }^{35}$ the centre of a new internationally funded commercial fishing industry that surfaced in the early 1970 s. Without this new industry the loss of the hide trade and its associated exchange networks would have constituted worse economic restrictions than those experienced under chief Epeot's interpretation of colonial taxation.

\subsection{Fishing nets, fibreglass boats and the NORAD scheme}

Throughout the colonial era, fishing had remained a subsistence strategy that sustained the lake-dwelling communities while they were involved in a dynamic trade in items made from lake animal hides, and by the 1970s the vast majority of the communities had still never traded the fish they caught in the lake. ${ }^{36}$ However, before the second Ekaru Etop Ekosim (the mid-1970s) most of the lakeside villages had been visited by officers from the Norwegian Agency for Development (NORAD), who were in the early stages of forming a new trade network along the western shore of the lake. ${ }^{37}$ Robert Ekuwom, a fisherman born in Merier Village, remembers these early meetings with NORAD operatives as follows:

'Some years before [Ekaru Etop Ekosim] there was a white man who came here... he was from the company NORAD. When he came he did educate the people in the village about new ways of fishing. He said that people could sell the fish they caught, where before we had

\footnotetext{
${ }^{35}$ This was ascertained during the collection of household object inventories.

${ }^{36}$ This does not include the villages surrounding Ferguson's Gulf, who sold some fish via an OXFAM scheme as early as 1962, and later in 1965 via a fisherman's co-operative set up by the National Christian Council. Also, the Catholic mission established some unofficial fishing co-operatives in the late 1960 s, but these were fairly inconsequential.

${ }^{37}$ Ekaru Etop Ekosim means 'The Year of Star Tail' and is applied to two distinct years during which substantial shooting stars were witnessed in the sky. The first year occurred in the early 1960s during the Shifta War (a secessionist conflict between ethnic Somalis and the Kenyan government), the second between 1975 and 1976.
} 
never sold [the fish]. He provided better equipment, before this there had not been one man with a net. This man was here often with other men from NORAD at this time, before Etop Ekosim, but his name we knew as mkono.' (Robert Ekuwom speaking during a group interview, Merier, 05/03/2015).

NORAD commenced operations in the early 1970s, having been invited by the national government to assist in the development of the fisheries of Lake Turkana as a solution to the persistent food insecurity faced predominantly by pastoralist communities. Its initial strategy was the development of a co-operative called 'The Turkana Fishermen's Cooperative Society' with eight branches located at nodal points along the western shore of the lake (the locations shown in Figure 4.1). These would sustain a commercial fish trade connecting the lakeside villages with markets in Zaire (present day Republic of Congo) and western Kenya. ${ }^{38}$ The TFCS branches were all operational by the end of the 1970s (although the Todonyang branch was quickly closed as a result of the increasing insecurity of the Ethiopian border region) and were known to local communities simply as 'the societies'. They were predominantly community-run, but were heavily financed by NORAD and purchased fish from surrounding villages to be processed and transported to the external markets. This practice is described in a report compiled in 1980 by an advisory group appointed by NORAD as follows: 'The fish, salted dried and sun dried, is sold from the fishermen to the nearest cooperative branches where it is stored. The salted dried fish is treated with insecticide, packed and later sold to private fish traders. The co-operative has a central store for the salted dried fish at Kitale to which the fish is transported from the branches at the lake' (Jorgensen et al. 1980: 16).

A necessary element in the initial success of the scheme was the provision of new equipment that could facilitate a dramatic increase in the yields that local fishermen were able to

\footnotetext{
${ }^{38}$ A market in Zaire (DRC) was developed as early as 1966 by OXFAM; this was then subsumed by the NORAD scheme.
} 
achieve. As such, the 1970s constituted a period of dramatic technological change for the groups along the western coast. Gill nets and hand lines with metal hooks flooded the region via intermediaries such as the man remembered by Ekuwom as mkono. ${ }^{39}$ To a large extent this equipment supplanted previous technologies, especially ngirokode (woven palm lines with bone hooks) and ngakwara (spears or harpoons). On top of this equipment almost two hundred fibreglass boats were introduced to the lake, which were owned and maintained by the TFCS and allocated to different cooperative branches. Training for the use of these boats, along with the corresponding equipment, was also provided by Norwegian professionals who visited the villages. Many who had accrued livestock and left the lake edge returned on the news of NORAD's arrival, Peikai remembers his own father's return as follows:

'My father was born in this area... Elelea [Village]. He left a long time before NORAD came... he went to Kangarisae where he got my mother ... and they married. I was born [at this time]... But he came back here when he heard of NORAD and all the things they were giving people; he came back here for business. There were so many people coming [to the lake]. Before NORAD it was erokode, emachar, epute... everyone was with [an] epute... and only on wooden rafts, not going far. Then very quickly everyone was selling to Kerio and Kalokol, everyone was on boats and going very far along the shore, everyone was with nets and there was no fish for any others [who did not have nets]' (interview with John Peikai, Merier, 09/03/2015).

The fact that NORAD's new boats allowed people to travel 'very far along the shore' was significant. Up until this point lake travel had been constrained by the physical qualities of the doum palm rafts that were used by the fishermen. It had not been possible to travel far out into the lake at all, and travelling along the shore was not possible without stopping regularly to dry the rafts in the sun. ${ }^{40}$ The incursion of fibreglass boats was therefore a fundamental

\footnotetext{
${ }^{39}$ Mkono is the Swahili word for 'hand'; some local people at Merier recall that he was called this because he was considered the hand of NORAD, whilst others suggest that it was because he was involved in the practical training of fishermen.

${ }^{40}$ Rafts made from doum palm trunks absorb water very quickly and are unable to remain buoyant for long periods of time. This was also picked up by Sobania (1988: 48) amongst the El Molo (who use the same kinds of rafts), who states that: "travel by El Molo was limited in large measure by the rafts that they constructed from the trunks of doum palm tress. They seldom ventured very far on these rafts because with extensive use the logs absorbed water and became unseaworthy.'
} 
factor in the shifting commercial focus of the lake edge communities from Lodwar (which is an arduous $50 \mathrm{~km}$ journey inland from the closest lakeside village) to Kalokol, on the coast of Ferguson's Gulf. This happened as the previously discussed trade in hippopotamus and crocodile skins was coming to an end, during a time when there was rapidly reducing commercial impetus to travel to Lodwar and many of the trade relationships that facilitated the influx of domestic objects from inland mobile groups were disintegrating.

This suggestion seems to contradict Broch-Due and Sanders' (1999: 35) point that during the 1970s 'the one time government outpost of Lodwar, was transformed... into a thriving economic centre sporting an array of shops and services' and that 'it was the poorer cattleless Turkana, more than any others, who most actively sought out new NGO-initiated opportunities in the Lodwar area'. However, as was the case during the earlier colonial labour projects, the 'cattleless Turkana' involved in these schemes were not necessarily all from fishing communities, and those who were tended not to maintain a home in one of the lakeside villages but rather to relocate altogether. In this sense, whilst Lodwar undoubtedly grew during the 'heyday of development donor spending' (Broch-Due and Sanders 1999: 35), and those primarily involved in its growth were ngikebotok, the impact of this growth on core Ngisiger, Ngibocheros, and Ngiesetou communities who remained in lakeside villages was minimal. From the perspectives of these fishing communities Kalokol was far more significant, and its development was directly interwoven with the severance of their trade relationships with inland herding groups.

Kalokol began to emerge as a regional hub during the early OXFAM projects of 1962, which facilitated the purchase of fish from lakeside villages for sale to inland famine camps. However, it was not until the commencement of the NORAD scheme that it began to 
supersede Lodwar in terms of its commercial advantage and accessibility for fishing communities. Not only was it the location of the TFCS 'boat building and maintenance section', but it also comprised a 'central store for consumers' goods, fishing gear and other items... [and] a petrol station selling petrol for the local vehicles and supplying the cooperatives own transport section with fuel' (Jorgensen et al. 1980: 17). Mark Ekamate, who moved to Kalokol from Todonyang in 1943, remembers how prior to the NORAD scheme there had been 'no road, no shops, no buildings, [and] no business' (interview with Mark Ekamate, Kalokol, 13/03/2015). The newly emerging Kalokol hub attracted small-scale entrepreneurs from Turkana and further afield who were interested in capitalising on a newly burgeoning centre with few trade kiosks, many of these individuals arrived with crowds of Luo fishermen from Lake Victoria in western Kenya, who had also come to exploit the NORAD scheme.

Throughout the 1970 s the scheme was reasonably successful. The new boats were let out on a village-by-village basis to groups of men who were generally related through kinship or bond friendship. A small number of boats were also brought by fishermen from western Kenya at this time; these wooden vessels were operated by Luo leaders with crews of Turkana who worked on a casual basis, usually until they had earned enough money to buy their own net, or had found a place on a 'society' boat. Those who were not able to attain a place within a 'net group' on a boat were able to sell their fish indirectly via contacts who were. Doum palm rafts thus remained in frequent use, as did epute hand traps for those who could not afford nets. $^{41}$

\footnotetext{
${ }^{41}$ NORAD's (1980: 10) report mentions 'an unknown but large number of palm tree rafts' in addition to their inventory of society and private boats in use on the lake.
} 
During this time the cash that emanated from the new trade was increasingly used to purchase domestic products and clothing at the rapidly developing Kalokol centre. Families began to use aluminium sufurias (cooking pots) and plastic containers, cups, and bowls on a large scale for the first time. In Merier, women agree that these items began to appear in the first Ekaru Aribokin (roughly 1973) and were extremely common by Ekaru Asur (roughly 1981). ${ }^{42}$ Sarah Ekuwom, a woman from Merier, remembers how 'People [in Merier] used to keep fish oil in pots, a mother would have one pot for cooking [and] one pot for keeping fish oil. In my family we ate from palm plates and plates made from turtle shells. After Ekaru Aribokin this changed' (Sarah Ekuwom speaking at a group discussion, Merier, 13/03/2015). Significantly, these new items had been widely available at Lodwar prior to Kalokol's growth, but few people had had incentive to buy them in the context of their strong trade relations with herding communities who brought items like agulu (cooking pots) and atubwa (wooden bowls) straight to their villages from further inland.

To the lacustrine communities, this transformation in the material conditions of everyday village life embodied a significant overhaul of their mode of production. Fishing was transformed from a purely subsistence based activity into a commercial livelihood via new technologies and specialisms. The essence of this transition was the commodification of a new entity: lake fish. However, this was not the most transformative element of the phase, especially considering that the trade in hippopotamus and crocodile skins had previously developed into a lucrative commercial activity beyond its source context of local gift exchange networks. Rather, the most significant changes experienced throughout the 1970s

\footnotetext{
${ }^{42}$ (Fieldnotes, Merier Village: 05/03/15). Ekaru Aribokin, meaning 'The Year of the Solar Eclipse', is applied to two different solar eclipses that occurred in the early 1970s, these were roughly 1973 and 1974. Ekaru Asur, meaning 'The Year of Fleeing' or 'The Fleeing Year', refers to the time of a large Pokot raid that reached as far north as the mouth of the Kerio River in the early 1980s. During this time many people fled north to settle along the Turkwel River.
} 
were those implicated in a discrete but radical shift in the entire structure of interaction that existed between the lakeside villages and the inland herders.

The economic viability of fishing complicated its former role in external herding communities as merely a refuge during times of fairly brief hardship, and whilst movement between the two livelihoods remained fluid it no longer occurred via local trade relationships between families. Those who came to the lake from the interior were far more likely to settle en masse in new villages than merge into pre-existing ones. It was incongruous that NORAD's trade had been implemented to deal with the destitution of inland communities, not because this was an unfamiliar role for fishing to play, but because it now came to embody a permanent alternative economic pursuit, instead of a brief respite. Previously, the end goal of most herders who turned to the ngikebotok fishing villages for support had been to acquire livestock and depart; and yet from the 1970s many envisioned staying indefinitely.

Waves of people from a mixture of inland territorial sections were relocated from various 'famine camps' and inserted into the bourgeoning industry. To the larger part of the population, who remained involved in the pastoralist lifestyle, these fishing communities were paradoxical. They remained ngikebotok, entirely without livestock, and yet they were endlessly capable of capital growth, and this took place in a sedentary setting of what initially seemed like unparalleled stability. In this sense, the 1970s saw a more profound economic division between the two lifestyles than had ever previously existed. Up until this point fishing had functioned as an occupation within a distinctly pastoralist economy, and even the core communities of Ngisiger, Ngibocheros, and Ngiesetou who remained at the lake edge permanently had been sustained, at least to some degree, by pastoralism via their trade with 
visiting herders. These two livelihoods were now capable of operating more or less independently of one another.

The largest-scale venture within the new industry, and its intended zenith, was undoubtedly NORAD's construction of a colossal fish processing plant at Kalokol in the early 1980s. This facility replaced the storehouse at Kitale as the core connection between the co-operative societies and the wider markets and not only facilitated fish drying but also freezing. Between two and three million US dollars were spent on its construction, which followed shortly after (and was probably largely influenced by) the 1975-1976 'tilapia boom' that saw roughly $75 \%$ of the fishermen on the lake (121 boats) converge around Ferguson's Gulf (Hopson 1982; Kolding 1989). On top of this, roughly twenty million dollars were spent on building a road to connect the facility to Kenya's highway system. On its completion the new facility served as the headquarters of the entire NORAD scheme. Its large imposing structure was like nothing rural Turkana had ever witnessed before and seemed to assert the newly emerging permanence and stability of the fisheries. Epuu Eriamun, who was in charge of a TFCS boat at the time, recalls how 'people rejoiced [when the factory was built]... Kalokol was full of fishermen from all of Turkana. People could not believe the size of the building...' (interview with Epuu Eriamun, Kalokol, 13/05/2015).

However, within a few years the Kalokol facility had developed into a disaster. The freezing of lake fish (with diesel generators) had proven to be financially impracticable, and quickly after its construction the large commercial freezers were all shut down. Then, a drought along Lake Turkana's main water source, the Omo River, caused the waters in Ferguson's Gulf to significantly recede and the surrounding area became drastically unproductive. Eriamun continues: 
'The waters disappeared and everyone was struggling to catch anything... People had come because of the many fish [that were here] before [during the mid-1970s], they began to leave [for the] north and south... and many who came from inside [herding communities] returned to them. NORAD had employed a man from close by... [his name was] Imana Ichor, he was the first manager of the Kalokol facility. Imana Ichor was sent for training... in Europe. By the time he had returned the factory had closed' (interview with Epuu Eriamun, Kalokol, 13/05/2015).

The complete closure of the Kalokol facility shortly after its construction heralded disaster for NORAD's intervention in Turkana's fisheries altogether. On top of this dramatically unsuccessful construction project, many of the co-operative branches were suspected of significant corruption; they required constant financial support and none were turning a profit. ${ }^{43}$ NORAD eventually pulled out of Turkana completely, as a result of 'a breakdown in diplomatic relations' (Broch-Due and Sanders 1999: 35). The community-run TFCS branches remained in place despite the withdrawal of financial assistance, but disintegrated over the ensuing years and were all closed by Ekaru a Nawokodou (roughly 1987). ${ }^{44}$ Unlike the facility at Kalokol (which was protected as a government asset), the TFCS stores were left derelict, many being eventually dismantled by members of the local communities who salvaged what they could from the empty structures. ${ }^{45}$ Materials from the Kerio branch store, for example, were harvested some years after the dissolution of the TFCS following catastrophic floods in the late 1990s. These materials were used to build new houses and shops during Kerio's expansion in the post NORAD years (Derbyshire and Lowasa forthcoming).

\footnotetext{
${ }^{43}$ The disappointment with the TFCS is made clear in NORAD's (1980) interim report, produced shortly before work began on the Kalokol facility, and ensuring their 'economic viability' is stated as one of the scheme's key objectives.

${ }^{44}$ Ekaru a Nawokodou means 'The Year of Clouds' and refers to a period of time in the mid to late 1980s when herders migrated several times to regions that contained large clouds, but in each cloudy location they found no rain.

${ }^{45}$ Several of these derelict storehouses were visited throughout the fieldwork behind this chapter. Photographs of them, the Kalokol facility, and the surrounding fishing villages, were exhibited in a display entitled 'The Ruins of Turkana' as part of the 'Remains, Waste and Metonymy: a Critical Intervention into Art and Scholarship' day at the British Institute in Eastern Africa (24/10/15), and subsequently in the month-long follow-up exhibition (of the same name) at the National Museums of Kenya, Nairobi (18/01/16-19/02/16).
} 
NORAD's withdrawal was, however, by no means the end of Turkana's new commercial fishing industry, and the economic division between herding and fishing populations has remained strong throughout the post-NORAD years. Following the failure of the original scheme, and the departure of many of those who had come from herding sections, the core lakeside communities used the infrastructure and materials that were left behind to create a system that has since been able to withstand political and environmental fluctuations to a far greater degree than was possible in the 1980s. In this system, dried fish are sold to traders in Kalokol predominantly via middlemen (from lakeside villages), who have either retained TFCS boats or purchased newer boats from other sources. In more recent years, groups from several villages have begun pooling resources to hire boats in order to transport their combined catches to Kalokol themselves. This system bypasses the need for the TFCS storehouses that used to operate along the lakeside (purchasing fish from surrounding villages and transporting them to the Kalokol facility in lorries). Today fish are conveyed directly to Kalokol along the shoreline from as far south as Mugur Village, and importantly, transportation does not take place according to a rigid schedule, which reflects the irregularity of both supply and demand. During periods of slow trade the villages rely purely on lake fish for survival.

The development of Kalokol centre during NORAD's involvement, and especially the construction of roads connecting it to the rest of Kenya's highway system, has ensured its continued role as the hub of this industry. This is despite the fact that the main freezing and drying facility has remained closed for over two decades. Many of the fishermen from western Kenya, who came during the emergence of the NORAD scheme, have remained after its collapse, taking on new entrepreneurial roles as traders who connect the lake's produce 
with emerging markets in the rest of Kenya. Furthermore, after a substantial period of disconnection with the fish markets in the DRC, the last few years have seen an influx of Congolese traders who have begun travelling to Turkana themselves to partake in the newly privatised industry, re-establishing the connection between their markets and the Lake. Whilst the new industry does not guarantee continuous employment for all involved, on the whole it is far more robust and certainly more sustainable. Unlike the rigid model developed by NORAD, which was neither economically viable nor physically capable of withstanding Turkana's volatile environment, the new system is fluid and mobile. It mimics the unpredictability of the lake environment, adapting to transformations as they come, and, importantly, is flexible enough to prevail when trade dies down for one reason or another.

The sharp contrast between NORAD's system and its re-invention by the fishing communities resonates in the dilapidated ruins of the failed original scheme, which still litter the lakeshore (Figures 4.5-4.10). Of these ruins, the most enigmatic is the main processing facility at Kalokol (Figures 4.7-4.10). This imposing building, standing empty and bolted shut, is encircled by the nine villages of Ferguson's Gulf, whose occupants sell their catches to traders a stone's throw from its closed gates. Unlike the NORAD structures, these villages (and the others along the shoreline) can be abandoned, partly dismantled, and rebuilt in a matter of days (which was the case during the previously mentioned drought that led to the recession of Ferguson's Gulf and the closure of the Kalokol facility). It is the impermanence of the woven palm structures that is their greatest strength. The fishing villages are dynamic and purposefully transient, they move to and fro with the lakeshore and laterally in relation to 
the infrastructure developing around them (see Figures 4.3 and 4.4). ${ }^{46}$ During an interview in Kerio, a fisherman known as Lotieng recalled how the villages close to the Kerio Delta relocated various times during several extensive floods in the 1980s and 1990s. During these floods the Kerio TFCS storehouse and connected settlement were inundated twice, and ultimately ruined, as a result of their immovability and their proximity to the water edge. Lotieng explains:

'To build a permanent house like that [the ruined cooperative society structures] is for someone who has chosen where to live [permanently]. The life of the fisherman, though, requires constant movement... you have to move to find fish. You have to move with the lake.' (Lotieng speaking at a community meeting, Kerio, 05/03/2015).

NORAD's intervention in Turkana, being mainly characterised by its preoccupation with physical permanence and systemic inflexibility, was therefore divergent from, even contrary to, both the pre-existing livelihood it engaged with and the trade network that arose following its demise. The scheme undoubtedly prompted significant transformations, namely the commoditisation of lake fish and the subsequent sustained separation of many fishing communities from the pastoralist economy. However, these changes had little to do with NORAD's management, vision or expertise and more to do with basic infrastructural development and the donation of new equipment. ${ }^{47}$ Moreover, while the arrival of these changes may be attributed to new technologies and infrastructure, their endurance into the

\footnotetext{
${ }^{46}$ Historical, photographic and environmental data show that Lake Turkana's shorelines have fluctuated dramatically throughout recent history. Shortly before the drought along the Omo River that caused Ferguson's Gulf to vanish Butzer (1971: 124) had outlined the lake's fluctuations as follows: 'The basic outline is that of a falling lake shortly before 1888 , a rise to a +15 - meter maximum in 1896, followed by a precipitous drop of 15 metres by 1908. Apart from a violent oscillation of at least 3 meters ca. 1918, the level continued to drop gradually until 1954-56, when the lake was about 5 meters lower than present. A rapid rise of some 4 meters, beginning early in 1962, brought the lake to about its modern level within 3 years. Contemporary trends are still impossible to verify but appear to be positive.'

${ }^{47}$ The infrastructure that NORAD built facilitated an influx of a range of commodities for sale in Kalokol. During the mid-1990s (several years after NORAD left) mobile phones began to flood the town and, with the coming of the Safaricom 'Mpesa' mobile money service in 2002, they became integral to the newly privatised network as a means of buying and selling large quantities of fish without banks or cash.
} 
present day is undeniably a result of the ingenuity of the lakeside communities, who integrated new elements into an already established human-environment relationship. 


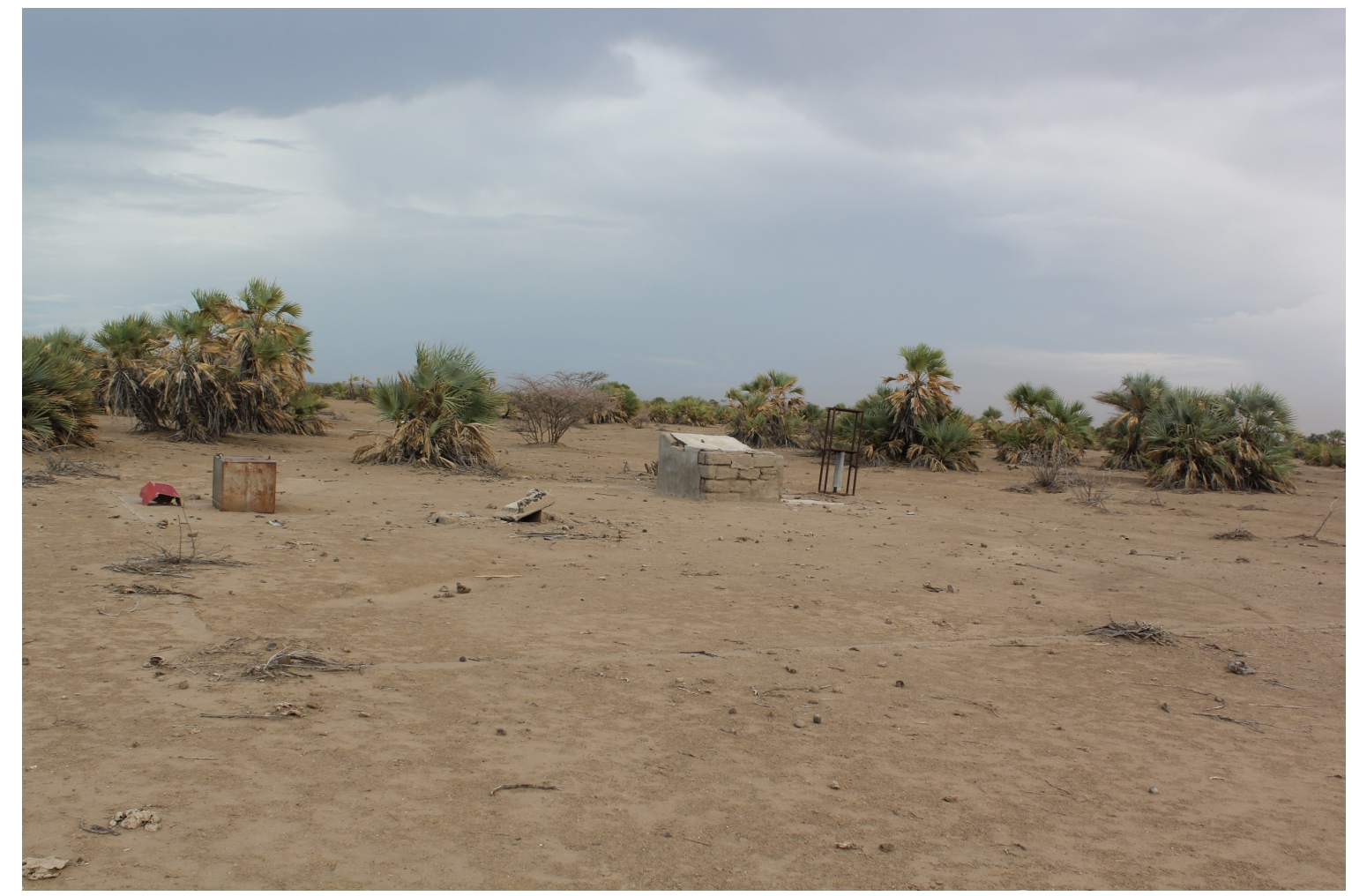

Figure 4.5. The remnants of the Kerio branch TFCS store, most of the building materials have been removed and used to build houses and shops in Kerio Village.

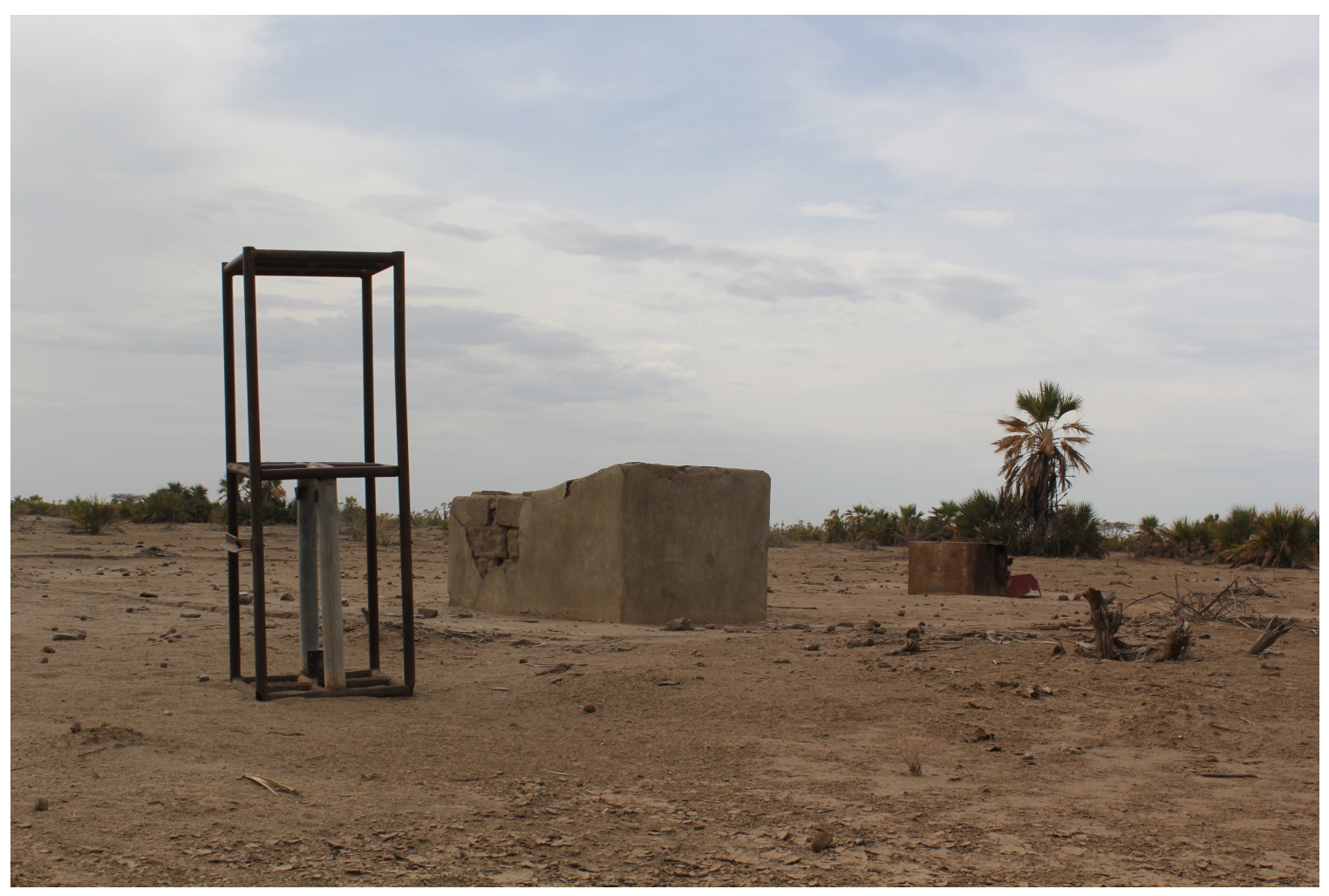

Figure 4.6. All that remains of the Kerio branch central store are its concrete foundations and an array of decaying implements that had once been central to its daily activities. The object on the far left of this image is the skeleton of a spring scale and to the far right lies a safe that has been broken-into but remains attached to the foundations of the building. 


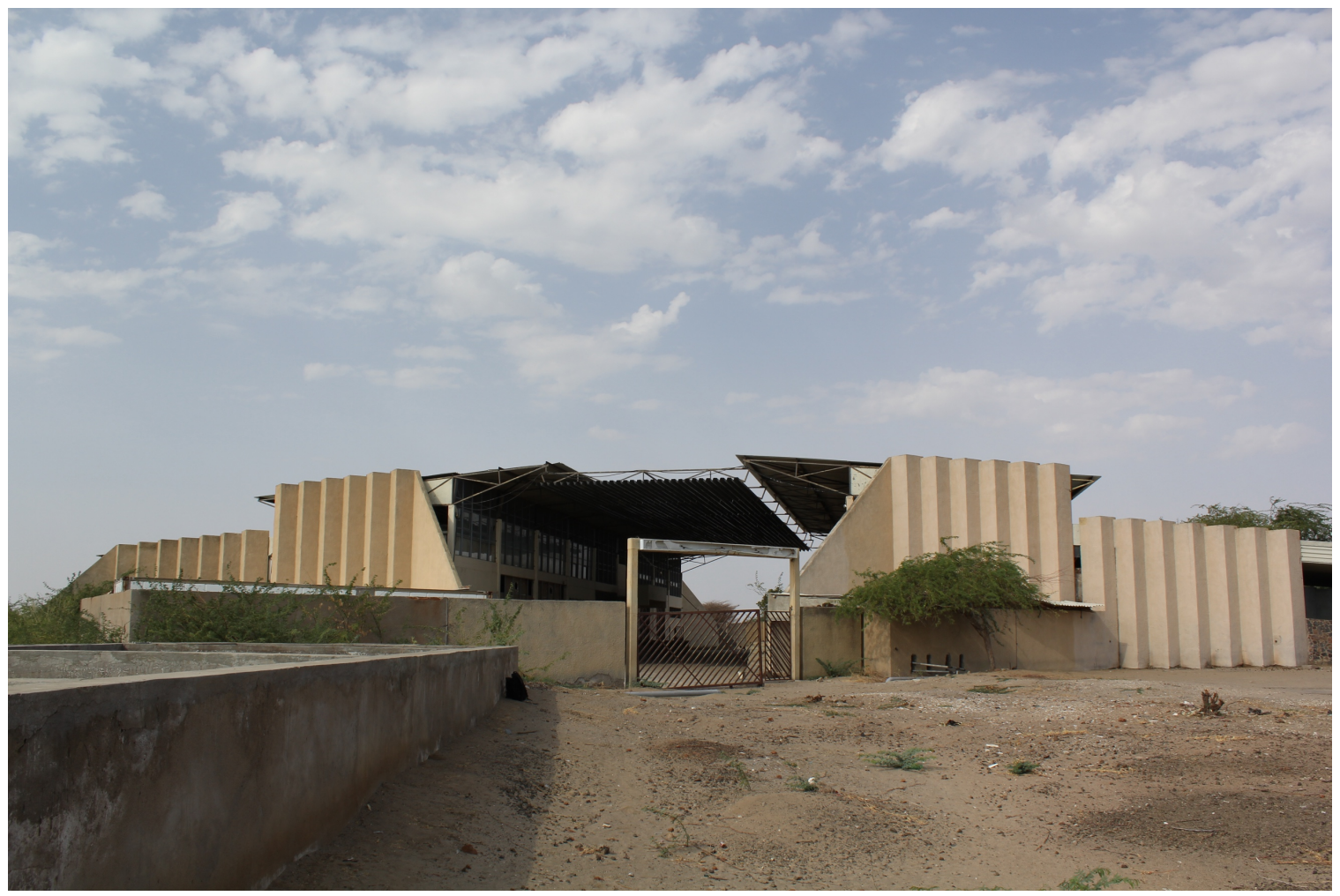

Figure 4.7. The Kalokol facility built by NORAD, which is now inoperative.

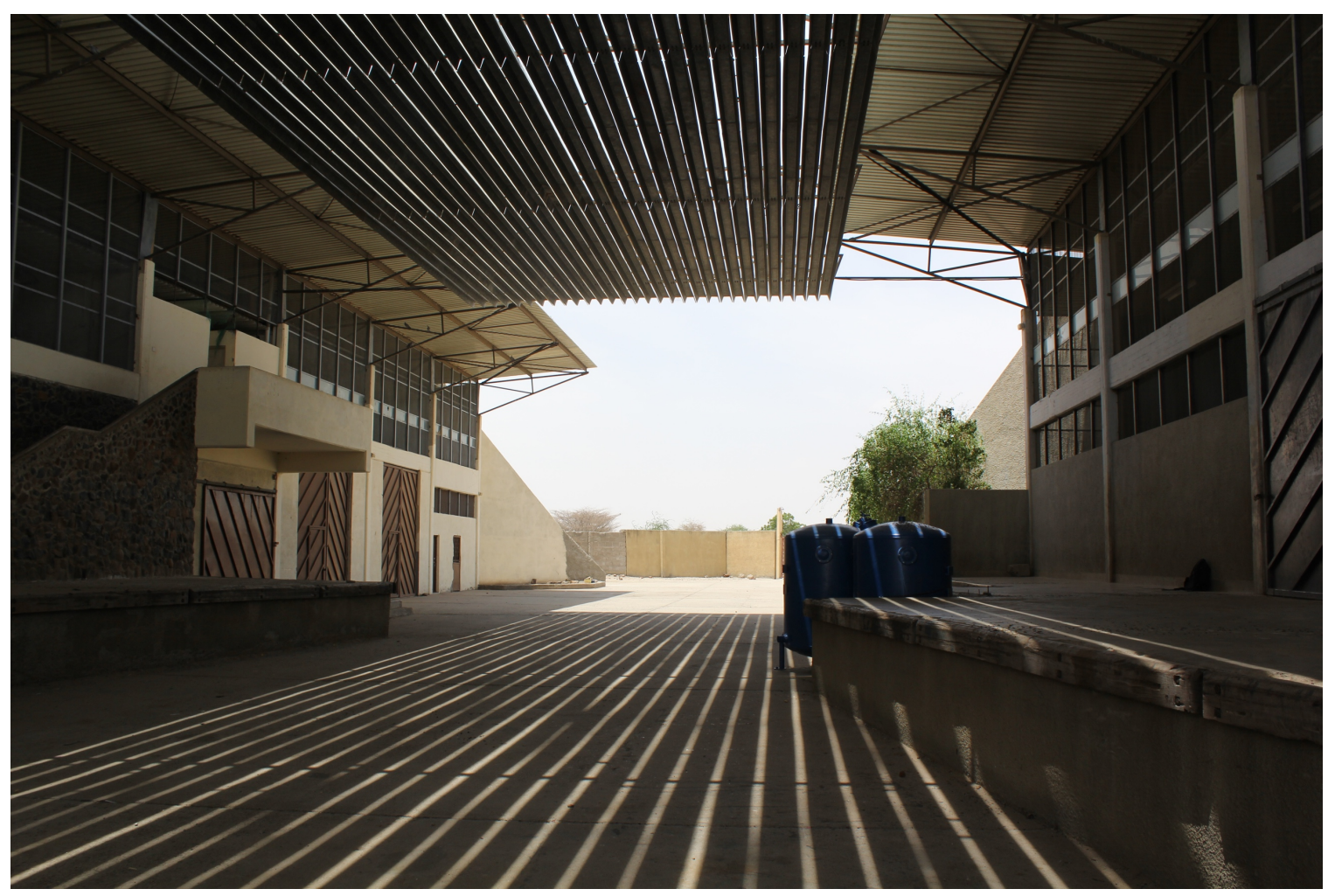

Figure 4.8. Internal main courtyard of the Kalokol facility. 


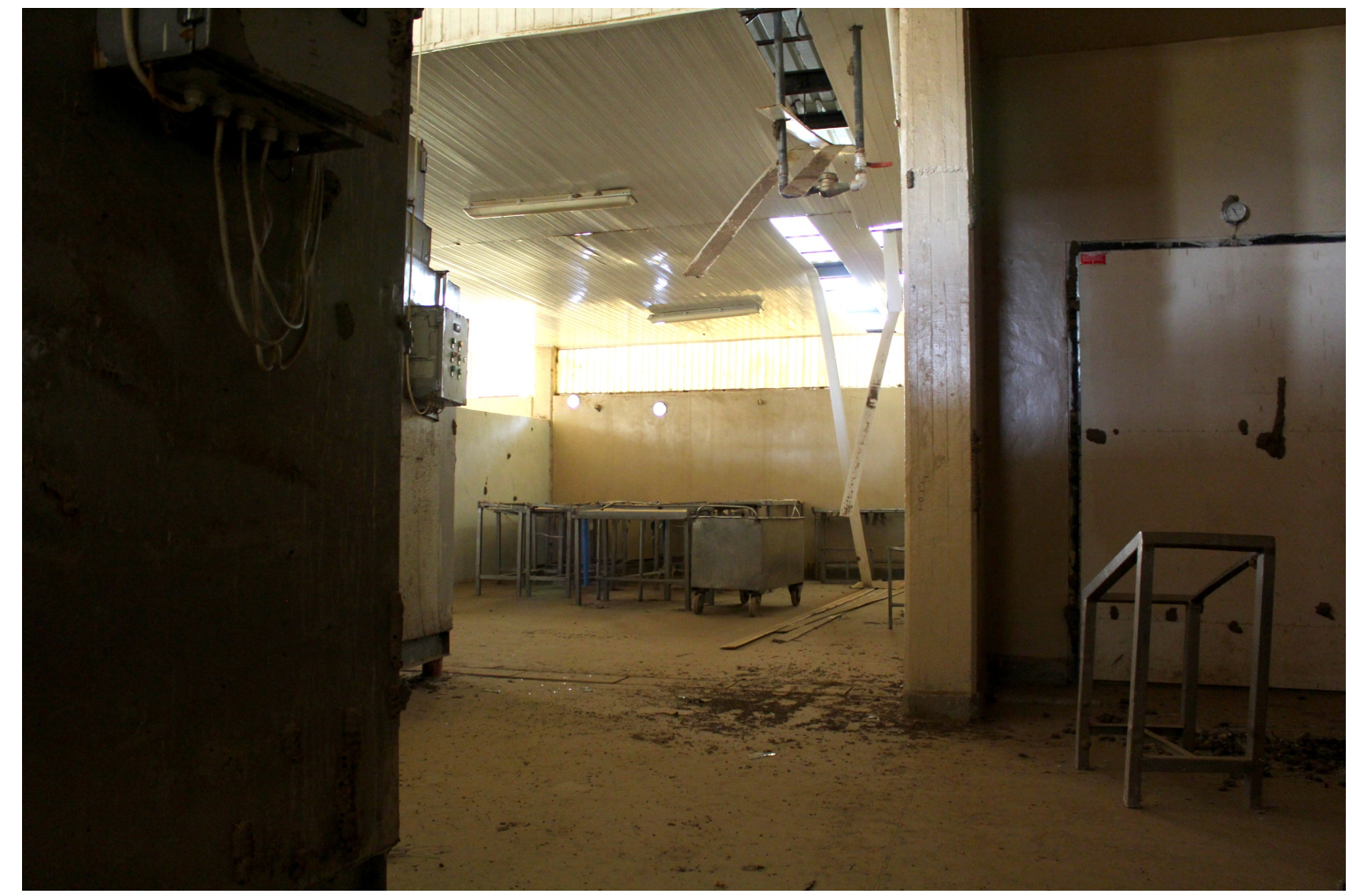

Figure 4.9. General view of the interior of the Kalokol facility.

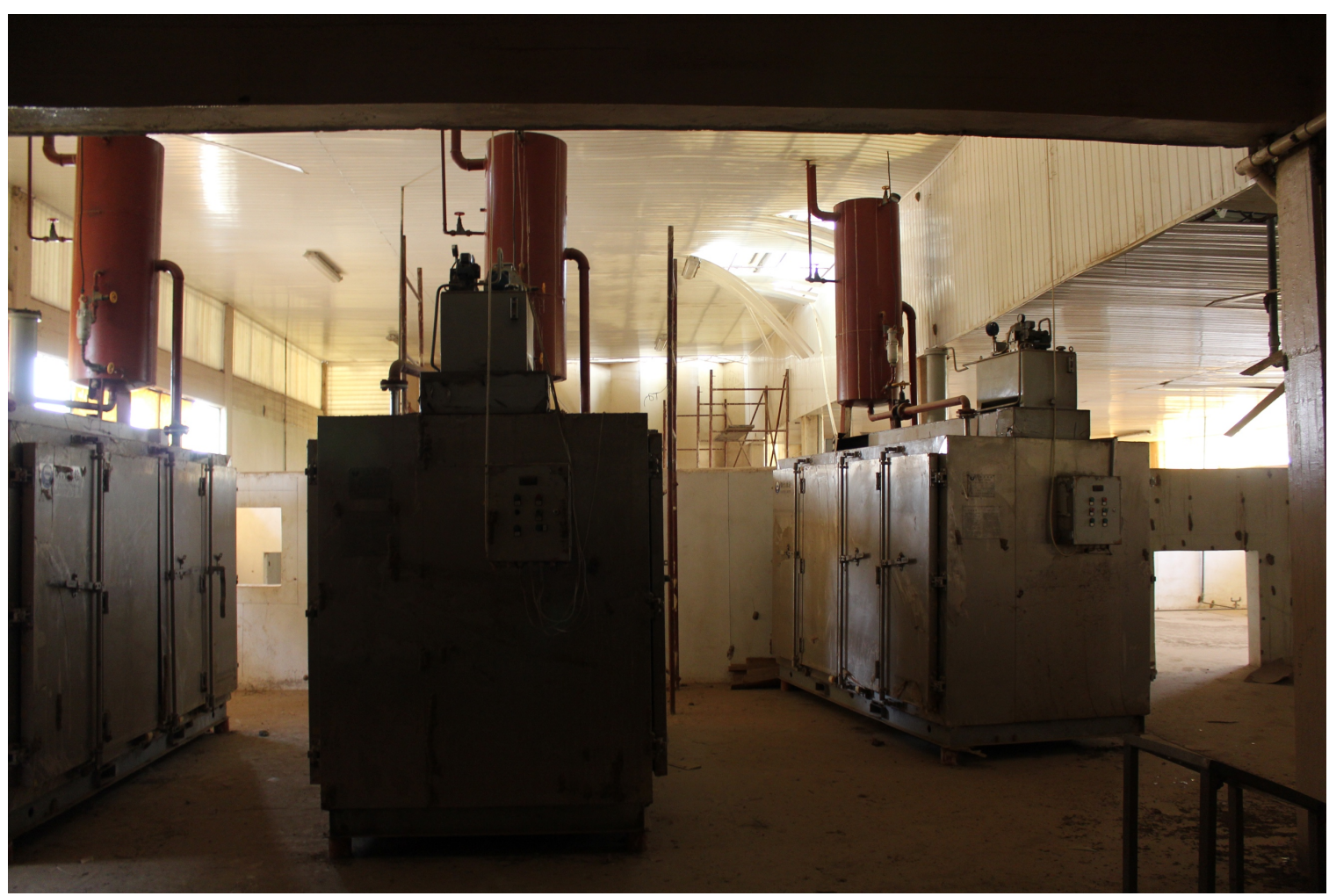

Figure 4.10. Industrial freezers inside the Kalokol facility freezing and storage wing. 
The need for a new externally planned organisational system was, for unknown reasons, presumed from the outset of NORAD's work and yet it was the application of experience and knowledge accumulated over several generations amongst the lakeside communities that ultimately led to the success of their new industry. In other words, it succeeded via its incorporation into a landscape that was, to use Ingold's (1993: 152) understanding of landscape, 'constituted as an enduring record of — and testimony to — the lives and works of past generations who [had] dwelt within it, and in so doing, [had] left there something of themselves.' In the context of international development schemes operating in Turkana (or indeed Africa more broadly), the disregard for local historical epistemologies demonstrated by the NORAD scheme is, of course, not unusual. Indeed, Oba (1992: 1) observes that 'there are few instances where development plans have relied on historical analysis to deal with development issues at a regional level'.

Adaptability, fluidity, and resourcefulness are traits that have surfaced consistently throughout the recent social history of the fishing communities. The ingenuity involved in remodelling the failed NORAD scheme in recent years recalls that which underlay the emergence of the previously explored trade in lake animal skins during the early years of the $20^{\text {th }}$ century and the later exploitation of larger markets in Lodwar during its expansion in colonial times. Indeed, first-hand experience of the dynamics of the earlier hippopotamus and crocodile hide trade, and its shifting entanglements with both local and external markets, must have featured prominently in the minds of the community elders who oversaw the development of the post NORAD fishing industry. In this manner, the endurance of lakeside communities throughout the various transitions of the last century has been ensured by their capacity for constantly reworking their economic strategies, social relationships (with other fishing communities and inland herding groups) and their physical location in and 
engagement with the environment around them. This all takes place in relation to previous episodes in the lives of villages, families and individuals. Therefore, whilst change has often been derived from external stimuli, it has always been negotiated from within and prevailed via its configuration within locally constituted grounded livelihood practices and 'taskscapes' (Ingold 1993, 2000). Figures 4.11-4.14 illustrate the changing nature of trade on the southwestern shore of the lake, Figures 4.15 and 4.16 scenes of the contemporary fish trade at Merier. 


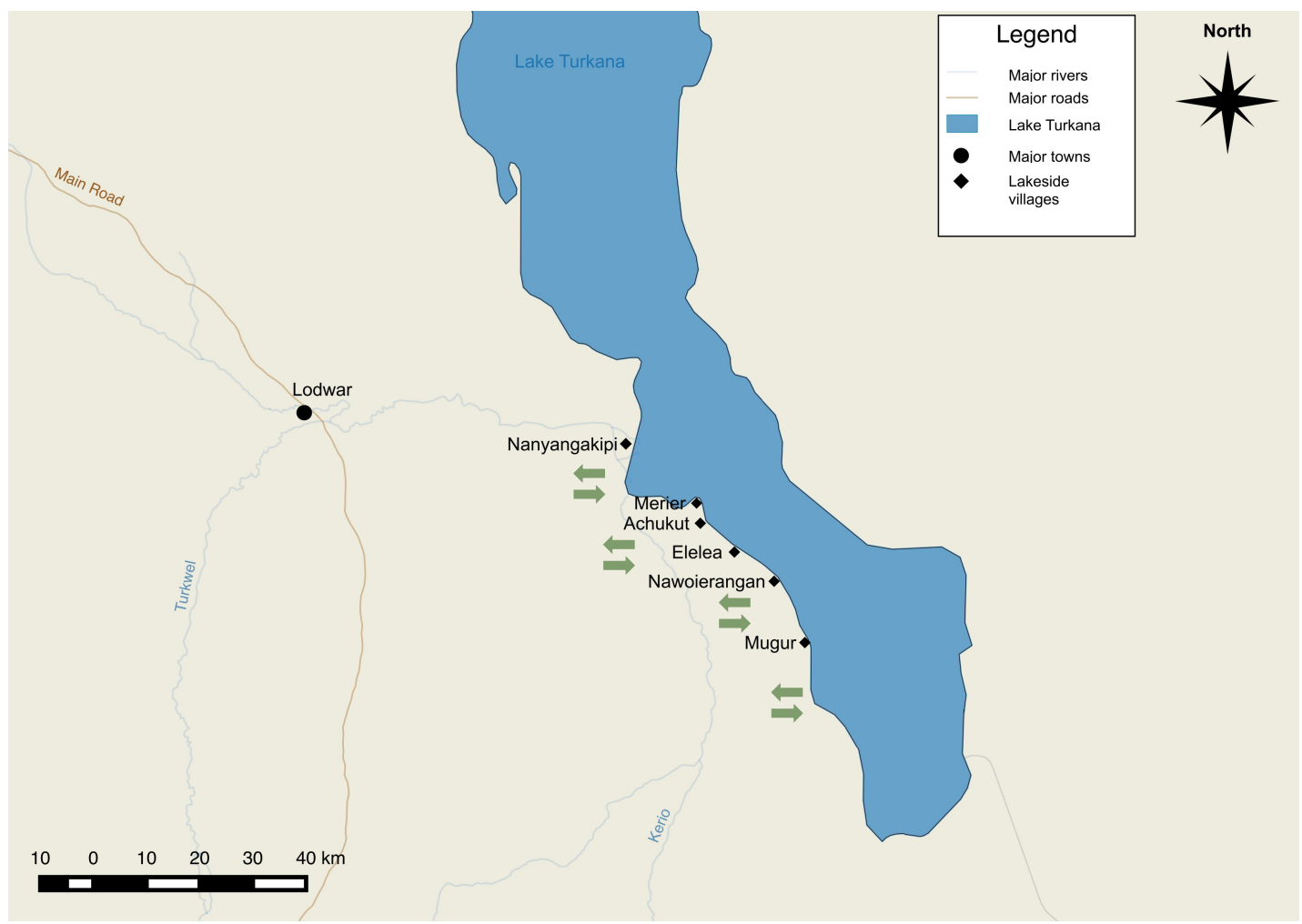

Figure 4.11. The early animal skin trade. Arrows illustrate exchanges between fishing communities and inland herders.

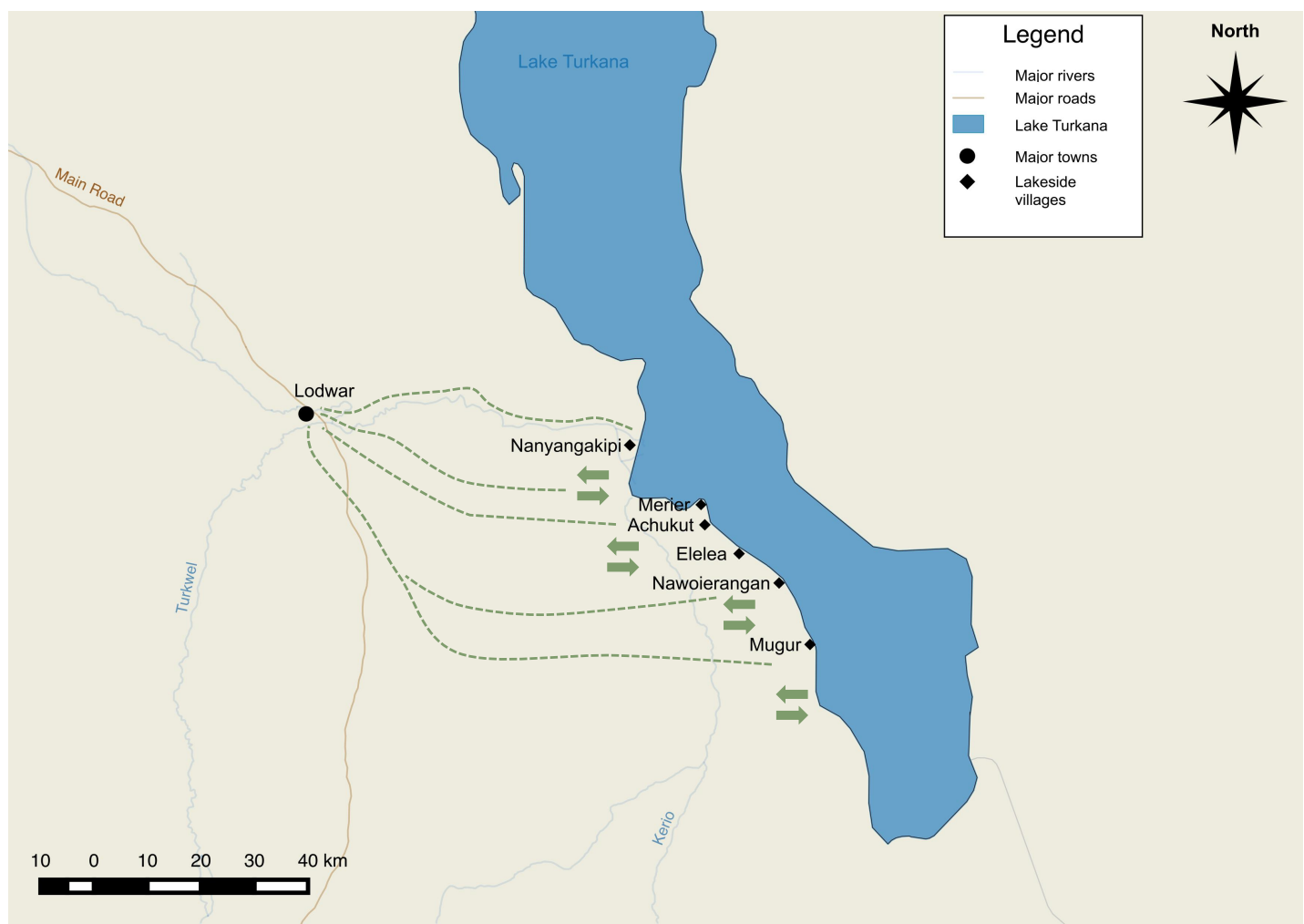

Figure 4.12. The lake animal skin trade in the late colonial and early postcolonial era. Dashed lines illustrate the movement of skins from lakeside villages for trade in Lodwar whilst the early lakeside exchanges between herders and fishing communities continue. 


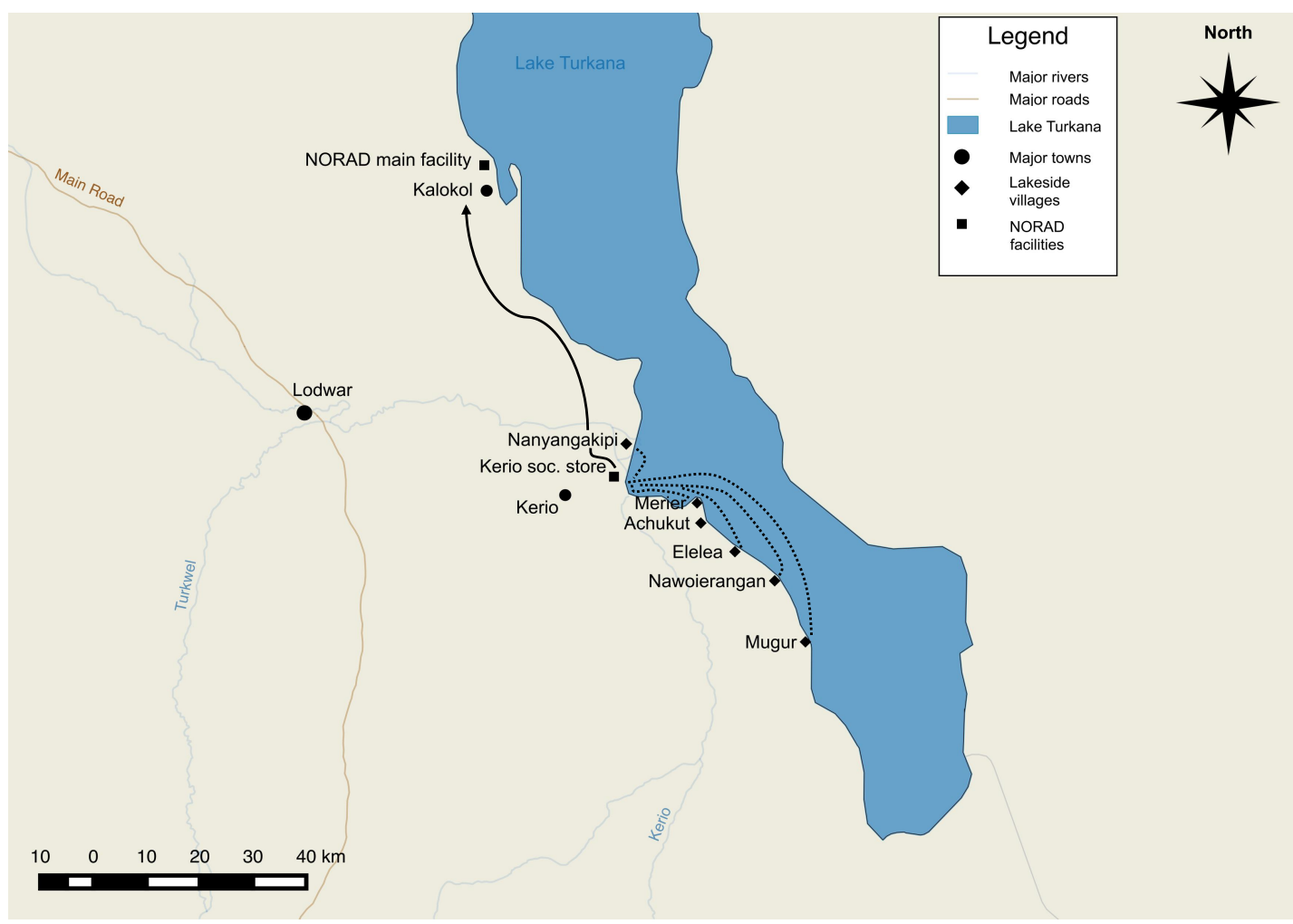

Figure 4.13. Trade during the NORAD commercial fishing scheme. Dotted lines illustrate lake fish being transported to the Kerio TFCS branch store by boat from fishing villages. Solid line illustrates fish being transported over land from the Kerio store to the main NORAD facility at Kalokol.

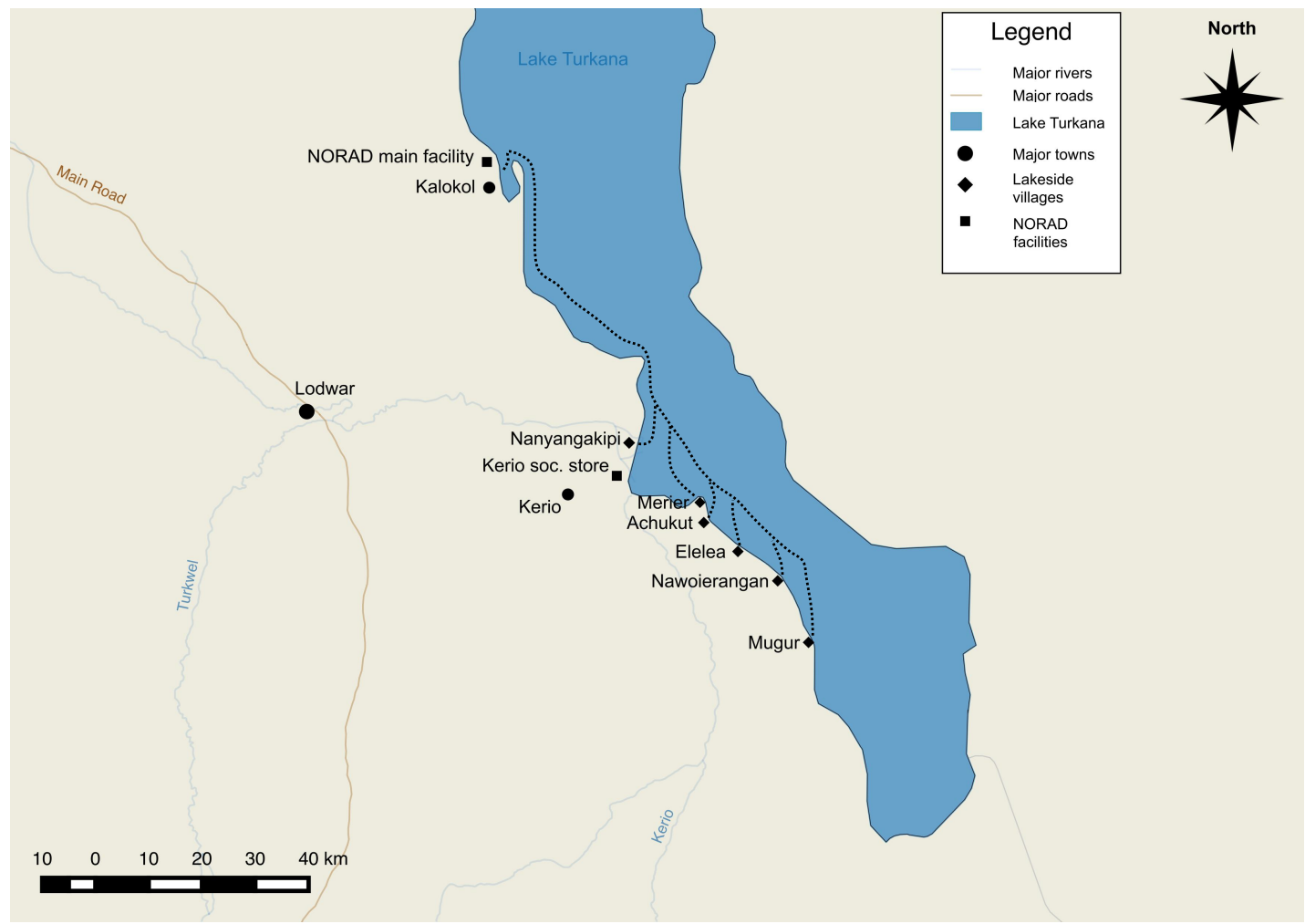

Figure 4.14. The post-NORAD fish trade. Dotted lines illustrate the transportation of lake fish from the lakeside villages directly to Kalokol. 


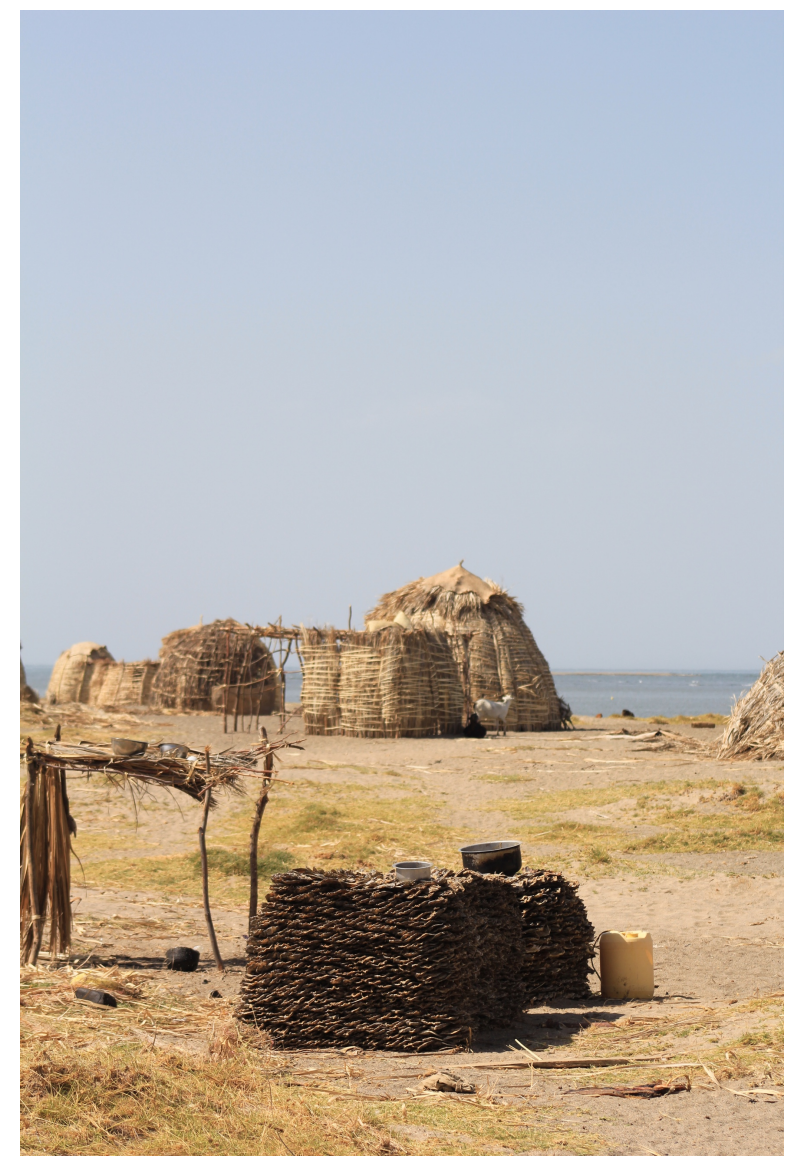

Figure 4.15. Dried fish in Merier awaiting transportation to Kalokol.

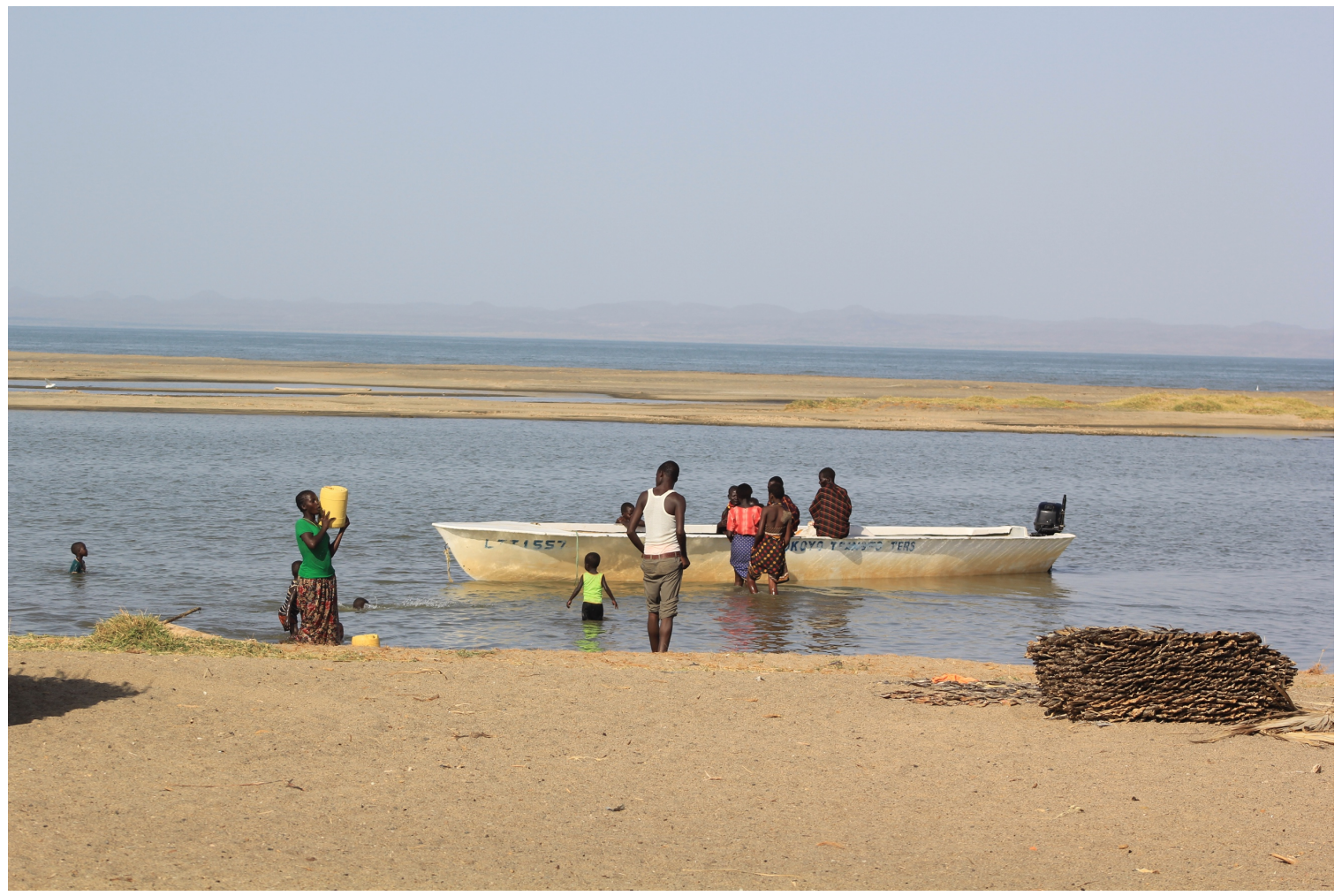

Figure 4.16. A fibreglass boat in operation at Merier. 


\subsection{Fish bone ornaments, ngakoroumwa and marriage}

The preceding sections of this chapter have traced the development of Turkana's fishing communities over several important junctures in the past century, examining their shifting economic standing as they went from being dispersed components in a predominantly pastoralist economy to becoming a detached and largely economically self-contained system of traders exploiting external markets via the burgeoning nucleus town at Kalokol. I have suggested that while this economic shift was facilitated by the intervention of an international organisation it was not fully realised until the various technologies and infrastructural improvements that were introduced were co-opted by the lakeside communities on their own terms and harnessed via an accumulated experience or 'tacit knowledge' (Polanyi 1966) of the changeability of both the lake environment and various external commercial markets.

In this sense, while the changes brought by the new industry were substantial, and included a new domestic material culture corpus and set of social relationships, it would be incorrect to consider them purely as reflective of dramatic socio-cultural disjuncture within the lakeside population. Rather, these economic changes figured into, and in fact articulated, a deeply rooted historical process of gradual social transformation that had already characterised the fishing communities as strongly culturally dissimilar to other territorial sections within Turkana society. In what follows, this historical process is traced in the stylistic development of women's neck ornamentation throughout the various ruptures and transitions that have been explored hitherto. 
During the early part of the $20^{\text {th }}$ century such ornamentation constituted a sharp materialsemiotic distinction between fishing and herding communities. Unlike those from herding communities, who wore bundles of ngakoroumwa (ceramic, plastic and ostrich eggshell beads; see Figure 4.17), women from fishing villages customarily wore necklaces and waistbands made from fish, crocodile and (less commonly) snake bones. This era was considered in great detail during several group discussion sessions held in Achukut, which were primarily focused on images of ornaments from the Pitt Rivers collection. Of particular interest during these sessions was an image of an ornate fishbone neck ornament collected from an unspecified lakeside village in Turkana around 1951 (Figure 4.18). Many older women put forward their personal memories of similar objects:

'It was before the NORAD societies [that] women wore the bones of fish around their necks, they wore the part called ngigece [vertebrae]. Like the women who were from...[further inland] who wore ngakoroumwa, we wore necklaces and [ornaments] around our waists. My mother would mix fish bones with small beads, or sometimes with the bones of ngimunio [snakes]... almost all women would dress in this way because they had no animals to trade for ngakoroumwa, [only] what the lake could provide. The women here did not marry with animals... because they could give nothing away at akinyonyo... [and therefore] none of the families who had animals [and were] used to ngakoroumwa wanted the women who had only fish bones, only snake bones, only small beads. It was very uncommon for women from here to marry outside until Ekaru Aribokin [roughly 1973]' (Ekalale Ekori speaking during a group discussion, Achukut, 20/04/2015).

Clearly, in the early half of the $20^{\text {th }}$ century there were marked differences between the groups' identities. It is significant that the differences in women's ornamentation held influence directly over their movement between the respective livelihoods via marriage. The ceremony of akinyonyo (which was not only mentioned in the above interview with Ekori, but also in several other interviews) takes place as part of the marriage process after bride price negotiations have been settled and a woman has taken up residency in her marital 
home. ${ }^{48}$ It requires a woman to give all of her neck ornamentation away to the women in her husband's family in the course of changing her costume from that of an apese (unmarried woman/ girl) to that of an aberu (married woman). ${ }^{49}$ The stark contrast in the economic value of each type of ornamentation (ngakoroumwa beads and fish bones) meant that it was uncommon for women from fishing communities to marry externally. Their fishbone ornaments were unacceptable outside of lakeside villages where, as Ekori points out, women had access to far more costly ngakoroumwa bundles.

\footnotetext{
${ }^{48}$ Turkana marriage is not a single occasion but rather a long and drawn out process entailing a series of ceremonial events (for an in-depth discussion see Dyson-Hudson and Meekers 1996; DysonHudson et al. 1998). Bride wealth payments tend to be exceptionally large by east African standards (Galvin 1985), and can take decades to fully complete. I worked closely with several men whose families had yet to finish paying their respective bride prices after twenty years.

${ }^{49}$ I witnessed the akinyonyo ceremony on two occasions and on both occasions it was likened to the male initiation ceremony asapan, which I also underwent. Both ceremonies entail a symbolic costume change and the distribution of ornaments and objects from the initiate to their welcoming family. In the case of asapan, this includes shoes, necklaces, cotton blankets, ekichielong (stools), abarait (wrist knifes) and apukot (hats/headdresses containing ostrich feathers). Significantly, a man undergoing asapan will usually wear newly purchased ngakoroumwa throughout the ceremony in order to distribute them later in the day to the women in his initiation father's home during the symbolic costume change.
} 


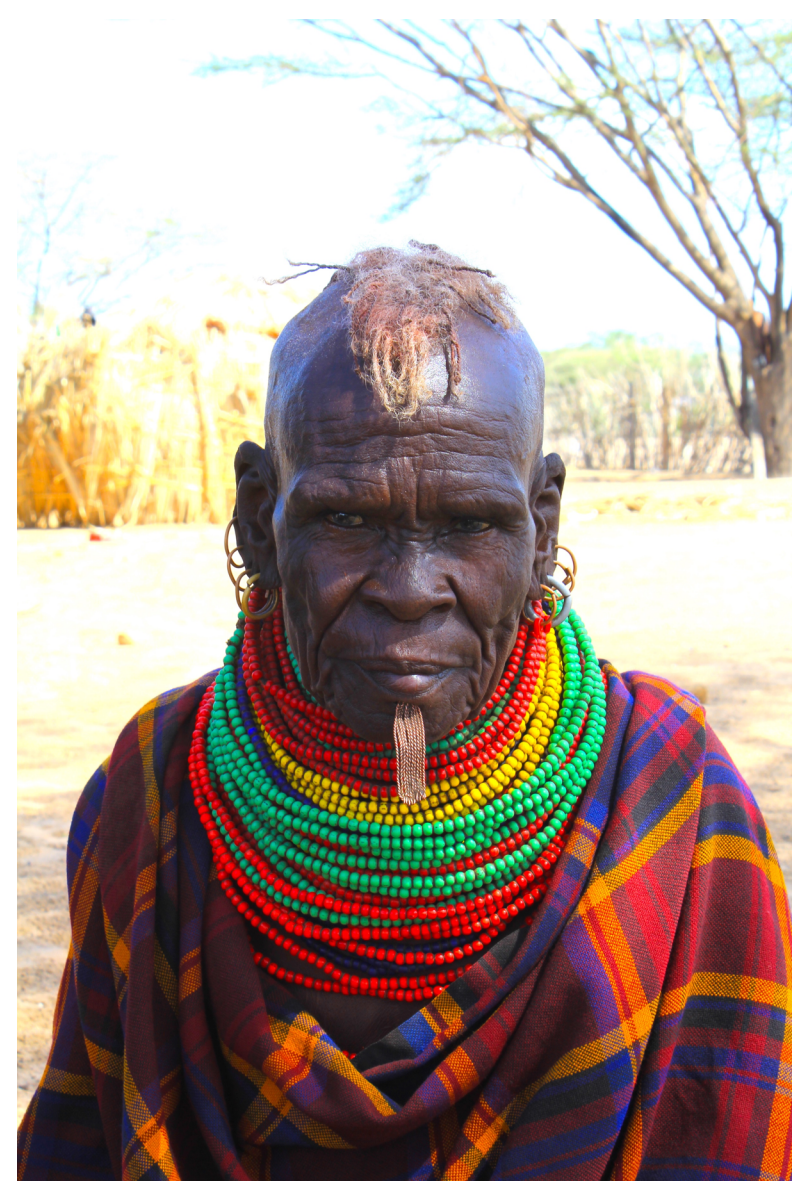

Figure 4.17. A woman in Nakoret wearing ngakoroumwa in a typical fashion.

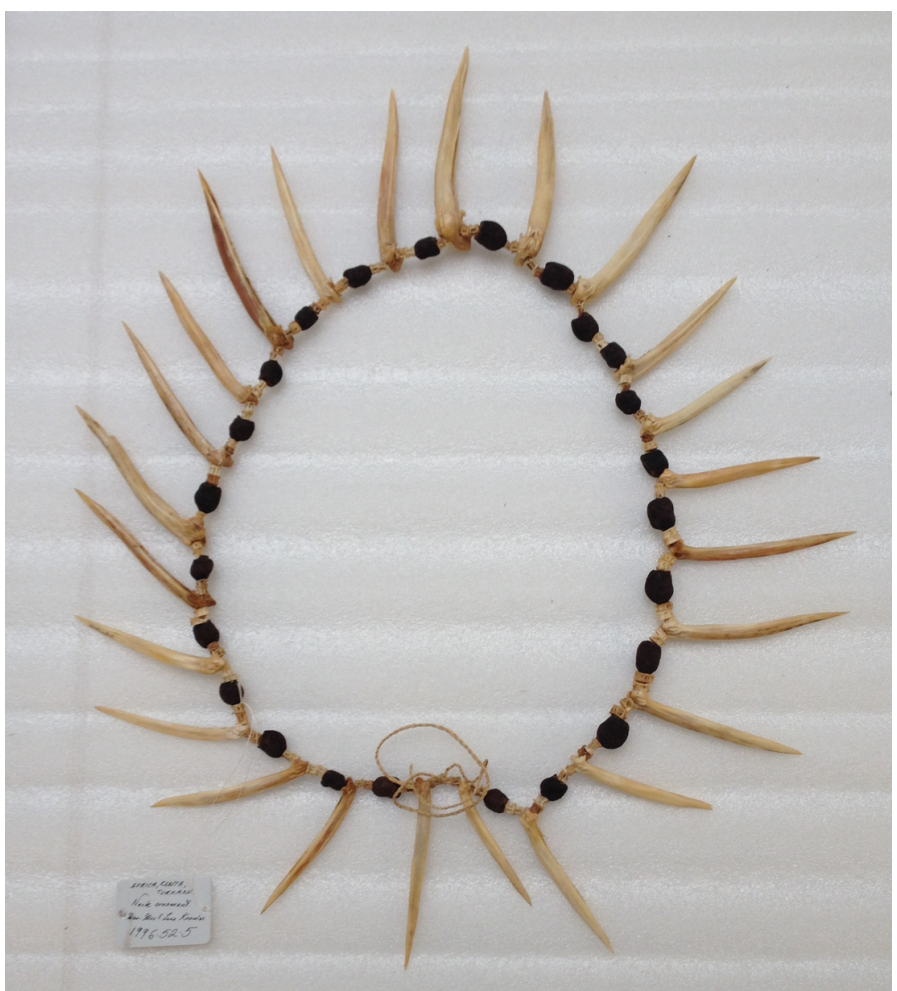

Figure 4.18. Fish bone neck ornament collected in the 1950s. Accession no. 1996.52.5. Pitt Rivers Museum, University of Oxford. Photographed on 14/03/14. 
Significantly, the ornamentation an unmarried woman wears when she is approaching marital age acts as a visual display of her family's wealth — it is at this time that 'she will wear as many beaded necklaces as the family can afford to provide' (Shell-Duncan and Wimmer 1999: 53). In this way, the differences between the two ornamentation styles were directly entangled with differences in the livestock wealth of women's natal families. During the earliest stages of marital negotiations a woman must be deemed suitable either directly by the father of the man who intends to marry her or by the man himself with his father's approval (Dyson-Hudson et al. 1998). Considering how important marriage was (and still is) as an 'opportunity to extend a herd owner's social networks' (Dyson Hudson et al. 1998: 23), it is easy to comprehend how discouraging fish bone ornaments would have been to potential suitors from non-fishing communities. ${ }^{50}$ The fathers and brothers of lakeside women at marital age, being entirely without livestock, were not valuable contacts to acquire.

Therefore, fish bone ornaments acted as a powerful symbol enforcing the women's separation from the pastoralist sections.

In this sense, ornamentation can be seen as both a cause and an effect of the cultural divisions between the two populations at this time. The different styles of bodily decoration were intimately entangled with differences in the groups' economic strategies, and also with each group's proximity to and experience with different assortments of materials around them. The lake communities used only 'what the lake could provide', whereas the herding communities had access to a far wider variety of markets and trading zones (as a result of their mobility) and, more importantly, were able to purchase ornaments more frequently by

\footnotetext{
${ }^{50}$ In the middle years of the $20^{\text {th }}$ century Gulliver (1955: 228) remarked that an integral element in the marriage process was 'the gradual binding together of the husband with his wife's full-brothers, and to a lesser degree the houses and even the families of each'.
} 
trading animals. ${ }^{51}$ However, rather than simply acting as an 'expression' or 'reflection' of these various livelihood differences, the ornaments in turn actively caused or justified separation through their curtailment of inter-marriage. Hodder (1982: 27) describes this recursive role of material culture, also with the example of ornamentation styles (although in his case amongst neighbouring communities in Baringo, to the immediate south of Turkana), as follows: 'It is insufficient to talk about material culture "expressing" group identity because it does much more than that. The material culture constitutes the group differences and is actively articulated in relations of negative reciprocity'.

Whilst the relationship between the two Turkana livelihoods was not defined by 'negative reciprocity', ornamentation had a comparably 'non-passive role', as a symbol 'justify[ing] the actions and intentions of human groups' (Hodder 1982: 36). However, this did not always happen in such a straightforward way as to cause social division. It has already been established that the colonial era saw a great deal of interaction between the two groups, with frequent incorporations of ex-pastoralist families into lakeside villages in times of hardship and the regular departure of many fishermen from lakeside villages in pursuit of a nomadic pastoralist lifestyle. Indeed, the evolving trade between the two communities was the key framework facilitating this early movement of people. Objects caused interaction and mobility through their stimulation of lasting trade relationships as much as, if not more than, they caused division through their implication in social institutions.

\footnotetext{
${ }^{51}$ Although the previously discussed lake animal skin trade was lucrative enough to provide some fishermen with expensive cotton wraps at this time, it generally did not provide enough money to purchase the numerous bundles of glass beads worn by pastoralist women. Today, these ngakoroumwa bundles often cost the equivalent of several heads of livestock.
} 
Therefore, while the identities of the two populations were frequently performed with or through material things, they had their roots in the communities' particular ways of dwelling in and interacting with the landscape. The various objects in circulation before Ekaru Aribokin (1973) emanated from the groups' contrasting 'regular pattern[s] of life' (Ingold 2000: 153). The fishing communities' proximity to the lake and familiarity with hunting lake animals facilitated the production of shoes and shields that spread across the region. Conversely, it was the particular migration patterns of the herding groups and their frequentation of wooded zones that facilitated the production of the various containers and domestic items that filtered into the lakeside villages. These objects, and others, operated in diverse ways, in some cases prompting interaction and in others (particularly in the case of ornamentation) causing division. Yet, most importantly, members of each community were clearly aware of the different worlds that the various objects had derived from and the different ways of life with which they had been intertwined. This is something that emerged consistently in interviews collected both in fishing communities and inland herding groups:

- 'At that time all Turkana would hunt animals... We would make shoes from many skins... but the best shoes [were those] made from hippopotamus. It was Ngisiger and Ngibocheros who made these... so that even if there were giraffes, or rhinoceroses... or any other animal, everyone would want the shoes from those lake people' (Nakusi Lokudo speaking during a group discussion, Nakurio, 19/09/2014).

- 'There are few people here who use atubwa, akurum... akutom, elepit. This is not like before. Before [buying objects] in Kalokol everything came from herders. They would make objects themselves. Sometimes, if you need milk you would trade for milk and be given an akurum... or you would decide that you needed an atubwa for drinking soup... and it would come from them. They made those things in Loriu, or beside the rivers... [where] there are many trees, and many [gourds]' (Interview with Ekaal, Merier, 04/03/2015).

As discussed previously, the emergence of the NORAD scheme in the early 1970s corresponded with a rapid imbrication of the two livelihoods. Following harsh and persistent droughts, many herding communities were persuaded to relocate to the lake edge and 
participate in the newly emerging industry. ${ }^{52}$ The number of ex-herders subsumed into the fishing trade at this time greatly surpassed any mixing that had gone before. This dramatic shift in the dynamics of the two populations, and the concomitant disruption to their 'economic symbiosis' (Hodder 1982, 103), was linked to interesting transformations in the ornamentation worn by lakeside women. Those who witnessed this era recalled in interviews how between Ekaru Aribokin (1973) and shortly after Ekaru Asur (1981) fish bone ornaments disappeared altogether. Families from core fishing communities that had previously been unable to purchase the expensive glass beads commonly worn in herding families now used the money they were making in the fish trade to purchase them in vast quantities, David Ekuam explains:

'There was great mixing... those who had come [from herding sections] all had ngakoroumwa... and it was a shame for those who did not, [those who] only had fish bones. When the men... [began] earning money with fish they bought ngakoroumwa for their wives and sisters, they bought them in Kalokol and Lodwar. The old people died with their fishbone necklaces and they were forgotten with them. The new generation wore ngakoroumwa' (interview with David Ekuam, Merier, 09/03/2015).

This homogenisation of ornamentation styles was not solely framed by the wealth emanating from the new fish trade. It occurred at a time when many of the pastoralist communities who had not been persuaded to settle along the shoreline remained in sedentary famine camps, reliant on relief food. Then, during a further severe drought that occurred between 1979 and 1981 'over $90 \%$ of cattle herds, nearly $80 \%$ of small stock flocks, and $40 \%$ of camels were lost in north Turkana' (Hogg 1982: 164), and 'over 80,000 Turkana people... left their pastoral lifestyle and migrated into famine relief camps' (McCabe 1990: 146; this drought is discussed in detail in Chapter 5). Whilst the situation was slightly less severe in the south,

\footnotetext{
${ }^{52}$ Droughts occurred in 1970-73, 1975-76, 1979-81, and 1983-85 (ILCA, 1986). According to McCabe (1990) the latter two droughts were particularly severe.
} 
throughout the entire region livestock herds were decimated..$^{53}$ Those who persevered as herders implemented a range of traditional coping strategies, with many gravitating to mountainous regions, rivers and areas that had previously been considered too dangerous to enter on account of their proximity to enemy territories. ${ }^{54}$ Fairly rapidly the differences between the two economic strategies were considerably reduced. The mobility and livestocktrading power of those in famine camps was effectively zero and those who persevered as pastoralists (these were predominantly in the south) could not afford to trade their dwindling herds for anything other than grain (McCabe 1990: 150).

This waning of the contrasts in the day-to-day lives of much of the fishing and pastoralist populations was arguably a key element in the lakeside communities' adoption of ngakoroumwa beads. Concomitant with the newly prevalent sedentism of much of the pastoralist population, the wealth inequality that the different ornamentation styles had previously represented (particularly in the years immediately prior to a young woman's marriage) had more or less comprehensively vanished, or perhaps even reversed. It was not contradictory that 'the new generation wore ngakoroumwa' in the lakeside villages because their families were at this time some of the wealthiest and most stable in Turkana. Thus, the change in ornamentation articulated and substantiated the emergence of fishing as a legitimate alternative economic pursuit in the wake of the prevailing adversity experienced throughout the pastoralist sector.

\footnotetext{
${ }^{53}$ McCabe $(1987,1990)$ suggests that the Ngisonyoka section (in southern Turkana) lost between 60 and $90 \%$ of their livestock during the 1979-81 drought but predominantly avoided entering famine camps. Barrett (1998: 204) recalls how for many others in the south this was not an option, and pastoralism became untenable like it was in the north: 'The period between 1981 and 1985 was a time of great famine in Turkana. Many people lost their stock and abandoned their homes on the Loima mountain range for the famine camps by the Turkwell River between Kekorongole and Kalemunyang.'

${ }^{54}$ For a detailed account of pastoralist movements during this period see McCabe $(1990,2004)$.
} 
Revealingly, the uniformity in ornamentation styles was almost as short lived as the NORAD scheme itself, which began to collapse just as the rains were returning to Turkanaland. At this time, the majority of the ex-pastoralists (from both fishing villages and famine camps) resumed a nomadic lifestyle. McCabe's (1990: 152) research, conducted throughout this period amongst the Ngisonyoka territorial section, suggests that by 1987 'the livestock population had recovered to pre-drought levels, and... many of the people who left the pastoralist sector during the drought had returned' (see also McCabe 1987). As the lakeside settlements reduced to their previous sizes the brief era of similarity came to a swift end and the differences between the two groups began to resurface in new contexts and practices. When the pastoralist sector began recuperating its livestock the lakeside communities' basis for wearing the new ngakoroumwa ornaments disintegrated entirely. As if to reaffirm the disparities between the two peoples, marriage became a key herd-growth strategy for many of the returning pastoralists (McCabe 1990) and the lack of significant livestock in the fishing villages was once more an extremely divisive feature.

Interviews from a wide range of villages indicate that ngakoroumwa ornamentation completely disappeared along the lakeside shortly after Ekaru a Eumbi (the early 1990s). ${ }^{55}$ However, despite the fact that more intensive levels of fishing now dominated the daily practice of lakeside life, the communities did not return to their fishbone ornaments, instead abandoning neck ornamentation altogether. They emerged from the NORAD years more intimately and straightforwardly connected to each other as a result of the new boats that filled the lake, and also to Kalokol centre where many now made regular journeys to sell their

\footnotetext{
${ }^{55}$ Ekaru a Eumbi means 'The Year of Millet', and refers to a period of time when the national government distributed sacks of millet as relief food in the early 1990s (1990-93). For many this was the first time they had come across millet, and so there was a great deal of confusion with regards to cooking methods. This year was by far the most widely referenced time for the discontinuation of ngakoroumwa wearing in lakeside settlements. However, in some villages women remember wearing ngakoroumwa into the late 1990s.
} 
catches. This new 'connectedness', which prevails to this day as a key ingredient in the postNORAD industry, is considered by many to be integral to the absence of both ngakoroumwa beads and fish bone ornaments. Robert Ekuwom explains:

'These days... women do not wear... [ngakoroumwa] and they do not wear the bones of any animal. There are no women here who wear them today. This is because people around here move a lot. They move to sell their fish... [this means] spending a lot of time in large centres... and large towns like Kalokol. These places have had a big impact... if you go to Kalokol you find Turkana people working together with Ngiconkoi [Congolese] and Ngijaluoi [Luos]. We are not people of animals and we are not people of ngakoroumwa. We fish every day and we are in Kalokol every week' (Interview with Robert Ekuwom, Merier, $09 / 03 / 2015)$.

It is significant that Ekuwom directly associates women's lack of any neck ornamentation in the present day with the fact that his community are not 'people of animals'. It seems that just as fish bone ornaments had previously been deeply and recursively involved in the divisions between the fishing and pastoralist populations, today a complete lack of ornamentation plays a similar role when contextualised by the enduring use of ngakoroumwa in the pastoralist sector. Moreover, the differences in each group's ornamentation continue to be framed by contrasts in the ways they dwell in and interact with their respective landscapes (following a brief period of relative equality in the 1970s and 1980s). For the fishing communities, these ways of dwelling and interaction have transformed constantly over the years through a series of fundamental shifts and ruptures in both the nature and the location of their primary trade. With the central position that Kalokol has come to occupy in lacustrine life after the most recent economic shift, it is unsurprising that it has become tightly bound up with the ornamentation preferences of lakeside women.

In this sense, it would be incorrect to view Kalokol's international culture and background of 'modernist developmentalism' as radical forces implicated in the upheaval of pre-existing ways of life. Nor do recent changes in lakeside ornamentation customs or material culture in general represent such disruptions. Rather, Kalokol and its various characteristics serve as the 
contemporary means for the manifestation of various continually emerging long-term processes of community change, which have historically always formed the basis of the division between pastoralist and fishing identities. The lack of neck ornamentation amongst contemporary Turkana fishing women is as much embedded within the social networks of lakeside life as the wearing of fish bone ornaments was in the early half of the $20^{\text {th }}$ century, or ngakoroumwa beads in the late 1970s and ' 80 s. In all cases neck adornment has been inextricably embedded within grounded livelihood practices and, via this position, has been imbued with symbolic value and power in the enactment of identity.

\subsection{Summary and conclusions}

Over the years, interpretations of Turkana's fishing communities have consistently been situated within broader considerations of economic or environmental adversity and destitution. Such analyses place great emphasis on the umbrella economic class 'ngikebotok' to which the lakeside groups belong and therefore their subservience or inferiority to the pastoralist sector. This has historically also been the case in studies of 'ndorobo' peoples in other regions of East Africa (eg. the El Molo, Dies, Okiek, Sengwer, Akie, Kisankasa), who have traditionally had similar close economic links to larger pastoralist societies (for discussion and critique see Blackburn 1974; van Zwanenberg 1976; Cronk 2002). The centring of such broad hierarchical economic relationships has perhaps served to silence the particular narratives of change and continuity within individual communities, which are doubtless far more significant. The implication is that archaeological and anthropological approaches to Turkana's fishing communities have sought to describe a category rather than a people (cf. Wilmsen 1989: xv). 
It is arguably as a consequence of this partiality that aspirations of returning to, or indeed newly adopting, the pastoralist lifestyle are often assumed to prevail through historical change, both on an individual and a community-wide basis. ${ }^{56}$ In Turkana these expectations seem recursively to enhance the sense of ephemerality or transience attributed to lakeside communities at the expense of an appreciation of their belonging within the landscape and the wider political economy. ${ }^{57}$ As this chapter has shown, Turkana's lakeside communities possess a complex social and economic history, which is identified and engaged with in a variety of ways in the contemporary world and throughout which fishing has by no means purely been the pursuit of destitute pastoralists. Instead, via a transforming trade, it has proven itself to be teleologically extraneous to the pastoralist sector, becoming in recent decades an economically independent and self-sustaining livelihood.

This process could potentially be understood as part of a much broader East Africa-wide trend, which has seen emerging lacustrine industries play a central role in recent large-scale economic transformations. Indeed, it is noteworthy that over the last few decades a very similar story has unravelled in Lake Victoria, to the southwest of Lake Turkana. Historically, the fishing communities surrounding Lake Victoria had been implicated in larger land-based agricultural and pastoralist economies through barter-based exchange systems (Geheb 1995; Geheb and Binns 1997; Pringle 2005). Following significant infrastructural developments, the introduction of Nile perch and the ensuing emergence of a cash-based economy, the Lake Victoria fishing industry has, according to Pringle (2005: 512), become 'globally significant',

\footnotetext{
${ }^{56}$ For example in Hodder's (1982: 104) analysis of hunter-gatherers on the Leroghi plateau he concludes that 'One factor affecting the maintenance of some overt cultural distinctions from the Samburu, and the very existence of earlier competitive relationships, is the intention of many Dorobo of reacquiring cattle and once more becoming full Maasai pastoralists.'

${ }^{57}$ And indeed, amongst other ' $n d o r o b o$ ' communities this denial of autochthony and belonging has manifested itself politically, in fraught inter-ethnic land contestations (see Lynch 2006, 2011; Médard 2010; Larsen 2015).
} 
transforming 'lifestyles, societies and economies around the periphery of the lake' (cf. Beuving 2013). It might not be unreasonable to envisage a similar future for the industry developed by Lake Turkana's fishing communities, although this would depend on the continued stability of the lake's fisheries, which, as I discussed in Chapter 1, are now under significant threat from the newly constructed Gibe III Dam on the Omo River in southern Ethiopia.

In any case, what is perhaps most significant in the context of this chapter and thesis is that throughout the sequence of social and economic upheavals explored, a strong sense of continuity and permanency can be apprehended. This is because amongst Turkana's fishing population identity has never been located in any perpetually static elements of daily practice (whether material or otherwise), but rather in the particular character of socio-cultural change. It has been intertwined with the enduringly unsolidified sedentism of the fishing villages and their adaptable exploitation of multiple lake resources in relation to shifting environmental, political and economic contexts. Cultural differences between the fishing and herding populations have been constituted by means of an ever-transforming set of everyday material conditions. In this way, while they have remained vibrant and mutually understood, their semiotic manifestation in each group's clothing, ornamentation and other material culture has constantly changed in relation to a variety of factors. I build on these arguments in the following chapter by exploring how cultivating communities along both the Kerio and the Turkwel have achieved a similar sense of continuity over the long term by co-opting and capitalising on a series of significant economic transformations in a context of increasing seasonal unpredictability. 


\section{Chapter 5: Akitare (Cultivation)}

'Many years ago... before the time of our grandfathers, the people of this area did not cultivate. The people in this place did not have seed, so they could not plant... At this time the people of the [river] Kerio knew of a people who lived far in the north, these people were called the Merile. The Merile were farmers of sorghum, they had seed, but they were very secretive about their crops. They would allow visitors, and they would welcome [them] ... but

they would not allow a single one to leave [their territory] with any seeds. The Turkana mostly walked naked at this time... it was before the time of cotton blankets, when some men wore edengo and some men wore nothing at all. One clever man thought of a plan to get the

Merile seeds out - his name is not remembered today. This man went to the place of the Merile sorghum gardens, he took seeds and stuffed them into his foreskin... the Turkana do not circumcise, which makes them different to many other peoples. He was searched on leaving but nothing was found, he walked back to Turkana with the seeds in his foreskin, and distributed them to the people here. The Turkana started farming the floodplains of the Kerio and the Turkwel in this way... with sorghum that had come from the Merile.'

- The story of the emergence of crop cultivation in southern Turkana as told by Emeri Lowasa, a flood-recession farmer from Nakurio Village on the Kerio River. ${ }^{58}$

\subsection{Introduction and overview of Turkana's cultivating communities}

Two large perennial rivers intersect southern Turkana's expansive semi-arid plains flowing east into the lake; these are the Turkwel and the Kerio (see Figure 5.1). Throughout living memory, and indeed since long before, these rivers have seen the cultivation of sorghum (Sorghum bicolor) gardens by small communities who practise flood recession farming along their meander scars. Much like the lakeside fishing communities discussed in the previous chapter, these groups are seldom the subjects of extensive historical research (but are mentioned in Gulliver 1951; Henrikson 1974; Morgan 1974; Adams and Anderson 1988).

\footnotetext{
${ }^{58}$ (Interview with Emeri Lowasa, Nakurio, 09/10/2014). Whilst Lowasa states that the name of the sorghum smuggler is 'not remembered today', others suggested that his name was Epetabong and that he had come from the Ngikomesoroko clan several hundred years ago.
} 
They are also frequently grouped into the same economic category as the lakeside population and referred to as ngikebotok by the rest of Turkana society on account of their lack of extensive livestock herds (see Broch-Due 1999). ${ }^{59}$ Over the last half century, communities settled along both the Kerio and the Turkwel have seen a long succession of farming-centred development initiatives, which have sought (and continue to seek) in various ways to improve crop yields and induce 'sustainability' (although these have been implemented more extensively along the Turwkel). The vast majority of these interventions have been wholly unsuccessful in meeting their initial aims, and have exhibited the same presumptive thinking and concomitant disconnection from local knowledge systems and experience that lay behind the NORAD fishing scheme instigated on the lake edge in the 1970s (as explored in Chapter $4)$.

Adams and Anderson (1988: 522) point out that, like their colonial predecessors, most farming-centred development initiatives in East Africa have rested on an inaccurate 'essentially static and passive picture of agriculture water use' (see also Kipkorir 1983; Adams and Grove 1984). It is significant that these understandings seem to emerge recursively through the years and have resurfaced in a range of recently initiated foreignfunded East African projects. For example, in the Marakwet region of western Kenya, which lies to the south of Turkana in the western Kerio Valley, an ongoing Red Cross-funded irrigation scheme (instigated in 2012) appears to exhibit a stark disregard for, and disengagement with, the dynamics of the already extremely resilient and successful Marakwet irrigation cultivation system (see Davies et al. 2014; Davies and Moore 2016).

\footnotetext{
${ }^{59}$ The term 'ngikebotok' applies to both a specific territorial section in southern Turkana and a general economic class that spans communities in several territorial sections. Confusingly, the Ngikebotok territorial section occupies a stretch of the Turkwel River to the southwest of Lodwar and has historically been heavily engaged in riverside cultivation. Other territorial sections, such as the Ngiesetou, also have long histories of riverside cultivation but are frequently referred to as ngikebotok on account of their lack of livestock.
} 
Davies et al. (2014: 488) suggest that this scheme looks to be 'just the most recent in [a] long history of external involvement, which, for all its good intentions, may have little, if any, enduring impact on the Marakwet landscape'.

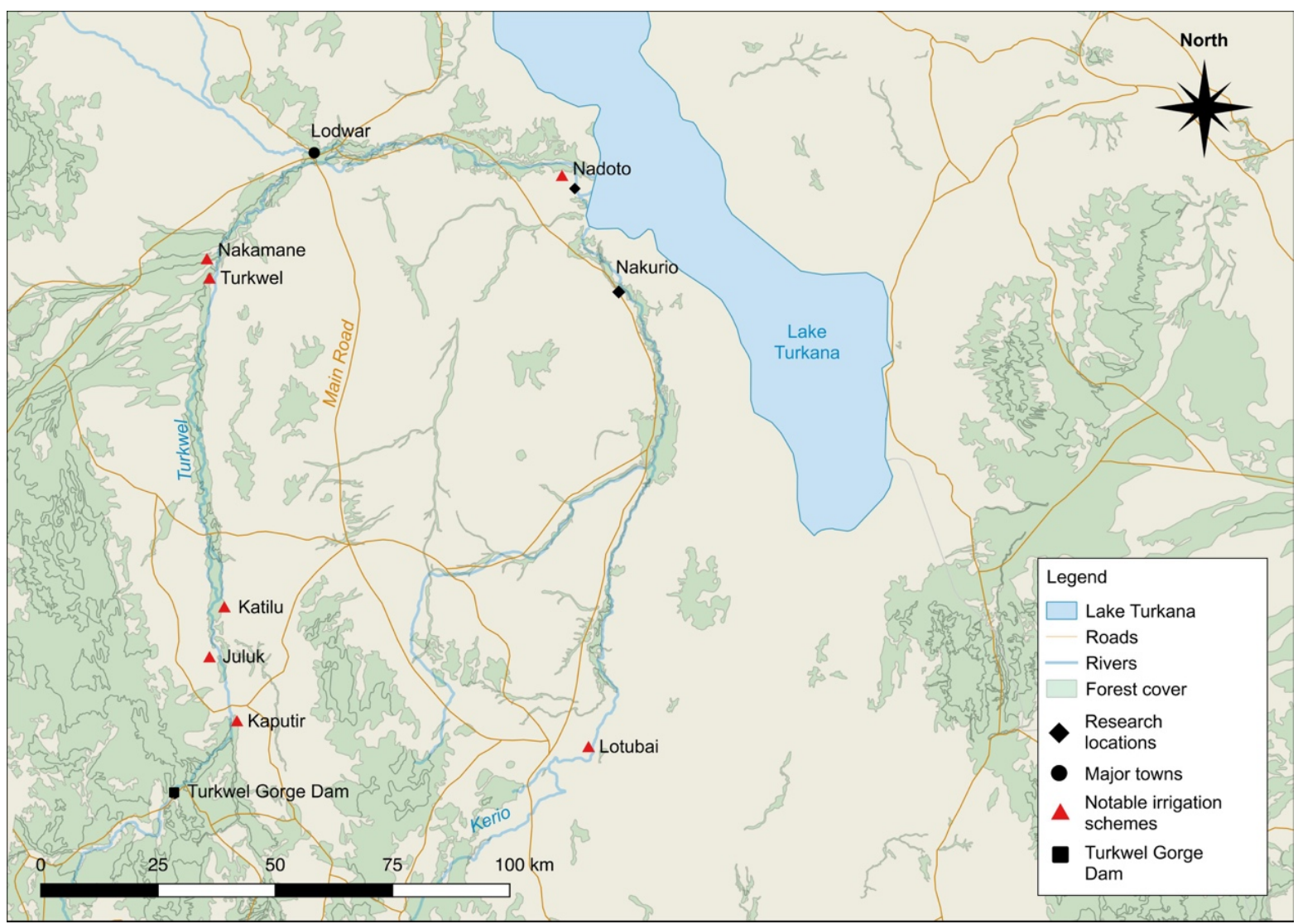

Figure 5.1. Map of southern Turkana showing the locations of the villages in which research was undertaken and of notable irrigation schemes. 
In Turkana, some significant outcomes of the last few decades of development intervention have been the emergence of 'formal' irrigation cultivation (primarily along the Turkwel) and the concurrent diversification of the crops that are grown by cultivating communities (along both rivers). Whilst the colonial administration had shown some interest in agricultural development, and had sporadically attempted to distribute new seed varieties (which were predominantly unsuitable to the Turkana environment), ${ }^{60}$ formal irrigation schemes only began to emerge in earnest in the early 1960s with several small-scale (and largely experimental) projects that were implemented on the middle stretch of the Turkwel by a Lodwar-based Catholic mission (Ministry of Agriculture 1962). The Nakamane project (roughly $40 \mathrm{~km}$ southeast of Lodwar on the Turkwel) was then instigated in 1965 by the Food and Agriculture Organisation of the United Nations (FAO) and the Kenyan government. Following its initial implementation in these early schemes, many Turkana-based development organisations began to envisage irrigation cultivation (and mixed agriculture) as a solution to the increasingly common famines occurring throughout the region and an alternative to pastoralism (Figure 5.1).

This was particularly the case in the 1980s when, through the Turkana Rehabilitation Project (TRP), various organisations sought to encourage destitute pastoralists to settle permanently into riverside cultivation camps (an era discussed in more detail further on). In more recent decades numerous other gravity flow and pump fed irrigation schemes have emerged, most of them funded and administered by a range of national and international organisations (see Oswaggo 1971; Hogg 1987; Cullis and Pacey 1992). These schemes have been supplemented by rainwater harvesting projects which, since the 1980s, have served to channel various

\footnotetext{
${ }^{60}$ This is mentioned in the North Turkana and Turkana District Annual Report from 1926 KNA/TDAR-DC/Turk/1/1.
} 
drought-resistant crop varieties into the region (see Hillmann 1980) ${ }^{61}$ At present, irrigation cultivation continues to be a key focus for many organisations operating in Turkana, despite the fact that such projects have regularly met with catastrophic failure. Indeed, Hogg (1987: 297) argues that 'none of the [past] schemes succeeded in achieving their most basic objective of providing destitute pastoralists with a viable alternative to pastoralism... almost invariably the destitute were the least able to benefit from scheme life, and were forced to depend on off-scheme interests' (see also Broch-Due and Störas 1983; Hogg 1983).

These agricultural development schemes (particularly the extensive projects undertaken in the 1980s) have nevertheless engendered numerous significant material, technological and infrastructural changes through the years. A process that has coincided with a series of critical transformations in the dynamics of, and rhythms in, Turkana cultivation practices. Perhaps most significantly, as examined in this chapter, the patterns of interaction and exchange that have historically existed between river-based communities and the mobile nomadic population have altered substantially in most cultivating areas. Moreover, many communities (primarily along the Kerio) have begun to use their cultivation plots (ngamanat) for the production of palm mats and charcoal, commodities that are sold either at local markets or to tradesmen who navigate the region in lorries.

However, interpreting the significance of these transformations and understanding the ways in which they correlate with the activities of various development organisations is far from

\footnotetext{
${ }^{61}$ The first rainwater harvesting initiative was based at a site in Lorengikippi and funded by OXFAM. At this site a system of bunds were built to slow river water runoff after short storms during the rainy season. This scheme remained the only of its kind for over twenty years, before the Salvation Army and Voluntary Services Overseas (VSO) instigated a new project in Lokitaung, which was influenced by rainwater harvesting schemes in the Negev Desert, Israel. Whilst this scheme sought to bolster the local cultivating regime rather than replace it, it faced great difficulties, required constant maintenance and ultimately recorded extremely low yields (for a summary report see Hillmann 1980; Cullis and Pacey 1992).
} 
straightforward. Indeed, the arguments presented in the previous chapter established that socio-economic change and continuity are poorly understood as mutually exclusive forces in Turkana, since these have rather been entangled in multiple nuanced ways over the last century. The accounts of the lakeside fishing communities show how seemingly dramatic recent changes might be better understood as the articulation of a deeply rooted process of adaptation, which has been informed most extensively by accrued historical experience and knowledge. The endurance and continuing economic success of the lakeside communities is not, and never has been, ensured by their maintenance of any kind of equilibrium but is instead located in their particular dynamics of change.

Building on these arguments, the following discussion explores recent transformations in the everyday practices of cultivating communities, and broader changes in the dynamics of the cultivation-herding relationship, by envisioning them as elements in a process of gradual livelihood reconfiguration that not only constitutes continuity and resilience but has also been directed at all times by the various Turkana communities involved in it, rather than by the national or international organisations that have intervened on regular occasions. Emeri Lowasa perhaps encapsulates this idea most effectively in her description, presented above, of the 'clever man' who first smuggled sorghum seeds away from the neighbouring Merile by stuffing them into his foreskin. ${ }^{62}$ Arguably it is this enterprising nature that has constituted the primary driver of socio-economic change through time and continues to define Turkana's cultivating population in the contemporary world. This myth's regular narration to younger generations in cultivating families today is perhaps reflective of the communities' own

\footnotetext{
${ }^{62}$ Broch-Due (1999: 58) includes an interview with a 'ngikebotok man' who recounts a similar story, although his version suggests that sorghum made its way down to the southern river cultivators via the lakeshore and the fishing communities. He states that 'the ngikebotok had seen sorghum growing along the shores of the lake and the Ngibochoros, those who eat fish, there showed them how to cultivate it. They had mixed somewhat with Merile (Dassanetch) and have learned to grow sorghum'.
} 
understanding of their livelihood's past and the ways in which it may change in the future. ${ }^{63}$ Indeed, as Hill (1988: 5) conjectures, 'both history and myth are modes of social consciousness through which people construct shared interpretive frameworks' (see also Assmann 1996).

The origin story also emphasises the significant time depth of Turkana cultivation; it is described as an activity that emerged 'before the time of our grandfathers'. Like the lakeside fishing communities, a population of riverside cultivators has existed in Turkana for an extremely long time, and was well established by the late $19^{\text {th }}$ and early $20^{\text {th }}$ centuries when Europeans first began to explore the region. Small riverside cultivation plots or 'gardens' are briefly mentioned in both von Höhnel's (1894: 235) account of his early expedition to the lake with Count Teleki and Austin's (1903) description of his later explorations. They are also referenced shortly after the reintroduction of the colonial civil administration (in 1926) in Emley's (1927: 169) overview of the region, and later by Gulliver in the early 1950s (Gulliver 1951: 30-33) ${ }^{64}$ It is important to point out, however, that, whilst it is probably of a similar age to the fishing livelihood, crop cultivation is fundamentally dissimilar in the sense that it has historically never served as the primary means of subsistence for those engaged in it. Unlike a wide range of intensive rural farming systems located elsewhere in East Africa (as explored in Widgren and Sutton 2004; Davies 2010) Turkana cultivation has tended to feature only as a minor element in the much broader and more varied Turkana pastoral economy, which in varying degrees has included (and continues to include) the collection of

\footnotetext{
${ }^{63}$ This folktale was recounted to me on a regular basis throughout my research into historical change amongst cultivating communities in Turkana.

${ }^{64}$ Emley confuses sorghum crops with finger millet, but in recording the Turkana term 'imuma' (mumwa) it is clear that he is describing sorghum.
} 
wild fruits, hunting and the maintenance of livestock. This is primarily a result of its seasonal nature and small scale.

Not only do those who own riverside plots usually keep small herds of sheep and goats, but they also maintain contact with nomadic family members who have much larger herds of livestock and return to the rivers several times each year (particularly during the dry season when riverside gallery forests become a key browsing resource for goats and camels; see Dyson-Hudson and McCabe 1983; Adams 1989: 195; Barrow 1990). Those who cultivate along the Turkwel and the Kerio generally belong to territorial sections whose areas encompass large segments of either river, although this is not always the case, and certainly in more recent years members of other territorial sections have become increasingly involved in riverside cultivation. Within these territorial sections, land is divided according to clan and is generally passed down through generations matrilineally.

The fieldwork behind this chapter was undertaken in Ngiesetou and Ngisiger cultivating communities located on the Kerio and the Turkwel respectively. In particular, extensive research was conducted in Nadoto on the Turkwel Delta and in Nakurio, roughly twenty kilometres inland from Lake Turkana on the Kerio (see Figure 5.1). The communities in these two villages were chosen for concentrated comparative research on account of the differences in their cultivation strategies. The Nadoto community has, since the implementation of a Turkana Rehabilitation Project (TRP) scheme in the 1980s, worked with a system of irrigation channels, which in recent years have been fortified with cement by the Ministry of Agriculture. Whilst there was a small community of cultivators in Nadoto prior to the TRP scheme, many of the families currently engaged in cultivation there were settled by organisations involved in the TRP from the pastoralist sector in the 1980s. The community at 
Nakurio, on the other hand, continues to practise a form of seasonal flood recession farming that was in existence prior to the emergence of irrigation development projects in the broader region, and is predominantly descended from those who did so in the past.

Importantly, despite these differences, the everyday practices of both communities are attached to and informed by congruent conceptions of time and change over the recent past. Both communities (and indeed the majority of cultivating communities in Turkana) tend to structure recent history, and describe events and processes that occurred within living memory, in reference to a narrative of significant environmental transformation. This narrative serves to embed recent changes to cultivation strategies and exchange relationships not in the extensive development activities initiated by various national and international organisations, but rather in the increasing unpredictability of river floods and rain and dramatic changes in the flora that predominates in riverside locations. These hydrological and ecological transformations serve to contextualise contemporary practices by means of their presence in both the remembered experiences of individual actors and the accrued communal knowledge of groups and families who have been engaged in cultivation for several generations. As this chapter outlines, the 'substantial' or 'experiential' time (Shanks and Tilley 1987: 128; cf. Gosden 1999; Lucas 2005; Johnson 2010) that underpins this shared knowledge is of great significance as a framework from which to counter conceptions of Turkana's recent past that envisage recent large-scale development interventions as either inherently disruptive (of pre-existing 'traditions') or generative (of new historical eras). Examining how it is used to structure and frame historical change over the recent past, as this chapter does, is a process that situates the activities and projects of development organisations within historical accounts that emerge from cultivating ontologies, rather than automatically framing these projects as antithetical to the context of their establishment and 
operation and therefore exaggerating both their consequence and their influence (cf. Fontein 2015, 2017).

\subsection{The changing hydrology and ecology of the Kerio and the Turkwel}

The Turkwel (Figure 5.2) rises on the slopes of Mount Elgon and the Cherengani Plateau to the southwest of Turkana as the Suam and Wei Wei rivers, and is roughly $300 \mathrm{~km}$ long. The Suam and the Wei Wei join together upstream of the Turkwel Gorge and run north for several kilometres before turning east to drain into Lake Turkana. The Kerio rises in the Metkei and Timboroa forests to the south of Turkana (west of Lake Bogoria). It is roughly $500 \mathrm{~km}$ long and comprises several main tributaries, all of which join it before it reaches Turkana. They are: the Chesegon, the Embobut, the Embamon, the Arror, the Torok, the Kimwarer and the Mong. The Kerio runs through Marakwet and enters Turkana from the south, running through Lokori and draining into Lake Turkana close to the Turkwel, roughly $60 \mathrm{~km}$ east of Lodwar.

Whilst they are for the most part perennial, both of these rivers have historically been seasonal in their lower courses (the stretches that lie within Turkana), remaining dry for at least half of the year. This is clarified in many of my interviews and described by Morgan (1971, 1974) and Adams (1989). However, in the last few decades both have undergone significant hydrological transformations. Since the construction of the Turkwel Gorge Dam (and connected hydroelectric power station) in 1991, the Turkwel has become perennial all the way through to the lake, almost certainly as a result of the flood mitigation effect of the Turkwel Gorge reservoir. Consequently, over the last 25 years the vast majority of irrigation projects in Turkana have been instigated on the banks of the Turkwel where a permanent 
water supply is guaranteed and flood recession farming is no longer tenable due to the lack of high-magnitude discharges.

The Kerio (Figure 5.3), on the other hand, has in recent years become increasingly unpredictable in its lower course. Until very recently its flood plain was perhaps the most suitable area for cultivation in southern Turkana, comprising an ideal combination of rich alluvial soils, a high water table and regular floods (Morgan 1971, 1974). Whilst neither rains nor floods have ever been completely reliable or predictable in Turkana, the cultivating community at Nakurio maintains that prior to the last few decades a normal non-drought year would provide at least one and sometimes two harvests. One crop would be obtained during Akiporo (the rainy season) at some point between Lokwang (January) and Lotiak (July) if the rains came and were heavy enough to induce flooding, and often a second crop would be obtained during Akamu (the dry season) between Lorara (October) and Lokwang (January; see Figure 5.4). ${ }^{65}$ This dry season flood was called angolol a ngatur, meaning 'the flood of flowers', because it coincided with the flowering of the ewoi tree (Acacia tortilis) and carried its flowers downstream. Over the last few decades both kinds of floods have become extremely infrequent and are often starkly out of sync with the cycle that had previously structured cultivating activities. ${ }^{66}$ It is difficult to say with certainty what has caused this change in the Kerio's flood regime. Human-induced global climate change is widely viewed to be a cause of increasingly erratic rainfall and general environmental unpredictability in East Africa (Postel 2000; Kundzewicz et al. 2007; Githui et al. 2009; Krätli 2015: 7) and, whilst its effects on river systems remain fairly uncertain (as pointed out by Goulden et al.

\footnotetext{
${ }^{65}$ This was also the case for the Turkwel prior to the construction of the Turkwel Gorge Dam.

${ }^{66}$ The two most recent floods, both of which I witnessed on visits either side of my core fieldwork, occurred in June 2013 and February 2016, almost three years apart.
} 
2009), it is probably a key factor. ${ }^{67}$ It is also possible that increased irrigation activity further upstream on the Kerio (along its perennial stretch) has had some impact.

The ecosystems of both rivers have also been profoundly affected by the recent introduction of the invasive species Prosopis juliflora (etirae in Ngaturkana; Figure 5.3). Prosopis juliflora is a drought-resistant shrub native to South America, Central America and the Caribbean, which was introduced to Kenya during the 1970s and early 1980s by a range of NGOs and government departments in response to concerns about deforestation, fuel wood shortages and desertification (Mwangi and Swallow 2005: 8; Choge et al. 2007). In the years since its initial introduction it has spread uncontrollably, in many cases outcompeting native flora. In Turkana, it currently covers vast swathes of both the Turkwel and the Kerio and its rapid growth rates have had a profound effect on the livelihoods of many cultivating communities, including those in Nadoto and Nakurio (which I discuss in detail further on). Le Maitre et al. (2015: 9-10) point out that Prosopis' deep root system is likely to have a significant effect on groundwater recharge rates; on the Kerio this feature has plausibly resulted in a far more regular lowering of the water table to below the level of the riverbed, and a subsequent inconsistency in flooding. Whatever the main cause may be, all of these factors have probably played some role in altering the Kerio's flood cycle.

\footnotetext{
${ }^{67}$ Opiyo et al. 's (2015) recent analysis of long-term rainfall data from the Kenya Meteorological service shows that extreme drought events have increased substantially in frequency over the last half century.
} 


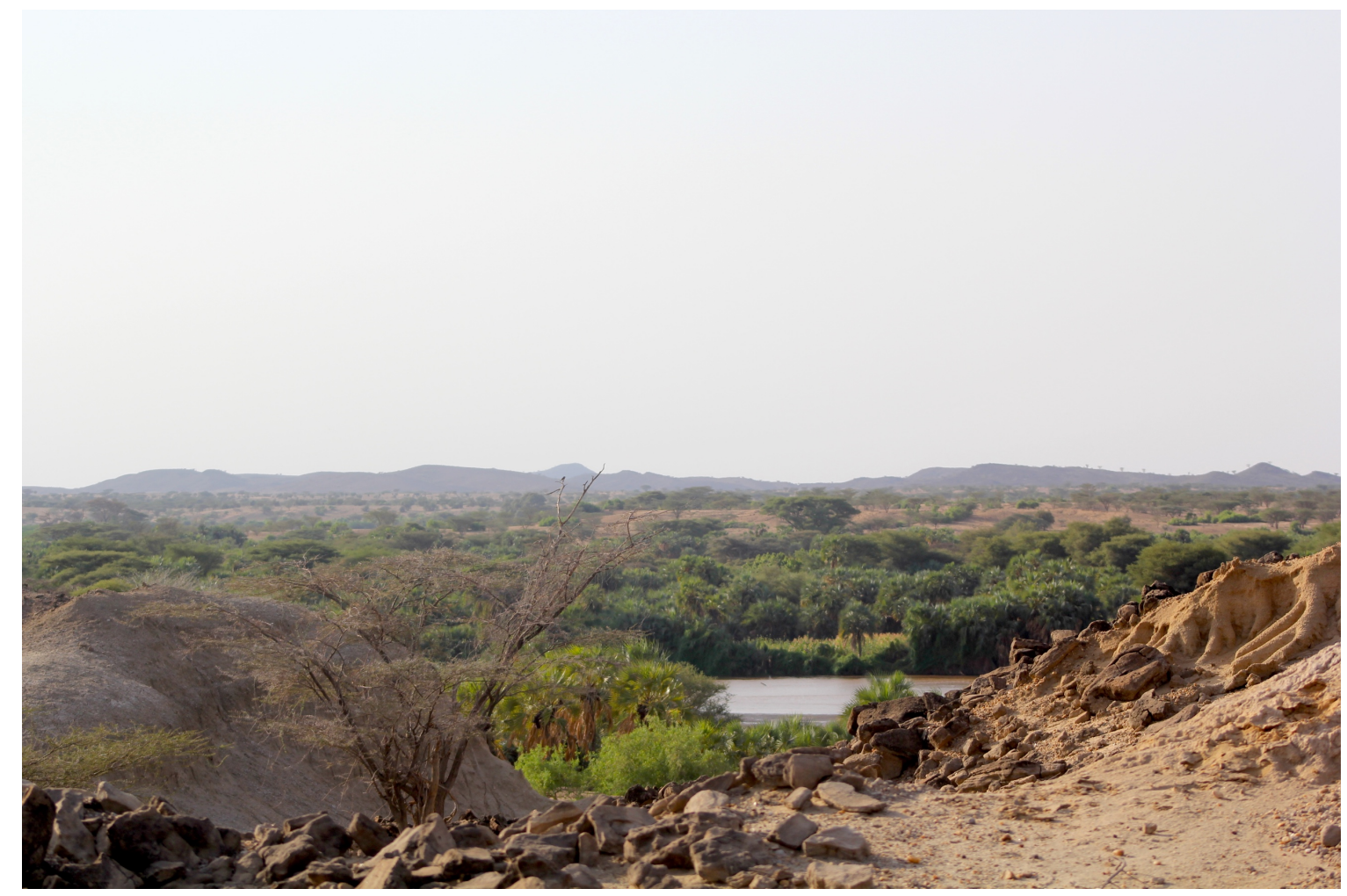

Figure 5.2. View of the Turkwel from Nakechichok.

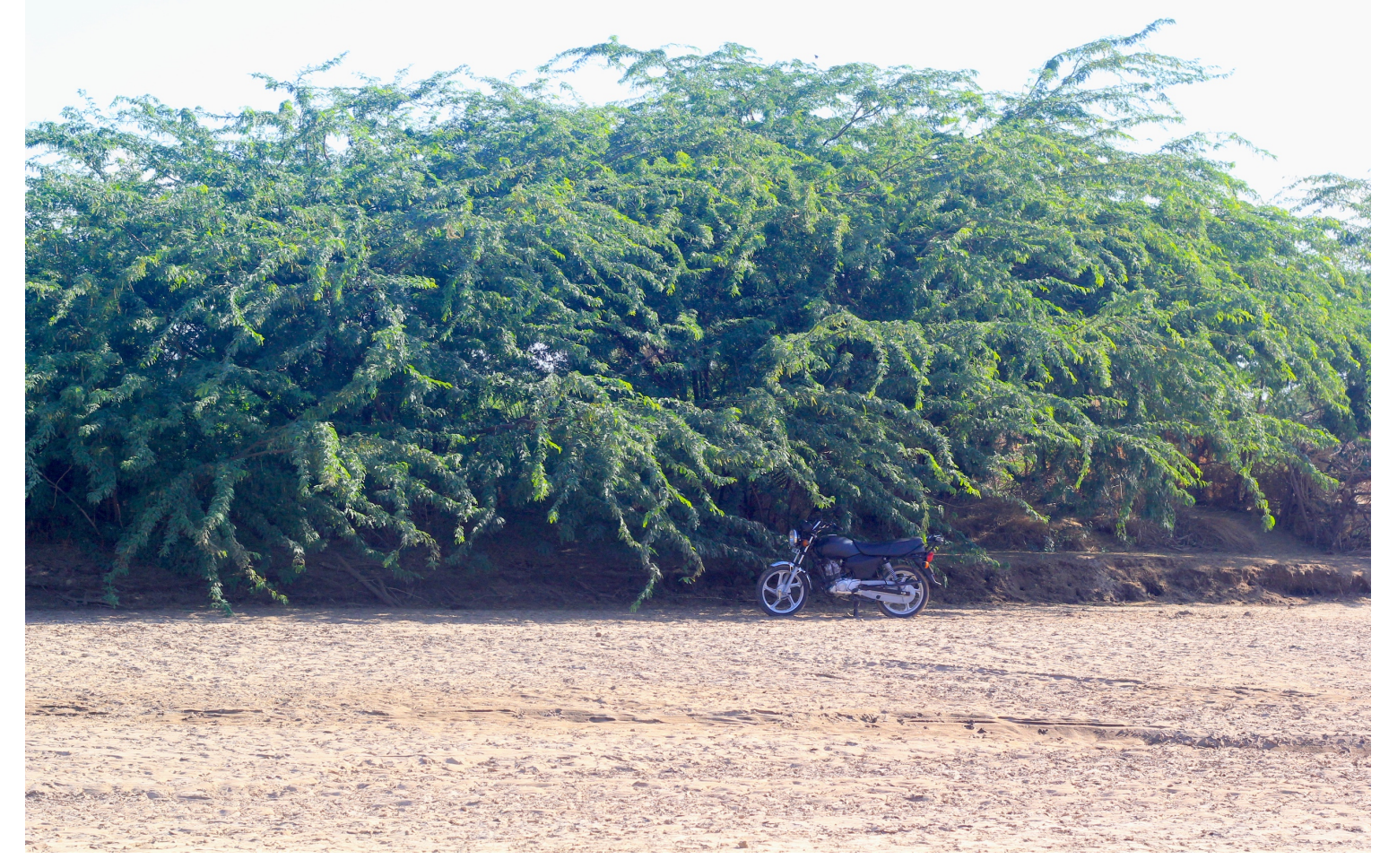

Figure 5.3. View of the Kerio's dry riverbed from Nakurio with extensive prosopis growth along its western bank - motorbike for scale. 
Figure 5.4. The Turkana calendar.

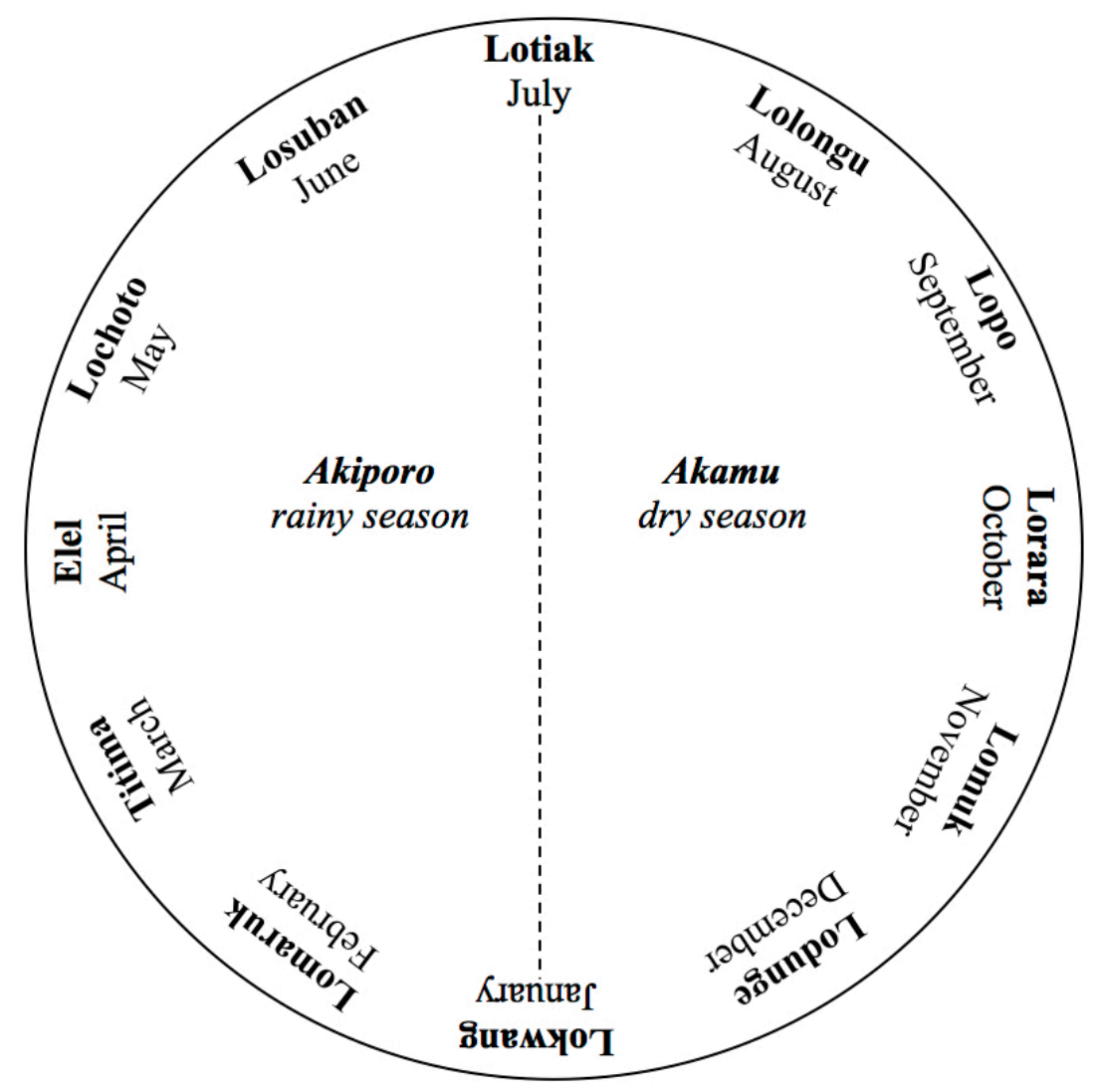

Lotiak: 'to divide'- the month that divides the rainy and dry seasons.

Lolongu: 'to almost happen'- trees start to change the colour of their leaves.

Lopo: 'to cook/ prepare food'- people begin preparing and eating the blood of livestock.

Lorara: 'to fall down'- the trees shed their leaves.

Lomuk: 'to cover'- trees flower and become green again.

Lodunge: 'to end'- the end of the dry season.
Lokwang: 'white or clear'- the sky is clear.

Lomaruk: 'to show signs of rain'- clouds gather and rain is anticipated.

Titima: 'the stage before flowering'- grass has not yet emerged.

Elel: 'flowering'- grass emerges.

Lochoto: 'animal urine'- the urine of livestock turns to a greenish yellow because they are eating a lot of grass.

Losuban: 'to act'- the month when rituals and ceremonies are carried out for children.

Note. This figure represents information gathered from a wide range of interviews and group discussions, Turkana months have been correlated with the months of the Gregorian calendar as closely as possible. 


\subsection{Mobility, seasonal exchange and atap: cultivation before Ekaru a Atchaka Ekipul (the Year of the Lost Padlock)}

Throughout recent history, the cultivating communities along both the Turkwel and the Kerio have implemented an assortment of indispensable locally produced objects in their activities. Perhaps the key implement is the akutwa (plural ngakutwae), a small wooden-handled and metal-headed hoe used for tilling land prior to planting. This is still used by some, but has become increasingly less common in recent decades following the adoption of massproduced hoes (jembe in Swahili) imported from markets external to the Turkana region. The abarait (plural ngabara), a circular wrist knife, is commonly worn by members of herding groups in the present day and is regularly used in cultivation areas to harvest. The elepit (plural ngilepito), a cylindrical wooden container used by herding groups to collect fresh milk, is employed in cultivation areas for the short-term storage of grain. The eleu (plural ngileui), a smoothed goatskin, was historically used for processing grain, but has recently fallen out of use following the emergence of locally produced palm matting (in the late 1980s). Similarly, the echwee (plural ngichweei), a large goatskin bag, was used for the longterm storage of grain in households during the dry season, but today this is primarily achieved using sugar and cement sacks. The atubwa (plural ngatubwae), a rectangular wooden bowl, is used in the herding sector to collect and drink both blood and the soup from cooked meat; it is used by cultivators to collect grain after threshing.

In group discussion sessions and interviews that I conducted in cultivating communities along both the Kerio and the Turkwel, these objects formed a key focus of conversation during explorations of memories from the early half of the $20^{\text {th }}$ century. Some of the key resources used in these sessions were Thesiger's photographs from the early 1960s. These 
were particularly effective in Nakurio, and other locations along the Kerio, where many of them had originally been taken. Images of a selection of items from the Pitt Rivers' object collections were also regularly discussed. It was made clear by informants early on (and indeed repeatedly) in this research that most families currently involved in cultivation considered their engagements with the region's major watercourses using these implements to be as well established as livestock herding and that these engagements have always been an integral feature of the Turkana pastoral economy. Such longevity was also implied by the regular recounting of the popular origin story featured at the beginning of this chapter, which was always situated in a time long before the arrival of Europeans and colonialism. It thus seems highly feasible that the cultivation of small riverside plots very quickly became a key element in the Turkana pastoral economy when herding communities first migrated into the region between 300 and 400 years ago. ${ }^{68}$

Indeed, by the end of the $17^{\text {th }}$ century a large number of well-established flood recession and irrigation cultivation systems were in operation amongst neighbouring communities. In the north, the Daasanach (or 'Merile' in Lowasa's story), who occupy a region split between present day northern Kenya and southern Ethiopia, practised (and continue to practise) a form of flood recession farming on the banks of the Omo that closely resembles that of the Turkana (Gebre 2012; Gebresenbet and Kefale 2012). ${ }^{69}$ To the south along the Kerio, the hill furrow irrigation systems of the Pokot and the Marakwet were also most likely well established by this time (Ehret 2002: 394; Davies 2008; Davies et al. 2014).$^{70}$ Indeed,

\footnotetext{
${ }^{68}$ Both Lamphear $(1976,1993)$ and McCabe (2004: 47) suggest that the ancestral communities of the Turkana incorporated cultivation as soon as they begun their southern migration, after AD 1500. 69 'Murle' crops and agricultural food production are also mentioned by Donaldson-Smith (1897) in his Through Unknown African Countries, extracts from which are stored in the Kenyan National Archives - KNA/PRB-DC/Turk/3/1.

${ }^{70}$ The Pokot population is broadly divided into two subsections, the plains (pastoralist) Pokot, pipagh-tich, and the hill (agricultural) Pokot, pi-pagh-pa. Here I am specifically referring to the agricultural Pokot.
} 
Morgan (1974: 88) suggests that the example of Pokot agriculture may have been a key influence in the development of cultivation systems in southern Turkana, although there is no direct evidence to back up this claim. Further south, on the alluvial flats between Lakes Bogoria and Baringo, the system of the Il Chamus Maasai was also most probably in operation by the early $19^{\text {th }}$ century (Petek and Lane 2017 ).

It was also made clear in numerous interviews that the interdependence of farming and herding communities in Turkana, and the ability of individuals and families to move between these two systems of production as and when required, have long been integral features of their relationship (for comparative arguments about the Karamojong of northern Uganda see Dyson-Hudson 1966, 1972). These are indeed common features of most pastoral-cultivating systems across East Africa. ${ }^{71}$ Like fishing, Turkana crop cultivation has, throughout history, comprised inherent mobility, both in terms of its role as a coping strategy undertaken by incoming herders during times of economic stress (particularly after periods of heavy raiding when livestock numbers are dwindling), and also in the sense that it was undertaken at multiple locations throughout the year by single individuals and families from communities that were permanently engaged in it. ${ }^{72}$

Whilst there have doubtless been numerous transitions and developments in Turkana cultivation in the centuries since its initial emergence (to understand which, a great deal of further fieldwork is required), this mobility was a central characteristic for many families in

\footnotetext{
${ }^{71}$ Adams and Anderson (1988: 529) emphasise this common interdependence with the example of Il Chamus irrigation in the $19^{\text {th }}$ century, the success of which, they argue, was 'dependent upon the linkages between irrigated cultivation and pastoralism as complimenting systems of production'. ${ }^{72}$ Whilst the plains of major rivers have historically been the most common sites for cultivation, crops are also raised at other sites including the lakeside and the banks of intermittent streams.
} 
Nakurio and elsewhere until fairly recently. ${ }^{73}$ During a day of discussions on her land in

October 2014, Emeri Lowasa, who began cultivating in Nakurio more than sixty years ago, explained her early memories of the system. Lowasa situated these memories in the decades preceding a year widely remembered as Ekaru a Atchaka Ekipul, literally translated as 'The Year of the Lost Padlock'. This was a year that occurred somewhere between 1965 and 1970 (shortly after Thesiger's earliest images from along the Kerio were taken), when southern Turkana saw extremely heavy rains without respite for four days, and it seemed as though the 'heavens had lost their padlock'. Lowasa explained:

'Farming was always associated with ngikebotok [those without animals] because it was often a way of surviving [after disease or raiding] and [at the same time] getting more animals if you were in need by waiting for family and friends to donate them, or exchanging grain after harvest... I came from the area between here and Merier many years before Atchaka Ekipul [1965-1970], and I married here in Nakurio when I was a young girl. At that time the only crops being grown were cowpeas and sorghum... but mostly sorghum. Unlike now, it would always rain in the months before Lotiak [July], usually between Elel [April] and Lotiak [July]... unless there was a drought... We cultivated after the floods and then afterwards, in the dry months, we either waited to plant after angolol a ngatur [the dry season flood] or moved to the lakeside, [to] the delta. It was at that time [the dry months] that the lake would move back and we planted in the delta soil. Then we would return to Nakurio to plant again' (Interview with Emeri Lowasa, Nakurio, 09/10/2014).

Lowasa describes a dynamism in her farming routine that was entangled with and contingent on the rhythmical shifting of the seasons and that facilitated her own and many other families' year-round engagement in cultivation, occasionally through opportunistic shortdistance migrations. Importantly, it was the regularity of cultivation at this time that underpinned the robust synergy between the activities of farming and herding groups. Life histories that I collected in a range of cultivating and herding communities outline how during the months of Akiporo (in non-drought years) between Lokwang (January) and Lotiak

\footnotetext{
${ }^{73}$ It is important to note that in some communities mobility remains a key component of the cultivating livelihood, particularly in the north. However, in the vast majority of cases (as this chapter goes on to outline) such regular movements have become less essential.
} 
(July) herding units with family members in cultivating areas were able to stop slaughtering animals on a regular basis (allowing them to reproduce rapidly), migrate to the river and turn to sorghum and milk as the principal elements in their diet (see Figure 5.4). For families with no relatives in cultivating areas, livestock and a range of wooden and leather containers (primarily ngilepito and ngatubwae) were exchanged for sorghum and cowpeas, particularly after large harvests when farming communities were more likely to have surplus grain. Likewise, for semi-sedentary cultivating families with herds of a limited number and no relatives in the herding sector, or those engaging in cultivation in response to livestock loss, the exchange of grain after large harvests constituted an important opportunity to accrue livestock, along with the various containers and implements used for cultivation activities. When these exchanges took place, a porridge called atap, consisting of ground sorghum and milk, was universally eaten.

In this sense, livestock herding and cultivation were mutually supportive, each providing an integral means of regular periodic respite for the other, to the extent that they should perhaps be envisaged as two sides of one diverse entangled livelihood, rather than two separate livelihoods regularly interacting with one another. These two pursuits were certainly more intrinsically inter-reliant than herding and fishing ever were. Whilst as outlined in the previous chapter fishing and herding communities were connected by strong exchange relationships throughout the first half of the $20^{\text {th }}$ century, these exchanges took place on a far more incidental and unplanned basis and did not necessarily articulate a mutual dependency. Indeed, a large number of those primarily engaged in either herding or cultivating at this time were members of a familial unit that was spread across both activities. The most common arrangement for this in Nakurio, as remembered in numerous interviews, was for the youngest and oldest members of a family to remain beside a river course with a small herd of 
goats and sheep on a year-round basis, whilst other more physically able family members moved across the plains in search of pasture with larger herds of cattle, camels, donkeys, goats and sheep, returning to the riverside to eat atap during times of harvest.

The social and economic intimacy between pastoralist and cultivating communities at this time was comprised and emulated by the material culture that was implicated in their relationship. For example, despite the widely held understanding that cultivating communities were ngikebotok, the wearing of ngakoroumwa neck beads was more or less ubiquitous. Consequently, unlike those born into fishing villages, who wore fishbone neck ornaments throughout the first half of the $20^{\text {th }}$ century, women from farming backgrounds regularly married into herding families. ${ }^{74}$ This continues to be the case today, and the provision of ngakoroumwa beads for young women in cultivating communities is made possible through extensive familial and social networks in the herding sector, members of which can raise capital regularly and quickly. It is the existence of these extensive networks that is alluded to through the ngakoroumwa displays of these young women and which makes intermarriage acceptable to the families of those with large livestock herds.

Similarly, as mentioned above, many of the implements and containers involved in cultivation were also used extensively throughout the herding sector. During a discussion about the recent adoption of agricultural tools via various development interventions (a

\footnotetext{
${ }^{74}$ This was documented in several life histories collected in both cultivating and herding areas throughout my research in Turkana. Significantly, Lokuruka (2006: 209) points out that the much firmer divide between fishing communities and pastoralists was also reiterated in ceremonial contexts. He explains that, 'I heard time and again when I worked with the Turkana fishermen in the 1980s that mudfish (Clarias lazera) used to be the inducement for a mother-in-law to accept a suitor as a potential son-in-law up until the 1960s. The pastoralist on the other hand offers a fat ram to the mother-in-law as an equivalent. The low regard for fish by the pastoralists therefore leaves livestockmeat to claim the lofty regard they attach to it.'
} 
subject explored in greater detail below), Eyanae Eyangan made the argument that 'items used in cultivation were originally adapted from a pastoralist lifestyle... then recently more specialised tools have come from elsewhere' (interview with Eyanae Eyangan, Nakurio, 01/10/2014). Many others recalled that throughout the early half of the $20^{\text {th }}$ century most of these items flowed into riverside communities directly from family members engaged in herding, or from non-relatives who exchanged them for grain following large harvests (with the exception of the akutwa, which was made by the cultivators themselves). Ekuleu Akiru, a lifelong pastoralist from the Kerio region, explained this as follows:

'When people are grazing they make things like akurum, ebur, etio, elepit, akutom, akalobotch... the materials can be found in the hills and there are many [materials]. If a relative comes to a family member's home he can get objects through that connection... People would [also] return [to the river] from the plains and come down from the hills in the summer months. They would trade animals and these things for grain with farmers by the river' (interview with Ekuleu Akiru, Nakurio, 09/04/15).

In the domestic sphere, the assortment of containers and items referenced by Akiru above facilitated the preparation of meals that further embodied the intimate relationship between cultivation and herding; sorghum from riverside plots was most commonly mixed with animal fats, oils and milk before consumption. Lokalimon Chila, a cultivator from Nakurio recalled this as follows:

'I remember... when I was young, before I married... my mother cooking sorghum in clay pots... sorghum was cooked in clay pots or mixed with milk [to make] atap in an atubwa [wooden bowl], after mixing it was eaten with an akaloboch [wooden spoon]. Often it was eaten with animal fat' (interview with Lokalimon Chila, Nakurio, 03/10/2014).

It seems clear that the success of both cultivation and pastoralism was, to a large extent, entwined with these regular seasonal interactions and exchanges. It is significant to point out that these exchanges were occurring at the same time as the lakeside trade between fishing and herding groups described in the previous chapter, which saw similar objects manufactured by pastoralist groups being exchanged for lake animal skins and products. 
However, despite the regular flow of objects produced by pastoralists into lakeside villages, the fishing communities also regularly produced a material culture corpus that was unique to their particular daily practices (including harpoons, fish traps and wooden rafts). Moreover, in the domestic sphere, and particularly with the material culture surrounding cooking and eating, many of the implements used on a daily basis were produced from materials unique to the lakeside. For example, as outlined in the previous chapter, many fishing families ate from plates and bowls made form turtle shells or woven doum palm. Their implementation of these livelihood- and location-specific items differentiated them from cultivating communities, whose every day material conditions (in both cultivation plot and household) closely matched those experienced throughout the herding sector (with the exception of the akutwa and the echwee). This further demonstrates the difference between the pastoralism-fishing relationship and the pastoralism-cultivating relationship during the early half of the $20^{\text {th }}$ century.

In any case, considering its historical correlation with the seasonality of river flooding regimes and rain, it is unsurprising that the pastoralism-cultivating relationship has transformed quite substantially over the past few decades in response to recent environmental changes. Before further examining the ways in which this has happened it is important first to turn back to Lowasa's account, and in particular her positioning of it before the year of Atchaka Ekipul. This should not be interpreted merely as a relation of her memories to a matter-of-fact historical chronology. Rather, as outlined above, Lowasa was invoking a very specific local narrative of change that structured 'old' and 'new' cultivation practices around a key dividing moment in history. Ekaru a Atchaka Ekipul was the most regularly referenced year in all of my research relating to cultivation in southern Turkana and was consistently outlined as an iconic period of productivity and illustriousness for cultivating families. This 
event has come to define the way in which many cultivating communities in southern Turkana envisage change and continuity in their various everyday practices. It has, in a sense, come to represent not just a period of unusually heavy rainfall several decades ago, but also the last season of its kind from an idyllic past, which disappeared in order to originate the contemporary situation. Indeed, it is widely remembered in Nakurio today that the harvest that followed Ekaru a Atchaka Ekipul was the last time that cultivators were able to trade surplus grain with visiting herders. ${ }^{75}$

Clearly, the vision of the past that this narrative establishes is imbued with a highly nostalgic and sentimentalising timbre, in that it selectively omits the many droughts, insecurities, raids and diseases experienced throughout the decades preceding Atchaka Ekipul. And yet despite these qualities, it is an extremely valuable expression of the complex temporality of the cultivating livelihood and of how the cultivating community at Nakurio (and indeed across southern Turkana) reckon time. Importantly, the narrative is established upon two distinct and yet interwoven and mutually informing kinds of time. The first of these is the cyclical seasonal time of the recurring ekaru (year) that historically underlined the rhythms of cultivation and structured exchanges between cultivators and herders; this perhaps corresponds with Evans-Pritchard's (1939: 189) concept of 'oecological time'. The second is the sequential time of unfolding events (Ekaru a Atchaka Ekipul being the most significant in this instance), which serves to 'anchor history in a framework of shared practical experience' (Dietler and Herbich 1993: 254). Time reckoning within cultivating communities in Turkana is a relational process built upon the reciprocity of these two kinds of time. Coming to terms

\footnotetext{
${ }^{75}$ Some informants stated that the last time they had traded surplus grain for livestock was not after Ekaru a Atchaka Ekipul but rather several years previously following a year known as Ekaru a Namotor, which means 'the thin year'. This was approximately 1960 and refers to a harsh drought that led to an extreme scarcity of grazing brush, making all livestock extremely thin.
} 
with the temporality of the cultivating livelihood, as encompassed by this process, is of critical importance to understanding how cultivating communities conceptualise the particular trajectories of change that prefigured the contemporary circumstances of their livelihood

Recent history is not structured around the emergence of numerous externally funded irrigation schemes starting in the 1960 s and 1970 s, as is often the case in nationally or internationally orientated accounts and reports of the region (for example Ministry of Agriculture, Animal Husbandry and Water Resources 1962; Ministry of Finance and Planning 1983; World Bank 1990; Cullis and Pacey 1992). Nor is it arranged around the implementation of the Turkana Rehabilitation Project in the early 1980s, which dramatically increased irrigation activities through food-for-work programs (as explored in the following section). Instead, these events are located in a sequential time that is comprehended purely by means of its articulation with the changing yearly ecological cycle. In other words, they serve as reference points within a narrative of change that is rooted in the significant ecological and environmental transformations that began to occur in the middle decades of the $20^{\text {th }}$ century and traces the cascading effects of these changes on the seasonal rhythms of production, exchange and consumption that are central to cultivation.

This is significant when one considers that, as I have mentioned above and explore further in the following discussion, irrigation development schemes have had a substantial material impact in southern Turkana over the past few decades. In some cases, such as Nadoto, their introduction of new techniques and strategies has been implicated in dramatic alterations to pre-existing cultivation systems. In others, where the pre-existing flood-recession farming method has not been abandoned (such as Nakurio), they have facilitated the influx of 
previously unattainable equipment and drought-resistant seed varieties. Whilst such processes are often implicitly assumed to equate to the 'modernisation' of 'traditional' farming systems, and in this sense a kind of transformative historical progression, they do not in fact constitute a significant disjuncture or the beginning of any kind of specific period in local understandings of historical change. To the communities explored in this chapter, the current historical era contains these schemes but is not defined by them. 


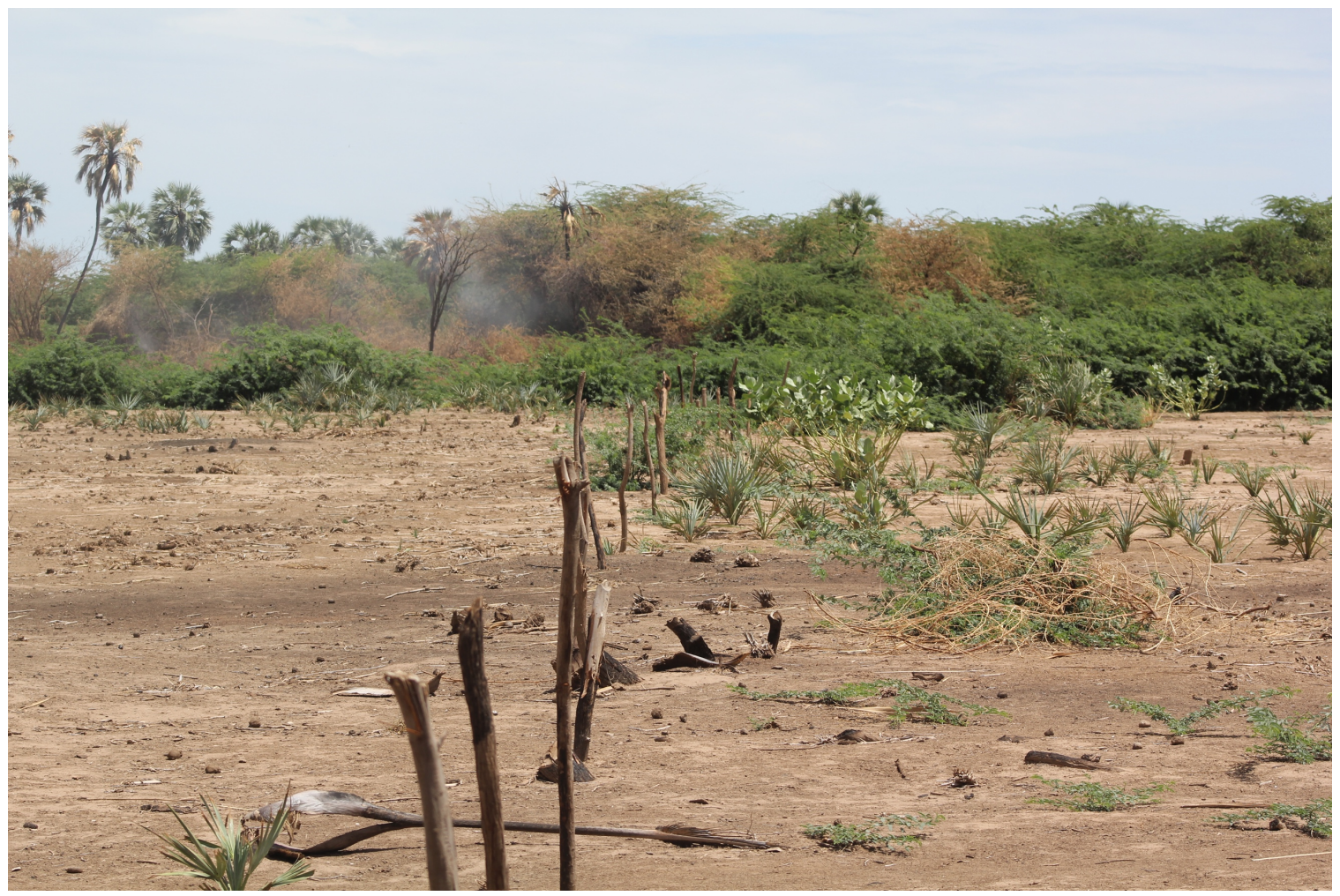

Figure 5.5. View of the division between two cultivation plots on the bank of the Kerio near to Nakurio.

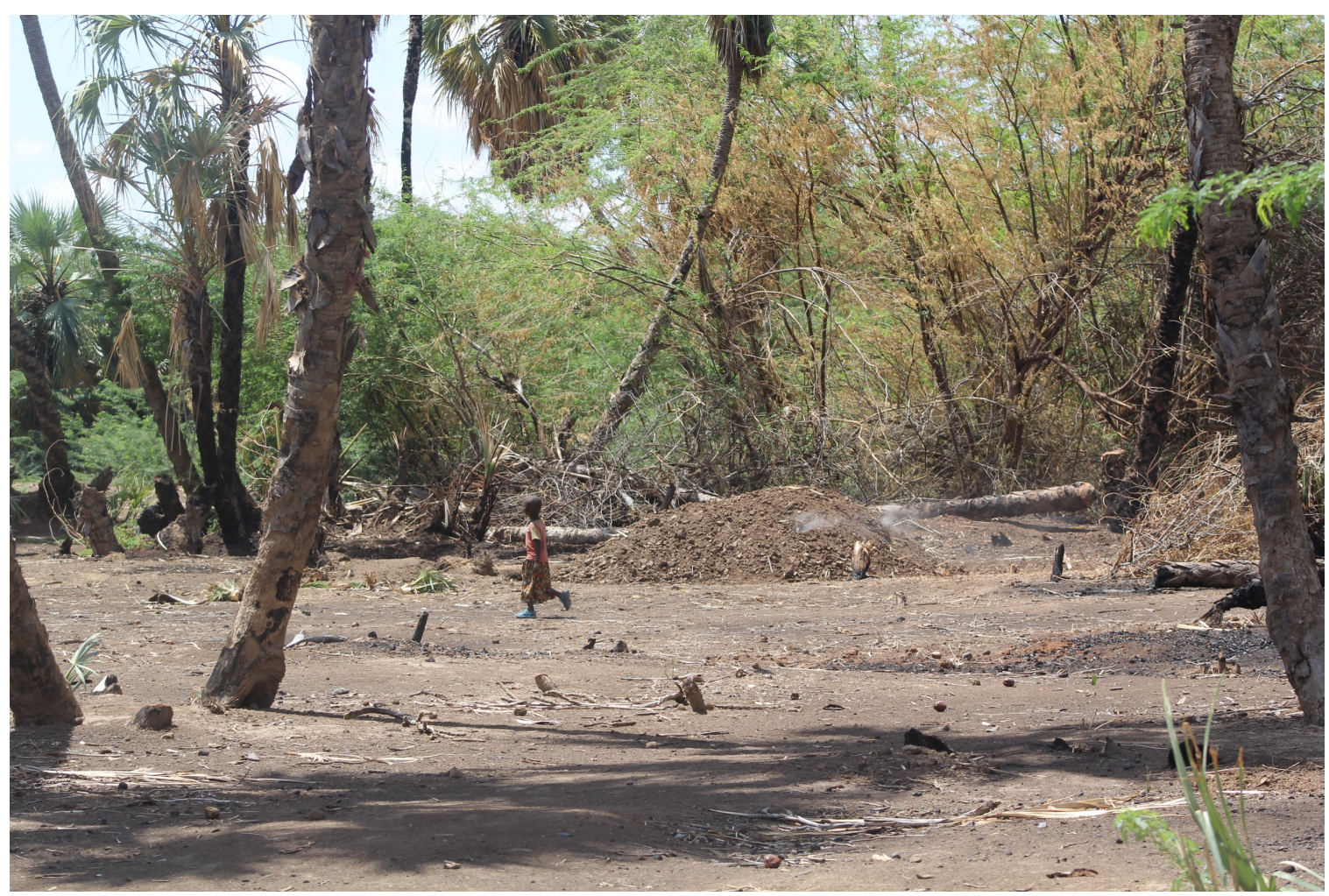

Figure 5.6. A cleared cultivation plot on the Kerio with prosopis growing along its far border. 


\subsection{Cars, relief food and irrigation canals: the 1980-1982 famine and the Turkana Rehabilitation Project}

Environmental degradation and increasing unpredictability are motifs that hold a central position in cultivating communities' explanation of the complexities of recent historical change in southern Turkana, but these themes have also come to dominate the last few decades of the international 'development discourse'. Indeed, Hogg (1987: 47) points out that 'the notion of a progressive deterioration in the world's drylands achieved prominence after the Sahel Drought of the late 1960s and early 1970s'. It seems noteworthy that this was roughly the same time as Ekaru a Atchaka Ekipul. These concerns came to occupy a position of central importance in development planning and practice following the 1977 UN conference on desertification, which took place in Nairobi. Significantly, during this conference Kenya's country position paper (Republic of Kenya 1984: 5) outlined 'overgrazing due to improper livestock and range management [as] one of the principal causes of desertification in Kenya' and went on to petition that 'the entire range should be developed, conserved and managed in accordance with ecological principles of proper land use'.

The idea that pastoralist systems in Kenya amounted to 'improper' land use would come to be deeply influential throughout the 1980s, an era that saw the most extensive and largestscale development interventions ever undertaken in Turkana. It is important to note that in the decades preceding this Turkana had seen the implementation of several formal irrigation schemes (primarily along the Turkwel), which were administered by a range of government and non-government organisations, including missionary societies, the UN and the Ministry of Agriculture (the most significant of these are shown in Table 5.1). However, whilst these 
schemes were largely a reaction to the same environmental concerns that would come to underlie the large-scale projects of the 1980s, they were relatively small in scale and inconsequential to the vast majority of the population. Moreover, the direct correlation between pastoralism and ecological destruction was far less prominent during these early schemes, and they seem to have not been imbued with the overarching sense of urgency and crisis that would define the later schemes.

Table 5.1. Major irrigation schemes undertaken in Turkana.

\begin{tabular}{|c|c|c|}
\hline Date & Location of scheme & Founding organisation \\
\hline 1965 & Nakamane & $\begin{array}{l}\text { UN Food and Agriculture } \\
\text { Organisation (FAO) and } \\
\text { Kenyan government }\end{array}$ \\
\hline 1966 & Turkwel & $\begin{array}{l}\text { FAO, Kenyan government } \\
\text { and Misereor (German } \\
\text { Catholic bishops } \\
\text { organisation) }\end{array}$ \\
\hline 1969 & Kaputir & Catholic mission \\
\hline 1970 & Katilu & $\begin{array}{l}\text { FAO and Kenyan } \\
\text { government }\end{array}$ \\
\hline 1971 & Juluk & $\begin{array}{l}\text { FAO and Kenyan } \\
\text { government }\end{array}$ \\
\hline 1972 & Loyapat & $\begin{array}{l}\text { Reformed Church of East } \\
\text { Africa (RCEA) }\end{array}$ \\
\hline 1975 & Amolem & $\begin{array}{l}\text { NORAD, FAO, United } \\
\text { Nations Development } \\
\text { Program (UNDP), RCEA } \\
\text { and Kenyan government }\end{array}$ \\
\hline 1977 & Lotubai & African Inland Church \\
\hline
\end{tabular}


The UN conference on desertification took place amidst a series of extremely harsh droughts that culminated in a severe and catastrophic famine that persisted in Turkana from 1980 until 1982. Hogg (1982: 164) points out that this famine followed a harsh drought in 1979-1980, which saw 'massive destruction of livestock'. He further explains that 'many were reduced to destitution and starvation. Over $90 \%$ of cattle herds, nearly $80 \%$ of small stock flocks and $40 \%$ of camels were lost in north Turkana'. It was during the response to this famine that the idea of pastoralism's inherently destructive and unsustainable nature (as raised during the conference) would come to dominate. At the onset of the famine a memorandum of understanding was signed between the Kenyan Government and the European Economic Community (EEC), outlining plans for the collaborative formation of a new relief programme. This programme, termed the Turkana Rehabilitation Project (TRP), was operational by 1981. It had two central objectives: to provide relief food for those affected by the famine on an emergency basis, and to implement a five-year 'land rehabilitation' plan (Hogg 1982; Adams 1986). By 1982 the first of these objectives had been met and, via a network of 'famine camps', the TRP was supplying relief food to roughly 80,000 people, a third of the entire population of Turkana at the time (Adams 1986: 318).

Whilst the core underlying cause of the 1980-1982 famine was undeniably a succession of harsh droughts, a range of other significant stimuli were overlooked by those involved in the TRP in their haste to deal with the starving population. Cullis and Pacey (1992), for example, place great emphasis on an epidemic of caprine pleuro-pneumonia and rinderpest that had broken out in the north and point out that the government's inability to deliver grain to the region over a protracted period of time because of a concurrent national cereal shortage significantly exacerbated this situation. Furthermore, McCabe (1990: 153) points out that a 
dramatic increase in raiding between the Turkana and communities in Uganda and southern Sudan (the Karamojong, Jie, Dodoth and Toposa) was also a great influence (cf. Hendrickson et al. 1996; Gray et al. 2003). Indeed, the interviews McCabe conducted with individuals settled into several famine camps at the time show that a large percentage of those who had become destitute considered increased raiding to be the root cause of their livestock losses. Significantly, following the Ogaden War (also known as the Ethio-Somali War) of 19781979 and the collapse of Idi Amin's regime in 1979, northern Kenya had seen an extensive proliferation of small firearms (Knighton 2003: 432; Mkutu 2008; this is discussed in detail in Chapter 6). In light of these arguments, it seems most likely that the 1980-1982 famine was caused not by drought alone, but rather by a series of simultaneous disasters that served to block the drought-coping strategies of the pastoralist population.

The TRP's misjudgement of the complexity of the underlying causes of the famine might have made little difference to its initial objective of feeding those who had become destitute, however it was a critical influence in the development of the longer-term program. Indeed, it was the presumption amongst the development community that the famine was singularly intertwined with environmental degradation that connected so strongly with the newly emerging view that Turkana's pastoralist population had reached the maximum size with which the ecosystem could cope (without the eventuality of constant resource scarcity and hunger). There were connected fears that the famine camps and relief food would engender an undesirable and unsustainable dependence amongst those who had been accommodated. The second phase of the TRP was thus to scale down the reliance on relief food through the establishment of food-for-work programs, which provided food only as payment for public 
works and participation in development schemes. ${ }^{76}$ These programs were closely entwined with the underlying strategy of the broader Turkana Rural Development Program (TRDP), which was to foster alternatives to pastoralism and encourage significant portions of the herding population to move into either fishing or cultivation. ${ }^{77}$ Indeed, NORAD's development of the fishing industry, as discussed in Chapter 4, was another key feature of this strategy.

The TRP's work programs comprised a very strong emphasis on the development of cultivation, which it considered to be a 'path to sustained economic development' (Hogg 1982: 166). Those who were not relocated to the lakeside to participate in the newly emerging fishing industry were settled into riverside camps. On top of general infrastructural development, food was delivered as payment for the clearance of riverside gallery forests (particularly along the Turkwel) and the development of new water harvesting and irrigation schemes. In collaboration with a range of other organisations, and through a team of surveyors (primarily from OXFAM), the TRP worked to develop 'Yemeni-style' spate irrigation systems across the region. These water management systems relied on the construction of diversion structures (a series of bunds, weirs and graded canals) to direct water into and across cultivation areas. These techniques were aimed at improving regional crop production by targeting rain-fed flash floods and increasing the amount of land that was viable for cultivation.

\footnotetext{
${ }^{76}$ Significantly, in scaling down this operation the TRP did, for a short time, focus on restocking selected families' herds (see Clay 1986). However, emphasis quickly shifted from this approach to the food-for-work programs, and a more transformative model of economic development.

${ }^{77}$ The TRDP is Turkana's Arid and Semi-Arid Land program (ASAL). The national government has various other comparable ASAL programs in ecologically similar regions.
} 
It was recalled numerous times during interviews in Nakurio that people fled north to these food-for-work projects along the Turkwel following extensive and brutal raids in 1981 from the Pokot in the south. These raids were closely intertwined with the resource scarcity that had resulted from the recent droughts, but significantly took place many miles to the south of the intense raiding along the Ugandan and Sudanese borders (as reported by McCabe 1990; Hendrickson et al. 1996). As outlined in the previous chapter, in many communities (including Nakurio) 1981 is referred to as Ekaru Asur, 'the fleeing year', in reference to these extensive raids along Turkana's southern border. ${ }^{78}$ Not only does this further substantiate the view that heightened raiding was a core component of the 1980-1982 famine, but it also demonstrates that this raiding was not limited to the northern border zones.

It was in this context of migration and instability that the irrigation scheme at Nadoto was first initiated, originally as a TRP food-for-work camp. Many of those I interviewed in 2014 recalled clearing large areas of riverside forest in the early 1980s to prepare their cultivation plots. Esot Emekwi, who arrived in Nadoto in 1982, outlined the scheme's emergence as follows:

'This irrigation began more than 30 years ago... in 1982 when... [everywhere] was suffering with hunger. At this time there had been a big raid which came up to Kerio. People were chased and were forced to stay here along the Turkwel. This scheme was introduced by a man who was called Tim... He was from TRP. Many people were given shambas, they were told to clear the bush. Before Tim came here there were only a few people, they were using the flood from the river to cultivate... but not every year. When I came [here] I cleared the bush for three months before the area was ready to plant' (interview with Esot Emekwi, Nadoto, 27/12/ 2014).

Like many other interviewees, Emekwi points out that Nadoto had only seen 'informal' seasonal flood recession cultivation before the TRP scheme. Indeed, prior to the TRP all of the cultivating communities along the Turkwel to the east of Lodwar had only ever farmed

\footnotetext{
${ }^{78}$ Namoe Lowasa, a close friend and key informant throughout my research in Turkana, was born in this year and is named after the events that took place. Namoe literally means 'raider' or 'killer'.
} 
using the flood recession strategy, and this had only been undertaken on parts of the river bank that were naturally inundated. Moreover, whilst irrigation schemes had been implemented in a variety of locations throughout the region prior to the severe famine of 1980 (with varying degrees of success), there had been no concerted effort to encourage large numbers of the population into them. The TRP's food-for-work schemes marked a significant departure from this, and for the first-time thousands of destitute pastoralists found themselves clearing forest and demarcating their plots.

During other interviews conducted in Nadoto, those who had witnessed the early years of the TRP recalled the immense scale of the operation by describing the arrival of new vehicles and the construction of numerous buildings. On top of the food stores, administrative compounds and other structures that arose, the TRP introduced a substantial fleet of tractors, lorries, cars and motorbikes, something also recorded in reports by the Overseas Development Institute (ODI 1985), and Cullis and Pacey (1992). The rapidity and excess of these changes to Turkana's material and infrastructural surroundings brought with them a sense of promise, and many still remember the widespread anticipation of ensuing dramatic economic transformation that took hold at the time. On a more immediate scale, this period of material transformation manifested itself in the form of new agricultural tools, which were distributed throughout the riverside camps by the TRP and its associated relief and development organisations. Agnes Nakorok left Nadoto as a young girl and returned shortly after the TRP had begun. During a discussion on her land in December 2014 she described the situation she encountered on her return:

'I left [Nadoto] when I was very young, at this time I was not even aware of many shambas [cultivation plots]... only a few. I came back when I had become a woman [after marriage] and there were many shambas being cultivated... the bush had been cleared. I heard stories of the man called Tim who had come from TRP. People had been given new things... Jembes [small mattocks], pangas [machetes], forks... before people had akutwa [only]. It was this time that the canals were built... these canals 
required the whole community to work together, to build them and repair them always' (interview with Agnes Nakorok, Nadoto, 20/12/2014).

What the organisations involved in the TRP at this time perhaps did not recognise was that their intensive concentration on irrigation along the Turkwel (and indeed elsewhere) actually served to restore and strengthen the pastoralist drought-coping strategy that had broken down as a result of the scale of the famine and the diversity of its causes. The food-for-work programs allowed an unprecedented number of people to focus on clearing large areas of riverside forest without concern for where they would acquire their daily food in the meantime. This was extremely significant considering that in many cases, as pointed out by Emekwi above, this clearance operation took several months. Moreover, whilst the new irrigation systems did not dramatically improve crop yields on a case-by-case basis, they did (to an extent) make it possible to cultivate in areas where it had previously not been viable due to the shape of the river and the extent of its floods. As a result, a much larger than usual population of destitute pastoralists was able to engage in cultivation.

Importantly, many of these new cultivators viewed the TRP schemes in a profoundly dissimilar way to the organisations that set them up. Quite contrary to the TRP notion of bolstering cultivation as a more 'sustainable' alternative to pastoralism, many did not envisage remaining in their riverside locations indefinitely, but rather saw the food-for-work schemes as a means to accumulate the livestock that they had lost and return to a pastoralist career. It is therefore perhaps unsurprising that the majority of those who had settled into the TRP schemes left them to return to pastoralism as soon as conditions began to improve. Throughout the latter half of the $1980 \mathrm{~s}$, at roughly the same time as the disintegration of the NORAD fishing scheme (discussed in the previous chapter), many of the irrigation camps were abandoned. In describing her return to Turkana in the 1990s (following previous visits 
in the 1980s), Broch-Due (1999: 66) paints a vivid picture of the aftermath of the 1980s development boom and the breakdown of its various projects:

'Amid old rusty machines on the sites of closed down irrigation and fishing facilities, there were now animals in abundance, the herders clearly in the process of claiming back old paths and pastures from which they had been expelled by "modernisation.",

Ferguson (1994a) describes a similar incongruity and incompatibility with local livelihood systems in a long history of failed development interventions in Lesotho. Ferguson's The Anti-Politics Machine roots the failure of these development schemes in the myth-making of the 'development discourse', which he argues works to produce an inaccurate image of Basotho society and livelihood systems in order for them to fit within the planning and policy conventions of development agencies. Whilst such myth-making was (and still is) undeniably a constituent element of development practice in Turkana, it is Ferguson's particular example of the Thaba-Tseka agricultural project that seems to be most pertinent to Turkana's TRP schemes. Like the TRP, The Thaba-Tseka project was founded upon an entirely inaccurate picture of the agricultural systems it sought to develop and an illogical goal for their development. Having persistently disregarded the local population's understanding of how agriculture should function within the regional economy, Ferguson (1994b: 178) explains how the project managers 'had to concede that local people were right that little beside maize for local consumption was going to come out of their tiny mountain fields, and that greater investment in agriculture was not going to pay handsome rewards.'

Despite its failure to achieve its long-term objectives, the TRP's intervention was irrefutably a period of significant and far-reaching transformation, particularly in terms of the arrival of new materials, structures, roads and cultivation equipment. Indeed, the importance of these components surfaces in many of the accounts of the period that I collected, some of which are discussed above. However, it would be fruitless to attempt to understand the role that these 
material and technological changes played in the historical development of the cultivating livelihood purely in terms of the immediate context of the TRP schemes. Indeed, the TRP did not in the short term underlie any dramatic change in cultivation practices; despite the new irrigation technologies and farming tools, cultivation was still ultimately contingent on the rivers' flooding regime (and the Turkwel did not become permanent in its lower course until the early 1990s). Nor did the TRP profoundly affect the dynamics of interaction between cultivating communities and pastoralists. Indeed, the widespread movement of pastoralists into cultivating areas during this time, as encouraged and facilitated by the TRP, must have felt decidedly conventional for those involved considering the long history of such famineresponses in Turkana.

It is for these reasons that cultivating communities in southern Turkana do not conceptualise the large-scale development projects of the 1980s as constitutive of a critical period of historical change, and indeed why Ekaru a Atchaka Ekipul is understood to be a much more pivotal year than Ekaru Asur. As outlined above, the notion of increasing environmental unpredictability that arises consistently in the cultivating communities' narrations of the postAtchaka Ekipul years correlates closely with concerns for the effects of human-induced global environmental change that have also influenced development activities in Turkana (and indeed world-wide) over the last few decades. However, whilst it would be reasonable to assume that the ecological and hydrological changes experienced in Turkana since Atchaka Ekipul connect at least to some degree to much broader trends in global environmental change, the response of the international development community (as represented by the TRP in the 1980s) could not contrast more strongly with that of Turkana communities. 
Perhaps the key error made by the TRP was their assumption that the famine of 1980-1982 was linked to a broader crisis in Turkana pastoralism. This was arguably not only based upon a poor understanding of the root causes of the famine, but also on a serious misinterpretation of the Turkana pastoral economy and the place of cultivation within this regional system. If the TRP and its associated organisations had possessed even a rudimentary understanding of the mobility and flexibility that was integral both to Turkana cultivation practices and the relationship between herders and cultivators (as outlined in the previous section), they would have perhaps reached different conclusions. ${ }^{79}$ The ways in which these aspects of Turkana cultivation have been transformed in the years since Atchaka Ekipul may be taken together to represent the response of Turkana communities to the increasing environmental unpredictability of the current historical era. In the following sections I argue that the TRP, along with its associated material and infrastructural transformations, did not engender socioeconomic change on its own terms. Rather, it served as one of many resources in a composite economic repertoire that was used by cultivating communities to reconfigure their interactions both with Turkana's major rivers and the rest of Turkana society in an already unfolding process of transformation.

\footnotetext{
${ }^{79}$ Adams (2003: 1) makes the further point that the notion of 'crisis' has, in recent years, become ingrained in the activities of development organisations operating in the 'third world'. He argues that 'the words written and spoken about development, the "discourse of development", have enormous power. Development action is driven forwards by texts ranging from humanitarian tracts to national development plans. These portray the world in particular ways, often in crisis of some kind, and almost always as requiring management and intervention by development planners'.
} 


\subsection{Sugar sacks, maize flour and the establishment of commercial markets}

The preceding sections of this chapter have outlined the intimacy of cultivation and pastoralism during the early half of the $20^{\text {th }}$ century and suggested that the mutual dependency of these two economic pursuits, as underpinned by a unitary cycle of seasonal interactions, was manifested in the material culture used on a daily basis across both sectors, from ngakoroumwa neck beads to ngilepito and ngatubwae containers. Furthermore, in examining the emergence of the TRP schemes in the early 1980s, I have argued that whilst this large-scale intervention brought with it extensive material, technological and infrastructural changes, these changes did not ipso facto constitute a consequential shift in cultivation practices or the interactions between cultivators and herders. Rather, changes to these features have been much more deeply entwined with the environmental uncertainty of the post-Atchaka Ekipul years. It is by shifting attention to this underlying stream of social and economic change in synergy with the increasing environmental unpredictability of recent decades, that it may be possible to underline the roles of the material and infrastructural changes brought about by the large-scale irrigation development projects of the 1980s in embodying and articulating (rather than originating) broad transformations within Turkana's cultivating livelihood.

Indeed, it was regularly pointed out during conversations I had in both Nadoto and Nakurio, that by the early 1980 s most cultivating communities had not produced enough grain to exchange with visiting herders for almost two decades. The TRP was unknowingly initiated at a time when the increasingly unpredictable flood cycles of both the Turkwel and the Kerio had already begun to place considerable strain on the inter-livelihood mobility and seasonal exchanges that had characterised the cultivation-pastoralism relationship throughout the first 
half of the $20^{\text {th }}$ century. It was this context that informed the ways in which cultivating communities responded to and indeed exploited the TRP intervention to their own objectives. Much in the same way as the context of multiple droughts, cattle raiding and livestock disease informed the pastoralist sector's utilisation of the TRP as a short-term buffer and a means of accruing livestock to return to pastoralism.

Following the return to pastoralism of large numbers who had come to take part in the TRP irrigation schemes along the Turkwel, small communities of semi-permanent cultivators remained in strategic riverside locations. Whilst the population at Nadoto shrank considerably, a significant number remained to make use of the new equipment and canal systems that had been developed in the early 1980s. Then, following the construction of the Turkwel Gorge Dam (completed in 1991) and its extensive hydrological repercussions, cultivating communities along the Turkwel began to grow in size and significance (and continue to do so in the present day). Indeed, many of those whom I interviewed in 2014-15 had joined the irrigation scheme in Nadoto fairly recently, having either occupied unused land or incorporated themselves into a friend or family member's plot. In the last few years, the Ministry of Agriculture (MOA) has begun reinforcing the canals that were initially constructed by the TRP with cement, a move that indicates the continuing interest of the government and its development partners in irrigation and agriculture and their commitment to them as a means of combatting a range of disparate issues (see also World Bank 1987; Blank 2000; Mati 2008).

Unlike the Turkwel, the Kerio was not a key focus of the TRP during the early 1980s and far fewer irrigation schemes were implemented along its banks. However, many of the Kerio cultivators did begin to receive regular visits from a range of agriculture-orientated 
organisations from the 1980s onwards (in correspondence with the trend towards irrigation and agriculture in regional development planning) including the Ministry of Agriculture, Oxfam and, more recently, Solidarités Internationales. At intermittent stages over the last few decades, these organisations have distributed similar agricultural tools to those distributed along the Turkwel in the early food-for-work programs (as discussed by Agnes Nakorok above) and, perhaps more importantly, the seeds of a range of 'drought-resistant' crop varieties. ${ }^{80}$ Michael Ewose, who was born in Nakurio in the early 1970 s, recalled the dispersal of these new crop varieties as follows:

'When I was a boy... before I did asapan [initiation] people were [cultivating] here. I remember that there was no etirae [Prosopis juliflora], in those days I did not have a shamba [riverside plot] but I can remember the crops grown. There was sorghum mainly, cow peas... watermelon had recently come from the farmers on the Turkwel... but since I have begun [cultivating] there is also maize, millet... Some people grow green grams and potatoes. They are successful sometimes, other times they are not. Whatever people try [to grow] everything is so difficult now because of etirae and because there are no floods... no one can tell when it is time to plant. Everyone is constantly clearing etirae' (interview with Michael Ewose, Nakurio, $03 / 10 / 2014){ }^{81}$

As Ewose outlines, whilst this seed and tool distribution has been welcomed by most, cultivators along the Kerio must still cope with the extreme challenges presented by the increasing uncertainty of floods and the predominance of the invasive foreign species known as etirae (Prosopis juliflora), which is fast-growing, moisture-depleting and generally destructive to cereal crops. It is significant to note that, whilst etirae was introduced to Kenya by a range of disparate organisations over several years in the 1970s and 1980s, it was most

\footnotetext{
${ }^{80}$ It is significant to note that the variety of sorghum grown historically in Turkana was almost certainly selectively bred by Turkana cultivators themselves over many years to a stage where a harvest could be raised within 65 days, which is extremely quick (even for sorghum; Morgan 1974). For comparison, experimental rapid-growth sorghum strains from Machakos in the 1960s were recorded as taking between 120 and 190 days to reach harvest stage (Dowker 1963). It was this rapidity of growth that gave Turkana sorghum such a predominant position in cultivation, and why other cereals could not be grown until new quick-growing or 'drought-resistant' varieties were introduced in recent years.

${ }^{81}$ In discussing the distribution of new seed varieties, Ewose and others also pointed to the year Ekaru a Eumbi ('The Year of Millet', in the early 1990s), which I mentioned in Chapter 4.
} 
actively introduced to Turkana throughout the 1980s by organisations involved in the TRP. The TRP's aims in doing so were to further combat the effects of desertification, but also to reforest riverside areas that had been cleared during the food-for-work schemes (subsequent to the realisation that such extensive de-forestation would create a serious resource scarcity for herders in future dry seasons; Muturi et al. 2013). Whilst etirae has caused significant problems for cultivators operating along both the Turkwel and the Kerio, it has been particularly detrimental to those cultivating along the Kerio due to the added constraint of the river's seasonal unpredictability.

However, despite the adversity that has in many ways come to define the last few decades, most of the Kerio's cultivating communities have neither abandoned their riverside locations nor been reduced to destitution. Rather, the extensive infrastructural development undertaken by the TRP in the 1980s (which was aimed at facilitating both the distribution of relief food and the construction and maintenance of numerous irrigation schemes) has served as a platform for these communities to develop a range of new economic interests. Over the past few decades, roads initially created during the early1980s have come to underpin the emergence of a trade network established and managed by a series of interconnected semisedentary communities, a large majority of them from cultivating backgrounds. This trade network rests upon a series of small settlements, most of them surrounding stores and structures that were originally built for relief food distribution, which have been growing gradually throughout recent years. Being orientated along tracks that lead to larger graded gravel roads, these settlements have come to serve as connections to Turkana's major towns.

In the Kerio region, such settlements host small but regularly occurring markets, where local traders sell produce gathered in Lodwar to visiting herders at a small mark up. During a 
further conversation with Emeri Lowasa, several months after our initial discussion about the seasonality of cultivation before Ekaru a Atchaka Ekipul, she explained the emergence of these markets as follows:

'I was here when cultivators were trading sorghum to herders for animals... before Ekaru a Atchaka Ekipul. During that time there were no kiosks, no markets, no roads... the first road was not like this one... there is a story of two local men... one built a kiosk in Nakurio, and the other built his in Kerio and they began to do business, this is when the markets started...This was before etirae, at the time Namoe was born [Ekaru Asur]. This was when ngichweei [large goatskin bags] began to be replaced by sugar and cement sacks for storing grains, and instead of ngileui [smoothed goatskins] people began to use amkeka [palm mats] for threshing' (interview with Emeri Lowasa, Nakurio, 06/04/2015).

Many of the cultivators in Nakurio have come to be deeply involved in these markets, making regular trips to Lodwar to purchase commodities and trading at several market locations per week. For these cultivator/traders, engagements with local markets have not replaced cultivation activities, but rather serve to fill the increasingly long periods of time for which the river remains dry. Market trading has come to provide economic security throughout periods when cultivation is untenable, but can be suspended when it is necessary to return to the river and cultivate following a flood. The central position of these markets to the cultivating community in Nakurio was emphasised numerous times throughout interviews and life histories I collected amongst them, and the broader regional importance of the markets was a strand that arose throughout my research in Turkana. As such, in order to ascertain a more detailed understanding of the configuration of commodities that flow through them, I collected regular inventories of three key markets close to Nakurio over a period of several months. The data from four consecutive months of these market surveys are outlined in Tables 5.2-5.4, the locations of the markets are shown in Figure 5.7. 
Table 5.2. Kerio market inventories, Dec 2014-March 2015.

\section{Commodity $\%$ of traders selling commodity on specified date}

\begin{tabular}{|c|c|c|c|c|}
\hline $\begin{array}{r}\text { Date of market } \\
\text { (no. of traders present) }\end{array}$ & $\begin{array}{l}30 / 12 / 2014 \\
\text { (71 traders) }\end{array}$ & $\begin{array}{l}20 / 01 / 2015 \\
\text { (78 traders) }\end{array}$ & $\begin{array}{l}03 / 02 / 2015 \\
\text { (91 traders) }\end{array}$ & $\begin{array}{l}10 / 03 / 2015 \\
\text { (113 traders) }\end{array}$ \\
\hline Maize flour/ wheat flour & $77 \%$ & $62 \%$ & $37 \%$ & $62 \%$ \\
\hline Beans/ peas & $70 \%$ & $46 \%$ & $24 \%$ & $33 \%$ \\
\hline $\begin{array}{r}\text { Salt/ cooking oil/ sugar/ } \\
\text { spices/ tea leaves/ } \\
\text { powdered milk }\end{array}$ & $76 \%$ & $70 \%$ & $62 \%$ & $65 \%$ \\
\hline Rice/ pasta & $30 \%$ & $24 \%$ & $34 \%$ & $27 \%$ \\
\hline Fish (from Lake Turkana) & $1-5 \%$ & $1-5 \%$ & $5-10 \%$ & $1-5 \%$ \\
\hline $\begin{array}{r}\text { Cooking implements } \\
\text { (aluminium pots, cups, } \\
\text { plates, bowls, charcoal } \\
\text { stoves, knifes) }\end{array}$ & $5-10 \%$ & $1-5 \%$ & $1-5 \%$ & $5-10 \%$ \\
\hline Tobacco & $1-5 \%$ & $1-5 \%$ & $1-5 \%$ & $1-5 \%$ \\
\hline Miraa* & $1-5 \%$ & $<1 \%$ & $<1 \%$ & $<1 \%$ \\
\hline $\begin{array}{r}\text { Household implements } \\
\text { (torches, batteries, } \\
\text { padlocks, ropes) }\end{array}$ & $1-5 \%$ & $1-5 \%$ & $1-5 \%$ & $5-10 \%$ \\
\hline Soap bars and powder & $1-5 \%$ & $1-5 \%$ & $<1 \%$ & $1-5 \%$ \\
\hline Fruits/ vegetables & $1-5 \%$ & $1-5 \%$ & $1-5 \%$ & $1-5 \%$ \\
\hline $\begin{array}{r}\text { Ornamentation (metal }+ \\
\text { plastic bangles, beads, ear } \\
\text { ornamentation) }\end{array}$ & $1-5 \%$ & $1-5 \%$ & $1-5 \%$ & $1-5 \%$ \\
\hline $\begin{array}{l}\text { Engine oil, puncture } \\
\text { repair patches, petrol (for } \\
\text { small-engine motorbikes) }\end{array}$ & $1-5 \%$ & $1-5 \%$ & $1-5 \%$ & $<1 \%$ \\
\hline
\end{tabular}




\begin{tabular}{|c|c|c|c|c|}
\hline $\begin{array}{r}\text { Mobile phone credit } \\
\text { scratch cards }\end{array}$ & $1-5 \%$ & $1-5 \%$ & $1-5 \%$ & $1-5 \%$ \\
\hline $\begin{array}{r}\text { Shukas (large body } \\
\text { wraps) }\end{array}$ & $1-5 \%$ & $5-10 \%$ & $5-10 \%$ & $1-5 \%$ \\
\hline $\begin{array}{l}\text { Footwear (plastic and } \\
\text { rubber tyre sandals) }\end{array}$ & $13 \%$ & $13 \%$ & $5-10 \%$ & $12 \%$ \\
\hline $\begin{array}{r}\text { Clothes (shirts, trousers, } \\
\text { hats, belts) }\end{array}$ & $10 \%$ & $17 \%$ & $15 \%$ & $18 \%$ \\
\hline $\begin{array}{r}\text { Fishing equipment (nets, } \\
\text { hooks, lines, floats) }\end{array}$ & $1-5 \%$ & $1-5 \%$ & $1-5 \%$ & $<1 \%$ \\
\hline
\end{tabular}

* Miraa, or Khat (Catha edulus); a flowering plant chewed as a stimulant. 
Table 5.3. Nakoret market inventories, January 2014-March 2015.

Commodity $\%$ of traders selling commodity on specified date

\begin{tabular}{|c|c|c|c|c|}
\hline $\begin{array}{r}\text { Date of market } \\
\text { (no. of traders present) }\end{array}$ & $\begin{array}{l}01 / 01 / 2015 \\
(58 \text { traders })\end{array}$ & $\begin{array}{l}28 / 01 / 2015 \\
(52 \text { traders })\end{array}$ & $\begin{array}{l}05 / 02 / 2015 \\
(50 \text { traders) }\end{array}$ & $\begin{array}{l}19 / 03 / 2015 \\
\text { (68 traders) }\end{array}$ \\
\hline Maize flour/ wheat flour & $50 \%$ & $58 \%$ & $64 \%$ & $54 \%$ \\
\hline Beans/ peas & $54 \%$ & $63 \%$ & $60 \%$ & $51 \%$ \\
\hline $\begin{array}{r}\text { Salt/ cooking oil/ sugar/ } \\
\text { spices/ tea leaves/ } \\
\text { powdered milk }\end{array}$ & $47 \%$ & $52 \%$ & $53 \%$ & $49 \%$ \\
\hline Rice/ pasta & $36 \%$ & $40 \%$ & $48 \%$ & $30 \%$ \\
\hline $\begin{array}{r}\text { Cooking implements } \\
\text { (aluminium pots, cups, } \\
\text { plates, bowls, charcoal } \\
\text { stoves, knifes) }\end{array}$ & $1-5 \%$ & $1-5 \%$ & $1-5 \%$ & $5-10 \%$ \\
\hline Tobacco & $1-5 \%$ & $1-5 \%$ & $1-5 \%$ & $0 \%$ \\
\hline Fresh milk & $0 \%$ & $0 \%$ & $0 \%$ & $1-5 \%$ \\
\hline $\begin{array}{r}\text { Household implements } \\
\text { (torches, batteries, } \\
\text { padlocks, ropes) }\end{array}$ & $1-5 \%$ & $1-5 \%$ & $1-5 \%$ & $1-5 \%$ \\
\hline Soap bars and powder & $1-5 \%$ & $1-5 \%$ & $1-5 \%$ & $16 \%$ \\
\hline Fruits/ vegetables & $1-5 \%$ & $1-5 \%$ & $0 \%$ & $0 \%$ \\
\hline $\begin{array}{r}\text { Ornamentation (metal } \\
\text { bangles, beads, ear } \\
\text { ornamentation) }\end{array}$ & $0 \%$ & $0 \%$ & $0 \%$ & $1-5 \%$ \\
\hline $\begin{array}{r}\text { Engine oil, puncture repair } \\
\text { patches, petrol (for small- } \\
\text { engine motorbikes) }\end{array}$ & $1-5 \%$ & $1-5 \%$ & $1-5 \%$ & $0 \%$ \\
\hline Herbal medicines & $1-5 \%$ & $1-5 \%$ & $1-5 \%$ & $1-5 \%$ \\
\hline
\end{tabular}




\begin{tabular}{r|cccc} 
Shukas (large body wraps) & $1-5 \%$ & $5-10 \%$ & $1-5 \%$ & $1-5 \%$ \\
$\begin{array}{r}\text { Footwear (plastic and } \\
\text { rubber tyre sandals) }\end{array}$ & $5-10 \%$ & $12 \%$ & $5-10 \%$ & $13 \%$ \\
$\begin{array}{r}\text { Clothes (shirts, trousers, } \\
\text { hats, belts) }\end{array}$ & $5-10 \%$ & $12 \%$ & $5-10 \%$ & $13 \%$
\end{tabular}


Table 5.4. Nakurio market inventories, Jan 2015-March 2015.

Commodity $\%$ of traders selling commodity on specified date

\begin{tabular}{|c|c|c|c|c|}
\hline $\begin{array}{r}\text { Date of market } \\
\text { (no. of traders present) }\end{array}$ & $\begin{array}{l}03 / 01 / 2015 \\
(76 \text { traders) }\end{array}$ & $\begin{array}{l}24 / 01 / 2015 \\
(74 \text { traders })\end{array}$ & $\begin{array}{l}07 / 02 / 2015 \\
(62 \text { traders })\end{array}$ & $\begin{array}{l}19 / 03 / 2015 \\
\text { (56 traders) }\end{array}$ \\
\hline Maize flour/ wheat flour & $68 \%$ & $62 \%$ & $61 \%$ & $57 \%$ \\
\hline Beans/ peas & $64 \%$ & $60 \%$ & $70 \%$ & $62 \%$ \\
\hline $\begin{array}{r}\text { Salt/ cooking oil/ sugar/ } \\
\text { spices/ tea leaves/ } \\
\text { powdered milk }\end{array}$ & $70 \%$ & $52 \%$ & $72 \%$ & $54 \%$ \\
\hline Rice/ pasta & $61 \%$ & $49 \%$ & $69 \%$ & $60 \%$ \\
\hline Fish (from Lake Turkana) & $1-5 \%$ & $1-5 \%$ & $1-5 \%$ & $0 \%$ \\
\hline $\begin{array}{r}\text { Cooking implements } \\
\text { (aluminium pots, cups, } \\
\text { plates, bowls, charcoal } \\
\text { stoves, knifes) }\end{array}$ & $5-10 \%$ & $5-10 \%$ & $5-10 \%$ & $20 \%$ \\
\hline Tobacco & $5-10 \%$ & $1-5 \%$ & $18 \%$ & $1-5 \%$ \\
\hline $\begin{array}{r}\text { Household implements } \\
\text { (torches, batteries, } \\
\text { padlocks, ropes) }\end{array}$ & $5-10 \%$ & $1-5 \%$ & $1-5 \%$ & $5-10 \%$ \\
\hline Soap bars and powder & $1-5 \%$ & $1-5 \%$ & $1-5 \%$ & $1-5 \%$ \\
\hline Fruits/ vegetables & $1-5 \%$ & $<1 \%$ & $0 \%$ & $0 \%$ \\
\hline $\begin{array}{r}\text { Ornamentation (metal+ } \\
\text { plastic bangles, beads, ear } \\
\text { ornamentation) }\end{array}$ & $14 \%$ & $1-5 \%$ & $5-10 \%$ & $13 \%$ \\
\hline $\begin{array}{r}\text { Engine oil, puncture repair } \\
\text { patches, petrol (for small- } \\
\text { engine motorbikes) }\end{array}$ & $<1 \%$ & $1-5 \%$ & $<1 \%$ & $0 \%$ \\
\hline Herbal medicines & $1-5 \%$ & $1-5 \%$ & $1-5 \%$ & $0 \%$ \\
\hline
\end{tabular}




\begin{tabular}{r|llcc}
$\begin{array}{r}\text { Mobile Phone credit } \\
\text { scratch cards }\end{array}$ & $<1 \%$ & $0 \%$ & $0 \%$ & $0 \%$ \\
Ostrich feathers & $0 \%$ & $0 \%$ & $1-5 \%$ & $0 \%$ \\
Spears & $0 \%$ & $0 \%$ & $1-5 \%$ & $0 \%$ \\
Shukas (large body wraps) & $5-10 \%$ & $13 \%$ & $13 \%$ & $14 \%$ \\
$\begin{array}{r}\text { Footwear (plastic and } \\
\text { rubber tyre sandals) }\end{array}$ & $13 \%$ & $5-10 \%$ & $15 \%$ & $32 \%$ \\
$\begin{array}{r}\text { Clothes (shirts, trousers, } \\
\text { hats, belts) }\end{array}$ & $12 \%$ & $18 \%$ & $24 \%$ & $46 \%$
\end{tabular}

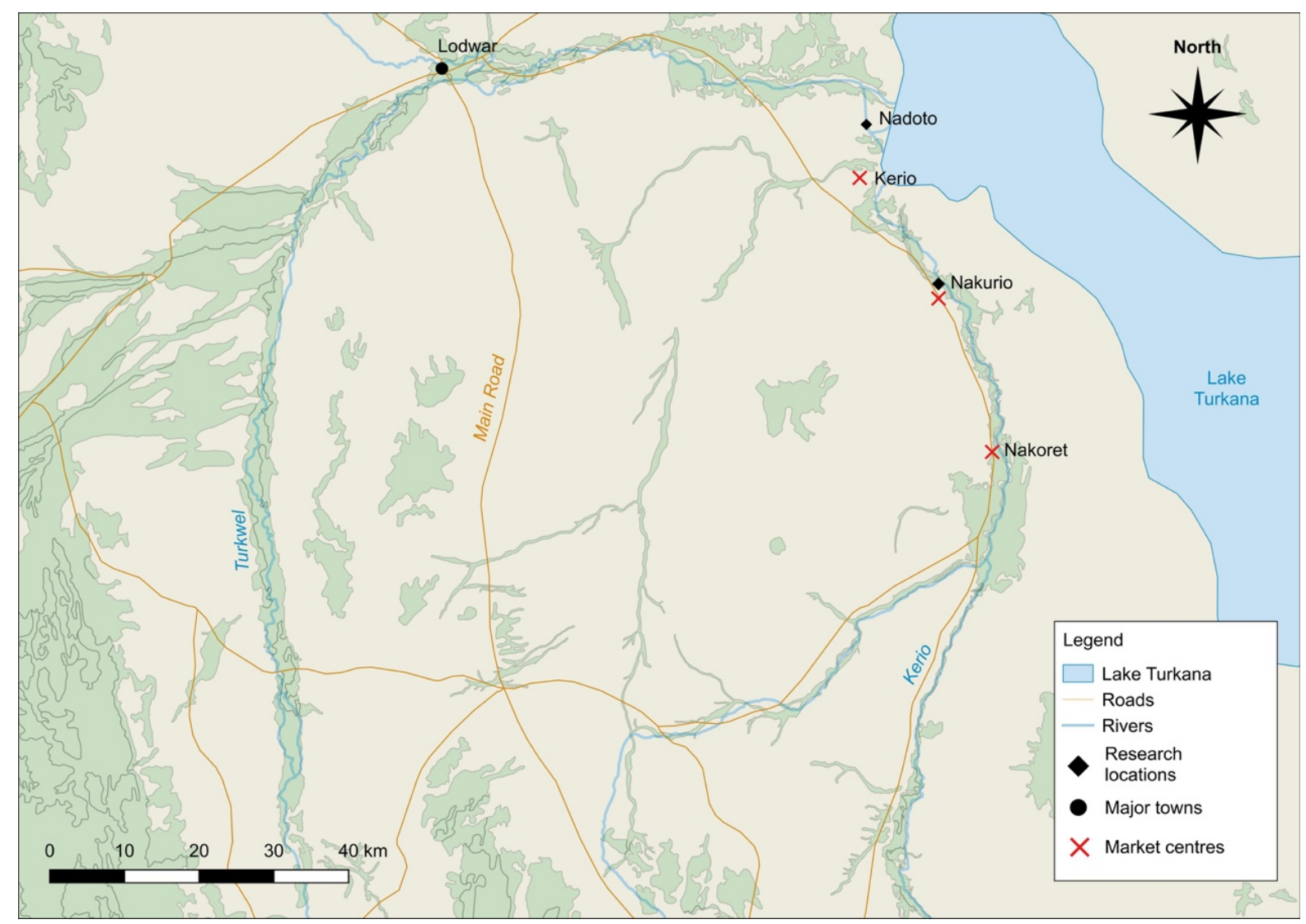

Figure 5.7. Map showing the locations of the markets at which inventories were collected. 
Perhaps the most significant detail that can be garnered from these data is the overarching predominance in traders' stock assemblages of maize flour, wheat flour, beans, peas and a range of other food items. Indeed, on most market days throughout the period represented, between 60 and $80 \%$ of the traders in attendance were selling such foodstuffs, whilst the large variety of other commodities being sold were, for the most part, limited to an array of less than $20 \%$ of the traders. It thus seems clear that, whilst these markets serve to channel a significant variety of commodities to their local clientele, their raison d'être is to provide food items. Indeed, the vast majority of those who utilise them come from herding groups who have altered their grain and legume procurement strategies following the disintegration of the seasonal trade relations with cultivating communities that facilitated their regular acquisition of sorghum in the past. In describing the role of these markets within the herding sector in the present day, Ekuleu Akiru went as far as associating them with 'less starving':

'I have been a herder my whole life, and I have [always] had animals... We move once or twice each year... moving in and out of the river... when there is no rain [we come] to the river... and we leave the elderly and the children behind at the river... Since the roads and the markets [came] people have been able to get money by selling animals, and in the dry months they can buy flour and beans... for this reason there is less starving' (interview with Ekuleu Akiru, Nakurio, 09/04/2015).

The establishment and ensuing function of these markets following the development activities of the 1980s raises a number of key points regarding the transformation of the cultivation-pastoralism relationship over recent decades. Perhaps most centrally, following the disintegration of the seasonal exchanges of sorghum for livestock and pastoralist products that had defined the first half of the $20^{\text {th }}$ century, those involved in cultivation seem to have exploited the infrastructural developments undertaken by the TRP in the 1980s to reshape and reinforce their role within the broader pastoral economy. Indeed, these markets' function of providing grain and legumes to nomadic herders strongly resembles the integral role that cultivators had previously played in the regional system of subsistence interactions. In this 
sense, whilst to a certain extent the emergence of these markets has been implicated in a consequential shift in the daily practices of various communities who had previously predominantly been involved in cultivation, it also represents the remodelling and consequent endurance of an extremely long-lasting system of interlocking livelihood strategies. In response to the increasing environmental unpredictability that has made it less feasible for this system to operate on a seasonal basis or depend on locally produced crops, new markets have served to enable grains and legumes imported from southern Kenya to fulfil the role previously played by local sorghum, and to do so on a year-round basis.

In Nakurio, whilst market trading has become a primary economic pursuit for a large portion of the population, the cultivation of local crops has not disappeared entirely. Rather, it continues as and when possible, with sporadic harvests offering a valuable contribution to the riverside communities' subsistence. In order to maintain and prepare their riverside plots, most cultivators implement the range of tools that have been introduced over recent years in the clearance of etirae (this is discussed in more detail further on). However, these agricultural tools do not constitute the only substantial material or technological shift that has been experienced in recent decades. In her description above of the post-TRP years, Lowasa outlines how the emergence of new markets has come to be associated with the adoption and implementation of a range of other novel materials and items in cultivation practices. For example, rather than large goatskin bags (ngichweei), grain from local harvests is now regularly stored in sugar and cement sacks. These sacks reach Turkana from the south (they are used by market traders to store and transport a wide range of commodities) and have become ubiquitous in small settlements throughout southern Turkana since the 1980s. The same is true of a range of plastic containers and aluminium pots (see Tables 5.2-5.4) which are now regularly employed alongside ngilepito (cylindrical wooden containers) and 
ngatubwae (rectangular wooden bowls) for grain storage, processing and transportation (see Figures 5.8 and 5.9). Lowasa also mentions the now-common usage of palm mats instead of goat skins for threshing (see Figures 5.10 and 5.11).

Such changes in the material conditions of cultivating life in Nakurio perhaps signify the level of intimacy that has come to exist between cultivation and the new trade system, an intimacy that has, to a certain extent, come to supersede the inter-dependence that had previously defined the cultivating-pastoralism relationship. However, these material changes arguably also reflect the opportunism and ingenuity of the cultivators themselves, who have exploited Nakurio's significance in an increasingly extensive commodity network to apprehend new objects and materials that are advantageous to their daily practices. A comparison might be drawn with the development of irrigation-based agriculture over the past few decades in Marakwet, to the south of Turkana in the western Kerio Valley. Recent and ongoing research focused on Marakwet irrigation has demonstrated its temporal resilience by outlining the Marakwet community's capacity for incorporating small-scale technical changes whilst resisting blanket technical and managerial cessation or organisational change (see Davies et al. 2014; Davies and Moore 2016). For example, in recent decades the maintenance of irrigation furrows in Marakwet has begun to include the use of plastic sheeting as a means of waterproofing, and aqueducts (poroi), having previously been constructed using timber, brush and mud, are today almost exclusively fashioned from cement and stone. Far from representing any kind of disintegration of the previous furrow network, these incorporations have served as a means for its reinforcement and expansion. In so doing they have acted to reiterate the centrality of Marakwet water harvesting technologies not only to farming, but also to a wide range of domestic and ritual activities. Like in Marakwet, cultivation practices along the Kerio in Turkana have not been radically impacted 
or transformed by the new materials available through the expanding market network per se, but have instead been strengthened through the selective and opportunistic adoption of certain new materials and items in correspondence with a transforming set of daily economic and ecological challenges.

It would seem reasonable to suggest that cultivation strategies have transformed on a much more substantial scale along the Turkwel where, unlike along the Kerio, seasonal flood recession farming has been comprehensively replaced by a network of formal irrigation systems. However, this radical overhaul in cultivation methods would be crudely interpreted as the straightforward consequence of the introduction of new materials, cultivating implements and seeds (both from markets and development organisations) and the construction of irrigation canals by the TRP (and the later reinforcement of these by the MOA). Rather, these components have attained and preserved both their relevance and their viability within the cultivating livelihood only by means of their continued use by local communities. In other words, if the Turkwel had not become permanent in its lower course following the construction of the Turwel Gorge Dam, the irrigation schemes initially constructed by the TRP would have almost certainly become very quickly redundant (in much the same way as the NORAD scheme did). Signs of such redundancy were already starting to emerge in the years prior to the completion of the Turkwel Gorge Dam. Not only did large numbers of pastoralists return to a nomadic lifestyle when conditions improved, but many of the projects still in operation began to report serious problems from very early on. Cullis and Pacey (1992: 31) recall that 'enormous problems developed... with expatriate volunteers and local site facilitators overwhelmed with routine work and unable to make progress and with people generally unconvinced of the value of what was being attempted.' 
Indeed, the Turkwel has seen a significant migration of cultivators to its banks in the years since the hydrological changes caused by the Turkwel Gorge Dam. These newcomers have actively exploited the canal structures and apparatus left behind from the early TRP schemes to take advantage of the new perennial nature of the Turkwel. This permanent supply of water can, if harnessed appropriately, facilitate a regular and reliable succession of harvests, which serve as the core element in many household economies today. In this sense, whilst cultivation has come to operate in substantially different forms along each river (in response to differing arrays economic and environmental influences), the ways in which change has been enacted over the recent past by the populations along both rivers are closely comparable. In both cases the cultivating livelihood has been actively reworked in line with the respective communities' aspirations, rather than impacted primarily by aspects ostensibly beyond their control. 


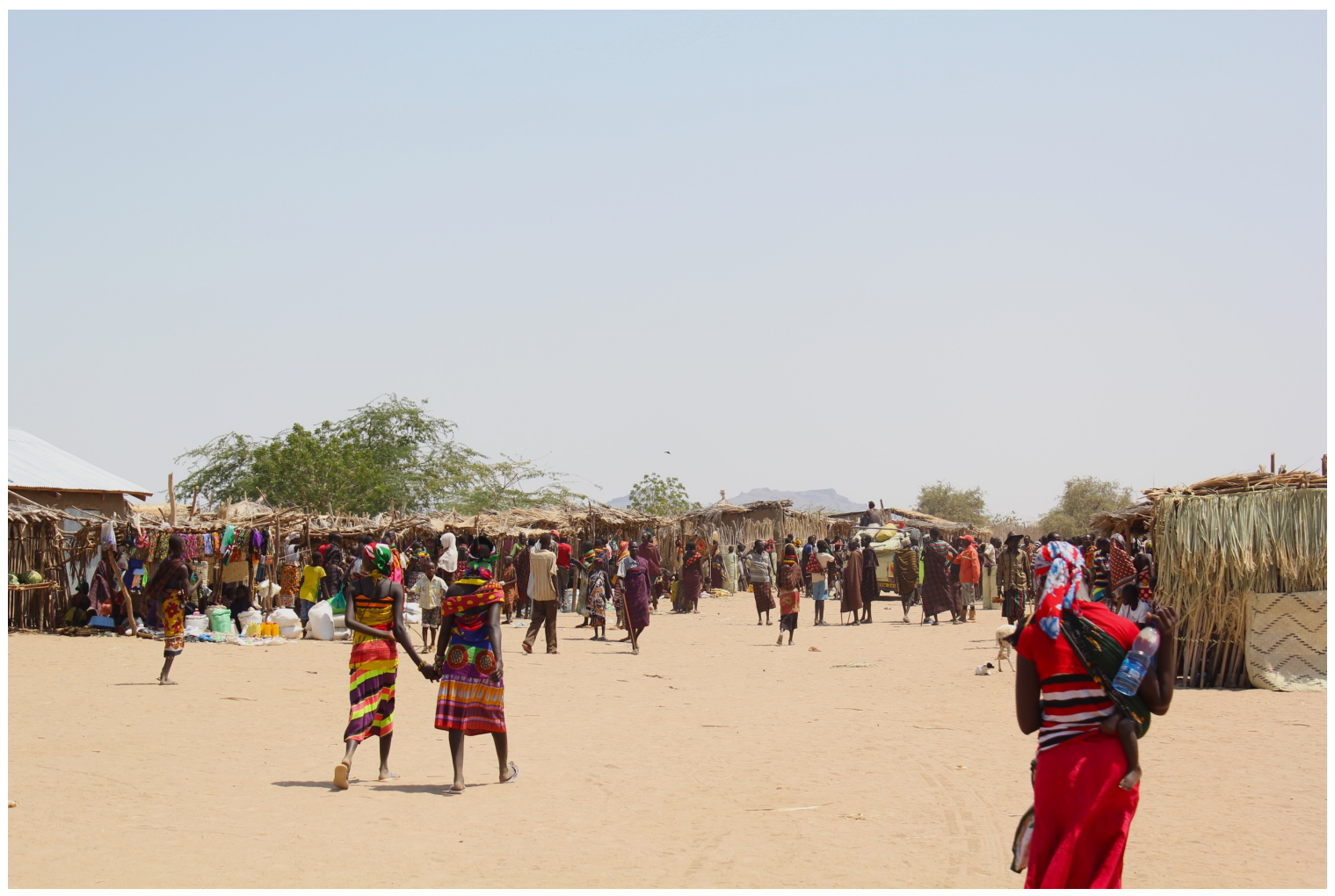

Figure 5.8. View of a market day at Nakurio.

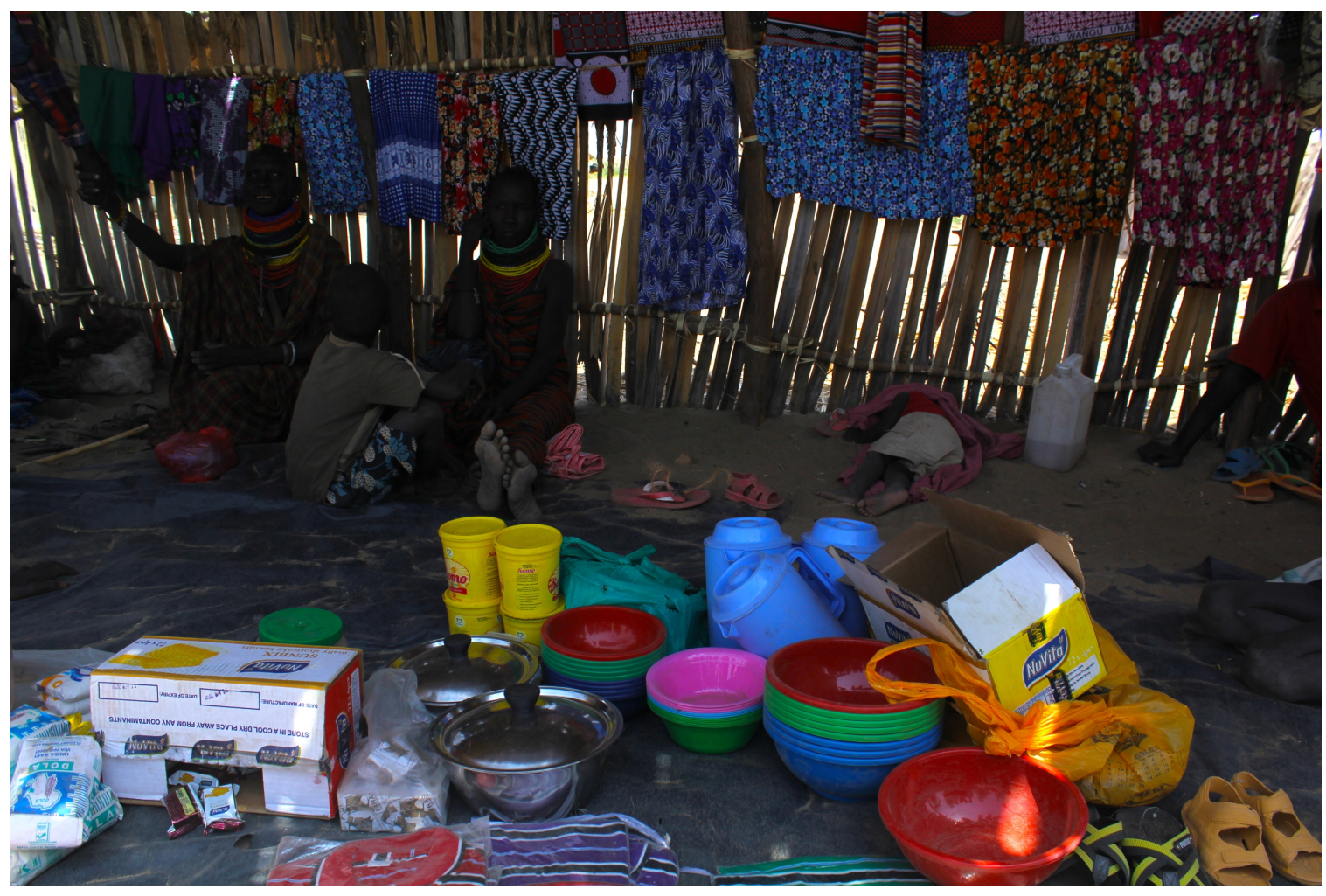

Figure 5.9. A market trader at Nakurio selling plastic bowls, metal pots and other items. 


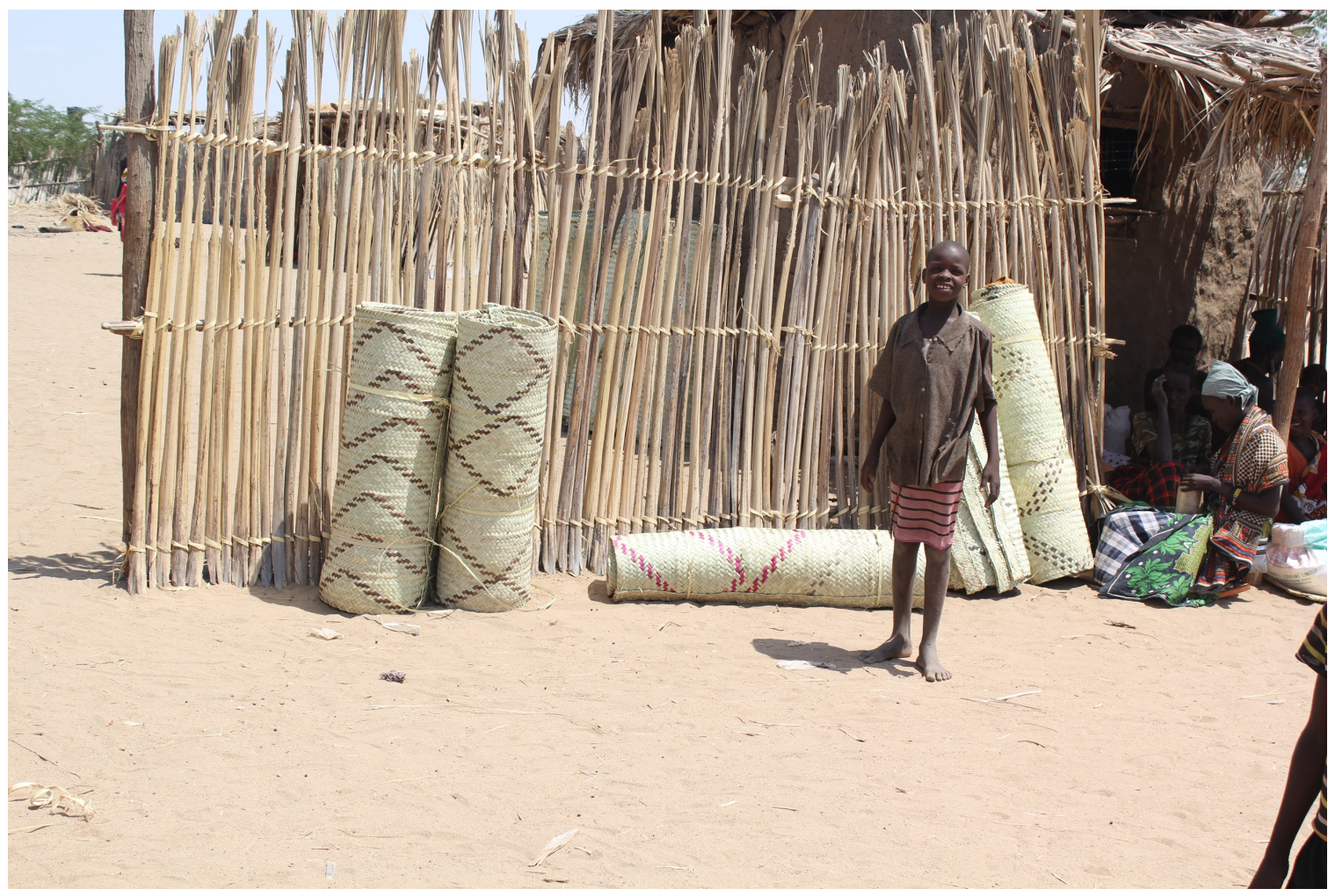

Figure 5.10. Palm mats on sale at a market day in Nakurio.

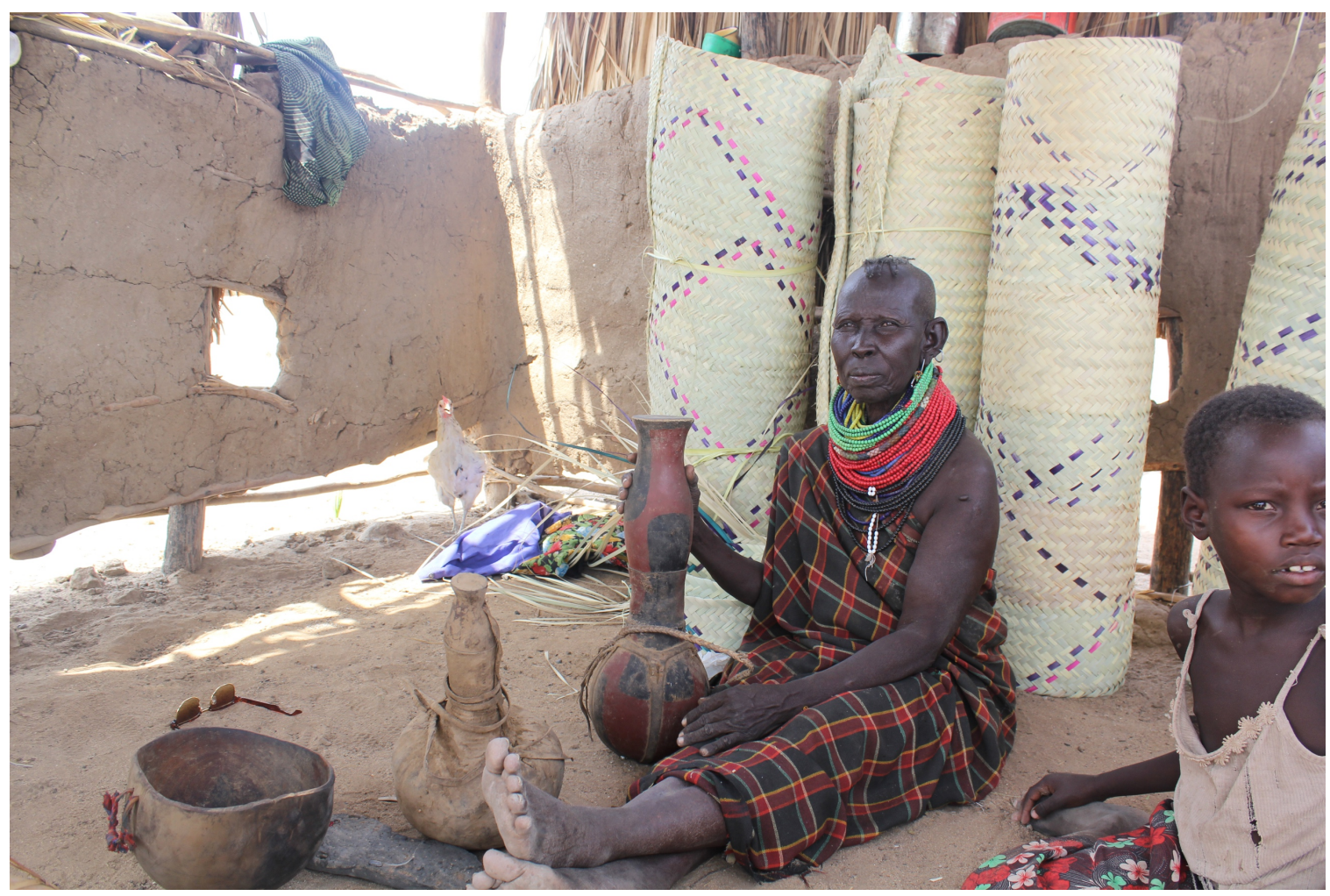

Figure 5.11. A woman from a Kerio cultivating family posing in front of mats she has made to sell at a nearby market. 


\subsection{Palm mats, charcoal and the changing nature of trade}

Significantly, whilst the widespread use of palm mats in Turkana cultivating activities (particularly threshing) is regularly associated with the emergence of commercial markets, group discussion sessions in Nakurio made it clear that this is not because these items initially appeared in Turkana via the markets. It is rather the case that the Kerio cultivating communities themselves began producing plaited palm mats in the late 1980s following the realisation that the new road and transportation infrastructure could support the regular consignment of these items to Lodwar for sale. A significant portion of the cultivating population at Nakurio (and many other locations throughout Turkana) speedily mastered mat and basket production (having no prior experience of these activities whatsoever) using strips of doum palm (Hyphaene thebaica), which grows most frequently along Turkana's major rivers, as a means of capitalising on new regional connections to Lodwar and the rest of Kenya. This new industry has since seen the emergence of a designated trading house in Lodwar, which serves to consolidate basketry items produced throughout Turkana and sell them to traders who channel them to other regions in Kenya. ${ }^{82}$ The emergence of this mat and basket industry has also been of great significance to nomadic herding groups, members of which frequently purchase mats from market centres for a range of purposes, including the construction of makeshift shelters, waterproofing the roofs of palm houses and sleeping.

\footnotetext{
${ }^{82}$ Turkana mats are easily distinguishable from mats made in other basketry producing regions in Kenya. They are unique not only in terms of the material of their construction, but also in the style of their construction and their subsequent form. Unlike along the Kenyan coast (the other major palm mat-producing region in Kenya), where mats are woven together in a spiral from one continuous plaited strip, Turkana mats are constructed in rows of parallel plaited strips. Over the last decade, I have noted their regular use in a range of disparate locations throughout Kenya, including West Pokot, Marakwet and Machakos (where they are also regularly used for agricultural purposes), which underscores both the success of this new industry, and the interconnectedness of Kenya's informal commercial market networks.
} 
Similarly, in more recent years an emerging trade in charcoal has come to occupy a central position in the Kerio cultivating communities' everyday activities (Figures 5.12-5.15). Much like the mat and basket industry, this trade arose through the network of commercial markets that surfaced in association with the infrastructural development undertaken in the 1980s. In Nakurio, despite having recently been made illegal following concerns about deforestation and environmental degradation, charcoal production has become an extremely lucrative pursuit. Using agricultural tools, which in many instances were distributed by development organisations, those occupying riverside plots work to produce charcoal primarily out of etirae. This was initially seen as a useful by-product of the constant clearance that became necessary following etirae's establishment, however more recently it has come to be envisaged as a core livelihood practice that facilitates a regular and reliable cash income when cultivation gardens remain fallow for long periods of time. Lotabo Loruya, a cultivator from Nakurio, explained that:

'The [charcoal] market has got better in the last few years... and trade is much easier. Before, there were very few people burning charcoal, then... after [the increase in] droughts many people started burning charcoal... when this great quantity of charcoal started being produced people communicated to traders and lorry drivers who came to buy in vast quantities' (interview with Lotabo Loruya, Nakurio, 01/10/2014).

Those engaged in charcoal burning pack their produce into the sugar and cement sacks that have become ubiquitous in cultivating communities over the last few decades and pile these sacks up by the roadside to attract lorry drivers who, as Loruya points out, now venture out far beyond Lodwar to acquire their stock (these traders are not from Turkana). Having purchased charcoal in Turkana, tradesmen make their way down to Nairobi with fully loaded lorries (often bribing their way through police check points). They purchase sacks of charcoal in Turkana for between 250-300 Kenyan shillings and sell each sack in Nairobi and other towns for between 1200-1500 shillings, turning a huge profit with each journey they make. Each lorry can carry roughly 300 full sacks of charcoal. Whilst their cut is comparatively 
very small, many of the cultivators at Nakurio described this charcoal trade as currently being their primary means of subsistence, outlining how the cash gained from selling sacks of charcoal to lorry drivers provides them with a means to acquire both livestock from visiting herders, or grain, legumes and other foodstuffs from local markets when they are unable to raise a crop on their riverside plots. ${ }^{83}$ Their local monopoly on this trade is secured by a number of key factors, including proximity to the Kerio and Nakurio market centres, possession of the relevant tools to undertake charcoal production and ownership of private wooded land that is not governed by the usufruct access rights that apply to large parts of the Turkwel and Kerio's gallery forests.

Clearly, the market trade network that arose following the infrastructural development of the 1980s has been utilised and manipulated by cultivating communities along the Kerio in a variety of distinct but overlapping ways. Not only has it served to channel a range of novel materials into cultivation plots and practices, but it has also facilitated the transmission of a set of new commodities (made from materials unique to the cultivators' riverside locations) away from Turkana and into markets further afield. By participating in and actively shaping this dual flow of objects both into and away from the new market centres, the communities along the Kerio have taken advantage of the residues of past regional development projects as a way of diversifying their livelihood strategy. Through their involvement in these markets over the last few decades, cultivating communities have worked to reshape their engagements with the river and re-establish their role in the regional economy as providers of grain and

\footnotetext{
${ }^{83}$ The fact that charcoal production predominantly takes place in cultivation plots which require regular clearance regardless of whether charcoal is produced or not, coupled with the fact that it has come to serve as a key source of income for communities along the Kerio in times of economic uncertainty, underscore how unwarranted the government's recent move to illegalise this activity was. Arguably a heavier regulation of the industry would facilitate the protection of riverine forests for use by herders whilst concomitantly allowing the cultivating communities to attain a more substantial cut of the overall profits of the trade.
} 
legumes to pastoralists. In this sense, whilst the market network does, to an extent, contrast with previous barter and gift exchanges that had taken place between cultivators and herders, it has nevertheless evolved through, and been structured around, a system of livelihood interactions that continues to be articulated in the contemporary world. ${ }^{84}$

The relatively recent emergence of commercial market networks in East African pastoralist regions, and the concomitant commoditisation (or partial commoditisation) of certain assets and goods that has taken place as part of this process, have had far-reaching and complex implications that defy straightforward explanations (Bates and Lees 1977; Dietz 1987, 1993; Zaal and Dietz 1999). In Kenya, such processes have lain at the heart of a fraught political and economic history (at times comprising direct government involvement in pastoralist exchange), which has been inextricably bound up in urban expansion and a growing demand for meat from pastoralist regions in the non-pastoralist sector (although arguably less so in Turkana than elsewhere; see Munro 1975; Raikes 1981; Zaal and Dietz 1999; Fratkin 2001). In this sense, attempting to reach definitive conclusions regarding the diverse costs, benefits and influences of Turkana's developing commercial markets is perhaps unhelpful. Having said this, it is arguably of great consequence that discussions surrounding markets and commoditisation in pastoralist societies seem often to implicitly conceptualise these entities as radically divergent from pre-existing exchange patterns, and even as socially and economically disruptive forces. As Bloch and Parry (1989: 7) underscore in their treatise on money and the morality of exchange:

'there is a tendency to postulate a fundamental division between non-monetary and monetary economies... it is easy to see how this opposition gets elided with a series of other dichotomies - "traditional" and "modern", pre-capitalist and capitalist, gift economies and commodity economies, production for use and production for

\footnotetext{
${ }^{84}$ Pollard et al. (2015) put forward a similar argument about women's tilia exchange relations in Marakwet, and their prevalence in ongoing engagements with commercial markets.
} 
exchange - with money acting as a major catalyst of the "great transformation" between them, or at least as a telling index of it.'

Bloch and Parry's argument about the exaggeration or overstatement of the division between monetary and non-monetary economies builds on arguments put forward by Appadurai (1986), Kopytoff (1986) and Harris (1989). Its broader implications, in terms of perceptions of social organisation and change, are extremely pertinent to Turkana. It is often the case that commodity exchange, much like formal irrigation agriculture, is seen as definitive or circumscriptive of a particular historical era in Turkana, a process that embodies a broader trajectory of social change essentially organised around a dichotomy of 'traditional' and 'modern' practices. This reasoning is clearly sharply out of sync with the time-reckoning of the Turkana cultivators themselves, and their construction and organisation of recent socioeconomic change, as I have outlined above. However, it is also problematic in its more general presumption that emerging pastoralist commercial markets serve only as the embodiments of change that is neither rooted in nor derived from the experiences and aspirations of the local communities involved in their establishment and operation. The case of Turkana's new commercial market network serves as a clear contradiction to such thinking. Whilst determining the extent of its numerous implications over the coming years may not be straightforward, it is clear that such an undertaking will require a consideration of the shifting yet durable dynamics of pastoralism-cultivation exchange and interaction upon which the market network was founded and through which it continues to operate.

In any case, perhaps the most significant feature of the Kerio cultivating communities' response to increasing environmental unpredictability using this new market network, is that it has been both profoundly dissimilar to, and far more successful than, the response of the international development community as manifested in the TRP in the 1980s. In a similar 
way to the fishing communities along the western shore of the lake, who refashioned the remains of the failed NORAD scheme to generate a thriving and adaptive new industry, cultivating communities have capitalised on the perhaps less obvious impacts of the TRP intervention (roads and regional centres) to adapt and bolster their livelihood on their own terms. Where the TRP failed through short-sightedness, parochial planning and a misconception of the core challenges to livelihood security in Turkana, the community at Nakurio has persisted by means of a series of incremental adjustments, rooted in a distinctively long-term perspective, which have ultimately been concerned with strengthening the architecture of the interlocking subsistence strategies that comprise the Turkana pastoral economy rather than radically altering or replacing it.

It should be noted that the community at Nadoto (and indeed many other cultivating communities along the Turkwel) have been substantially less involved in the establishment and running of the post-TRP market network, and the concomitant mat and basket trade, than the Kerio cultivating communities. This is primarily down to the hydrological changes that occurred following the construction of the Turkwel Gorge Dam and the fact that (quite contrary to cultivation along the Kerio) it has become much easier to plan for and predict each harvest. However, despite the differences between the livelihoods employed along the Kerio and the Turkwel, the communities settled along both of these rivers are comparable in their continued maintenance of small herds of goats and sheep, and their enduring links with the broader herding sector through familial connections. Whilst the two livelihoods are no longer directly interdependent to the same degree as they were prior to Ekaru a Atchaka Ekipul, the ecological cycle that underpins pastoralist migrations continues to bring herders back to the major rivers on a regular basis. This is no longer a time for animals and objects to be exchanged for sorghum harvested in riverside plots, indeed it very often does not coincide 
with a sorghum harvest at all. Nevertheless, objects made by herders continue to flow into cultivating homesteads either as gifts to friends and family or through cash purchase. Similarly, cultivators often use this time of mixing to buy livestock from herders (in Nakurio this is done using cash made through the charcoal and mat trade, or trading at local markets).

Thus, despite significant changes in the processes and interactions involved in exchange (vis$\grave{a}$-vis commoditisation and the emergence of commercial markets), the fundamental interconnectedness of cultivation and pastoralism has not been diminished. Importantly, the economic versatility engendered by this enduring relationship continues to serve as a core component of the increasingly regularly employed Turkana drought response strategy (and indeed cultivation continues to serve as a temporary subsistence occupation for herders during times of hardship and ecological stress). In this sense, despite substantial differences in the ways cultivation has developed along each river over the last few decades, the vast majority of cultivators throughout Turkana County are united in their divergence from the development planning of the 1980 s, which advocated mixed agriculture as an alternative to nomadic pastoralism rather than a core component of it. It is only very recently that conceptions of African pastoral economies as inherently unstable and unsustainable have begun to be replaced by calls for their strengthening and protection, following new recognitions of their resilience and adaptability (e.g. Homewood 2008; African Union 2010; Krätli et al. 2013). 


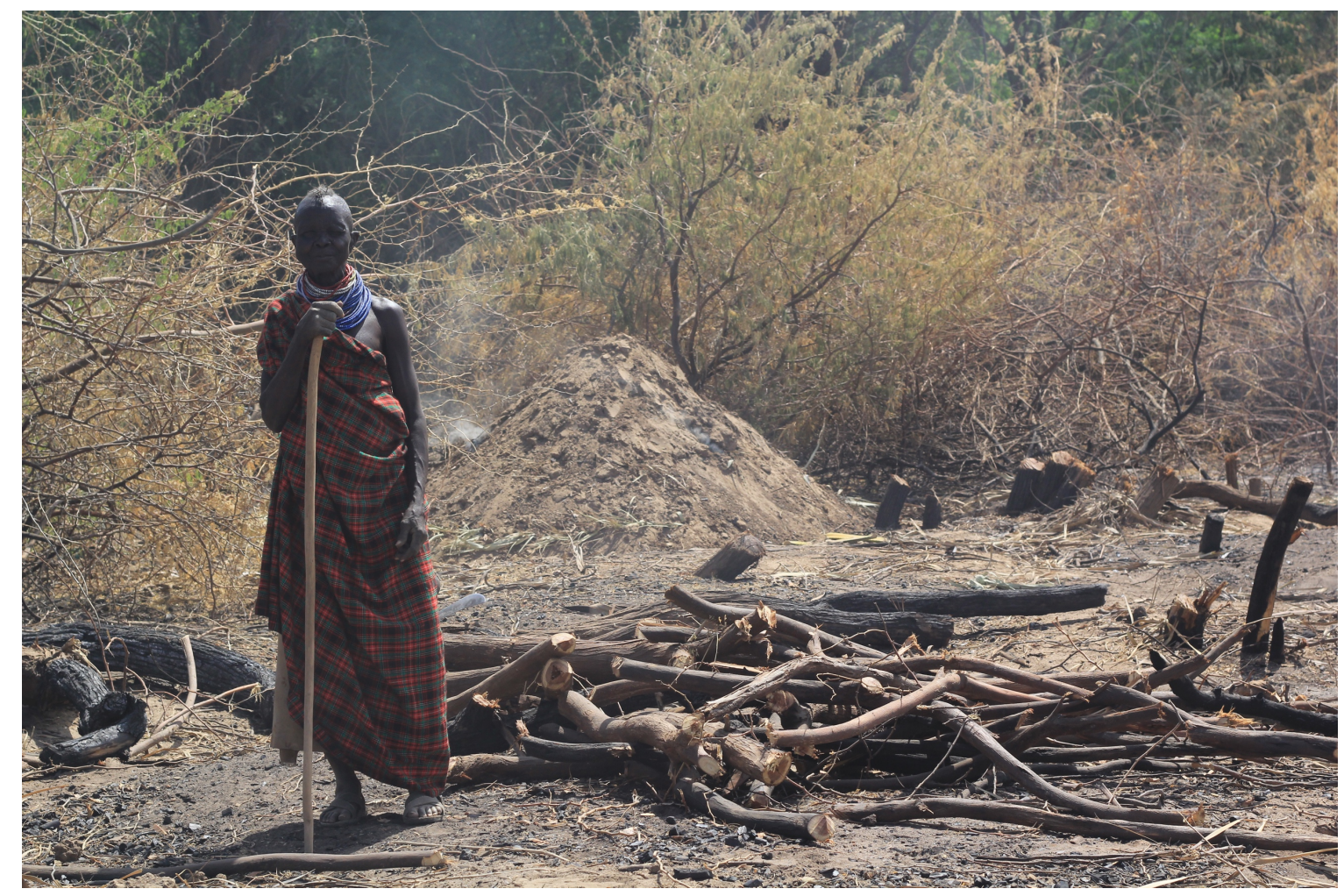

Figure 5.12. Charcoal production in a riverside cultivation plot.

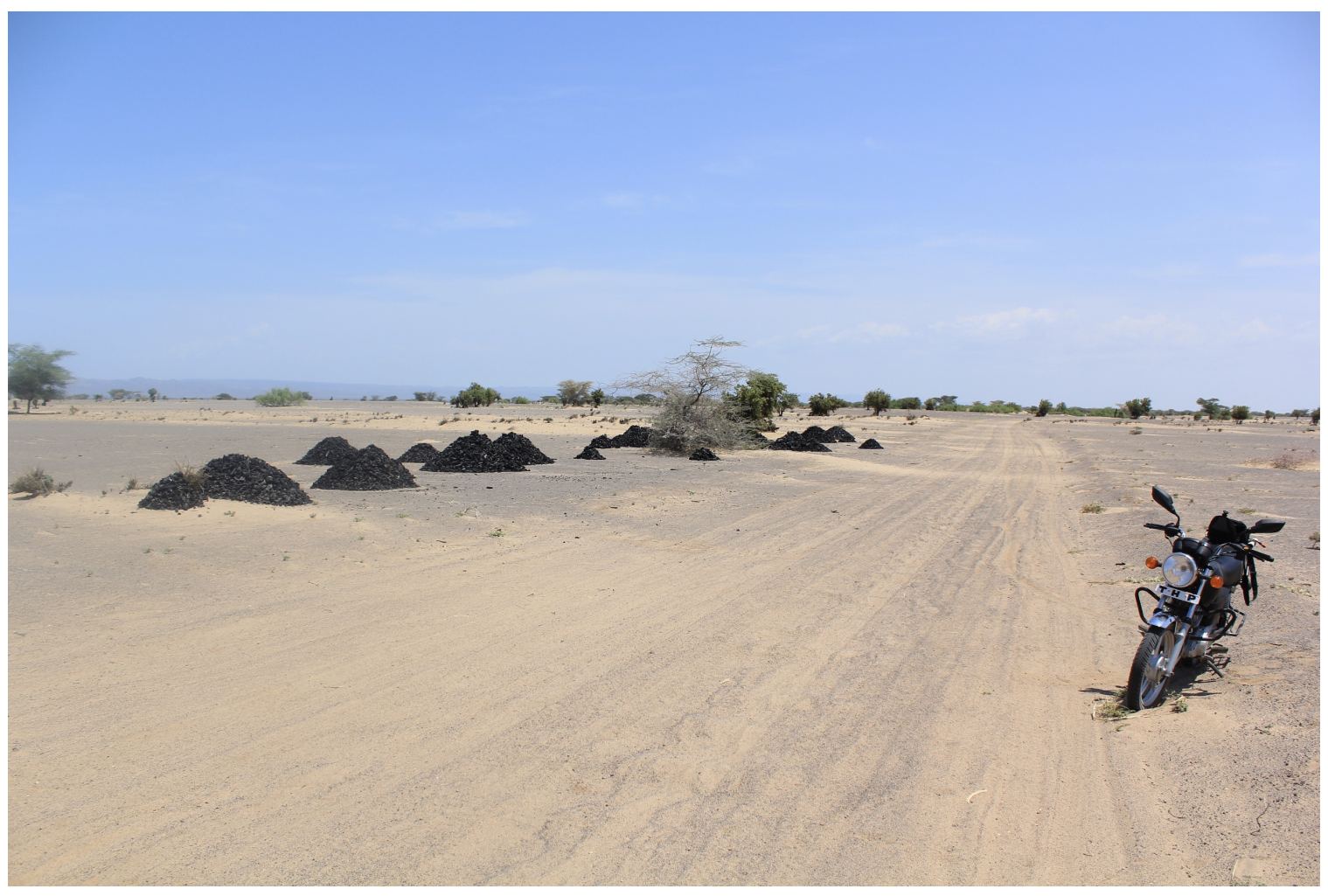

Figure 5.13. Charcoal mounds along the roadside in southern Turkana. 


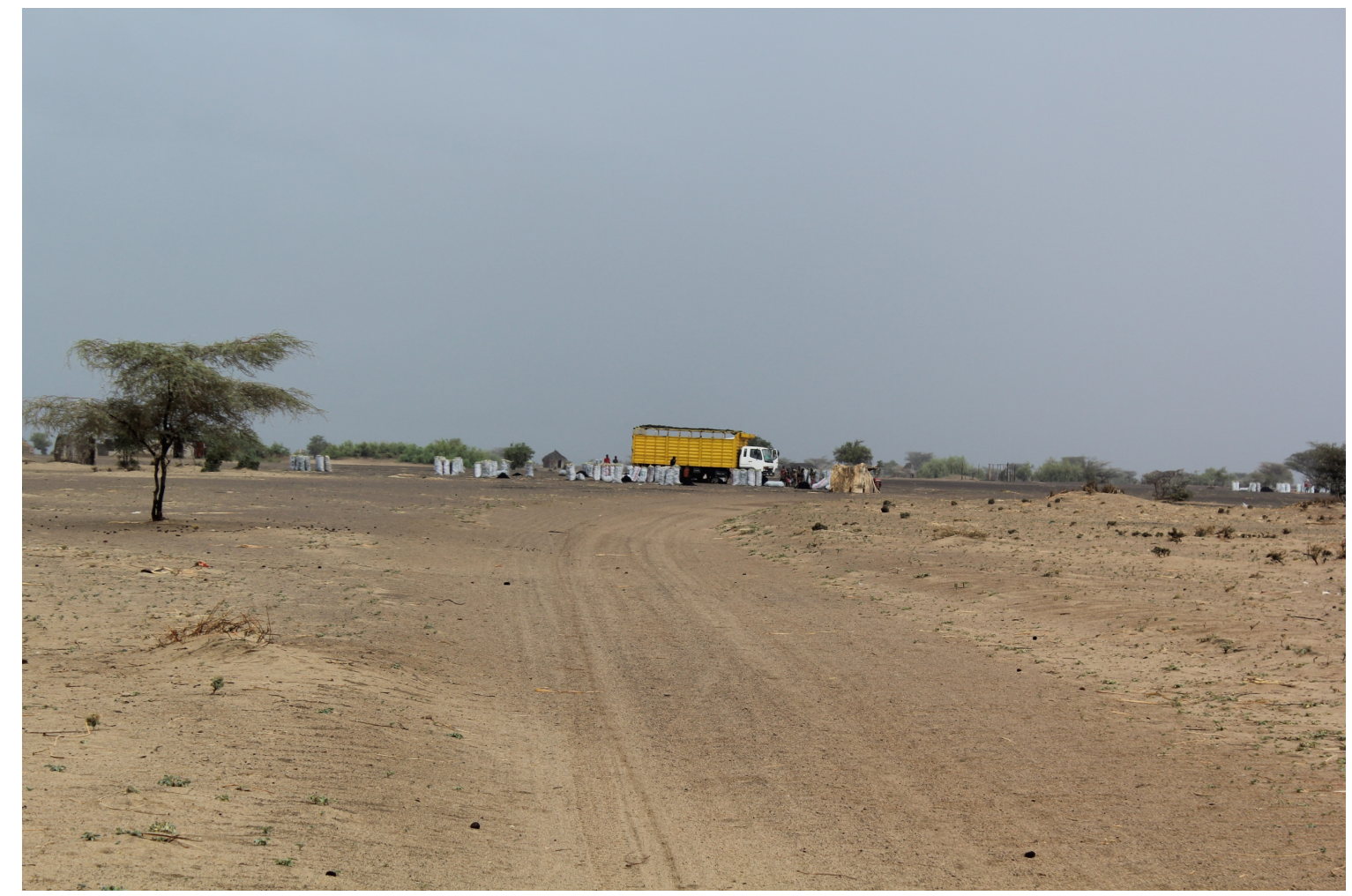

Figure 5.14. A lorry loading charcoal from the roadside for transportation to Nairobi.

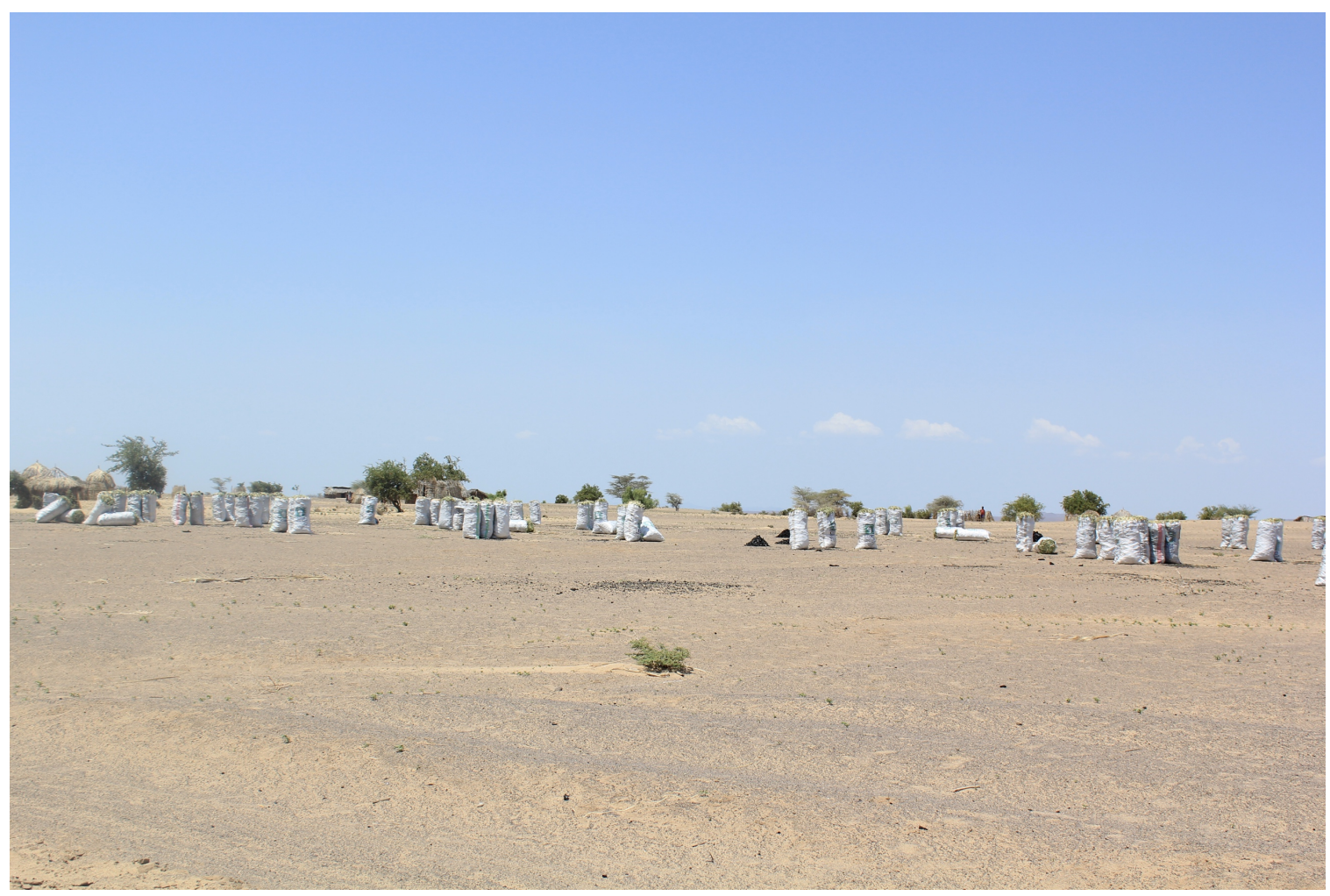

Figure 5.15. Sacks of charcoal produced in riverside cultivation plots are propped up along the roadside awaiting sale. 


\subsection{Summary and conclusions}

Some clear similarities can be noted between Turkana's cultivating communities and the fishing communities that were the subject of Chapter 4 . One key similarity is the fact that both groups have historically been categorised under the same economic term 'ngikebotok' by the wider Turkana population. As I outlined previously, this term is both deeply rooted and widely utilised across many of Turkana's diverse territorial sections, clans and livelihoods as a means of designating rich and poor factions of society. However, the regionwide conceptualisation of wealth to which it pertains, a perspective rooted in and indicative of Turkana's livestock-centred universe of social relations (which is discussed in more detail in Chapter 6), seems often to be misconstrued and distorted by the development community. Whilst the term 'ngikebotok' itself only rarely finds its way into development-related literature, in many cases the underlying and prevalent stigma attached to being cattle-less in a pastoralist society is misinterpreted as being an indication of these groups' intrinsic poverty, destitution and instability. Connected to these assumptions is the perceived need for these groups' drastic socio-economic development in order for their livelihoods to be considered as viable alternatives to pastoralism (which, of course, correlates with the assumption that nomadic pastoralism has no place in the future), and for herders to be enticed into new, more 'sustainable', ways of life.

Indeed, the dominant and implicit conception amongst actors and organisations involved in irrigation development in Turkana that cultivating communities' engagements with Turkana's rivers took (and continue to take) place purely through necessity, or in times of personal or regional crisis, has arguably significantly inhibited understandings of the dynamic role of cultivation in the broader pastoral economy. This failure to comprehend the critical historical 
importance that riverside communities have held as grain producers was without doubt very persuasive during the planning and implementation of the TRP schemes, and must have been partly responsible for the fact that the TRP sought to replace regional systems of interaction, movement and exchange rather than reinforce them. In this sense, the basic lack of contextual information, and the failure to take local experience and knowledge into account during the design and development of the TRP irrigation schemes, bear a striking resemblance to the activities of NORAD at roughly the same time (Chapter 4). Ultimately, both development interventions were largely unsuccessful as a result of very similar over-simplistic interpretations of participating societies and a comprehensive failure to register, and therefore support and assist, the spatial and temporal dynamism, adaptability and ingenuity that characterise everyday life throughout the region.

In much the same way as has occurred in many lakeside villages, cultivating communities have worked to engage with and negotiate large-scale development interventions, and their material and infrastructural legacies, by means of their interactions with the local landscape and ecology (the river), their utilisation of a corpus of locally available raw materials (for example, palm trees and etirae) and their knowledge of and experience with regional trade. Importantly, these core features of the cultivating livelihood have by no means been static or inert throughout the recent past. Their endurance has instead relied upon their fluid renegotiation (by the riverside communities) in response to the dual processes of increasing environmental unpredictability and broad infrastructural and economic transformation. Whilst the cultivating livelihood has itself changed in seemingly dramatic or disruptive ways, these changes have been proactively managed and coordinated by the cultivating communities themselves through a set of unique skills and specialisms. Significantly, these skills and specialisms have been (and continue to be) rooted in the shared temporality 
through which daily river-side practices are constituted, organised and divided. In light of these points, I would posit that the transformations that have occurred both within the cultivating livelihood and within the relationship between cultivation and the broader pastoral economy, are best understood as articulations of a resilience that is both long-established and fundamental.

Importantly, these similar modes and methods of transformation amongst both fishing and cultivating groups have not precipitated the formation of livelihoods that operate in exactly the same manner within the broader social context. Indeed, whilst in many locations fishing represents an economic pursuit that is detached from the pastoral economy, cultivating communities have clearly reconfigured their livelihood to continue functioning as an element within it. Arguably, this further demonstrates the ways in which Turkana communities are able to embed iterative material, technological and methodological changes within a broader sense of continuity and permanence. Cultivation's past role as a core component in the broader pastoral economy, and the history of regular marriage and familial dispersal between livelihoods, have worked to inform the manifestation of this livelihood in the contemporary world. In the same way, fishing has come to operate as an alternative economic pursuit in the region following a history of more pronounced social and economic detachment.

The kind of deeply problematic and routinely unsuccessful large-scale intervention discussed and critiqued both in this chapter and Chapter 4 has perhaps now been consigned to a past era in the history of development practice. It would at least appear to represent a recent past that many development-orientated organisations are currently seeking to distance themselves from. Indeed, the notion of 'sustainability', as championed by many such organisations has, particularly in more recent years, come to encompass more of an emphasis on local strategies 
and histories of adaptation, and as part of this process 'indigenous knowledge' is often promoted as an integral component of development practice. However, Lane (2015) recently identified a range of glaring paradoxes in the ways that this response to past shortfalls in development planning and practice has manifested itself. Of particular relevance to this thesis is his point that the underlying rhetoric of such approaches continues to rest on, and indeed propagate, a stark opposition between 'tradition' and 'modernity'.

In numerous development-related visual tropes and general descriptions of pastoralist societies in the popular press, a form of static cultural resilience is implied that is somehow separate from the more general adaptability of the pastoralist livelihood, and enduringly juxtaposed with 'modern life'. In this vision of contemporary pastoralism, culture is seen as a set of timeless values, institutions and practices around which the trappings of modernity have come to be organised in an almost hybrid manner. As Lane (2015:276) comments, various images and texts insinuate that 'new technologies may be embraced - even happily... but tradition, the fundamental core of society, remains secure'. In attending to the points raised by Lane, Chapter 6, which focuses specifically on herding and raiding, seeks to explore the trajectories and modes of change that continue to be obscured by such idealised, timeless and essentialist images of pastoralist culture. It does so by paying particular attention to the notion of resilience not only as a trait that characterises the pragmatic adaptability of socio-ecological systems over time, but also as a paradigm that explains the equally complex and dynamic processes of community-led transformation that have taken place (and continue to take place) within social institutions, value systems, cosmology, the political organisation of daily life and the construction of identity. 


\section{Chapter 6: Akiyok ka Aremor (Herding and Raiding)}

'It is said that Lokerio walked on his hands and legs... like a baboon, and people say that his body was covered in hair like a baboon. But he was a very powerful emuron [diviner/ seer]... [one day] he dreamed and saw many fat camels living on the other side of the lake [they were] Borana camels. He found... a Ngibilae emuron and he told him "I have seen many camels on the other side of the lake, if you are so powerful do something to get those camels here"... the Ngibilae emuron could not think of any way to get the animals across the lake... he said "I can do nothing"... then Lokerio went to the lake and stood there looking at the water... he took his staff [made from] edome, he used it to hit the water... at this time the waters divided and many Turkanas rushed across the lake to take the camels. When all had come back [with the camels] the waters crashed together. From this time Lokerio became very respected... he was buried in the Lothagam Hills'

- The story of Lokerio and the parting of Lake Turkana to raid Borana camels, as told by Marko Ekeno. ${ }^{85}$

\subsection{Introduction and overview of herding and raiding in Turkana}

The story of the iconoclastic and charismatic figure Lokerio, and his parting of Lake Turkana to allow the raiding of Borana camels, is regularly narrated throughout Turkana today. The contemporary popularity of this folktale is not only a consequence of its fantastical and legendary qualities (although these are, of course, important), but also its encapsulation of some of the key pillars of collective Turkana identity, and its location of these features within a central narrative. The story's main character was a historical figure who rose to prominence in the mid- $19^{\text {th }}$ century, a time when the Turkana were undergoing a process of radical social and political reorganisation following their split from Ateker communities in what is today northern Uganda, and their migration into the region to the west of Lake Turkana. Lokerio was an emuron (plural ngimurok), one of the first of a new genre of powerful diviners who

\footnotetext{
${ }^{85}$ (Interview with Marko Ekeno, Nakurio, 20/04/2015).
} 
emerged in tandem with the escalating conflict involved in the Turkana's southern expansion and the establishment of Eturkan, their current territory (Lamphear 1992, 1993; McCabe 2004). Like the ngimurok who followed him, he was extremely politically and militarily influential and capable of galvanising large military forces, which he deployed in raids against neighbouring groups. To the wider community, it was Lokerio's superlative supernatural power that underpinned his social standing and dominance. Indeed, in the story outlined above his abilities both to see where the Borana camels were and to command the lake to do his will (an ability that a different emuron did not possess) are what encouraged the party of raiders to cross over and take the livestock. Lokerio's influence would have been reinforced both by the gifts of livestock he received from the raiders on their return from the east side of the lake and by the fact that he had proven himself more capable than his competitor (an emuron remembered today only by his territorial section and not his name).

The integration of supernatural power and divination with politics and warfare during the second half of the $19^{\text {th }}$ century was a determining influence in the formation of some of the most central and enduring components of Turkana culture and identity. The aim of this chapter is to examine the ways in which these aspects of 'being Turkana' have continued to be critically influential throughout the $20^{\text {th }}$ century and into the present, and to demonstrate some of the diverse ways in which they have manifested themselves materially and socially through time. Lamphear (1993: 97) describes Lokerio's era as 'a powerful stimulus to the process of Turkana ethnogenesis' and the office of Lokerio in particular as a 'mechanism by which the loose fabric of a widely-dispersed Turkana community could be knitted together'. It was almost certainly during this time that cattle raiding came to be envisioned as a fundamental ingredient in Turkana pastoralism, largely through its role in allowing the Turkana to establish themselves within the territory they currently occupy against several 
bordering groups (Sobania, 1980; Lamphear 1993). Much of the in-depth anthropological and ecological research undertaken in Turkana in recent years has thus emphasised the enduring centrality of livestock raiding and inter-group conflict to the Turkana pastoralist livelihood (Lamphear 1976, 1992, 1993; Bollig 1990; Hendrickson et al. 1996, 1998a; Hendrickson et al. 1998b; McCabe 2004). This chapter builds on these arguments by examining the changing modes, implications and social significance of these practices throughout their continual reinvention over the recent past and illustrating some of the ways in which they have both instigated and embodied far-reaching transformations within political landscapes, economic strategies and the environment. In doing so, it develops the theories of change outlined in Chapters 4 and 5 by exploring resilience not only as a quality that is ingrained in temporally fluid and adaptive grounded livelihood practices, but also as a cultural and political process rooted in, and sustained by, the actions of individual actors as much as by co-operating groups.

The themes covered in this chapter also reflect the specific circumstances of my fieldwork in southern Turkana, and are explored here largely by means of the extensive experience, expertise and historical knowledge of a network of active ngimurok spanning both the Ngibilae and Ngimeturuana clans with whom I worked closely and was in regular correspondence. My position within a Ngimeturuana family and my regular interactions with the wider Ngimeturuana community naturally placed the subjects of cattle raiding and divination at the centre of many conversations, discussion groups and interviews. The Ngimeturuana are known throughout Turkana as the originators of the earliest ngimurok, including Lokerio and his father Epetapus (who is argued by many to be the founder of the Ngimeturuana). Indeed, Lamphear (1993: 97) makes the point that 'in the second half of the nineteenth century it was one's allegiance to the Meturona [sic] (and briefly the Katekok) 
diviners which primarily defined one's status as a Turkana'. On top of this historical significance of the Ngimeturuana, the regular occurrence of armed conflict throughout southern Turkana's border region, and in many of the locations where I routinely conducted interviews and group sessions (including Kangarisae, Nakaalei and Nakoret), also naturally led much of my research pertaining to the pastoralist livelihood to revolve around the subjects of cattle raiding, conflict, divination and amurunot (magic).

As has been the case in the changing practices that have comprised the worlds of cultivation and fishing over the recent past (Chapters 4 and 5), resilience within the social and political institutions implicated in cattle raiding should by no means be understood as a ramification of stability, stasis or equilibrium within the pastoralist livelihood through time. The politics of raiding and conflict in Turkana have, throughout the last century, been intricately embedded in the actions and initiatives of a mosaic of shifting national governments, international organisations and prominent local individuals. Indeed, the dominance of Ngimeturuana diviners and military leaders came to be regularly contested shortly after Lokerio's death by leaders from competing clans. Throughout the first half of the $20^{\text {th }}$ century, Turkana raiding and the broader political economy of which it was a part were deeply affected not only by the regular and widespread conflict of resistance to colonial rule, but also by new structures of governance that actively sought to challenge the legitimacy of local leaders and institutions. In the decades following Kenya's independence, and throughout the second half of the $20^{\text {th }}$ century, livestock raiding and inter-group conflict came to be tightly bound up in and influenced by national politics, peacebuilding and reconciliation initiatives, the activities of numerous missionary organisations and, more recently, the devolution of power from national to local governments. 
The recent history of warfare and raiding in Turkana has also been closely intertwined with the dispersal of small firearms, a phenomenon that occurred most extensively throughout the second half of the $20^{\text {th }}$ century (and primarily in the 1970 s and 1980s). Changing technologies of warfare amongst pastoralist communities both within northern Kenya and throughout northern Uganda, southern South Sudan and southern Ethiopia have not only been implicated in significant shifts in the dynamics of inter-group conflict, but have also been deeply entangled with transformations in regional trade systems (Fukui and Turton 1979; Tornay 1979; Fukui and Markakis 1994a; Turton 1994; Hutchinson 1996). In examining these changes in Turkana weaponry and raiding strategies, and outlining their complex material consequences throughout the last century, the aim of this chapter is not to suggest that the social significance of raiding has remained the same regardless, nor is it to claim that the Turkana are somehow culturally predisposed to war and conflict. Such generalisations are arguably not only inherently misguided but also unscrupulous. They are redolent of early colonial accounts of East African pastoralists, which depicted them as warlike and aggressive for what were almost certainly commercial and political reasons (Jacobs 1979; McCabe 2004) and also evoke the often ethnically charged anti-pastoralist sentiment that has found its way into national and local politics in Kenya on many occasions over the last few decades. ${ }^{86}$ The aim of this chapter is rather to outline how the recent history of raiding and warfare practices in Turkana need not only be understood in terms of devastation, loss and disaster. Whilst livestock raiding and conflict are, of course, usually devastating and disastrous in one way or another, this somewhat perfunctory nomenclature captures only a small fragment of the complex and constantly changing social and political worlds that envelop these practices.

\footnotetext{
${ }^{86}$ Drought-stimulated conflicts and land invasions amongst pastoralist groups in Baringo and Laikipia have recently been afforded wide coverage in the Kenyan popular press. In many of these reports and articles familiar associations of pastoralism with 'primitiveness' and 'backwardness' are prevalent. It seems clear that the current situation is deeply entangled with both county-level and national politics in relation to the 2017 general election.
} 
It likewise does little to reflect the diverse conceptions and experiences of those who are actively involved in or affected by them.

The southern border of Eturkan (Turkanaland) abuts the territory of the Pokot, a group considered by nomadic Turkana herding groups and semi-sedentary communities alike to be a cardinal enemy. During my core fieldwork in Turkana, and on various shorter visits either side, I collected numerous stories and anecdotes (some allegorical and some factual) that centred on warfare with the Pokot at various different times and locations, detailing both particular Pokot raids (and counter raids) and renowned individual raiders. Whilst this folklore and oral history is not analysed extensively in this chapter, its regular recitation and performance in the contemporary world at marriage ceremonies, initiations and other formal and informal meetings is worthy of commentary. Not only does it reflect the importance that continues to be attributed to warfare and raiding in the present day, but it also arguably demonstrates the integral role that the ongoing conflict with the Pokot plays in the constant construction and re-construction of Turkana identity. A comparison can perhaps be drawn between this ongoing Turkana-Pokot conflict and that which exists between the Mursi and the Bodi in the Lower Omo Valley, southern Ethiopia. Indeed, from his own extensive experience of the Mursi-Bodi conflict Turton (1979: 196) conjectures that 'the main function of the periodic wars which take place between these two groups is to precipitate public redefinition of their respective political identities' (see also Turton 1994; McCabe 2004). Turton's notion that identity may emerge through conflict rather than vice versa is extremely persuasive and seems particularly relevant to the subjects explored in this chapter.

The focus of conflict in southern Turkana is, however, far from limited to the Pokot. For several decades herders in the south have been tremendously aggravated by groups of men 
perpetually organised in warrior bands and referred to as ngoroko. These ngoroko groups are ethnically Turkana. In the past they tended to occupy remote hill ranges in the north, but descended south in the 1970s and 1980s to raid the Pokot (McCabe 2004: 101-103). Lamphear (1992) argues that the existence of the ngoroko can be traced back to the $1920 \mathrm{~s}$, when many Turkana warriors fled to remote hill ranges following the end of unified resistance to colonial rule under the leader Ebei (see also Dyson-Hudson 1999: 34). Since migrating to the southern reaches of Turkana, ngoroko groups have maintained a more-orless constant presence there. It was reported to me on several occasions that they are known to demand livestock from Turkana communities for their sustenance, killing any protesters and often raping their wives or daughters (this is also reported by McCabe 2004 and Skoggard and Adem 2010). Importantly, many of those who join these groups in the present day do so for commercial gain, selling the livestock they retrieve from Pokot and Turkana alike to traders for cash. In this sense livestock raiding has, for some, become a livelihood in its own right rather than a core practice within the pastoralist livelihood. Consistent with this, ngoroko communities do not maintain extensive livestock herds and do not migrate in search of pasture like other pastoralists.

There is thus a considerable complexity to raiding and warfare in Turkana, with different kinds of conflict overlapping and imbricating in the present day. When one considers the changing historical relationships between the Turkana and the various groups that surround them (relationships defined at times by war and at others by peace), and the fluctuating violent encounters of the Turkana with both the colonial and Kenyan governments, the scale of this complexity becomes apparent. This chapter is too limited in length to offer a comprehensive account of this mosaic of conflict, however it does outline some of the key trajectories of change that connect the many different events and individuals that comprise it. 
As mentioned above, some of the key data explored in the following discussion are drawn from repeat interviews that I undertook with various ngimurok. However, important information was also collected via a series of large photographic discussion sessions held in Kangarisae, Nakurio, Nakaalei, Nakoret and Kerio, and during one-on-one interviews with herders at a range of locations across southern Turkana (which I undertook intermittently throughout my fieldwork).

\subsection{Livestock, divination and the era of the abuzibuzi headdress}

Livestock raiding and warfare have been central livelihood practices for numerous pastoralist communities in the region surrounding the Omo-Turkana Basin for most of the last century. This area has often been referred to as the 'tribal zone' (Abbink 1993), an appellation that goes some way to expressing the ethos and sentiment of many of the non-local development planners, policy makers and stakeholders who operate there. The inter-group warfare that characterises this region has been the subject of much in-depth research. In South Sudan, conflict between the Dinka and the Nuer was first examined in detail by Evans-Pritchard (1940) and has since been the focus of much debate (Johnson 1982). Discussions of different forms of pastoralist conflict have also worked their way into numerous analyses of the communities that comprise the Ateker cluster spread across both South Sudan and northern Uganda, including the Toposa (Müller-Dempf 2009), the Nyangatom (Tornay 1979; Glowacki and Wrangham 2015), the Jie (Mirzeler and Young 2000; Nannyonjo 2005), the Karamojong (Jabs 2005; Meier et al. 2007; Eaton 2010) and the Dodoth (Mkutu 2007). In southern Ethiopia, Turton's $(1979,1994,2003)$ research into conflict between the Mursi and their neighbours is of particular relevance to interpretations of conflict in Turkana. Not only does Turton outline the role of conflict in the construction and reconstruction of identity (as 
mentioned above), but he also points out the central function of divination in Mursi raiding practices. He describes the reading of animal intestines by 'certain men, with acknowledged divinatory skills, [to] predict the direction and intensity of future raids' (Turton 1979: 190). Of similar importance are Abbink's $(1993,2000,2006)$ analyses of warfare between the Suri and the Dizi, who also occupy territories in southern Ethiopia.

In considering this history of widespread and reciprocal conflict, McCabe (2004: 93) emphasises the fact that this border region has always been at the very 'margin of state influence' (see also Fukui and Markakis 1994b). Its geographical remoteness from administrative centres has led to a de facto exclusion, in many contexts, from intensive government regulation. This limitation of state control in the daily functioning of society has not only comprised a lack of government authority (and in many cases interest) in matters of inter-group violence, but has also engendered a deep distrust amongst the pastoralist communities themselves of state institutions and personnel. Indeed, the national governments of all the countries that extend into this region have historically included very few or no representatives from any of the respective pastoralist groups. It is therefore perhaps unsurprising that on occasions when government forces have intervened in pastoralist conflicts in this region, or indeed attempted to exert control with military force, the sharp social and political discord between them and the local communities involved has often precipitated disastrous consequences.

In Turkana, distrust of the distant national government can be traced back to the earliest interactions with the colonial administration, a time characterised by widespread and recurring violence and devastating livestock confiscations. Having said this, Turkana animosity toward the colonial authorities had most probably developed during the preceding 
decades in response to the earliest European expeditions to the region. Many of the earliest European explorers to reach Turkana, including Count Samuel Teleki (who reached the region in 1888), were reported to have been extremely hostile toward local communities, attacking cattle camps and killing indiscriminately (Lamphear 1976, 1992).${ }^{87}$ By the time the colonial administration had begun its push north from Baringo to establish permanent control in the early $1900 \mathrm{~s}$, much of the male Turkana population had begun to assemble into a large fighting force which, over the years, would be directed in raids and retaliatory attacks against the British by a handful of powerful military leaders. One of the most significant and influential of these leaders was called Ebei, and came from the Ngiesetou section. Ebei featured prominently in many of my interviews and discussion groups and is remembered to have surrounded himself with powerful diviners, who advised him throughout what Lamphear (1976) describes as the 'era of primary resistance'.

Before examining this period of colonial conflict in more detail it is important first to consider the strategies and routines of raiding that both preceded and informed it. As outlined above, the emuron Lokerio is widely regarded in Turkana today to have been one of the earliest leaders capable of galvanising large fighting forces and inciting them to raid the livestock of neighbouring groups with his powers of divination. Whilst none of the leaders of Lokerio's raiding parties are now remembered, his pivotal role in territorial expansion and identity formation via widespread and regular conflict with neighbouring groups to the south in the middle decades of the $19^{\text {th }}$ century was made clear to me during numerous discussions. Importantly, since this early period ngimurok have rarely been actively involved in combat. Their roles have rather been to bless the fortunes of Turkana raiders, to curse their enemies and, perhaps most importantly, to prophesize the location of enemy livestock, the fate of

\footnotetext{
${ }^{87}$ Descriptions of these initial hostilities between European explorers and the Turkana can be found in the early reports of Cavendish (1898), Bright et al. (1902) and Austin (1903).
} 
raiding expeditions and the occurrence of future raids from enemy groups. In payment for advising and directing successful raids, ngimurok are accorded a significant portion of the captured livestock. Indeed, most of the ngimurok I came to know owned livestock herds of an unparalleled size, which were ever-growing in line with the clarity and accuracy of their prophecies. By means of this process raided livestock have, throughout recent history, not only been central to the regional power and pragmatic survival of the Turkana as a whole (especially during periods of drought and disease), but also to individual leaders' establishment of political authority. As many still are today, ngimurok were deeply reliant on regular successful raids prior to the colonial period both as a means of demonstrating their supernatural powers to the wider community and of increasing their own herds, which would in turn facilitate their maintenance of extensive social networks through stock friendships, marriages and gift exchanges.

Following Lokerio's death toward the end of the $19^{\text {th }}$ century, the unity that had emerged during the extensive raids he commanded began to disintegrate. Influential ngimurok throughout southern Turkana began to compete for control of raiding forces and allegiances began to form that divided the population once again. In summarising oral histories that he collected in the late 1960s and early 1970s, Lamphear (1993: 100) describes this process as follows:

\footnotetext{
'After the death of Lokerio in about 1880, a virulent rivalry grew up between his Meturona line and Lokorijam, a challenger from the Katekok clan, who eventually usurped the office by about 1895 . The new line of diviners enjoyed only a short period of unrivalled ascendancy, however, before another bitter feud broke out between the Katekok and yet another contender, Loolel Kokoi of the Pucho clan, in the early years of the $20^{\text {th }}$ century. These rivalries substantially eroded the sense of Turkana corporate unity which had been bequeathed by Lokerio.'
}

Significantly, while the regular conflict and raiding of enemy groups that had correlated with territorial expansion is argued to have been instrumental to the formation of a collective 
Turkana identity several decades previously, by the late $19^{\text {th }}$ century (when most of Eturkan had been established) the politics of raiding seem to have been much more socially divisive. Far from being a contradiction, this illustrates how the social ramifications of and engagements with inter-group conflict in Turkana have always been unsettled, changeable and inherently contingent on both the influence of individual leaders and the broader political context in which such conflict occurs. Whilst the strategies of and rhythms in raiding almost certainly did not undergo radical transformation throughout the second half of the $19^{\text {th }}$ century, their political instability and malleability rendered them capable of engendering both ethnic unity and bitter internal division within a relatively short space of time.

Interviews that I conducted with ngimurok in Nakurio and Nakaalei suggest that the power struggles that ensued following Lokerio's death were both widespread and fierce into the early years of the $20^{\text {th }}$ century. One such interview with Marko Ekeno, a practising emruon and advisor to the chief of Nakurio, followed on from a group discussion that had concentrated on styles of head ornamentation amongst warriors prior to and during the colonial era. Ekeno recalled a story of a rivalry between two ngimurok in the years preceding the conflict with the British colonial forces:

'Before the time of war [with colonial forces], and when many people still were wearing abuzibuzi... there was much competition... [between] ngimurok... it was as though the ngimurok from the Ngibilae believed that they were better than the ngimurok from here, the Ngimeturuana from the Ngiesetou. The Ngimeturuana who were here [Nakurio] believed that they were the most powerful... even though the Ngibilae said that they were cheap... they said that they used honey in their ceremonies and that they asked for very little in return. The ngimurok from the Ngibilae did big ceremonies... they used animals... cows, camels. This dispute between them became very big... there was a war between two powerful ngimurok. One from the Ngibilae called Looya Lodip and one from the Ngimeturuana [of the Ngiesetou] called Kuwam. Each of them [was] using their powers to curse and kill ngimurok from the other side... there was also fighting between them and their followers. The ngimurok of the Ngimeturuana rejected those of the Ngibilae. First, Kuwam cursed all of the people from his own side who were following ngimurok from there [the Ngibilae]... all of them died as a result. Then he began to curse the Ngibilae themselves... he drove his staff deep into the sand at a place this side of Nakoret and he said "you Ngibilae living here will never have a successful life. If you stay here, near to the lake, there will be many crocodiles to eat you. If you live in 
Lothagam there will be many wild animals to eat your livestock." He drove his staff into the ground and cursed that other emuron. Each of these two ngimurok had their own trees that they sat under... when Kuwam put his curse on Looya Lodip, Lodip's tree withered... even the name "Lodip" [to escape/flee] was a name that was given to Looya from Kuwam... this is because there was a time Looya dreamed and saw enemy raiders coming... Looya ran away with his animals to Turkwel, but Kuwam used his power to save his people and called Looya "Looya Lodip"” (interview with Marko Ekeno, Nakurio, $20 / 04 / 2015){ }^{88}$

The deep entanglement of livestock with the politics of prophecy and divination and its attendant capacity for legitimising the ritual activities of ngimurok can be noted in Ekeno's description of how the rivalry between Kuwam and Lodip first emerged. The work of Kuwam and his Ngimeturuana colleagues was branded as 'cheap' in relation not only to the accusation that animals were not constituent components in their acts of divination (which were instead undertaken with 'honey'), but also to the claim that they did not receive extensive livestock gifts as payment for successful raids. Of equal significance is Ekeno's explanation of the centrality of 'cursing' (noun ngilam, verb akilam) in the dispute. As was the case in several other interviews I conducted concerning ngimurok power relations during the early $20^{\text {th }}$ century, Ekeno's story highlights the direct correspondence between an emuron's political dominance and his capacity to cast effective curses (this correspondence is also present in numerous other East African pastoralist communities and is outlined by Mkutu 2008). Importantly, one's ability to cast such curses was (and continues to be) directly reliant on his communion with familial ancestors (ngipen). In inhabiting a realm that straddles human action and $A k u j$ (God), ngipen serve an integral connective and communicative function in any invocation of celestial power and petitions to $A k u j$ must, I was informed by Ekeno, by necessity begin with phrases such as 'Akuj a apa kang' — 'God

\footnotetext{
${ }^{88}$ To clarify, the Ngibilae are a territorial section not a clan, whereas the Ngimeturuana are a clan, hence Ekeno's description of the 'Ngimeturuana from the Ngiesetou' (Ngiesetou is the territorial section here, but there is also a Ngiesetou clan spread throughout the Turkana region). In this account, Ekeno does not reference Looya Lodip's clan.
} 
of my father'. ${ }^{89}$ For this reason, an emuron's supernatural power was (and continues to be) not only contingent on the size of his social network, in the sense that good relations with numerous families in most cases engender the assuagement of their ancestors, but also on his particular family history and the influence and potency that previous generations of ngimurok in his blood line exerted. In the case of Ekeno's description of the rivalry between Kuwam and Lodip, Kuwam's capacity for casting strong curses was indicated to have been a product of his ancestral link to Lokerio, one of the earliest and most powerful diviners.

Ekeno's situation of this story in a time when a style of head ornamentation called abuzibuzi was widespread was prompted by a conversation that had occurred during the preceding group discussion (of which he was a part), but also correlates with descriptions that emerged during several other interviews. It was often explained to me that the abuzibuzi headdress comprised supplementary human hair woven into a long bulk at the back of the head, sometimes coated with clay. In September 2014, during a discussion session in Kangarisae focused on photographs from the early $20^{\text {th }}$ century, abuzibuzi headdresses were picked out in two images featured in Pavitt's (2008: 218) photographic collection from the early colonial period. One discussant explained that:

'Abuzibuzi was most common before the white men came... sometimes it would be made from [the hair of] ancestors, but also friends and family members... People stopped wearing it during the time of [colonial] taxes, everyone wore an apukot during that time' (discussant at group discussion session, Kangarisae, 19/09/2014).

Whilst abuzibuzi headdresses were worn by many into the early colonial era, their gradual disappearance throughout the 1930s and 1940s has led many to associate their widespread

\footnotetext{
${ }^{89}$ There is very little literature that deals exhaustively with Turkana cosmology; the only vaguely accessible publication that pays attention to it is the missionary priest Anthony Barret's (1998) Sacrifice and Prophecy in Turkana Cosmology. Whilst Akuj has, in certain contexts, come to be imbricated with Christian versions of God through the efforts of church and missionary organisations, it is important to clarify that to many (and especially in the context of prophecy and divination) $A k u j$ is not envisaged to have a personality or to be powerful in a politically kingly sense. Rather, $A k u j$ is a force of power attributed in varying contexts to a range of enigmatic natural features, that can be engaged with and harnessed by certain unique individuals (primarily ngimurok).
} 
popularity with precolonial times. Similarly, whilst apukot (plural ngapukoto) headdresses (consisting of two small mounds of packed clay with ostrich feathers; Figures 6.1 and 6.2) were widespread long before the colonial era and worn alongside abuzibuzi, they came to be ubiquitous when abuzibuzi were no longer worn. Descriptions of Turkana head ornamentation can be found in several surviving records from the early colonial period and the last accounts of headwear resembling the abuzibuzi date to the early 1940s, at which point it was attributed primarily to old men. ${ }^{90}$

Some interviewees proposed that the disappearance of abuzibuzi head ornamentation and the concurrent universality of the apukot were part and parcel of the collaboration between territorial sections and clans that emerged during, and followed on from, the Turkana military response to colonial oppression. Indeed, it is more than conceivable that the necessity for broad co-operation amongst warriors and leaders during this time both engendered and was reinforced by a new stylistic homogeneity amongst those in the Turkana fighting force. Whether or not this was the case, it seems clear that military resistance to colonial rule signified the end, or at least the suspension, of much of the discord and division that had characterised the decades following Lokerio's death. Ebei was one of the earliest leaders of this resistance, and early colonial documents record him issuing threats of war to the British post at Kolowa, in the Kerio Valley, as early as 1901. During many interviews and conversations I had concerning Ebei's rise to power, he was described as being under the advice and guidance of two powerful diviners, Oinyo and Lokorijem. Significantly, whilst both Ebei and Oinyo are reported to have been from the Ngimeturuana clan, Lokorijem was from the Ngikatekok and, along with many of his kinsmen, had been engaged in a fierce

\footnotetext{
${ }^{90}$ Eg. S. B. Kittermaster's History of the Turkana from 1911 and J. Douglas-McKean's Notes on Northern Turkhana History from 1929 - both contained in KNA/PRB-DC/Turk/3/1.
} 
rivalry with Ngimeturuana diviners throughout the post-Lokerio years. ${ }^{91}$ His intimacy with and support for Ebei during his leadership against the British is perhaps demonstrative of both Ebei's authority and of the extent of the co-operation between clans and sections that characterised resistance to colonial rule in general.

${ }^{91}$ Like the Ngimeturuana, the Ngikatekok (or Ngikateok) are widely known for producing powerful diviners. I was informed several times that their name stems from the word ngiketeok 'those who see' in reference to the power of prophecy that is common amongst them. 


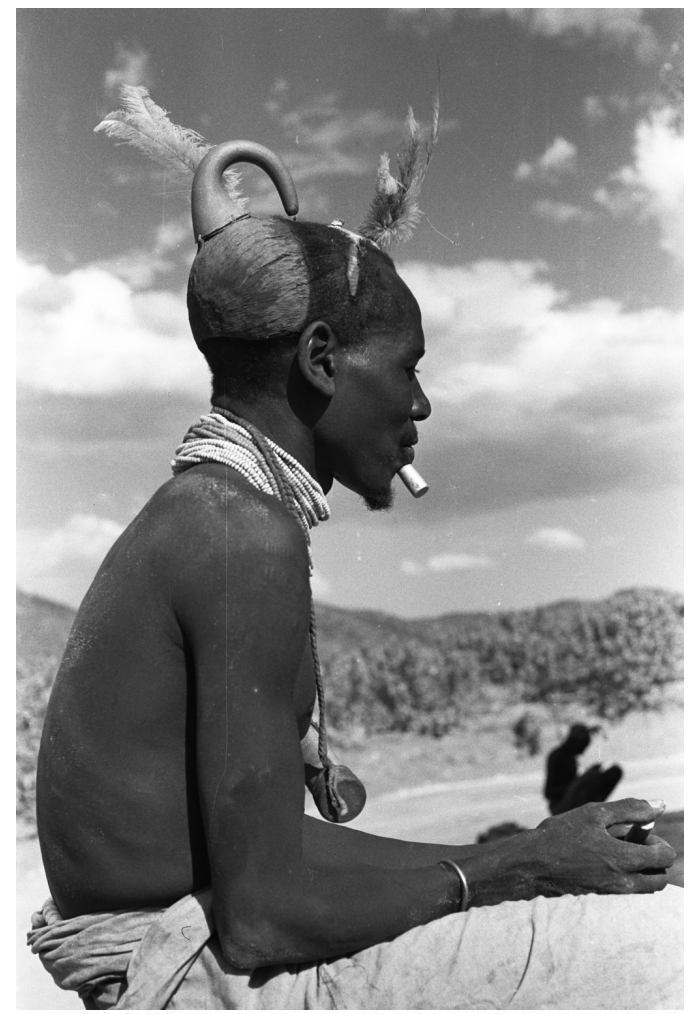

Figure 6.1. Photograph taken by Thesiger on his first visit to Turkana in the early 1960s of a young man wearing a typical apukot headdress. Accession no. 2004.130.30284.1. Pitt Rivers Museum, University of Oxford.

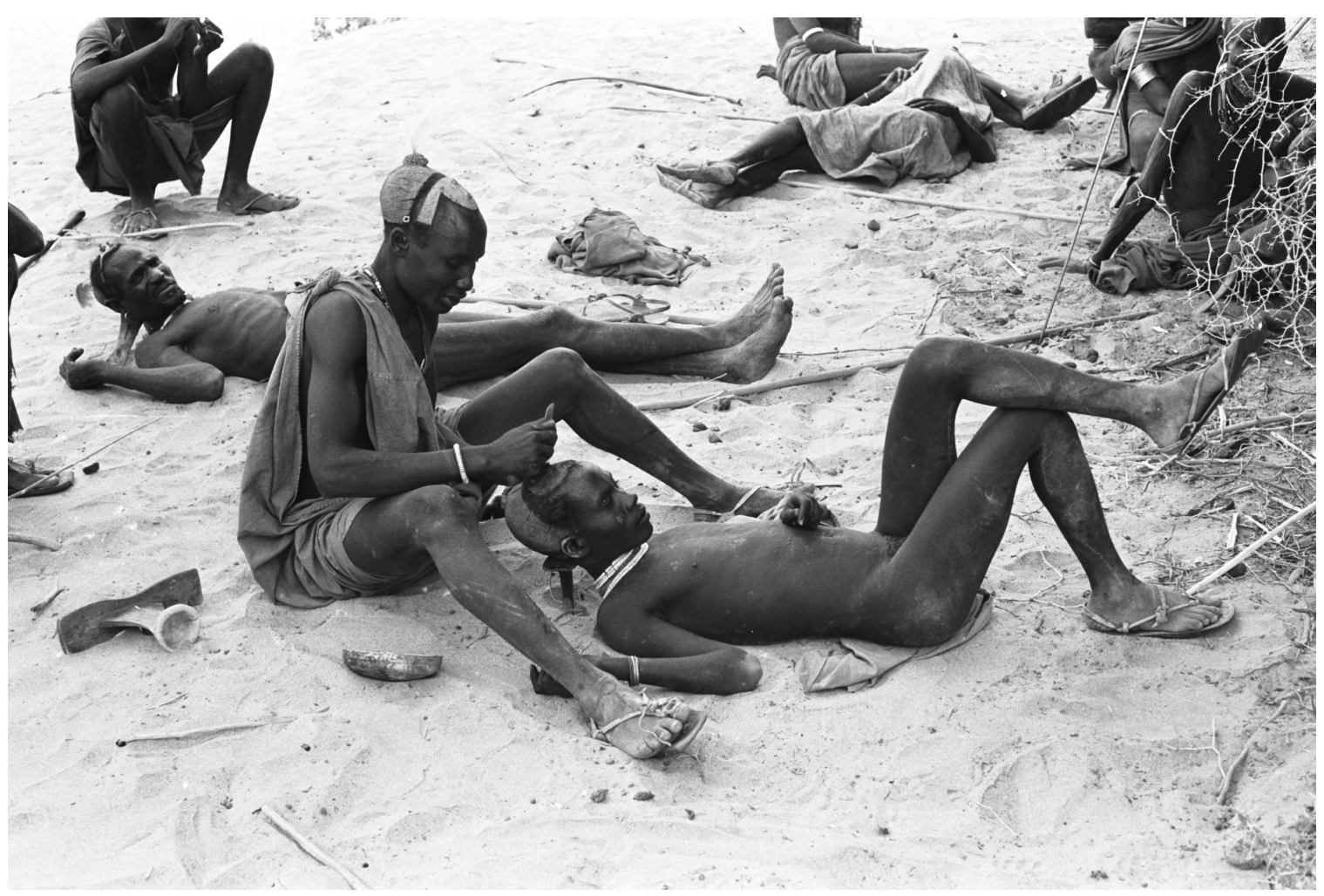

Figure 6.2. Photograph taken by Thesiger in the early1960s of a young man applying his colleague's apukot headdress. Accession no. 2004.130.30280.1. Pitt Rivers Museum, University of Oxford. 


\subsection{Spears, shields and colonial conquest}

Following Ebei's pre-emptive threats (which did not initially come to fruition), the British began their gradual conquest of Turkana in 1906, during which time 'hut taxes' first began to be collected (in the form of livestock).$^{92}$ A general timeline of the British conquest of Turkana is outlined in Table 6.1. The collection of these taxes, along with the more general regular confiscation of extraordinarily large numbers of livestock from communities throughout southern Turkana, unsurprisingly engendered bitter resentment and unrest. This unrest seems to have intensified from 1910 onwards in line with the escalation of British 'punitive' patrols and more sweeping livestock confiscations, activities which lay behind the designation of a year between 1910 and 1915 as Ekaru a Pumpum (the Year of Gunfire). In a report written in 1945, M.W. Kelley describes the confiscation by the King's African Rifles of ' 16,000 Turkana stock in compensation and punishment for Turkana raids' in 1910, and an operation in 1915 during which '407 Turkana were killed and 19,000 cattle, 215 camels, 14,000 donkeys, 17,000 small stock were captured'.$^{93}$ These are only two examples of a multitude of similar incidents that characterised the British campaign to subdue the Turkana, a campaign that ultimately culminated in the 'Labur patrol' or 'Turkana patrol' of 1918. This patrol was a joint operation by the governments of the Sudan and British East Africa aimed at disarming and pacifying the Turkana 'once and for all'. Lamphear (1976: 241) explains that its force was 'composed of 700 regulars, 600 armed levies and huge numbers of porters, drivers and other casuals drawn from East Africa, Uganda and the Sudan' and was equipped with 'heavy weapons including machine guns, mortars and even a field gun' ${ }^{94}$ Following the

\footnotetext{
${ }^{92} \mathrm{KNA} / \mathrm{PRB}-\mathrm{DC} / \mathrm{Turk} / 3 / 1$.

${ }^{93}$ These operations are outlined as part of phase two of Kelley's 'four phases of recent history' in his 1945 report entitled Turkana District (1045-1047) - KNA/PRB-DC/Turk/3/1.

${ }^{94}$ This information is also evident in the 1926 document Reports of the Labur Patrol, Notes on the Merille Patrol - KNA/LR-DC/Turk/8/1.
} 
Labur patrol, Ebei's force was largely disbanded, and along with other influential leaders he was subsequently unable to amass large followings. Taxes came to be collected regularly and systematically either 'in kind' (in the form of livestock) via government appointed headmen, as outlined in Chapter 4, or through labour (primarily road construction in Turkana). ${ }^{95}$

Arguably one of the most significant features of British operations in Turkana during the early $20^{\text {th }}$ century is that colonial policy seems to have very quickly become deeply involved with, and to an extent ensconced within, the prevailing systems of Turkana raiding and warfare that had historically characterised the region. That is to say that, from the outset of their conquest, the British sought to exert control by engaging actively with historical conflicts between the Turkana and their neighbours. Indeed, documents that survive from this time demonstrate that the vast majority of livestock confiscations undertaken by the British were declared to be responses to Turkana raids on Pokot, Samburu and Karamojong communities. The British exerted extreme bias in favour of the Turkana's neighbours by regularly confiscating thousands of heads of livestock as a punishment for Turkana raids (only small percentages of which ever made it back to the neighbouring groups), but rarely responding to Turkana claims or, in instances where they did, returning to the Turkana only a small percentage of the livestock that had been stolen from them. ${ }^{96}$ In this sense, the British subjugation of the Turkana did not take place by means of straightforward military imposition and martial contest, but rather through the calculated manipulation of recursive raids and inter-group relations. Although never explicitly stated in surviving memoranda,

\footnotetext{
${ }^{95}$ Indeed, the 1948 Report on Northern Frontier Province and Turkana mentioned in Chapter 4 (and contained in the Lord Hailey Papers) outlines how 'the chiefs and headmen have begun to collect the poll tax (10/- a head) introduced some years ago... but the system requires improvement, and chiefs are now being given tax clerks' - UKNA/CO1018/24: 2 .

${ }^{96}$ The inequality of British responses to raiding is evident in many early colonial documents, but outlined most clearly in J. Douglas McKean's (1929) Notes on Northern Turkhana History KNA/PRB-DC/Turk/3/1.
} 
letters or reports, it seems highly plausible that this manoeuvring was aimed at reinforcing ongoing inter-ethnic conflicts, and that by acting as (and being envisaged as) a raiding partner of the Turkana's enemies the colonial authorities were not only seeking to cripple the Turkana pastoralist livelihood and economy, but also to impede the possible formation of 'tribal alliances' between the Turkana and neighbouring groups.

Livestock confiscations did indeed serve to dramatically exacerbate hostilities between the Turkana and groups to the south. Critically low livestock numbers drove many groups, including Ebei's following, to raid by necessity on a more regular and exhaustive basis. It is noteworthy and rather revealing that many of those I interviewed in 2014 and 2015 conceived of Ebei as having been primarily a powerful raider, rather than purely the leader of a political resistance movement (as he is often portrayed in reports from the time). Indeed, it seems clear that this latter role was in fact articulated through his command of regular raids which, along with (and to a large extent by means of) his association with powerful ngimurok, served to underpin his authority. Ebei's ability to galvanise regular and extensive raids positioned him not only as the provider of drastically needed livestock, but also as the administrator of retribution against both the Pokot and the British (who were effectively allies). The notion that the colonial government purposefully manipulated the regional politics of raiding and warfare is perhaps further evidenced by the level of detail that is afforded descriptions of these practices in numerous early reports and by the importance that is clearly given to the whereabouts and activities of powerful ngimurok. Not only are ngimurok mentioned both by name and title on a regular basis in many of the surviving documents from this time, but attempts were also made to arrest them and hold them as 'political prisoners'. Such a fate befell a Ngiesetou diviner called Koletiang (who was associated with Ebei) from 1913 until 1919, around the same time that a well-known and influential emuron called Lowallel was 
also arrested. ${ }^{97}$ According to J. Douglas McKean's (1929) Notes on Northern Turkhana

History, Lowallel was charged 'under the witchcraft ordinance' and sent to Eldoret; a handwritten note in the margin of this text records that he died there. ${ }^{98}$

Just as in the preceding decades, the role of livestock as a medium for the expression of political power and dominance was a critical component of the period of colonial conquest and resistance (both for Turkana leaders and the British). Indeed, conversations that I had concerning this period often gravitated toward the point that it was by means of this enduring centrality of livestock to the construction of authority that the raiding of enemy groups and the offices of powerful ngimurok (who relied on livestock in numerous ways for their authority) came to serve as the primary avenues for both diplomatic and military interaction between the Turkana and the British. In other words, the livestock-centred political wrangling of the early colonial era took place in an arena of social action that had its roots in a range of regionally specific processes of authority making. Perhaps the most obvious comparison to be made here is to the rise of Lokerio in the mid- $19^{\text {th }}$ century, whose unprecedented authority was established through an equally unprecedented volume of raiding. Indeed, Lamphear $(1976,1988,1992)$ has likened the emergence of corporate identity that occurred in response to colonial conquest to that which characterised the era of expansion under Lokerio. However, the activities of the early $20^{\text {th }}$ century were arguably also largely informed by the contestations between ngimurok and other clan leaders that had taken place after Lokerio's death throughout the years leading up to the arrival of the British. In a general sense, whilst the violence of the British forces was substantially disruptive and unsettling, and of course

\footnotetext{
${ }^{97}$ Koletiang's arrest is mentioned in several early colonial documents, but is most comprehensively outlined in a letter written by D.R. Crampton about hut tax at some point after 1919 - KNA/PRBDC/Turk/3/1. Crampton explains that 'no Turkana would dare to oppose Koletiang. If any one does so it is firmly believed that either he himself or else his cattle will die' and further suggests that Koletiang had been 'responsible for many raids against the Suk [Pokot]'.

${ }^{98} \mathrm{KNA} / \mathrm{PRB}-\mathrm{DC} / \mathrm{Turk} / 3 / 1$, Lowallel's arrest and death are mentioned on page 283.
} 
directed towards and embedded within the objectives of the colonial project, it also clearly drew on and established itself within a long history of livestock-centred regional conflict.

Direct violent skirmishes between the Turkana and colonial armed forces occurred almost exclusively in immediate association with livestock seizures (both 'punitive' confiscations and forced tax collection). During a conversation with Lomoru Ima, who is without doubt one of the oldest living ngimurok in southern Turkana and a descendant of Lokorijem himself (one of Ebei's advisors), he summarised his knowledge of direct conflict with the British during Ebei’s leadership as follows:

'During that time... there were two who had power, the white men and the ngimurok... My brother walked with Lokorijem... he knew Lokorijem well. Lokorijem was my grandfather. Ebei was under him [Lokorijem] and when things were difficult Lokorijem gave [Ebei] advice... Ebei was very popular [and] very known, he lead many successful raids. I was a child during the time of the British...the raiding was serious and constant, not [like] the little going on today. I was a child... I remember at that time my father [also an emuron] made a prediction, he said "one day the white men will leave. What they have brought here, their things, their houses will stay, but they will leave"... The information I had at that time was that the Turkana were only with spears but the British had guns. Turkana would charge into the British and many would be shot and killed... but many would reach the British and the fight would continue at close range with spears' (interview with Lomoru Ima, Nakurio, 06/04/2015).

Ima clearly outlines the entanglement of Ebei's individual political authority with that of the distinguished ngimurok who surrounded and advised him (in this case particular attention is paid to Lokorijem, Ima's ancestor). Indeed, whilst Ebei was extremely popular throughout Turkana in the early $20^{\text {th }}$ century, and remains one of the most well-known and regularly remembered figures from recent history, his authority was never absolute. The extensive raids he undertook to bolster dwindling livestock numbers after colonial confiscations were, by necessity, directed and blessed by powerful ngimurok. Ebei's reliance on regular raiding both to physically sustain his fighting force and to maintain his political authority meant that these ngimurok were indispensable to him. He was therefore, as Ima points out, 'under' them 
in the chain of command and obliged to follow their advice and guidance in all matters (including direct conflicts with colonial forces). Indeed, Ima begins his account by conjecturing that there were two entities exerting control in Turkana during this time 'the white men and the ngimurok'; others pointed out that both entities were comparable in their command of combat without direct involvement and their receipt of the lion share of livestock from successful raids.

Ima further describes how most in the Turkana fighting force at this time were armed with spears (akwara, plural ngakwara), a detail that is also documented in numerous colonial reports. ${ }^{99}$ It seems clear that whilst some warriors were able to obtain rifles from Abyssinian traders (and this trade is described as a point of concern in some colonial reports) these were comparatively very few. Such rifles were also seized on a regular basis by the British, usually during livestock confiscations, and inventories of these seizures never recorded high numbers (usually fewer than five rifles were taken). Aside from the sheer length of time that the Turkana resisted outright domination using their spears in the face of machine guns, mortars and field guns, perhaps the most compelling detail about their use during this period is that none of them originated in Turkana! During discussions of a selection of Wilfred Thesiger's photographs in Nakaalei and Nakoret it was pointed out that both prior to and during the colonial era spears were predominantly acquired via long distance trade connections with neighbouring groups. In particular, a trade with the Jie and Labwor communities in northern Uganda was outlined on several occasions. ${ }^{100}$ Thesiger's images did not date to the time being discussed in these sessions, a point acknowledged by all discussants, but nevertheless

\footnotetext{
${ }^{99}$ This is made clear in numerous documents contained in KNA/PRB-DC/Turk/3/1, KNA/PRBDC/Turk/3/2 and KNA/LR-DC/Turk/8/1.

${ }^{100}$ The spear trade connecting Turkana communities with the Jie and Labwor was also picked out in Lamphear's (1988: 36) oral histories.
} 
served to elicit knowledge of the early colonial era by means of their comparison to it. Considering the fact that they facilitated the dispersal of spears across a fighting population of several thousand, most of whom carried at least two (a point made regularly by discussants in the sessions at Nakaalei and Nakoret), trade connections such as this one must have been both stable and consistent.

It was also clarified during numerous discussions of weaponry during this period that, along with two spears, most warriors were equipped with a rectangular shield (Aupwal, plural Ngaupwala), and on several occasions I encountered elderly men who still owned shields (although, since the mid-20 $0^{\text {th }}$ century, they have slowly gone out of use). Ngaupwala were roughly body-width and waist-height, made from a variety of animal hides but invariably fastened to a single wooden shaft and adorned with an ostrich feather pompom. A hippopotamus hide shield is stored in the ethnographic object collections of the Pitt Rivers Museum having been donated by Cecil James Juxon Talbot Barton in 1928 (Figure 6.3). A further example is displayed in the collections of the Kenyan National Archives in Nairobi, along with a buffalo hide version also from the early half of the $20^{\text {th }}$ century. Moreover, as mentioned in Chapter 4, a crocodile skin shield collected at some point prior to 1948 is stored in the Turkana ethnographic object collection at the American Museum of Natural History in New York. ${ }^{101}$ During discussions of these examples and others in 2014 and 2015 it was generally agreed that a significant portion of the shields used by warriors from southern territorial sections during the era of resistance to colonial rule had been derived from the internal exchange network that existed between herding and fishing communities throughout

\footnotetext{
${ }^{101}$ The shields in the Kenyan National Archives are on permanent display in the main exhibition hall. The crocodile skin shield at the American Museum of Natural History has catalogue no. 90.1/8255.
} 
the early decades of the $20^{\text {th }}$ century (as explored in Chapter 4), although it was also clarified that many were made from buffalo, elephant and rhinoceros hides.

A closer consideration of the primary weapons employed by the Turkana during the early decades of the $20^{\text {th }}$ century thus sheds light on characteristics of this era that are perhaps often eclipsed by its definitive political turbulence. Clearly, despite the accelerating conflict and unrest, the regular movements and interactions that underpinned exchanges between lakeside fishing communities and inland herding groups persisted. In fact, it is highly likely that the increasing regularity of both incoming and outgoing raids actually stimulated more intensive interactions between these two divisions of Turkana society than had previously been common. Thus, rather than serving purely to disrupt and disorganise the routines and practices that had been established in Turkana following the territorial expansion of the mid$19^{\text {th }}$ century, colonial conquest and conflict also comprised a partial framework for their endurance and development. In this sense, perhaps Turton's $(1979,1994)$ arguments (mentioned above) about the role of conflict in the formation of ethnic identity are not limited to the political, semantic and symbolic manifestations of violent engagements with a common enemy; they might also be explored in the materiality of social relations away from the 'front line'. In the case of Turkana shields, escalating warfare was the overarching context for increased cooperation and reciprocity between the fishing and herding livelihoods. The construction, movement and use of these objects were likely to have been processes that both created and expressed a closer involvement between the various clans and territorial sections spread throughout the eastern half of Turkana. This point connects both with arguments made previously about the mutually informative relationship between identity and material culture in western Kenya (Hodder 1982) and with more recent analyses of objectification as a core 
feature of personhood (see Miller 1987; Chapman 1996: 206-210; Tilley 2007b). This latter

notion is perhaps most clearly outlined by Fowler (2010: 8), who states that:

'the practices by which people make things, live with them, and use them also make those people, so the process of objectification is also a process of personification. Identities are produced out of ongoing interactions between people and things, not just different groups of people'.

Considering the ways in which things make people, and by extension collective identities, is also crucial to understanding the role of spears during this time. The long-distance trade of these items clearly indicates that the Turkana were not as insular as the growing hostilities between them and many of their neighbours would imply. Indeed, the diverse and widespread conflict of this period was actively sustained not through isolation and detachment but rather through enduring trade routes that connected the Turkana with communities in northern Uganda and facilitated the dissemination of weapons throughout the region. Arguably, experiences of spear exchange, and thus recurring contact with individuals and communities from neighbouring groups, would have been as influential to their owners as experiences of their use in battle against the British. The re-emergence of Turkana corporate identity in the early $20^{\text {th }}$ century was thus embedded in and formed through inter-group cooperation in the north-west as much as it was through violent conflict with the British and other groups elsewhere. Significantly, and somewhat surprisingly, inter-group trade networks were also extensive in the south. Despite the system of recursive raiding that existed between the Turkana, the Pokot, the Karamojong and the British, many of those I interviewed in 2014 and 2015 expressed knowledge of a parallel southern trade network that comprised regular exchanges not only with the Pokot and the Samburu, but also with the Marakwet. Many pointed out that this trade in commodities such as salt, tobacco, livestock and neck ornaments was able to exist alongside intensive inter-group conflict because automatic weapons were not widely possessed at this time and conflict was predominantly confined to large group 
forays and defensive clashes leaving individual traders and families relatively free from danger. Intimations of its existence can found in several early colonial documents. For example, J. Douglas-McKean (1929) mentions 'two Suk [Pokot] traders' who were met as far north as Kerio in 1911. Moreover, the North Turkana and Turkana District Annual Report from 1926 notes that 'many went last year to Marakwet to buy their own tobacco'. ${ }^{102}$

Ebei's leadership, and resistance to colonial rule in general during the early $20^{\text {th }}$ century, were thus not only entangled with the general intensification of different forms of regional conflict, but also with the invigoration of a range of interlocking exchange systems and networks. As I have outlined above, the re-emergence or reinforcement of Turkana corporate identity during this time was a process that comprised and articulated various resilient forms of conflict/livestock-centred authority construction. However, it can also clearly be understood in terms of the inter-clan, inter-section and inter-ethnic co-operation and reciprocal action that were necessary to sustain the exchange networks that made accelerating conflict materially possible. In being constituted by the material conditions of war as much as by acts of war themselves, identity emerged through violent interactions and peaceful exchanges in equal measure. This does not mean that the role of conflict in identity formation during this time should be doubted, but rather that the ways in which these two processes were interwoven (in terms of the networks of people and objects that comprised them) were as elaborate, pervasive and complex as they were longstanding. In the following section I explore the development of raiding following Ebei's death (which occurred in 1924 during a conflict with Daasanach communities in the north) and the end of the resistance movement in which he was involved. I examine the initial widespread incorporation of firearms into

102 KNA/PRB-DC/Turk/3/1 (Douglas-McKean's report) and KNA/TDAR-DC/Turk/1/1 (the 1926 annual report). 
raiding practices and the changing relationship between pastoralism, raiding and range of different exchange systems and trade routes throughout the middle decades of the $20^{\text {th }}$ century.

Table 6.1. Timeline of the British conquest of Turkana.

\begin{tabular}{|c|c|}
\hline 1905 & $\begin{array}{l}\text { - District commissioner of Baringo travels down the Kerio River } \\
\text { into southern Turkana, British administration officially } \\
\text { established. } \\
\text { - Hut taxes are collected by the end of the year. }\end{array}$ \\
\hline 1910 & $\begin{array}{l}\text { Lobwin, a southern Turkana leader, is arrested and taken to } \\
\text { Nairobi. } \\
\text { livestock confiscated by British in compensation and punishment } \\
\text { for Turkana raids. Confiscations amount to over } 16,000 \text { heads of } \\
\text { livestock. }\end{array}$ \\
\hline 1911 & $\begin{array}{l}\text { - Regular and intense raids between Pokot, Karamojong, Samburu } \\
\text { and Turkana. }\end{array}$ \\
\hline 1912 & $\begin{array}{l}\text { - Ebei refuses to cooperate with colonial officials and encourages } \\
\text { his followers to refuse paying taxes. The emuron Koletiang does } \\
\text { the same. } \\
\text { - Ebei leads raids against Pokot, Samburu and Maasai. } \\
\text { - Unpaid tax collected by force by British. } \\
\text { Bands of Turkana around the Loriu Hills yield } 175 \text { cattle, } 25 \\
\text { donkeys, } 75 \text { camels and } 200 \text { sheep/goats, all of which are sold at } \\
\text { auction by the British. }\end{array}$ \\
\hline 1913 & - Koletiang and Lowallel arrested. \\
\hline 1914 & $\begin{array}{l}\text { - Southern Turkana clans engaged in heavy raiding of } \\
\text { Karamojong and Pokot. } \\
\text { - General hostilities toward colonial authorities reported. } \\
\text { - Hut tax is collected throughout Turkana without major incident. }\end{array}$ \\
\hline 1914-1915 & $\begin{array}{l}\text { - No hut tax collected throughout Turkana because of Turkana } \\
\text { hostility to colonial forces. }\end{array}$ \\
\hline 1915 & $\begin{array}{l}\text { - 'Punitive patrol' undertaken with the aim of (1) capturing Ebei, } \\
\text { (2) disarming any armed individuals and (3) punishing the } \\
\text { population for previous hostiles. } \\
407 \text { Turkana killed, } 86 \text { wounded, } 63 \text { captured. } \\
\text { - Livestock confiscations amount to } 19,403 \text { cattle, } 8262 \text { camels, } \\
6868 \text { donkeys and } 123,273 \text { sheep/goats. }\end{array}$ \\
\hline
\end{tabular}




\begin{tabular}{|l|ll|}
\hline 1916-1917 & $\begin{array}{l}\text { Resumption of hostilities. No hut taxes collected again } \\
\text { throughout Turkana. }\end{array}$ \\
\hline 1917 & $\begin{array}{l}\text { Heavy and extensive raids undertaken throughout the year by } \\
\text { Turkana, particularly on Pokot. Raids are primarily led by Ebei. } \\
\text { - }\end{array}$ & $\begin{array}{l}\text { Turkana take an estimated 13,000 head of cattle. } \\
\text { Thousands of warriors are involved, Turkana force splits into } \\
\text { two parties. One party is intercepted and fought by British } \\
\text { forces. }\end{array}$ \\
\hline 1918 & $\begin{array}{l}\text { Labur patrol, the largest of all punitive expeditions mounted by } \\
\text { the British. } \\
\end{array}$ & $\begin{array}{l}\text { Massive livestock confiscations and disarmament. } \\
\text { - }\end{array}$ \\
\hline 1919 & Administration of Turkana taken over by military authorities. \\
\hline 1924 & Ebei killed in conflict with Merille (Daasanach) \\
\hline
\end{tabular}

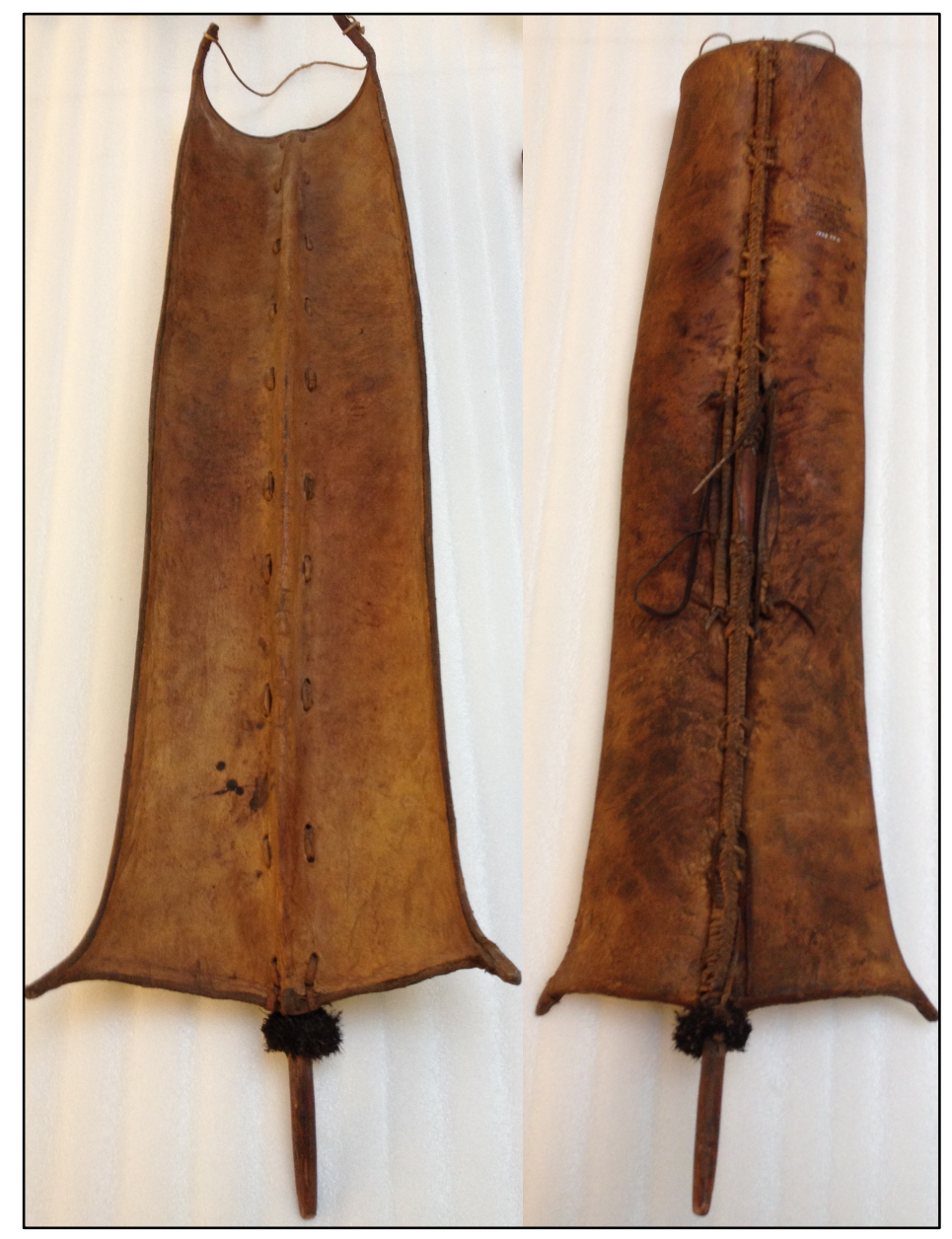

Figure 6.3. Turkana shield collected by Cecil James Juxon Talbot Barton and donated to the Pitt Rivers Museum in 1928. Left — front, right — back. Accession no. 1928.22.2. Pitt Rivers Museum, University of Oxford. Photographed on 21/02/2014. 


\subsection{Guns, cloth ngapukoto and Ekaru a Ngatuk a Nakirionok (the Year of Black Cows)}

So far, this chapter has outlined some key aspects of the changing politics of raiding and warfare during the late $19^{\text {th }}$ and early $20^{\text {th }}$ centuries in Turkana. In exploring the historical context of the British incursion into Turkana, and the ensuing dynamics of conflict between British and Turkana forces, I have indicated that the unrest of the early colonial era need not necessarily be conceptualised as an inherently disruptive process in terms of its implications for local social and political institutions. Whilst widespread violence, cattle confiscations and escalating warfare on multiple fronts were undeniably extremely disruptive and distressing in an immediate sense for many of the Turkana individuals and communities who were involved, it also seems clear that these activities were engaged with by means of, and came to be deeply intertwined with, an assortment of prevailing values, practices and systems. These ranged from livestock's deep interfusion with authority and its associated role in political contestations to the centrality and social importance of raiding, and from the long-distance trade networks connecting the Turkana and their numerous neighbours to shorter distance exchanges occurring between communities involved in different livelihoods within Turkana.

This is not to say that the social and political structures in which the Turkana pastoralist livelihood was embedded were entirely unaffected or unchanged from the time of the establishment of Eturkan through to the significant transformations experienced in the early colonial times. Nor is it to suggest that the systems of production, use and exchange that permeated it persisted through the years passively or statically. To the contrary, these interconnected worlds modulated to absorb and actively define numerous different political processes occurring at a range of scales and with diverse stimuli. The key point is that, whilst the British ultimately succeeded in their attempts to coerce a large portion of the population 
into compliance, they clearly found it necessary to do so largely by incorporating their own authority and objectives into pre-existing conflict and leadership dynamics. In this sense, their victory after several years of war and their establishment of authority in Turkana would be poorly understood purely in terms of supersession and systemic replacement. Whilst most of the political change that occurred during this time was of course unwanted and unwarranted, it is significant that in a pragmatic sense it was not merely impressed upon Turkana society, but rather (at least to a certain extent) emerged through and was crafted by a set of dynamic pre-existing socio-political conditions. As I discuss below, the unique ways in which the relationship between the colonial regime and the Turkana political structure was forged during the early years of conflict played an enduring role in its evolution throughout peacetime colonial rule.

By the time the initial resistance movement had crumbled and the colonial civil administration had been reintroduced (in the mid-1920s), both the Turkana and the British had begun to reconfigure their methods of asserting power and authority in the region. For the British, this meant moving away from their deep involvement in, and manipulation of, intergroup conflict and the assumption of a less immediate political role, as the policy of indirect rule was enacted (Lugard 1923; Crowder 1964). As in many other regions of East Africa, this period saw the establishment of a network of local 'chiefs' and 'headmen', charged with administrative duties and the collection of taxes. It also saw the formation of a local paramilitary district police force, often referred to as the 'tribal police', who were tasked with the monitoring and prevention of raiding, and the pursuit of stolen livestock in the event of theft. These two new authorities came to be closely interwoven with each other, Lamphear (1992: 203) describes how 'the chiefs were given insignia of office - a red and white plaque attached to a pole near their homestead — and were authorised a force of 
kangas ("native police")'. However, I was informed on several occasions in discussion groups throughout fishing and herding communities that both the police and the new chiefs very quickly came under the influence of prominent ngimurok whose social standing and centrality to Turkana cosmology vastly overshadowed any powers that had been bestowed upon individuals by the colonial authorities. Much like Ebei had done during his campaign against the British (as outlined by Lomoru Ima above), the new appointees were only able to win support amongst local communities through close relationships with highly esteemed ngimurok.

During several interviews and group discussion sessions, the emergence of the new police force was argued to have occurred synonymously with the development of yet another style of head dress. As outlined above, many today associate the colonial era with the gradual disappearance of abuzibuzi head ornamentation and the emerging ubiquity of the apukot. In the years following the end of the initial conflict with the British, the form of ngapukoto and the ways in which they were worn also came to be adapted. Many began producing cloth versions of this headdress, comprising ostrich feathers attached to wire holders that were sewn into a single fabric cap. The idea that this new cloth apukot was linked to the new police force was first put forward by a discussant in the Kangarisae discussion session mentioned above:

'Many of us here [today] used to wear clay in our hair. It was during the time of the first [colonial] government that ngapukoto made from material became popular...The soldiers [tribal police] who were employed by them did not want to wear clay in their hair, it was them who designed these headdresses made from material that hold feathers... it was only clay up until the time everyone paid taxes [roughly the 1930s]... they [cloth ngapukoto] were not worn by everyone but became more and more popular over the years' (discussant at group discussion session, Kangarisae, 19/09/2014). 
These new hats could be removed quickly and without difficulty, unlike the clay versions which required regular maintenance and took much effort to remove (see Figure 6.4). The precise reasons for their popularity were difficult to clarify during interviews — some suggested they were widely adopted purely for practical reasons, while others associated their use with the dress requirements of early wage labour outside of Turkana. There were most likely numerous unrelated influences, and indeed the availability of the materials used in their construction was closely linked to the establishment and development of Lodwar as a regional trading centre. Importantly, whilst these cloth caps were worn by many, clay ngapukoto remained the most common style of head ornamentation into the 1970s and 1980s (a point clarified in numerous interviews and evidenced in Thesiger's photographs) and continue to be worn by some today. Indeed, the way in which these dual styles of Ngapukoto came to coexist through the years is perhaps the most significant detail here in the sense that it recalls a very similar set of circumstances that had existed when abuzibuzi were worn extensively. Kittermaster's 1911 History of the Turkana contains a description of the abuzibuzi in which he explains that 'they are not infrequently shaved off... in which case they are attached to a little skull cap of similar make and kept at home for state occasions. Some men have several changes of these headdresses'. ${ }^{103}$ Like the dual forms of apukot, the abuzibuzi had in the deeper past come to be worn in two distinct manners, as a semipermanent adornment woven into the subject's hair and as a stylised removable version of that adornment. In this sense, whilst the new cloth ngapukoto were undoubtedly both formed through and reflective of the particular socio-economic and political conditions of their emergence, they also seem to have comprised a historicity that was not contingent on the materials used in their construction or indeed their overall form. This historicity was instead

${ }^{103}$ Kittermaster's history is contained in KNA/PRB-DC/Turk/3/1. 
articulated in the ways in which they pertained to and evoked past practices of head ornamentation in their performance alongside clay ngapukoto.

These new headdresses embodied change and continuity in equal measure, being entangled both with pre-existing practices of head ornamentation in Turkana and with a set of new material and economic possibilities. In this regard, they perhaps encapsulated broader processes of socio-political and economic change that were at play at the time of their emergence. They might, for example, inform the way we think about the novel institutions in which they were initially implicated. The police force and the network of chiefs established in the 1920s were actively formed by and in relation to a set of new conditions (the colonial administration) and yet inevitably came to function as elements within a system of authority and leadership constituted and performed by means of historical knowledge and experience. In a seemingly paradoxical sense, these new offices represented the control of the newly established colonial government and yet, through their dependence on powerful ngimurok, behaved as mere extensions of a pre-existing power structure that revolved around livestock, divination and raiding.

Along with the new ngapukoto the tribal police wore a number of other unique items, including cloth kilts and leather belts, but perhaps most significantly many of them were supplied with rifles. Rifles had been attained by some warriors during the era of primary resistance via Abyssinian gun-runners, but up until this point spears had always remained the most central and widespread weapon, one tightly interwoven with warrior status. By means of their centrality to warriorship and masculinity, spears were (and continue to be) by extension extremely potent symbolically in the ritual organisation of Turkana society. They perform key roles in many of the important ceremonies that an individual will be involved in 
throughout their life - from birth, when a spear is used to cut the umbilical cord, to asapan (initiation), when one is used by the initiate to kill a goat, cow or camel. Moreover, the word for clan 'emachar' (plural ngimacharin) literally means 'spearhead' and relates to the identifiable marks deployed by each clan in the branding of their livestock, which is itself done with a spear.

The deadly power of rifles, and their superiority to spears, had been made obvious during the many early clashes between the Turkana and the King's African Rifles. However, their effectiveness in raiding contexts came to be especially recognised following the emergence of the tribal police, who were often the first responders to enemy raids or the first point of defence in cases where news of an incoming raid preceded it via word of mouth or the prophetic dreams of an emuron. Mkutu (2008: 45) points out that by as early as 1932 'an estimated 2,000 Turkana warriors, with over 1,600 rifles, were engaged in raiding'. By the 1940s, stories of the prowess and skill of prominent warriors had begun to include gun battles and sharp shooting and some ngimurok began to claim that they were able to make themselves and others impervious to bullets. Many of my oldest interviewees recalled stories they had heard in their youth of such supernatural power. Lomoru Ima, whom I mentioned above, claimed that he had made himself invulnerable to bullets on numerous different occasions, and that he had been recognised by a Pokot warrior at a recent governmentorganised peace and reconciliation meeting, the warrior exclaiming that he had tried to kill Ima many times but that his bullets had been ineffective. It was through such stories that guns became firmly embedded in the mythology that emanated from and recursively crafted the practice of raiding very quickly after their initial adoption. In a similar way to spears, they featured in accounts of heroism and bravery that were essential to the process of idealising and ideologising warfare. They thus came to be imbued with an extremely potent symbolic 
value within the 'social logic' (Robinson et al. 2005) that both resulted from and engendered conflict. Stories that originated during this time continue to be recounted during both informal and formal occasions and re-enacted at dances on a regular basis today.

The newly emerging status of firearms, and their incorporation into an assemblage of implements and accessories that connoted warriorship, was closely and recursively linked to the prestige that came to be associated with the tribal police. By receiving payment for their services in the form of livestock these combatants came to be some of the largest herd owners (and therefore most powerful individuals) in Turkana. It was almost certainly this same prestige that lay behind the widespread adoption of the new cloth ngapukoto head dresses. The growing popularity of the rifle was amplified when an even larger portion of the male Turkana population were armed by the colonial government and encouraged to fight against Italian forces to the north in the early 1940s. The outbreak of World War II in East Africa determined abrupt changes to colonial firearm policies, of which the formation of the 'Turkana irregular infantry' was probably one of the most extreme examples; many of those armed during this time had fought against the British with spears just over two decades previously. A similar policy of rearmament was undertaken by the Italian government in Ethiopia, and many Turkana soon found themselves involved in gun battles with their longstanding Daasanach neighbours. Thus, in the decades following the war a significant portion of Turkana's raiding population had either come to possess a firearm or had experienced using one in battle.

It was in this way that small arms were gradually adopted across Turkana and it should be borne in mind that throughout the first half of the $20^{\text {th }}$ century several gun-runners remained active, trafficking small arms between Ethiopia, Sudan and Kenya and making a considerable 
profit from the escalating and diverse regional conflicts (Mkutu 2008: 47). This propagation of guns, however, and their increasing centrality to both the institution of cattle raiding and the identities of young Turkana warriors, did not at first correspond with dramatic changes either to the routines or the social context of intergroup conflict in northern Kenya. This is clear from accounts of significant raids that occurred in the middle decades of the $20^{\text {th }}$ century, a time when rifles were widely owned throughout Turkana. Of these raids by far the most regularly recounted in the present day is that of the leader Etangan and Ekaru a Ngatuk Nakirionok (the Year of Black Cows). Etangan's raid of Borana livestock, which occurred in the early 1960s, was so extensive that in the subsequent months distinctive black cows that had been bred on the eastern side of Lake Turkana were dispersed throughout Turkana. The emuron Marko Ekeno described this raid to me during a conversation we had in Kerio as follows:

'Ekaru a Ngatuk Nakirionok [the Year of Black Cows] [happened] somewhere between Ekaru a Namotor [the Thin Year, roughly 1960] and Ekaru Etop Ekosim [the Year of the Star Tail, roughly 1964]. It was Akiporo [winter/rainy season]. A war leader by the name of Etangan took a group of raiders south and then back up to Borana country. They raided black cows from the Borana, many [cows]... There were many songs about Etangan. He is remembered today as a sharp shooter and a great leader... [There were] two groups who went forward led by Etangan. The others feared for their lives and returned home. The ones who fled are remembered in the song... The song says "go to fight and die and let your mothers weep. That is what you must do or there will be no cows. You will go, you will die and the people of Etangan will be with cows"' (Interview with Marko Ekeno, Kerio, 24/03/2015).

Ekeno's account of Ekaru a Ngatuk Nakirionok is complimented by a description of a different raid that occurred around the same time, in which Lomoru Ima was an active participant. Ima described this raid as follows:

'We would go raiding... Hundreds of warriors. 280 or so with guns, 200 or so with spears. My role in raids... [is to] stay behind and to guide the warriors by my dreams. Many ngimurok would go [raiding], they stay at the back like that and direct the raiders... During one raid [of the Pokot] the [warriors]... kept running into trouble and everyone did not know what to do until eventually they realised that I am the most powerful of them all [the ngimurok]. I took control... the raiding party succeeded' (interview with Lomoru Ima, Nakurio, 06/04/2015). 
Both accounts, but particularly Ekeno's, depict the coordination of large-scale cross-border raids undertaken over long distances. This raiding formula clearly emulated the kind of raiding that had been undertaken throughout the first half of the $20^{\text {th }}$ century (and before) when only spears were available. The relatively widespread use of firearms by the time of Ekaru a Ngatuk Nakirionok had not coincided with significant constrictions in cross-border mobility and long-distance movements. Indeed, Etangan's campaign involved the navigation of the territories of the Pokot, Samburu and Borana along a route that stretched over $100 \mathrm{~km}$ and would have required several days to traverse. Moreover, like the earlier spear-era raiding, raids such as that undertaken by Etangan during Ekaru a Ngatuk Nakirionok were driven by specific economic needs, they were focused on restocking the herds of those who had been detrimentally affected by drought, disease or indeed raiding itself. As I outlined in the preceding sections, the escalation of raiding during the initial conflict with colonial forces in the early $20^{\text {th }}$ century had been tightly entangled with, and usually undertaken in response to, livestock confiscations (which were seen by most simply as raids). This reactive and economic necessity-driven basis of raiding remained central during the time of Etangan, whose raid of Borana cows was a response to a preceding drought that had led to the designation of the year Ekaru a Namotor ('the Thin Year').

These points are significant in light of the crucial role that guns have eventually come to play over more recent decades in the rapid intensification of raiding and conflict, and the general worsening of inter-group relations, throughout northern Kenya. These changes have occurred in tandem with a general constriction of cross-border mobility and a breakdown in the fluidity of territorial boundaries. They have also coincided with the more widespread emergence of border-orientated groups involved in commercial livestock theft, such as the ngoroko (whom I mentioned in the introduction to this chapter). The intensity and regularity 
of violent clashes throughout border areas in Turkana in the present day is such that travel on foot between territories, whether by an individual or a large group, is extremely difficult. Whilst the kind of large-scale raiding outlined in the above accounts is still undertaken on rare occasions, ${ }^{104}$ such raiding parties are obliged to make their return home as soon as possible, with or without livestock, and thus do not often venture deep into enemy terrain. Quicker raids, undertaken in the space of a single night and comprising smaller groups of men, are far more common. I discuss these changes in the dynamics of raiding in more detail in the following section, but it is significant to note here that one significant influence behind them has been the spread of automatic weapons, which first began in the late 1970s. Prior to this time the firearms owned throughout Turkana, including those used in the raids described by Ima and Ekeno above, were of either the single-shot or semi-automatic varieties. ${ }^{105}$

Grasping the significance of this technological shift (from single-shot/semi-automatic to automatic rifles) and, crucially, its coincidence with a range of other environmental, economic and political influences in the 1970s (which are examined in the following section), is of critical importance to developing an understanding how firearms have been implicated in social change in Turkana over the long-term. There is a tendency amongst many of those concerned in one way or another with pastoralist conflict in Africa (including national governments and other organisations promoting conflict resolution) to attribute great significance to the dissemination of guns, and to implicitly assume that these weapons have been agents of socio-cultural change in their own right. White (1971: 173) points out that the

\footnotetext{
${ }^{104}$ One of the most recent of these large-scale raids came from the Pokot in July 2013, at which time I was involved in archaeological fieldwork in the Lothagam Hills (where the emuron Lokerio is purportedly buried). I paid a visit to Nakurio in the aftermath of this raid to find hundreds of displaced families who had fled their homes in the area surrounding the Loriu Hills.

${ }^{105}$ On several occasions, I visited the homes of elderly men who showed me rifles they said they had obtained during the time of World War II, when many Turkana were fighting the Italian forces in the north. These weapons had become prestigious and nostalgic heirlooms that held great sentimental value for those who owned them.
} 
attribution of such transformative magnitude to firearms is common in considerations of war and history throughout the African continent, arguing (albeit in a discussion of firearms from an earlier period) that:

'the impact of firearms in African warfare was not as decisive as had been expected. Perhaps the expectation itself was the product of some unhistorical ideology. The collection and lore of firearms have attracted impartial scholars and enthusiasts, but they have also attracted devotees who regard firearms as symbols of industrial or social or other prowess. To such devotees it is impossible for those with firearms to loose battles to those without firearms, and to some it is impossible for those who have not developed or made firearms to maintain or use them properly.'

In Turkana, the spread of automatic weapons in the 1970s, and their involvement with transformations in regional conflict, was not only interwoven with numerous other catalytic processes of change, but also took place in a world where both the symbolic value and functionality of guns had already come to be constructed by means of their integration with and implementation alongside practices and technologies of warfare that came before. Ima's account shows that by the mid- $20^{\text {th }}$ century guns were being deployed in raids alongside spears rather than completely replacing them in the fluid socio-material universe of raiding. Indeed, as I outlined above, the gun as an entity had been gradually incorporated into the mythology of warfare in Turkana long before the arrival of automatic weapons. Thus, by the time automatic rifles were eventually adopted, the gun had not merely shaped but had also been actively shaped by the existing social, economic and political dimensions of raiding. It had not 'impacted' Turkana society so to speak, but had rather come to perform particular histories, practices and values that were associated with conflict and raiding in new ways.

The notion that guns did not initially have a radical effect on the routines and social implications of raiding, or on the cross-border mobility of the Turkana and their neighbours, was not only discernible through discussions that were specifically focused on conflict. It also emerged during interviews and discussion groups that targeted other material worlds and 
issues. In the previous section I argued that, despite the escalating conflict between the Turkana and their southern neighbours during the early decades of colonial subjugation, commodity exchange via long-distance trade routes that crossed ethno-territorial borders remained a core component of everyday life and therefore of the construction, enactment and experience of Turkana identity. This seemingly contradictory nature of Eturkan's borders (in the sense that they were at once zones of fierce ethnic rivalry and thresholds in exchange networks that were perpetuated through deep inter-ethnic cooperation; cf. Anderson and O’Dowd 1999) was also alluded to during discussions of female neck ornamentation during the middle decades of the $20^{\text {th }}$ century. For example, it was pointed out to me on several occasions that alongside the kinds of raids described by Ima and Ekeno above (and indeed the use of single-shot/semi-automatic rifles in these raids) neck ornaments made from seeds called ngimusio were worn extensively by women across southern Turkana (Figure 6.5). Importantly, the closest source of these ngimusio seeds was the higher reaches of the Marakwet Escarpment in the western Kerio Valley, over $200 \mathrm{~km}$ south of Lodwar on the other side of what is today West Pokot County and to the west of Baringo County (the plains inhabited by Pokot herders).

In October 2014, during a conversation about the history of neck ornamentation in a discussion session with women in Nakaalei, I noticed that one elderly woman was wearing a strand of ngimusio seeds. I asked her why such seeds were uncommon in the present day. She replied:

'These ngimusio are the seeds from a certain tree that grows towards the place of the Marakwet... the Cherengani Hills. Since raiding has got very bad people have stopped walking that way... people used to travel all the way down to Marakwet... [during Ekaru a] Etop Ekosim [roughly 1964] and [Ekaru a] Atchaka Ekipul [19651970]' (Discussant at group discussion session, Nakaalei, 16/10/2014). 
Later that day, back in Nakurio, a similar picture of unrestricted long-distance movements across the border between Pokot and Turkana was painted by Emeri Lowasa, who described the collection of shells to the south of Lake Turkana. Lowasa had seen such shells in Thesiger's photographs of women in the 1960s, many of whom wore large single mollusc shells in prominent positions in front of their ngakoroumwa neck beads. In explaining to me why these shells were no longer commonly worn Lowasa said that:

"There... [used to be] far less insecurity to the southeast of Turkana in the region between here and Isiolo Town... families would frequently travel down to those parts without worry. It was during those trips that women would pick up shells from the dry riverbeds down there, many would bring them back for their relatives, or even trade them. Since my youth that area has become very insecure, there is much fighting between Turkana, Pokot and Samburu. People rarely travel there and therefore we rarely have shells" (Interview with Emeri Lowasa, Nakurio, 16/10/2014).

The trade route described in the first of these extracts, which stretched down to Marakwet and facilitated the widespread use of ngimusio seeds as recently as Ekaru Etop Ekosim (roughly 1964) and Ekaru a Atchaka Ekipul (1965-1970), is in fact the same as that mentioned at the end of the previous section, which had existed in the early decades of the $20^{\text {th }}$ century alongside the escalating conflicts that characterised the early colonial era. This longstanding exchange route clearly continued to facilitate the diffusion of various regionally specific commodities (the Turkana primarily traded salt and livestock) across cultures, livelihoods and ethnicities in tandem with the regular raiding and fluctuating inter-group conflict into which rifles were gradually incorporated. It was arguably the endurance of the particular model of raiding and counter-raiding described in the accounts of Ekeno and Ima above that made this biformity in the interactions between the Turkana and their southern neighbours possible. In a similar way to the raiding of the early $20^{\text {th }}$ century, the consolidation and centralisation of inter-ethnic violence and competition into recurring large group forays into enemy territory (rather than constant border orientated conflict) meant that peaceful trade-related movements and interactions between ethnic groups and territories 
could continue to coexist without difficulty. As late as the early 1970s, border zones were not necessarily areas of turbulence and insecurity. As Lowasa describes above, they were areas that were accessible and safe enough for herders to frequent and collect shells for their family members further north. Moreover, during other discussions I had with those who had memories of the 1950s and 1960s it was pointed out on several occasions that by the time of Ekaru a Ngatuk Nakirionok a robust trade in spears (or, as some suggested, spear heads) had come to exist between the Turkana and Borana and Rendille communities on the east side of Lake Turkana, near Loiyangalani.

In the following section I explore the changes to raiding, border zone conflict and inter-group exchange that began to occur during the 1970s and the range of social, economic and political stimuli that lay behind these changes. However, before doing so it is useful to first summarise the arguments presented thus far. Building on the ideas outlined in the previous two parts of this chapter, I have suggested in this section that despite the introduction of the colonial administration in the $1920 \mathrm{~s}$, and the ensuing attempted distribution and inculcation of colonial authority across Eturkan through the establishment of chiefs/headmen and the new police force, ngimurok maintained their positions as the nuclei at the cores of the clanorientated social networks that in aggregate form constituted the Turkana nation. It was around this enduring cosmological centrality and authority of the ngimurok that the political and administrative development of Turkana District unfolded, following the end of the era of primary resistance and the establishment of indirect rule.

Whilst the chiefs and the tribal police were put in place by the colonial regime, and performed a range of pragmatic duties (such as tax collection) for the government, they were also deeply enfolded within local power structures and ultimately subordinate and amenable 
to ngimurok. In this way, their influence on Turkana society emanated from deeply rooted, resilient and yet fluid forms of socio-political organisation and hierarchy as much as from the hand of the distant colonial government. Just as pre-existing forms of livestock and raidingorientated authority-making had absorbed and determined the course of the initial British conquest of Turkana, the establishment and gradual solidification of the civil administration from the 1920 s to the 1960 s was a process that was subsumed, and thus continually crafted, by Turkana society and culture more than it was a source of their disruption or disintegration, and indeed more than it was a process by which they became rigid or inflexible as is suggested to have occurred in other sub-Saharan African contexts through the colonial invention of African traditions (Snyder 1981; Ranger and Hobsbawm 1983; Chanock 1985). This idea articulates to a certain extent with arguments presented by Berry (1992: 328) in her analysis of the effects of indirect rule on the control of agricultural land in sub-Saharan Africa during the colonial period, when she suggests that:

'Colonial regimes were unable to impose either English laws and institutions or their own version of 'traditional' African ones onto indigenous African societies. Colonial "inventions" of African tradition served not so much to define the shape of the colonial social order as to provoke a series of debates over the meaning and application of tradition which in turn shaped struggles over authority and access to resources.'

In Turkana, throughout the post-conquest colonial period the raiding of enemy livestock continued to serve as the primary mechanism for maintaining and reiterating the inherited supernatural abilities and ancestrally rooted authority of ngimurok and, by extension, was a practice that enacted and perpetuated Turkana cosmology. Indeed, the sustained centrality of ngimurok to raiding (and vice versa) during the middle decades of the $20^{\text {th }}$ century can be noted in Ima's description of the raid of Pokot livestock in which he participated shortly after Ekaru a Ngatuk Nakirionok (which was guided by and successful because of his visions). As firearms spread gradually throughout the region, and were adopted by a significant portion of those engaged in raiding both inside and outside of Turkana, the strategies, rhythms and 
routines that had historically characterised this practice did not undergo radical transformation. Rather, guns were incorporated into an open-ended material assemblage that revolved around, and was largely symbolically constituted by, the mythology of raiding and warfare. Their arrival in Turkana was (and continues to be) considered not as an inevitable technological replacement (as it is perhaps understood by many from the outside world), but rather as an opportunistic utilisation of a new element in an already existing, expansive and constantly fluctuating network of similar material incursions. This outward-looking and dynamic network of trade routes and exchange relationships, which seems to have harmonised with the structure of raiding alongside which it existed, had been integral to the material constitution of Turkana corporate identity since long before the commencement of colonial conquest. As I argued in the preceding section, Turkana identity had been continually constructed and re-constructed by means of the relationships, experiences and knowledge that emanated from these interactions with neighbouring groups as much as it had been by means of conflict with them. This seemingly dual or perhaps even paradoxical nature of the Turkana's relationship with the societies surrounding them clearly endured long into the middle decades of the $20^{\text {th }}$ century, a time when ornamental seeds filtered up from Marakwet and spears were obtained from communities on the east side of Lake Turkana at the same time as regular and extensive raids and counter-raids. 


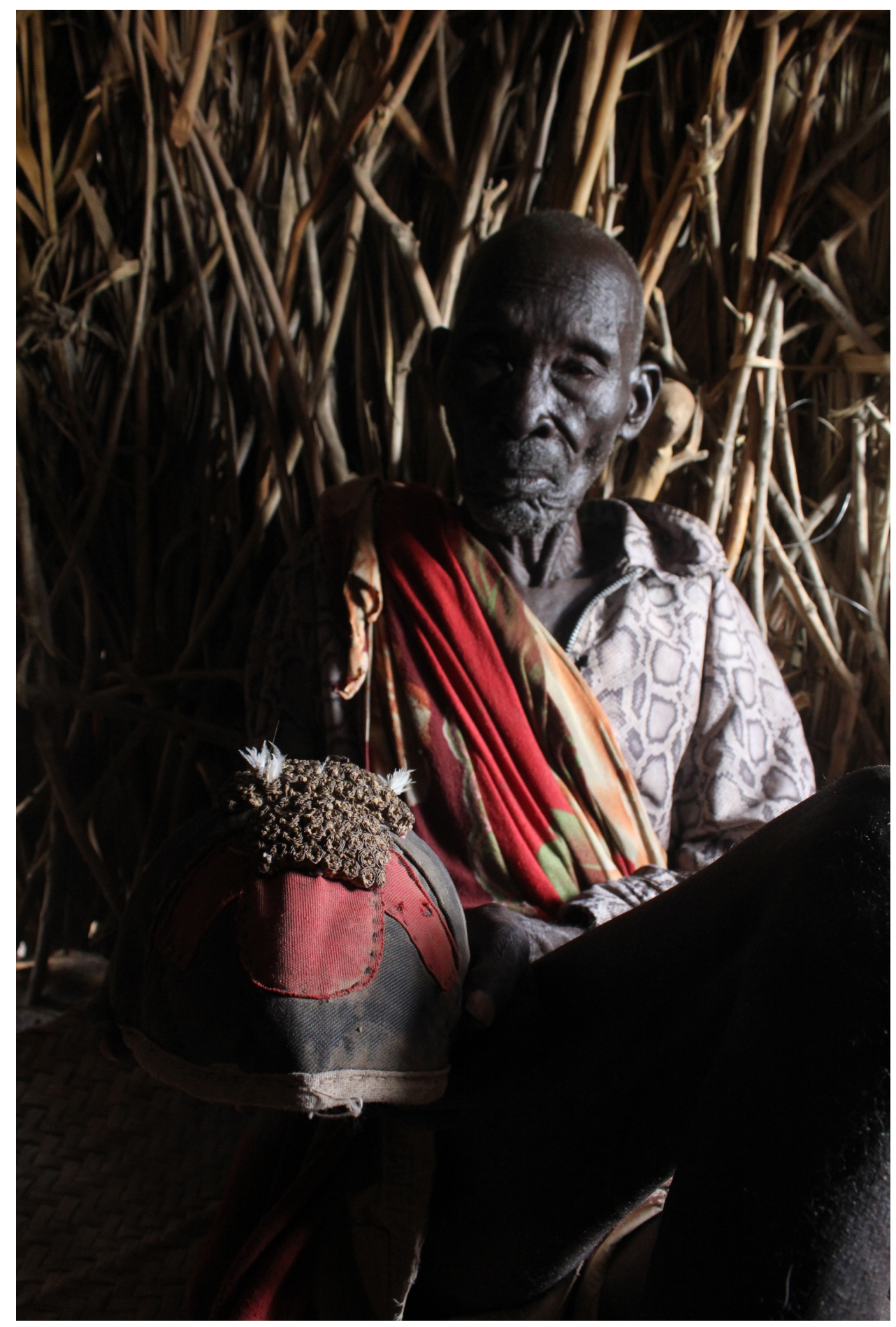

Figure 6.4. Nkumo Lodio displaying his cloth apukot during an interview near to the Lothagam Hills in July 2014. 


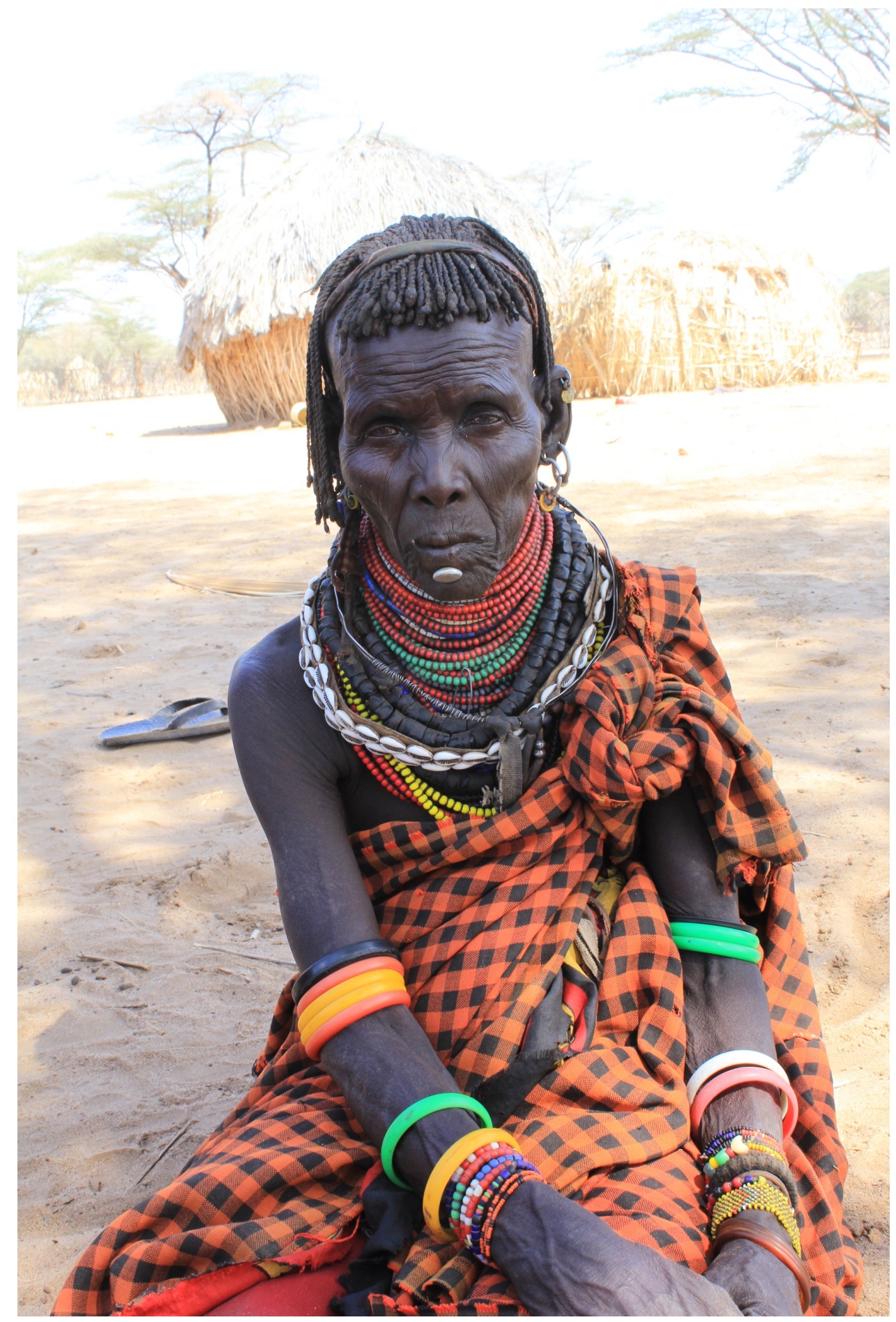

Figure 6.5. A woman at a discussion session in Nakoret in October 2014 wearing a ngimusio seed ornament amongst her ngakoroumwa. Ngimusio ornaments have become very uncommon in the last few decades. 


\subsection{Synthetic fibre hats, plastic spoons and ngoroko: herding and raiding in the years after Ekaru Asur (the Fleeing Year)}

Ekaru Asur, the Fleeing Year, was mentioned in Chapter 5. Occurring around 1981, this period of heavy Pokot raiding comprised great turbulence and instability for many families and communities in southern Turkana. I noted in Chapter 5 that to many cultivating communities it is far less prominent in terms of the ordering of time and recent history than Ekaru a Atchaka Ekipul (the Year of the Lost Padlock), a year that marks a critical divide between previous trends in seasonality and river flooding regimes and the unpredictability that has come to characterise the recent past. However, to communities of southern Turkana primarily engaged in herding Ekaru Asur is most definitely a crucial temporal boundary. Not only was it a time of monumental livestock losses (enough to finally push many herders into famine camps and irrigation schemes), but it also marked a turning point in the development of regional conflict. The years since the late 1970s have seen some of the most violent, dangerous and generally distressing years of conflict that many in Turkana have ever witnessed, especially those who frequent or permanently occupy areas in border regions (McCabe 2004: 89). It would not be an exaggeration to suggest that these recent decades have encompassed some of the most profound transformations in the daily practices and general dynamics of both conflict and pastoralism, and the relationship between these two activities, that have occurred in Turkana's recent history.

This has taken place as part of a process of transformation that has unfolded not only in northern Kenya, but also throughout the area referred to by many as 'the tribal zone' (which, along with northern Kenya, encompasses northern Uganda, southern South Sudan and southern Ethiopia), and it has been experienced by numerous pastoralist communities (Gray 
et al. 2003). As I mentioned above, this recent intensification in regional conflict has been closely interwoven with the dissemination of automatic rifles, the initial commencement of which can be traced back to the Ogaden War of 1978-1979. Mkutu (2008: 46) describes this war as a 'turning point in arms availability in the region' and makes a direct correlation between the arms proliferation that resulted from it and 'increased communal resource conflicts' (2008: 45). Prior to and during the Ogaden War both Somalia and Ethiopia had obtained unprecedented quantities of automatic weapons via direct government assistance and a series of trade deals with numerous co-operating countries, most prominently the Soviet Union and the United States. Hundreds of millions of dollars' worth of small arms accumulated on both sides of the conflict (Halliday 1977; Chaliand 1978; Hutchinson et al. 1991: 61-62; Brzoska and Pearson 1994: 186) and quickly dissipated across the region via an expanding cross-border arms trade network when the war was over.

Following the Ogaden War, US-Soviet rivalry continued to play out in arms deals that were central to numerous East African wars including the Tanzania-Uganda wars (1978-1979 and 1980-1985) and the civil war in Sudan (1983-2005). The dramatic expansion and development of the cross-border arms trade network that began to occur immediately after the Ogaden War has been iteratively supplemented by the automatic weapons that have emanated from these subsequent wars. As I pointed out in Chapter 5, the collapse of Idi Amin's regime in the late 1970s was also an influential event (Knighton 2003: 432). Mkutu (2008: 46), who undertook pioneering research on the small-arms trade in northern Kenya in 2003, paints a vivid picture of its complexity and pervasiveness, explaining that 'those involved... range from racketeers to vigilantes, from warriors to wealthy businessmen, from small traders to UPDF or Kenya Police Reserve personnel' (Muhereza 1997; Cappon 2003; Mkutu 2003). This trade has served to import small arms into Turkana from all directions, a 
process that has been bolstered by the region's proximity to numerous international borders (Figures 6.6 and 6.7).

However, whilst the link between worsening conflict and the spread of automatic weapons is clear, one must be careful about over-emphasising this correlation and attributing a single technological shift with such monumental clout as an agent of socio-cultural change. As I outlined above, prior to the 1970s single-shot and semi-automatic weapons had not provoked consequential transformations in either the practice of raiding or the pastoralist livelihood on their own terms, but had rather come to take part in them, serving (along with other material things) to articulate gradual and historically-informed processes of change. Whilst both raiding and pastoralism have transformed substantially in recent years, this has occurred in response to a diverse range of critical factors, of which the spread of automatic weapons is only one. The general increase in disastrous droughts and famines that was discussed in Chapter 5, for instance, has arguably been an equally if not more important influence. This point was made clear during many of the interviews I conducted with members of herding families who had witnessed the changes of the last few decades. Lotonea Ngipetain Epur, whom I interviewed in Loue in April 2014, explained that:

'When... [my] parents told stories they said that the whole place [Turkana] was very lush. [In the past] one man could look after all the different animals [in his herd]... he could take the goats out, then the cows, then the camels, like that, and he would not go far at all because grass and [bushes] were everywhere... During my time it began to be the case that a family's herds must be tended by several different individuals. They have to take each group of animals very far just to get enough... There has been a very big increase in raiding through my life. Before it would happen less often... raiding has become more frequent' (interview with Lotonea Ngipetain Epur, Loue, 09/04/2015).

The resource scarcity described by Epur has, in recent years, been exasperated by immense population increase, while regional conflicts have (following independence) been ever more tightly interwoven with Kenya's profoundly ethnicised political system (cf. Ajulu 2002). To 
clarify this latter point, the Turkana's historical conflict with the Pokot to the south came to take on political connotations of national importance following the late 1970s when Daniel Arap Moi, a Kalenjin, became president of Kenya (the Pokot are members of the Kalenjin cluster). It is necessary to consider all of these components when examining the causes of the dramatic intensification of conflict and raiding that has in many ways come to define the last few decades in Turkana. The proliferation of automatic weapons has not been a stand-alone influence, but rather part of an intricate and deeply unfortunate interfusion of many disastrous economic, political and environmental processes of change, which have co-functioned to precipitate widespread violence and insecurity. The conjoined and inseparable nature of herding and raiding, both in terms of their revolution around the same nucleus (livestock) and the role that their recursive relationship plays in constituting central components of Turkana cosmology and society, renders them mutually catalytic and responsive to an especially broad array of contextual stimuli.

The increasing insecurity of the last few decades has not only led to significant transformations in raiding practices (i.e. large-scale long-distance group forays have become less common than small over-night raids), but also to the rise and expansion of unofficial cross-border livestock trade networks (Little 2013). The increasingly prominent unofficial trade in livestock (particularly across the border between Kenya and Ethiopia) has, for many, come to represent an alternative livelihood in its own right (Teka et al. 1999). It is one sustained by a style of border-orientated livestock theft that contrasts starkly both with the longer-distance incursions into enemy territory that were once common in the past and with the shorter distance raids that have become more widespread in recent years. 
In the present day, bands of raiders (or 'bandits' as they are usually termed in the Kenyan national press) are known to often comprise members of several different pastoralist groups, and to raid indiscriminately with the intention of accumulating livestock purely for its commercial value. They are known to many in Turkana as ngoroko, a deeply rooted term that, as outlined at the start of this chapter, reaches back to the years immediately following Ebei's demise when the remainder of his army allegedly scattered into various hill ranges in the north. Little is known about the historical foundation of this term and even less about the changes in its meaning that occurred throughout the period of time separating Ebei's death in 1924 and the 1970s-1980s, when ngoroko migrated down to engage in raiding in the south. But regardless of this, the ngoroko of the $21^{\text {st }}$ century tend not to draw on or utilise the power of ngimurok (in fact, they are regularly cursed by them) and, given that they are not yearround herders, the livestock they amass is not integrated into the complex web of exchangeorientated social relations that is crucial to authority, identity and overall long-term survival throughout Turkana.

As I described in the previous section, this commercial livestock theft, along with the general increased regularity, length and degree of violence in livestock-centred clashes of all kinds, has underpinned relatively abrupt changes in the nature of Eturkan's borders. I regularly visited villages and settlements located along the southern border of Turkana (which divides Turkana from Pokot County) throughout 2014 and 2015. In many of these settlements conflict has come to dominate almost every aspect of daily life. The communities in Kangarisae, Nakoret and Nakaalei, for example, have all in recent years been known to experience more than two armed skirmishes in a single week. Indeed, having commenced the collection of market-stall object inventories in Kangarisae in 2014, I was forced to discontinue this activity within a matter of months when its regular markets were 
comprehensively abandoned through fear (primarily on behalf of the mobile market traders) of the unpredictability and ferocity of Pokot and ngoroko raids.

Thus, my regular visits to Kangarisae, much like my visits to Nakoret and Nakaalei, came instead to be concentrated on the collection of interviews and large discussion sessions, although I did collect market inventories in Nakoret and have included them in Chapter 5. What was most apparent to me throughout all of these and other research trips to areas in the deep south was the acuteness of the constriction in movement that has resulted from the rising insecurity of recent years. During many of the discussion groups I held with women in southeastern Turkana it was pointed out to me that most people have stopped making regular trips up into the Loriu Hill range, which is orientated along a roughly north-south line on the east side of the Kerio river. These trips had previously served as a means of collecting the various raw materials that are integral to the construction of a wide range of domestic containers and implements, objects that have historically been central to inter-livelihood exchange systems within Turkana (see Chapters 4 and 5).

Indeed, the effects of this severe restriction in movement across and in the general vicinity of Eturkan's southern border have manifested themselves even more conspicuously in the systems and practices of trade and exchange that had previously connected the Turkana with many of their southern neighbours. Trade routes that had for many years endured alongside regular raids and counter-raids, facilitating the influx of a wide array of commodities not widely available within the boundaries of Turkana, have in the recent past collapsed. The trade with the Marakwet (mentioned in the previous two sections), for example, has been unable to withstand the growing insecurity. This is clearly outlined in the extract referenced in the preceding section from a contributor to a Nakaalei discussion session in October 2014, 
whose ngimusio ornamental seeds dated to a time before 'raiding... got very bad'. Similarly, Lowasa's account (also referenced in the preceding section) describes how the violence and insecurity of Turkana's southern border has caused the disappearance of shells from women's neck ornamentation, items that had previously been collected from areas that are close to or within Pokot territory. These are just two examples of many that reflect a substantial shift in the ways that communities in Turkana engage with neighbouring groups and regions.

It thus appears as though the picture of Turkana herding and raiding over recent decades, and the daily practices, social interactions and rhythms of movement with which these activities are integrated, is one of dramatic and pervasive disjuncture. The recent past seems, on the surface, to have comprised sudden and profound change emanating in all directions from uncontrollable and irrepressible external forces. Yet clearly such an understanding would constitute an abrupt and unreasonable contrast to the manner of socio-economic and political change that has characterised these activities over the last century and beyond, as has been described in this chapter so far. It is therefore altogether unsatisfactory. As Fontein (2017) recently conjectured (and as I discussed in the introduction to this thesis; Chapter 1), the notions of rupture and radical change are themselves only lenses through which an inherently excessive past is made sense of in the present, lenses that can therefore never be entirely accurate or all-encompassing reflections of historical change. This is not to say that the extent and gravity of the recent transformations in herding and raiding practices should be denied or ignored. Rather, their often-implied synonymy with the comprehensive erosion of preexisting values, practices and ways of life, and the accompanying premise that they somehow pertain to a fragility in Turkana society, or its susceptibility to the 'impact' of the outside world, must be interrogated and debunked (cf. Wolf 1982; Moore 2011). 
Indeed, perhaps the most crucial and persistent motif of this chapter's analysis thus far has been that regardless of the apparent scale or momentousness of the numerous and diverse transformations that have occurred within the dynamics of pastoralism and livestockorientated conflict in Turkana over recent history, change has always served, at least in part, to provide a means for performing and re-imagining an enduring yet open-ended repertoire of values and meanings. In doing so, it has been embedded in a set of longer-term continuities. New materials, practices and forms of interaction have repeatedly come not to exert change on their own terms, but rather to reveal and reiterate enduring and uniquely Turkana ways of being in and making sense of the world. Therefore, whilst the unfortunate co-manifestation of several seemingly calamitous events (the proliferation of automatic weapons, environmental change, population increase and the politicisation of inter-ethnic violence) has perhaps engendered particularly prominent transformations to everyday life in recent years, it is important to locate and reveal some of the ways in which these processes of change have, through their co-option, also come to serve as a platform for the perpetuation of various resilient aspects of Turkana society and culture.

In turning back to the question of Turkana's outward connections with neighbouring groups, and the collapse of key southern trade routes in association with the constriction of borderzone mobility from the late 1970 s onwards, a number of important points can be made. Firstly, it was arguably largely as a reaction to the severance of these trade ties that many communities in Turkana began to engage more actively with markets in Turkana's major population centres during the 1980s and 1990s. I outlined in Chapter 5 how, in taking advantage of the infrastructural development of the late 1970s and early 1980s, and the increased access to objects and foodstuffs that began to make their way into Turkana by means of the Kitale-Lodwar road, many individuals from cultivating settlements (particularly 
along the Kerio) have worked to establish a network of regular markets that now serve to disseminate a range of goods throughout more remote regions. Importantly, it has not only been those from cultivating communities who have come to engage more actively with Lodwar and other growing towns. Across southern Turkana, these regional centres are coming to occupy a progressively central position in the everyday practices of communities in a wide variety of locations.

This has not only been the case in areas where burgeoning weekly markets have begun to provide access to various new commodities, but also in areas with no markets whatsoever, such as Kangarisae and Nakaalei, where a general increased availability of transportation links into larger towns provides a means for many to make more regular use of them for purchasing supplies. In this sense, the growth of Lodwar and other regional centres has not only provided a means for cultivators to reformulate their socio-economic relationship with the herding sector (as outlined in Chapter 5), but also for Turkana communities in general to reconfigure and reinforce Turkana's relationship with the broader region in which it lies. As the influx of various locally unavailable objects and materials into Turkana by means of deeply rooted trade routes and connections to the south was cut-off by the insecurity of the post Ekaru Asur years, the population turned increasingly to Turkana's growing towns and their connections to external cities and populations as a means of acquiring exotic items.

In this sense, whilst recent critical changes in the dynamics of regional conflict have without doubt underpinned a breakdown in the kind of long-distance ambulatory trade that had existed throughout most of the $20^{\text {th }}$ century, making many of the items that this trade had provided (such as ngimusio seeds and shells) inaccessible for the first time, many Turkana communities' outward-looking nature and dynamic involvement with materials from external 
regions have not diminished at all. Rather, these aspects have been re-aligned to find a basis within the contemporary circumstances. Most importantly, the assemblage of new materials and objects that now make their way into Turkana almost solely by means of the LodwarKitale road are, in a wide variety of cases, used to refabricate, reform and restate a diverse array of deeply rooted practices and styles of ornamentation and clothing. One such example can be identified in the case of the ornamental shells (described above) worn in front of women's ngakoroumwa neck bead bundles. When these decorative shells became widely unavailable in the early 1980 s, their position in neck ornamentation displays was by no means abandoned or forgotten, but came to be fulfilled by a variety of circular white plastic items, most commonly the heads of white plastic disposable spoons, which are obtained in Lodwar. This practice of utilising disposable spoon heads as decorative items remains very common in the present day.

A further example can be located in the still-unfolding story of the apukot headdress. As I outlined above, these originally clay and feather headdresses were refabricated during the colonial era, when many people began to wear cloth versions (a trend probably started by the 'tribal police'). In more recent years, not only have these cloth ngapukoto increased in popularity, but they have also begun to encompass a range of previously unattainable materials. For example, the mechanism that serves to grip the primary feather display, which had previously been commonly made from wire and metal, is now often constituted by a circular piece of foam cut out of a pair of flip flops. Moreover, in many cases the entire body of the apukot is now comprised of a synthetic fibre 'beanie' style hat (these are often adorned with the logos of popular football teams). These hats, which are mass-produced in India and began to flood Lodwar's markets in the early 2000s, are worn high up on the head so as to resemble the shape of the custom-made cloth versions of the apukot, and feathers are sewn 
directly into them. They are referred to as ngapukoto and are commonly worn at important rituals, ceremonies and other formal occasions (Figures 6.8 and 6.9).

These two examples are by no means unique or uncommon. They have been emphasised here because they correlate with examples outlined in the previous parts of this chapter, but are only two cases amongst an immeasurable assortment of similar engagements with the commercial objects and materials that have made their way into Turkana in more recent years. As I noted above, they encapsulate the ways in which various communities have negotiated the growth and expansion of Turkana's urban centres to reconfigure their engagements with external markets, territories and populations. However, perhaps more importantly, they also point to the resilience of the acts of remaking and reconstituting that serve to underpin and maintain Turkana's complex socio-material networks. As was the case during the colonial era, for example, when cloth ngapukoto first came to be adopted, the new materials deployed in the production of ngapukoto in the $21^{\text {st }}$ century have neither come to exert significant changes purely on their own terms (by means of their new properties and qualities) nor have they simply been subsumed into a pre-existing inert category. Indeed, the 'apukot' category itself is not rigid but inherently fluid, by now comprising several slightly different styles of headdress from different points in history and, at least in part, expressing elements of older abuzibuzi head ornamentation too. The new materials used in $21^{\text {st }}$-century ngapukoto have thus been incorporated into a durable process of socio-cultural transformation whereby their contemporary performance is imbued with, and symbolic of, the remembered history of apukot production, use and exchange, whilst simultaneously providing a means for the creation (within the historical context that they embody) of new values and practices in accordance with the interests and aspirations of the individuals and 
communities who wear them (Also pertinent to this argument are the case studies outlined by Thomas 1999; Davies and Moore 2016 and Fredriksen and Bandama 2016).

Everyday life in Turkana is thus structured through recursive relationships, between humans and the material conditions of the present, which continuously invoke and engage with subtle and complex histories by means of contemporary circumstances. Arguably, this manner of constituting daily life serves by its nature to impede and obstruct the rigidification of customs, meanings, values and practices, all of which are inherently fluid on account of their emergence at the continuously moving nexus between historical experience/memories and various daily economic, political and environmental pressures. Indeed, only by locating and coming to terms with this fluidity, and the resilient and community-led process of change that underlies it, is it possible to build an understanding of the recent development of the livestock-centred universe of herding and raiding in Turkana that goes beyond the simplistically desolate and dramatic picture that is commonly painted. Whilst the most effective way of doing so is arguably by means of specific examples of material culture categories and their social entanglements, these features can also be elucidated through a broader-scale perspective of the activities, incidents and occurrences of which daily life in Turkana is composed. This is what I attempt to do below. 


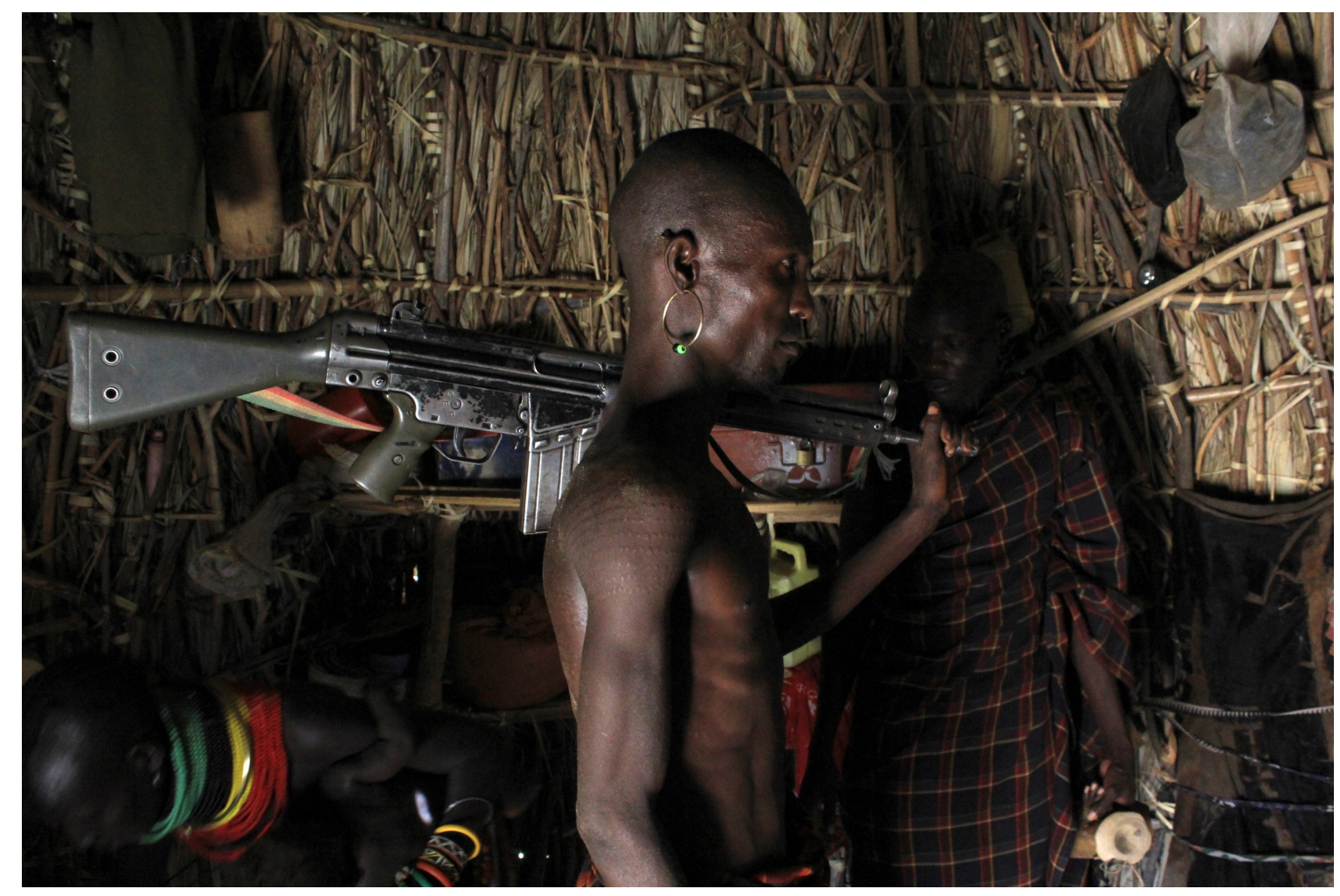

Figure 6.6. A man posing with his rifle following an interview in September 2014.

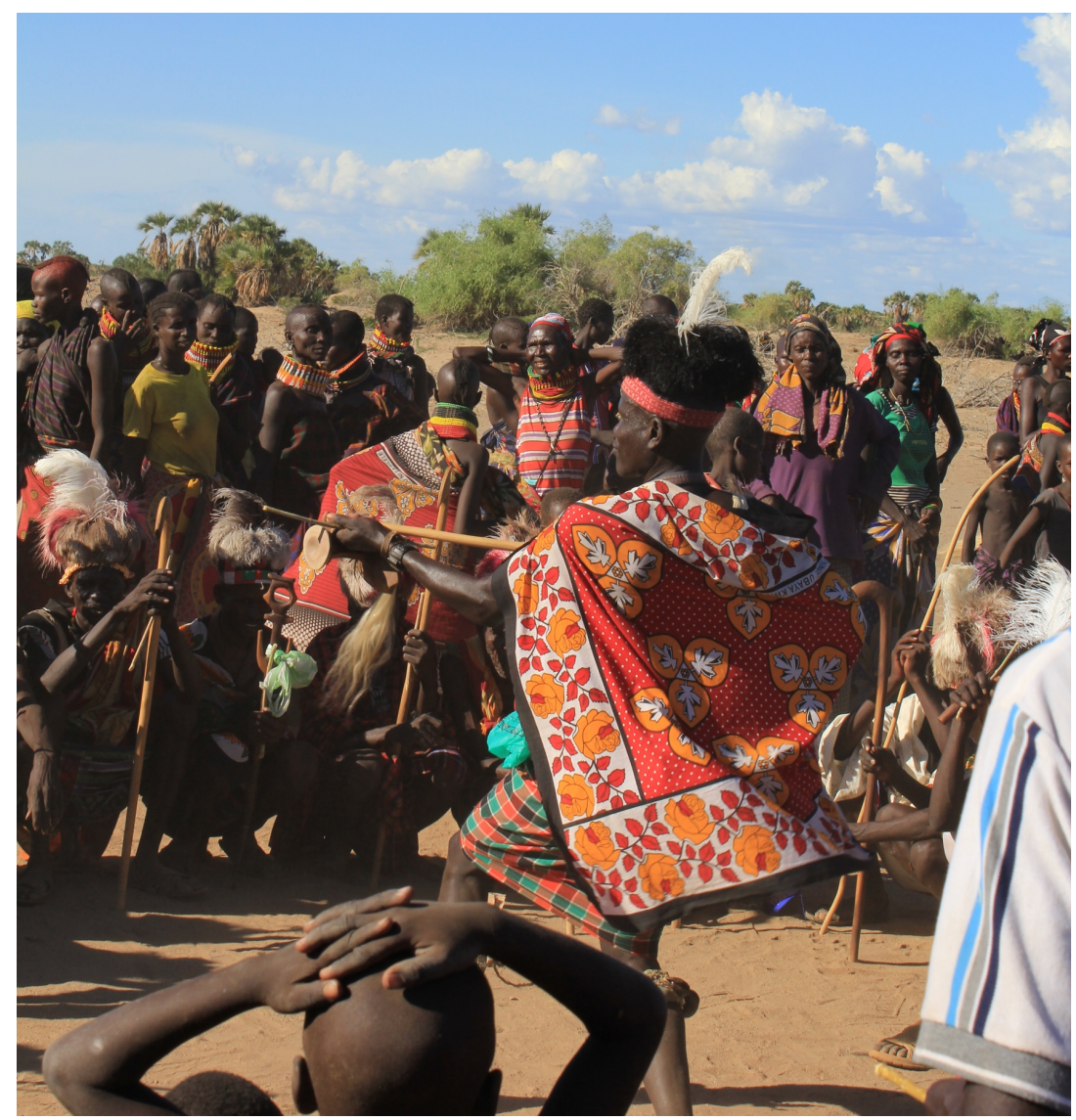

Figure 6.7. A man acting out a gun battle with a wooden staff at a wedding dance, October 2014. 


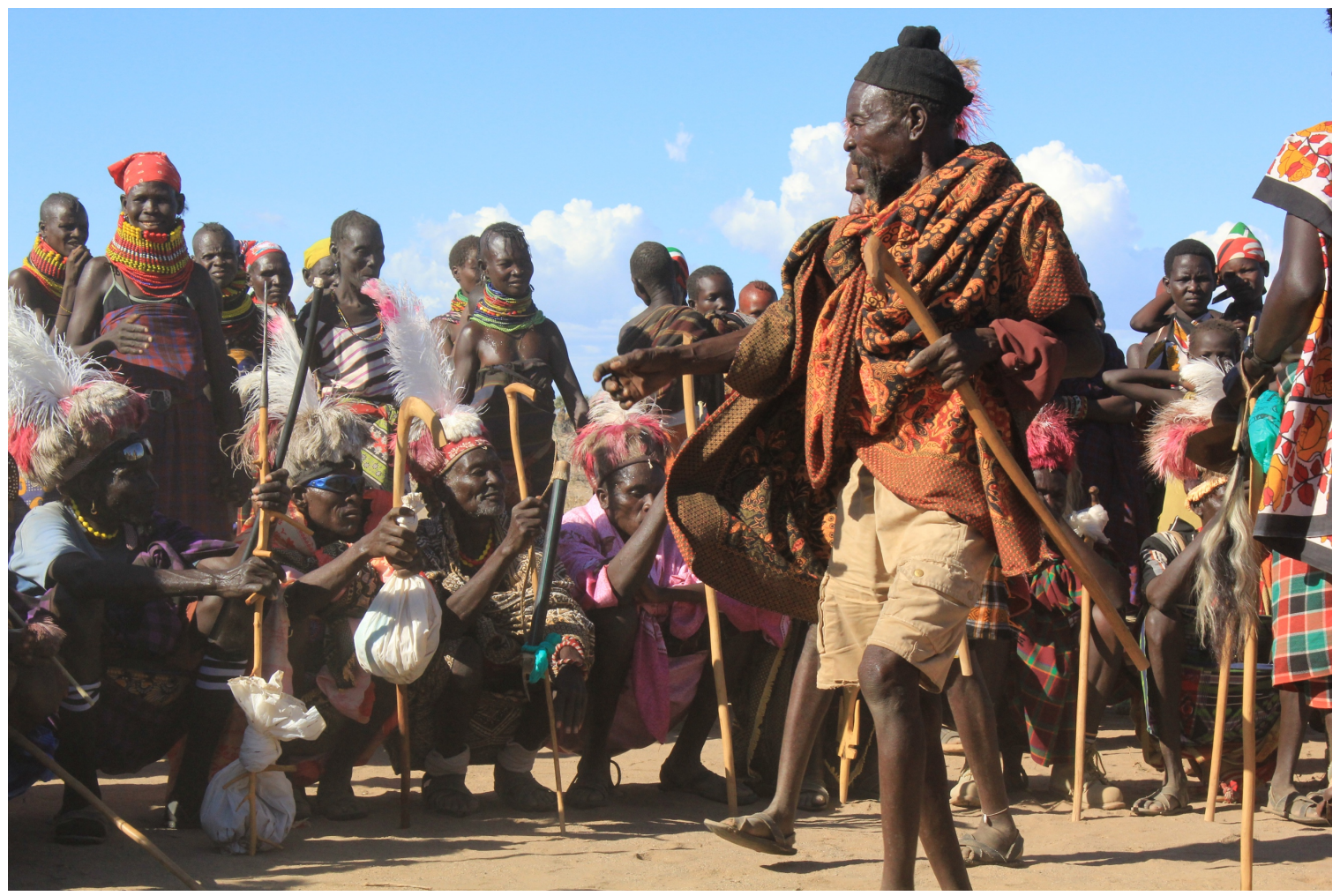

Figure 6.8. A man wearing a synthetic fibre hat as an apukot as he leads a dance at a wedding ceremony, October 2014.

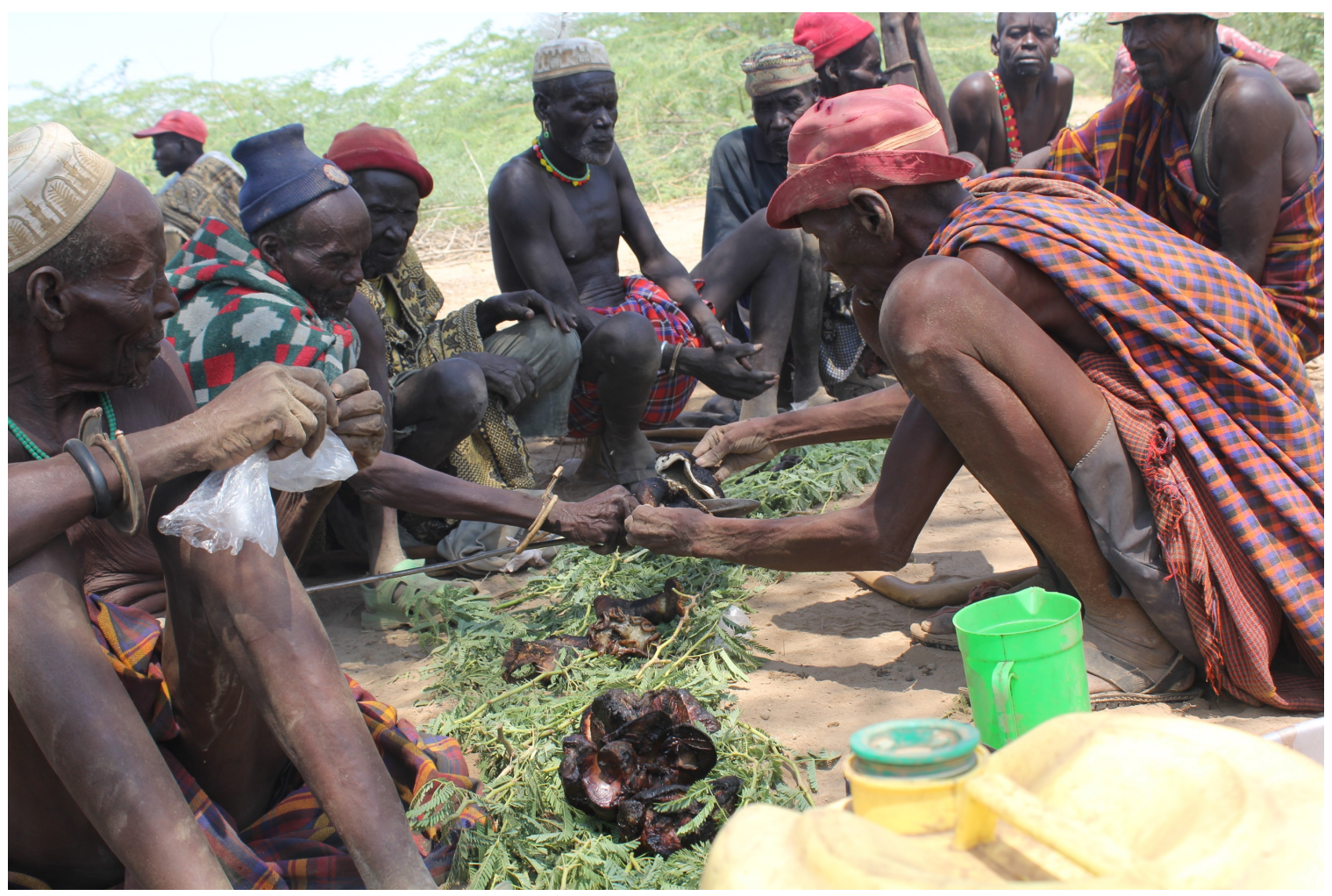

Figure 6.9. Elders wearing a variety of hat styles as ngapukoto during an akiriket ritual feast at an asapan (initiation) ceremony. 


\subsection{The curse of the Loriu Hills}

With regard to the themes of authority, livestock and the role of ngimurok, one particular incident, which I witnessed in September 2014, seems worthy of recounting before bringing this chapter to its conclusion. I attended a gathering of elders close to the Loriu Hills, which had been convened to address the livestock theft and violent conflict that had been impacting local communities in the area. During this meeting, the root cause of a recent intensification in raiding was quickly clarified to be a curse that a powerful emuron had placed on the hills several months previously. This emuron had gone raiding over the Loriu Hills on his own (an uncommon and fearless act for any raider, let alone an emuron), but many of the small livestock he retrieved had been appropriated by other individuals on his return, and he was left with almost nothing. Having been made angry by what he saw as an intolerable injustice, he returned to the Loriu Hills and fired several rounds of his AK-47 rifle into the air, placing a curse that would bring forth more raids than ever before for the Turkana communities who lived nearby; he then left abruptly for Kalokol. This episode was not only marked out by the local elders who had organised the meeting, but also by the Member of the County Assembly (MCA) for the ward in which the area lay, who was in attendance. Indeed, the MCA concluded the discussion by calling for arrangements to be made for livestock to be contributed to the emuron in question, so that his curse might be appeased. Many of those present responded by claiming that they would have to embark on further raids in order to accrue the livestock that were required.

This incident conveniently situates several of this chapter's key arguments within a contemporary setting. Perhaps most prominently, it indicates that the centrality of powerful ngimurok who are able to demonstrate their supernatural abilities to surrounding communities 
has by no means been diminished in recent years. In Section 6.2 I outlined how ngimurok invoke genealogies and corresponding histories of power contestations, cursing and raiding to substantiate their own abilities and, by extension, their authority. The activities of the emuron in the above story were no exception to this. Like any other emuron his power was entangled with, and made possible by, a communally accepted and regularly retold historical narrative. It is important to clarify however, that such narratives do not simply serve as backdrops for contemporary action. Influential ngimurok draw their power from their ancestors not simply by referring to them or remembering them, but by communing with them. Ancestors are decidedly present, they are often seen or heard, are able to harm or kill and occasionally possess mediums. Their enduring role in facilitating the activities of powerful ngimurok, such as the man mentioned in the above story, is not merely illustrative of the affectivity of the historical past but rather of its deep interfusion with the circumstances of the present. Histories do not simply contextualise or inform contemporary social, economic and political issues, but rather take part in them, serving as fundamental guiding ingredients.

Fontein (2015: 15) sees this dynamic, which he refers to as 'the imminence of the past', as something that inheres in the materiality of landscapes as much as it does in interactions with ancestors. He suggests that it 'further collapses conventional linear temporalities, so that it is the present that appears subdued as the past spills into (or out of) anticipated futures'. I would suggest that Fontein's interpretation might also inform the way we think about the embroiled historical processes of objectification and personification in Turkana and their entanglements with broader-scale shifting social, economic, environmental and political transformations. What I mean by this is that in the same way that contemporary practices are actively influenced by ancestors, everyday objects such as ngapukoto, plastic spoon/shell ornaments and guns, and the assortments of values, practices and institutions in which they are 
implicated, are not only made, used and experienced in relation to the past but are in fact continually and actively engaged in it. Their embodiment and enactment, through the sociomaterial conditions of the present, of histories of changing production, use and exchange render these histories enduringly imminent, and in so doing structure both the past and the present in equal measure by means of each other (cf. Miller 1987: 19-33, 2005; Rowlands 2005; Fowler 2010).

For example, the story entails an AK-47 performing as a medium for the conduction of formidable supernatural power, much like Kuwam's staff had done during his cursing of Looya Lodip in the story recounted by Marko Ekeno (in Section 6.2), or Lokerio's staff during his parting of Lake Turkana. It also involves a representative of Turkana's new County Government, which was established as part of the devolution of power from the national to local governments that followed Kenya's 2010 referendum. In both cases, novel components are not merely incorporated into inert categories (i.e. 'weaponry' and 'political leaders'), but rather implicated in a mutually transformative interplay with these categories (and their histories) that actively generates new social contexts. Automatic weapons affect the way ngimurok cast curses, and in so doing serve to subtly recast certain weapon-orientated histories, but their value and use is also a product of those histories. Similarly, the MCA's new office (and those of new local County Government officials in general) has served to redefine local politics in Turkana and to forge new historical interpretations in the process, but it is also legitimised (much like the offices of colonial-era chiefs were) by historically informed pre-existing socio-political dynamics. The maintenance and expression of his new authority is clearly interwoven both with his successful arbitration of livestock-centred predicaments (he protected local livestock from future raids and arranged for livestock reparations to be made to the emuron who cursed the hills) and with his pacification of, and 
identification with, a revered emuron. These explanations build on arguments put forward by Thomas (1999) in his examination of Polynesian tiputa ponchos, garments initially made primarily in Tahiti and widely associated with conversion to Christianity. Thomas (1999: 18) argues that these items are "neither inventions of tradition nor wholly unprecedented forms. They are at once implicated in the material history of Polynesian societies and departures from that history'.

Recognising the imminence of the past in contemporary practice, and its recursive entanglements in processes through which various broad economic, political and environmental changes are absorbed into daily life thus engenders an interpretation of the recent past that moves beyond a focus on apparently transformative disjuncture. The story of the curse of the Loriu Hills illustrates that whilst there have been substantial changes within the routines and strategies that structure contemporary raiding practices (as outlined above), livestock continue to be deeply entangled with power contestations and authority making. By extension, raiding arguably remains as firmly embedded in local politics as it was during the time of Etangan's famous raid in the 1960s, or indeed the era of resistance to colonial rule and the various periods that preceded it. However, the endurance of these characteristics (and the histories that they entail) as integral components of Turkana society and culture have also clearly emerged through their taking part in, and re-invention through, the various significant economic and political transformations of the post-Ekaru Asur years.

\subsection{Summary and conclusions}

The ideas presented in this chapter perhaps correlate to some degree with Galaty's (2013) recent discussion of the 'indigenisation of pastoral modernity', which develops a concept 
initially formulated by Sahlins (1999). Galaty's (2013: 474) work examines 'how pastoralists, whose herding strategies have relied on time-tried techniques and technologies and whose social relations are defined by customary institutions, confront and indeed embrace the modern world and bend it to their needs and interests'. Whilst the general sentiment that material and economic changes do not inevitably lead to radical social disjuncture or discontinuity clearly aligns with the arguments outlined in the latter half of this chapter, Galaty's explanation of this notion seems to rest upon a markedly dichotomous interpretation of pastoralist societies. They are envisioned as entities that comprise stable and unchanging repertoires of techniques, technologies and institutions that serve to domesticate and 'indigenise' the trappings of 'modernity'. This chapter has outlined a narrative of change that is at significant variance with such a picture, focusing less on the ways the Turkana have been concerned with merely contextualising novel materials, objects, institutions and practices and more on the resilient processes by means of which such elements become implicated in the production of new contexts through time (cf. Thomas 1999).

The relationship between herding and raiding, and the place of these activities in Turkana society, were by no means inert or passive prior to the increased infrastructural and economic development of the recent past. Nor were they contingent on rigid or perpetually static institutions, technologies or values. The livestock-centred universe of herding and raiding has instead been inherently fluid and compliant since beyond living memory, a constantly moving process of socio-material interaction, established upon and maintained through active adaptation and reshaping in relation both to shifting contemporary circumstances and a continually reinterpreted past. In this sense, whilst recent developments (emanating from 'modernity' or 'globalisation' etc.) may, from the outside, appear to be more pronounced than those that occurred in the past, the manner of their negotiation and incorporation (or 
'indigenisation') by Turkana communities is not novel or peculiar, nor does it preclude the generation or absorption of new values and practices. As I have argued in Chapters 4 and 5, this deep-seated and longstanding habitude of change is engrained in the daily activities of a broad spectrum of Turkana livelihoods and constituent communities, and indeed the relationships between these livelihoods and communities. It can be recognised, for example, in cultivating and fishing communities' adaptive engagements with both the environments and developing infrastructures around them as much as in the socio-political and economic dynamics of raiding and conflict.

As the final chapter of this thesis will discuss, the notion of a resilient process of adaptation at the heart of Turkana society and culture, which is not established upon the resistance of change but rather its dynamic integration and enactment, has numerous implications. Perhaps most importantly though, it serves to reframe the critical processes of socio-economic and environmental change that are expected to result both from ongoing oil exploration and extraction activities and the recent construction of the Gibe III Dam in southern Ethiopia. These activities, which I mentioned in Chapter 1, were key points of discussion, concern and activism within communities dispersed throughout southern Turkana during my fieldwork in 2014-2015. In Chapter 7, I consider how the arguments presented in this chapter, along with those presented in Chapters 4 and 5, cast them in a new light and emphasise the need for future research to focus on their complex local political ramifications and responses.

With regard to the specific themes of herding and raiding, it is clear that prevailing conceptualisations of these activities inadequately grasp both the complexity of their history and the modes of their interrelationship with the recent socio-economic development of northern Kenya. This is not by any means to suggest that the recurring and widespread 
devastation caused by regional conflict and inter-ethnic warfare (especially in recent years) should be repudiated or disregarded. Rather, current understandings of these issues, and indeed government and non-government organisations who are seeking actively to promote peace and security in the region, would arguably stand to gain a great deal from a temporally richer and more nuanced perspective as they come to terms with Turkana's unfolding future. 


\section{Chapter 7: Summary, Implications and Conclusions}

Throughout the central discussions of this thesis, I have woven together a series of historical narratives by exploring the changing organisation, constitutive practices, social institutions of and interactions between four of the most fundamental occupations sustaining the Turkana pastoral economy — fishing, cultivation, herding and raiding. In doing so, I have addressed a range of crucial questions concerning the ways in which Turkana society on the whole has coped with, experienced and adapted to the critical processes of socio-economic, environmental and political change that have manifested themselves in northern Kenya throughout the $20^{\text {th }}$ century. As outlined in Chapter 1 , one of my key underlying intentions has been to build an understanding of Turkana's history that diverges from more standard, implicitly accepted notions of recent change in such regions of the world as constituted by a linear progression of externally derived ruptures which accumulate over time and gradually serve to disintegrate or replace various pre-existing practices, cultural values and ways of life. I have instead drawn attention to the overarching continuities that can be apprehended over the long term, and argued that these strands intertwine to reveal a far more accurate picture of the overall nature of social change in Turkana than can be ascertained through synchronic examinations of seemingly decisive phenomena. Whilst not contingent on any kind of stasis or stability, these continuities nevertheless reveal a form of dynamic resilience that remains deeply rooted in Turkana society and culture today.

In this final chapter, I discuss the implications of this concept and of the thesis more generally. I do so firstly in relation to the overall issue of aid and interventionist development, considering some of the unquestioned and pervasive ideas that characterise these activities and the pressing need — emphasised by this thesis — to dismantle such ideas 
amidst the major socio-economic and political concerns that are currently facing the Turkana. I then consider the implications of my work for key ongoing debates and research areas within both the study of Turkana and of pastoralism in Africa more broadly. In Section 7.3 I discuss some methodological considerations, outlining how my research contributes to archaeological approaches to the recent past in Africa and how it argues for the importance of such research in the coming years. I conclude by outlining several key avenues of enquiry for the future.

\subsection{Aid, development and intervention in Turkana: past, present and future}

At the outset of this thesis, I remarked upon the impending socio-economic transformations that the Turkana region currently faces. I highlighted both the imminent downstream impacts of the recently constructed Gibe III Dam in southern Ethiopia and the socio-economic implications of the ongoing exploration and extraction of Turkana's extensive oil reserves. In doing so, I set my arguments up against the prevalent notion that these enterprises herald a future that departs dramatically from what has gone before - a supposed intensification of the forces of capitalist expansion and globalisation, which themselves are perhaps envisaged to have so far touched, but not yet comprehensively transformed, life in Kenya's remote northwest. If one is to accept many of the articles, reports and other commentaries that have emerged in the last few years, the Turkana, and indeed many other communities in the wider region, appear to be poised upon a precipice facing a set of ominous socio-economic and ecological outcomes. Whilst interpretations remain varied, social, environmental and political scientists, development analysists and journalists alike largely concur that the predicted ecological and economic transformations will not correlate with success, prosperity or continuity either within the Turkana pastoral economy or the cultural values and social 
institutions that uphold it (Johannes et al. 2015; Schilling et al. 2015; Enns and Bersaglio 2016; Carr 2017).

These sentiments are, on one level, understandable, particularly when envisioned in distinction to the rhetoric and policies generated by the governments, investors and private organisations who stand to benefit so extensively in the coming years. Cynicism and distrust are arguably not only warranted, but of critical importance in situations where communities as marginalised as the Turkana are set to endure the consequences of large-scale profitorientated projects managed and led by external bodies. However, the notion that various ensuing transformations will be inherently catastrophic for the livelihoods, practices or sociocultural institutions that organise daily life in Turkana is also clearly at odds with the picture of dynamic adaptation and recursive continuity that I have outlined in this thesis. More significantly, such a viewpoint is dramatically inconsistent with the perspectives of many Turkana communities and individuals in the present day who harbour great optimism and expectation for the unfolding future, particularly following the devolution engendered by Kenya's new (2010) constitution.

In this respect, one of the critical points of divergence between this thesis and much previous work dealing either with Turkana's recent past or its impending future is the regularly unacknowledged and unquestioned idea that the changes wrought by large-scale interventions into Turkana (past, present and future): (a) emerge entirely on their own terms, and (b) remain circumscribed in perpetuity by the conditions of their initial manifestation. This view, which I have attempted to dismantle by exploring numerous accounts of colonialism, commoditisation and development intervention (all often envisioned as points of rupture within linear temporalities), is perhaps an articulation of what Ferguson (1994a, 2006) sees as 
a more general, overly simplistic and outmoded vision of globalisation in Africa. Indeed, Ferguson (2006: 21) argues that many of the theories and discussions that have sought to characterise globalisation in Africa in recent years have presupposed trajectories of homogenisation or convergence that seem to invoke a tired and familiar 'continuum between a "premodern" tradition on the one hand, and a Euro-centrically conceived modernity on the other'. Such a view runs so deep in the so-called 'development discourse' that the policies, strategies and solutions pursued by development-orientated organisations are, for the most part, all subject to it in one way or another (cf. Escobar 1988, 1991, 2011; Schneider 1988). Moore's (2011: 9) response to this inadequately nuanced theoretical framework has been to argue for the abandonment of a view of globalisation 'that is too dependent on the binaries of impact/response, capitalism/culture, western/ non-western' altogether, and for a concentration instead on the ways in which 'new connections, new meanings, [and] novel forms of relation' are created.

Such a repositioning is pressing, for without it debates over processes of change that are widely seen to represent globalisation, whether conceived as social, economic or political in nature, will remain limited to questions of whether such change is 'good' or 'bad', 'right' or 'wrong' within a theoretical framework that implicitly reinforces a 'before-after' scenario. In recent years, such constrained debates have produced no shortage of studies seeking to portray the consequences of globalisation in Africa as profoundly negative (e.g. Smith 1997; Castells 2000; Bauman 2004; cf. Ferguson 2006). Still sorely missing in many contexts though, and particularly in Turkana, are studies that approach large-scale interventions and economic or political transformations in general as events within locally constituted histories to explore how they are embodied, coerced and reformed beyond the technological and methodological limits of their initial commencement and outside of the meanings more 
generically ascribed to them. This is not to suggest that development interventions are, on the whole, yet to be considered within their local historical contexts (to the contrary, see Berstein 1977; Heyer et al. 1981; Williams 1987), but that it remains relatively uncommon for research to explicitly seek out and explore the particular dynamics of their entanglements with, susceptibility to and efficacy within such contexts (although for an exception see Fontein 2015).

In addressing this absence with case studies from Turkana, one of my underlying intentions has been to extend the bounds of inquiry beyond the appealing yet reductive question of why or how Turkana's development interventions 'fail'. I have sought instead to emphasise the complex ways in which (regardless of their initial goals and whether these were achieved) their material and economic impacts, residues and possibilities have come to be entangled in already-ongoing locally-rooted processes of iterative transformation that are neither readily recognised nor easily impeded. In this sense, my arguments echo Ferguson's (2006: 29) point that deliberations that start and end with development's 'failures' are largely unhelpful, both in the sense that they rest on a tacit vision of development as an ideological force for good (which either succeeds or founders) and also because their negative characterisations 'risk ignoring the social, political, and institutional specificity of Africa and reinventing Africa as a $21^{\text {st }}$-century "dark continent”" (see also Ferguson 1994a; cf. Mudimbe 1988). My analyses might also, to a certain extent, be seen to build on various arguments made for viewing 'modernity' as grounds for the re-emergence (rather than obliteration) of socio-cultural differences (e.g. Hannerz 1987, 1992, 1996; Ong 1999; Sahlins 1999; Galaty 2013). However, as I stressed most prominently in Chapter 6, all the narratives I have explored defy interpretations of the recent past that envision practices, traditions or values as somehow 
fixed or stable prior to their reconstitution by means of the various economic, political and material trappings typically seen to represent 'modernity'. ${ }^{106}$

In addressing the question of Turkana's ongoing and anticipated socio-economic transformations, therefore, it is both inconsistent and inappropriate at this stage for me to dispense recommendations for how development might be executed more successfully in the coming years. To do so would not only be presumptuous, but also largely irrelevant considering that, according to the clear precedent I have explored in this thesis, the actual aims and objectives of large-scale projects, schemes and interventions rarely have any relevance to, or bearing on, the overall form of socio-economic change in Turkana. In other words, throughout recent history lasting changes within Turkana livelihoods, practices and social institutions have never simply been 'introduced' by intervening agents or organisations (despite their many attempts to do so), but rather have always been 'fought for and made... [by] all those with something at stake' (Ferguson 1994a: 281). Colonial and postcolonial government interventions, aid and development schemes, infrastructural growth, connections with urban centres and new commodities and many other seemingly intractable and transformative processes have all come to imbibe the 'active and affective traces of earlier lives and regimes forged in the substance of milieu' (Fontein 2015: 309). In doing so, they have served as the means for the limitless expression (rather than the constraint) of the innumerable possibilities and relationalities upon which such past traces insist.

\footnotetext{
${ }^{106}$ And in this sense, they question the general suitability of the term 'modernity' as a frame of reference within studies that engage with history and change across the 'developing world'. Arguably, labelling social, economic or material changes as articulations of 'modernisation' presupposes dramatic disjuncture and obscures numerous strands of continuity. It does so, moreover, by means of reasoning that is entirely extraneous to the local historical epistemologies that contextualise such changes.
} 
In this regard, whilst there is rightfully great uncertainty as to whether the extraction of Turkana's oil will engender the kind of widespread beneficial transformation that is forecast by establishment pundits, it is of great importance that socio-economic change in general is no longer venerated to the extent that it is afforded unwarranted gravity and significance, whether as the 'ghostly spectre' (Moore 2011: 5) that threatens to eradicate past values and traditions or as the saving grace that promises to alleviate poverty. As the future unfolds, it seems clear that the diverse segments that comprise Turkana society will each endeavour, as in the past, to find ways of crafting out and making real their desires and aspirations amidst the new contexts and possibilities that will be afforded by expanding industries and connections. Their dynamic orientation toward the world's shifting opportunities and constraints remains unchallenged and unthreatened no matter how transformative or decisive the encroaching era promises to be.

Arguably, if the satisfaction of these communities' varied hopes and ambitions is to be obstructed this will not be as a result of any particular type, rate or scale of socio-economic, political or even ecological change, but rather of bureaucratic and managerial exclusion and political suppression. Indeed, the only recommendation that it seems feasible for me to make would be for those engaged in the production of any form of Turkana-related knowledge that might carry influence to draw attention to such issues. It remains a common characteristic of development in Turkana (whether led by private investment or public funds) that communities are prevented from taking part in decision-making processes and marginalised from the elemental co-ordination and maintenance of the very economic and infrastructural change that is proclaimed to comprise their advancement and prosperity. Indeed, as oilrelated activities have escalated throughout the region over the past few years, local dissatisfaction with the lack of work opportunities, administrative participation, education 
and training has manifested itself in regular organised action. Roadblocks obstructing oil rigs and workers' camps and mass protests in various towns and centres have become a common occurrence, as I witnessed regularly throughout 2014 and 2015.

This unrest is, to a certain extent, amalgamated with and heightened by the discontent engendered by a long history of similar marginalisation reaching back to early colonial times. Yet, when one considers the ingenuity and productivity that have emerged throughout this history in the face of such significant disadvantages, there is no reason to doubt that the present unrest will become a fertile ground for new forms of political engagement, organisation and activism. Indeed, the devolution secured through Kenya's adoption of the 2010 constitution arguably provides a commensurate framework for such a political shift, and there is much evidence, although little discussion in academic contexts, to support the argument that the politics of land, belonging, identity, ethnicity and ownership will remain critical and productive points of debate within local grassroots movements and alliances for many years to come. I would argue that it is to these nascent discourses that international attention and support (both academic and otherwise) should be diverted in the coming years, and more urgently than to producing reports, proposals or recommendations that might assist the paternal guiding hand of governments, companies, planners and practitioners.

Clearly, the issues raised by the Gibe III Dam are strongly dissimilar to those raised by oil exploration and extraction, primarily because Gibe III is an already completed and largely irrevocable project that is unlikely ever to engage with the concerns and objectives of Turkana communities or leaders, despite the significant ecological impacts expected from it. This is not only because the dam has no physical presence either in Turkana or Kenya, but also because the Ethiopian government and its financial backers clearly have little concern 
for the numerous rural societies that have been, and will be, affected by their immense undertaking. ${ }^{107}$ It remains extremely difficult to discern which (or indeed which combination) of the many predictions made by hydrologists and other environmental scientists regarding Lake Turkana's future will eventually come to pass. Nevertheless, conversations with fishermen on either side of the lake point to an already significant reduction in water level. Of course, putting pressure on the Ethiopian government and its investors both to discontinue the diversion of water from the Omo into the Kuraz sugar plantation and to suspend the construction of any future dams can only be encouraged, no matter how futile this might seem. Within Kenya, it would arguably be extremely worthwhile to make fresh appeals to the national government to open up new lines of dialogue with the Ethiopian government on the issues facing Lake Turkana, and indeed to adopt a position that is more explicitly opposed to further damming of the Omo River. These objectives have already been assumed by various civil society groups in Turkana, whose work is a vital cause for assistance, attention and promulgation.

\subsection{Change, continuity and resilience}

With regard to the broader question of socio-economic change, and the manner in which gradual processes of transformation have been sustained within and between the core livelihoods that support the Turkana pastoral economy, I would argue that this thesis has implications for several key ongoing debates and research areas. First and foremost, it builds

\footnotetext{
${ }^{107}$ Indeed, not only did the Ethiopian government show an initial comprehensive lack of concern for informing rural communities within the Omo Valley of the ensuing construction of the Gibe III Dam several years ago, but they later forcibly relocated many of those communities to distant locations in a process termed 'villagisation' (Hathaway 2009; Abbink 2012; Allibhai 2014). They continue to demonstrate a patent disregard for the future livelihoods and collective prosperity of those affected by the dam.
} 
on works that have outlined the 'nonequilibrial' nature of Turkana pastoralism (Ellis and Swift 1988; McCabe 1990, 2004; as discussed in Chapter 3). In developing the core concept put forward in these discussions - that the Turkana pastoral economy endures by means of its capacity for incorporating and reflecting the uncertainty of its surroundings — I have uncovered a series of clear examples that testify to the temporal depth of this dynamic disposition. On a fundamental level, the histories I have explored demonstrate that Turkana's core livelihood systems and the networks of interaction that exist between them have never withstood change and uncertainty by resisting these forces or by maintaining stability or equilibrium despite them. Neither, for that matter, would any of the moments of crisis that have manifested themselves in recent history (such as the 1980 famine) be accurately envisaged as the breakdown of some form of balance or symmetry. Rather, the flexibility and open-endedness outlined in various recent more synchronic studies has been shown to be a deeply rooted characteristic that, over many decades of change, has facilitated the continual reworking and reshaping of the varied modes of subsistence procurement undertaken in the region.

Turkana's livelihoods, therefore, and the socio-economic avenues through which they cooperate, interact with and support each other are arguably poorly understood as secure or fixed forms of socio-ecological interaction that comprise a stable repertoire of responses to shifting circumstances. They might instead be more appropriately understood as modes of being characterised by particular orientations toward the world. Such orientations are resilient but not immutable. They are rooted in habitual daily practice and informed by the gradually accumulating knowledge and experience that is learned through collaborative interaction with the changing world. They surface continually in, take shape through and recursively influence the shifting and unpredictable circumstances of contemporary social action. 
Secondly, and by extension, inferences can be drawn from this thesis that bear on the broader question of how African pastoralism in general is to be engaged with in the contemporary world, particularly by individuals and organisations who wield the power and authority to galvanise large-scale action and investment from the international community. As I have argued above and throughout this thesis, high modernist technocratic development channelled through sweeping interventions has clearly experienced little to no success in Turkana, at least in relation to the initial aims and objectives that various schemes have been implemented to pursue. Despite this chronicle of apparent failure (which is by no means unique to either Turkana or Kenya), and despite the gradually accumulating critiques of development ideology and practice (Escobar 1988, 1991, 2011; Schneider 1988; Moyo 2009; Malkki 2015), it seems highly unlikely that the development industry and its pervasive culture will change substantially in the near future. Coupled with the enduring political marginalisation of the vast majority of pastoralist societies in Africa, this means that their immediate prospects remain tightly intertwined with the policies, financial contributions and activities of the network of international organisations that have taken on the mantle of assistance.

In this sense, one of the most central values of this thesis is its contribution to bodies of work that have emphasised the acute simplicity and inadequacy of the understandings of African pastoralist systems that continue to be held by the individuals and organisations with the greatest political and economic clout (Galaty and Bonte 1991; Fratkin 2001; Bollig et al. 2013; Krätli et al. 2013). As I outlined above, it is reductive for me to offer here specific recommendations for future development interventions either in Turkana or pastoralist regions of Africa more broadly. However, it seems clear that on a basic level a more detailed 
and nuanced picture of how various forms of African pastoralism operate within their socioeconomic, political and environmental contexts, and transform by means of these contexts over time, is well needed. Without this understanding, the present phase of initiatives, interventions and projects is fated to produce yet another series of challenges and barriers rather than the economic assistance and livelihood security that is generally intended. Schemes and projects will, once again, inevitably need to be overcome, repurposed and refashioned by the communities who uphold and sustain pastoral economies across Africa, rather than utilised as they stand. Sentiments along a similar line to this were recently expressed (specifically in relation to the issue of global climate change) by Krätli et al. (2013: 42), when arguing that:

'unless investments are shifted from replacing pastoralism to developing pastoralism on its own terms, we risk jeopardizing food security well beyond the limits of the drylands, and we risk missing the important lessons on turning environmental instability into an asset for food production'.

I would suggest that the pertinence of this thesis, both to debates over the nature of the Turkana pastoral economy and to more general questions regarding the future of pastoralism in Africa, stems from its overarching argument that resilience is best conceptualised and explored as a long-term process articulated by means of (rather than despite) broader socioeconomic change. As I outlined in Chapter 1, such a perspective diverges significantly from the conceptualisations put forward in many previous considerations of resilience in rural, non-industrialised societies. It does so most consequentially in its apprehension of socioeconomic, political and environmental change not as processes that are merely mediated through deeper, more stable, cultural values or knowledge repertoires, but rather as media for the continual making and remaking of Turkana identity, culture and society. 
A similar argument was recently put forward by Davies and Moore (2016) in relation to the agricultural systems of the Pokot and the Marakwet in western Kenya who, in distinction to many communities in Turkana, have dwelt in sedentary yet flexible settlements within irrigated agricultural landscapes for several centuries. Davies and Moore (2016: 82) envisage the management of resources along the Elgeyo Escarpment and the Kerio Valley as regulated by social and ecological cycles — 'technologies of life' — which contain 'inherent flexibilities with regard to movement, innovation and improvisation'. These cycles have, by means of their flexibility, accommodated a series of significant changes over the recent past in Marakwet and Pokot, whilst at the same time retaining 'broader balances between land, water, fertility and population'. To Davies and Moore (2016: 82), this propensity for retaining certain balances equates to a sense of 'enduring stability over the longue durée'.

Whilst the arguments I have presented largely concur with the concept of resilience as a feature of life that is articulated in long-term recursive cycles, I am less inclined to relate it in Turkana to the notion of stability. This may simply be a question of terminology, or may in fact stem from inherent dissimilarities between the long-term characters of societies engaged in intensive agriculture and those of societies that sustain pastoral economies. Either way, I would suggest that resilience in Turkana is not established upon stability, but rather forged through open-ended and dynamic interactions with a profoundly uncertain and unpredictable set of circumstances. In this sense, socio-cultural dispositions are not retained over the long term, so to speak, but rather implicated in a generative process of remaking that facilitates their regular subtle reorientation in relation to the changing possibilities and constraints of everyday life, whilst at the same time serving to refashion the operation, organisation and relationality both of grounded daily practices and of broader systems of subsistence procurement. Despite this minor dissonance, I would argue that the case studies I have 
explored in this thesis correspond closely with the arguments outlined by Davies and Moore, and make a strong case overall for the value of rethinking resilience in rural African societies.

\subsection{Methodological considerations and avenues for future research}

With regard to both its methodological and theoretical configuration, this thesis also contributes to the growing (both in size and diversity) corpus of archaeological research that focuses on recent African pasts and engages with the historical epistemologies of living African populations. On one level, both my initial fieldwork and my subsequent discussions of Turkana history have drawn on and combined various aspects of the full spectrum of such existing research, ranging from historical and postcolonial archaeologies (Lane 2011; Giblin 2014) to contemporary archaeology (González-Ruibal et al. 2008, 2011; Giblin 2016) and community archaeology (Chirikure and Pwiti 2008; Davies et al. 2014; Schmidt and Pikirayi 2016). In doing so, however, it has also offered a range of original ideas and examples that collectively underline the values, advantages and potentials that can more specifically be found in the application of archaeological reasoning to long-term ethnographic research in Africa.

Archaeology can, of course, lay claim to a long history of engagement with ethnographic methods and theories in the form of ethnoarchaeology (for key debates see Gould and Watson 1982; Wylie 1982; David and Kramer 2001; Lane 2005). However, I would suggest that there remains a great deal of undiscovered theoretical and methodological potential (of significance to both archaeology and anthropology) in the development of archaeological ethnographies that are conducted not for analogical reasoning but for the sake of exploring the histories, politics and current issues of contemporary African societies as important topics 
in their own right (cf. Gosden 1999). In a straightforward sense, I hope this thesis may attest to the fact that ethnographic approaches to African topics and case-studies still stand to gain a great deal from archaeological reasoning. Whilst my research in Turkana was largely organised around a rich, multi-temporal collection of historical photographs, this is by no means the only, or indeed the most desirable, form that future archaeological engagements with long-term ethnography in Africa might take. Neither, for that matter, should such engagements necessarily be structured around the theme of livelihoods or be focused on the concept of resilience, even though I have found these to be particularly profitable lines of enquiry in my own work. Many uncharted avenues remain and, considering the decisive impact that African livelihoods, identities and exchange systems have already had on the development of anthropological and archaeological understandings of the world (WynneJones and Fleisher 2015), great potential exists for identifying and exploring new African interpretations and explanations of globally significant events and processes.

Indeed, building on the groundwork laid down by those who have reframed precolonial East African history by emphasising the dynamism of its populations in distinction to the passivity implied by world-systems theory (Prestholdt 2004), there is now surely substantial scope for archaeology to significantly alter the way in which socio-economic change in the $20^{\text {th }}$ and $21^{\text {st }}$ centuries throughout the region and across Africa is envisaged. As outlined above and in Chapter 1, similar notions of passivity continue to dominate understandings of how African populations have coped with such recent changes. This thesis has emphasised the potential for archaeology, in conjunction with close community collaboration, to be used as a vehicle for unravelling the diverse local narratives, temporalities and socio-cultural continuities through which colonialism, postcolonialism, environmental change and globalisation make sense (cf. Fontein 2015). Realising this potential in other African contexts, and the 
'developing world' more generally, would arguably provide further opportunities for archaeology to confront, challenge and subvert the active legacies of its colonial past.

With regard to future research that might specifically be undertaken in Turkana, the potential is no less significant. As I outlined in Chapter 2, the fieldwork behind this thesis was predominantly limited to the southeastern portion of Turkana County. In this sense, there is fairly obvious scope for future studies to engage with histories in the northern and southwestern portions of Turkana, neither of which have seen extensive historical, anthropological or archaeological research focused on aspects of the last century. Having said this, even within Turkana's southeastern reaches many unexplored aspects of the recent past remain in significant need of attention. The discussions presented here have arguably done more to open up unexplored avenues of enquiry and emphasise various unanswered questions than to offer resolution. A closer, more intensive analysis of changing patterns of exchange over the last few decades would, for example, contribute invaluable insights to understandings of the process of commoditisation, which I considered in Chapter 5. Similarly, the arguments I presented in Chapter 6 concerning the changing constitution of Turkana corporate identity, would be greatly enriched by more exhaustive exploration of the complex politics of Turkana identity in the contemporary world, particularly in relation to the concurrence of devolution and the discovery, exploration and extraction of oil.

Moreover, all of these potential routes of investigation articulate with an even more significant and overarching scarcity in research, i.e. studies focused on the period between the initial Turkana migration into northern Kenya in the early $18^{\text {th }}$ century and the advent of colonial conquest at the turn of the $20^{\text {th }}$. Whilst Lamphear $(1988,1993)$ has considered this period in some depth via oral histories collected in the 1960s and 1970s, innumerable gaps 
and inconsistencies remain in what is currently known. An abundance of heretofore unexplored archaeological sites holds great value for ameliorating these deficiencies. Particularly noteworthy is the irrigation system of the Ngikebotok territorial section (as opposed to the general economic class) in the far southwest of Turkana, close to the border of Pokot County, which is potentially as old as the system employed by the neighbouring agricultural Pokot (i.e. several hundred years; Morgan 1974; Lamphear 1993; cf. Davies 2008). Of similar importance is the site of Moru a Nayeche, which lies at the headwaters of the Tarach River. As I noted in Chapter 2, this site is attributed in oral histories to the earliest arrival of Turkana herders into their current territory. A community-led archaeological investigation of this area would surely generate both data and discussions that would unveil invaluable new perspectives on Turkana origins and history more broadly. It might also be a positive enterprise for the communities and individuals who participate.

Whether focused on precolonial migration and expansion or the $20^{\text {th }}$ and $21^{\text {st }}$ centuries, future investigations of Turkana's rich history have a diverse array of questions to tackle. In providing new historical narratives they have the opportunity and, I would argue, the responsibility to actively dismantle the prevalent visual and rhetorical tropes that have arisen from the region's longstanding political and economic marginalisation. Challenging such prevalent visions may not solve any problems in the short term, but it would surely draw attention, as I hope this thesis has begun to do, to the silences and inequalities that continue to emerge within and by means of development-led intervention, thereby helping to counter and obstruct the emergence of new forms of marginalisation in the socio-economic and political contexts of the future. 


\section{Bibliography}

\section{Archival Documents}

UK National Archives (UKNA):

CO/1018/24 - Report on the Northern Frontier Province and Turkana, Colonial Office:

Lord Hailey Papers.

Kenyan National Archives (KNA):

TDAR-DC/Turk/1/1 — North Turkana and Turkana District Annual Report 1926.

PRB-DC/Turk/3/1 — Through Unknown African Countries; Notes on Northern Turkhana History; Letter Written by DR Crampton; History of the Turkana; Turkana District Report; Political History.

PRB-DC/Turk/3/2 - Handing Over Report; Reference Frontier Tribes.

LR-DC/Turk/8/1 — Reports of the Labur Patrol, Notes on the Merille Patrol.

\section{General References:}

Abbink, J. (1993) Reading the entrails: analysis of an African divination discourse. Man, 28: 705-726.

Abbink, J. (2000) Violence and the crisis of conciliation: Suri, Dizi and the state in southwest Ethiopia. Africa, 70: 527-550.

Abbink, J. (2006) Ethnicity and conflict generation in Ethiopia: some problems and prospects of ethno-regional federalism. Journal of Contemporary African Studies, 24: 389-413.

Abbink, J. (2012) Dam controversies: contested governance and developmental discourse on the Ethiopian Omo River dam. Social Anthropology, 20: 125-144.

Adams, M. (1986) Merging relief and development: the case of Turkana. Development Policy Review, 4: 313-324.

Adams, W. (1989) Definition and development in African indigenous irrigation. Azania, 24: 21-27.

Adams, W. (2003) Green Development: Environment and Sustainability in the Third World. London: Routledge.

Adams, W. and Anderson, D. (1988) Irrigation before development: indigenous and induced change in agricultural water management in East Africa. African Affairs, 87: 519-535. 
Adams, W. and Grove, A. (1984) Irrigation in Tropical Africa: Problems and Problem Solving. Cambridge: African Studies Centre.

African Union. (2010) Policy Framework for Pastoralism in Africa. Addis Ababa: African Union Commission.

Agade, K. (2015) Changes and challenges of the Kenya police reserve: the case of Turkana County. African Studies Review, 58: 199-222.

Ajulu, R. (2002) Politicised ethnicity, competitive politics and conflict in Kenya: a historical perspective. African Studies, 61: 251-268.

Amin, M. (1981) Cradle of Mankind. London: Chatto and Windus.

Anderson, B. (1983) Imagined Communities: Reflections on the Origins and Spread of Nationalism. London: Verso.

Anderson, D. (2000) Identity and Ecology in Arctic Siberia: The Number One Reindeer Brigade. Oxford: Oxford University Press.

Anderson, J. and O'Dowd, L. (1999) Borders, border regions and territoriality: contradictory meanings, changing significance. Regional Studies, 33: 593-604.

Appadurai, A. (Ed.). (1986) The Social Life of Things: Commodities in Cultural Perspective. Cambridge: Cambridge University Press.

Appiah, K. (1992) In My Father's House: Africa in the Philosophy of Culture. Oxford: Oxford University Press.

Ardener, E. (2007) The Voice of Prophecy: And Other Essays. Oxford: Berghahn.

Assmann, A. (1996) Texts, traces, trash: the changing media of social memory. Representations, 56: 123-134.

Austin, H. (1903) With Macdonald in Uganda: A Narrative Account of the Uganda Mutiny and Macdonald Expedition in the Uganda Protectorate and the Territories to the North. London: Edward Arnold.

Avery, S. (2012) Lake Turkana and the Lower Omo: Hydrological Impacts of Major Dam and Irrigation Developments. Oxford: African Studies Centre.

Balée, W. (1998) Introduction. In W. Balée (ed.) Advances in Historical Ecology. New York: Columbia University Press, 1-11.

Balée, W. and Erickson, C. (2006) Time, complexity and historical ecology. In W. Balée and C. Erickson. Time and Complexity in Historical Ecology: Studies in the Neotropical Lowlands. New York: Columbia University Press, 1-17.

Barret, A. (1998) Sacrifice and Prophecy in Turkana Cosmology. Nairobi: Paulines. 
Barringer, T. and Flyn, T. (1998) Colonialism and the Object. London: Routledge.

Barrow, E. (1990) Usufruct rights to trees: the role of Ekwar in dryland central Turkana, Kenya. Human Ecology, 18: 163-176.

Batchen, G. (1997) Photography's Objects. Albuquerque: University of New Mexico Art Museum.

Bates, D. and Lees, S. (1977) The role of exchange in productive specialization. American Anthropologist, 79: 824-841.

Bateson, G. (1972) Steps to an Ecology of Mind: Collected Essays in Anthropology, Psychiatry, Evolution, and Epistemology. New York: Ballantine.

Bauman, Z. (2004) Wasted Lives: New York: Polity Press.

Bayley, P. (1982) The commercial fishery of Lake Turkana. In A. J. Hopson (ed.) Lake Turkana: A Report on the Findings of the Lake Turkana Project (1972-1975). London: Overseas Development Agency, 349-557.

Behnke, R. and Scoones, I. (1993) Rethinking range ecology: implications for range management in Africa. In I. Behnke, I. Scoones and C. Kervin (eds.) Range Ecology at Disequilibrium: New Models of Natural Variability and Pastoral Adaptation in African Savannahs. London: Overseas Development Institute, 153-172.

Bell, J. (2003) Looking to see: reflections on visual repatriation in the Purari Delta, Gulf Province, Papua New Guinea. In L. Peers and A. Brown (eds.) Museums and Source Communities. London: Routledge, 111-122.

Bell, J. (2008) Promiscuous things: perspectives on cultural property through photographs in the Purari Delta of Papua New Guinea. International Journal of Cultural Property, 15: 123139.

Bell, J. (2010) Out of the mouths of crocodiles: eliciting histories in photographs and stringfigures. History and Anthropology, 21: 351-373.

Berkes, F. and Folke, C. (1998) Linking Social and Ecological Systems for Resilience and Sustainability. Cambridge: Cambridge University Press.

Bernstein, H. (1977) Notes on capital and peasantry. Review of African Political Economy, 4: 60-73.

Berry, S. (1992) Hegemony on a shoestring: indirect rule and access to agricultural land. Africa, 62: 327-355.

Beuving, J. (2013) Chequered fortunes in global exports: the sociogenesis of African entrepreneurship in the Nile perch business at Lake Victoria, Uganda. European Journal of Development Research, 25: 501-517. 
Bicker, A., Sillitoe, P. and Pottier, J. Eds. (2004) Investigating Local Knowledge: new directions and approaches. Aldershot, Hampshire: Ashgate Publishing.

Binney, J. and Chaplin, G. (2003) Taking the photographs home: the recovery of a Maori history. In L. Peers and A. Brown (eds.) Museums and Source Communities. London: Routledge, 100-110.

Blackburn, R. (1974) The Okiek and their history. Azania, 9: 139-157.

Bloch, M. and Parry, J. Eds. (1989) Money and the Morality of Exchange. Cambridge: Cambridge University Press.

Boivin, N. (2008) Material Cultures, Material Minds: The Impact of Things on Human Thought, Society, and Evolution. Cambridge: Cambridge University Press.

Bollig, M. (1990) Ethnic conflict in north-west Kenya: Pokot - Turkana raiding 1969-1984. Zeitschrift für Ethnologie, 115: 73-90.

Bollig, M., Schnegg, N. and Wotzka, H. (Eds.). (2013) Pastoralism in Africa: Past Present and Future. New York: Berghahn,

Bourdieu, P. (1977) Outline of a Theory of Practice. Cambridge: Cambridge University Press.

Bourdieu, P. (1984) Distinction: A Social Critique of the Judgement of Taste. London: Routledge.

Bourdieu, P. (1990) The Logic of Practice. Cambridge: Polity Press.

Broch-Due, V. (1986) From Herd to Fish and from Fish to Food Aid: The Impact of Development on Fisherfolk Along the Shores of Lake Turkana. Bergen: Centre for Development Studies.

Broch-Due, V. (1999) Remembered cattle, forgotten people: the morality of exchange and the exclusion of the Turkana poor. In D. M. Anderson and V. Broch-Due (eds.) The Poor Are not Us: Poverty and Pastoralism in Eastern Africa. Oxford: James Currey, 50-88.

Broch-Due, V. and Sanders, T. (1999) Rich man, poor man, administrator, beast: the politics of impoverishment in Turkana, Kenya, 1890-1990. Nomadic Peoples, 3: 35-55.

Broch-Due, V. and Störas, F. (1983) Fields of Foe, Factors Constraining Agricultural Output and Farmers' Capacity for Participation. Bergen: University of Bergen, NORAD.

Brokensha, D., Warren, D and Werner, O. (1980) Indigenous Knowledge Systems and Development. Lanham, Maryland: University Press of America.

Brown, L. (1971) The biology of pastoral man as a factor in conservation. Biological Conservation, 3: 93-100. 
Brown, M. (1989) Where Giants Trod: The Saga of Kenya's Desert Lake. Long Beach, California: Safari Press.

Brzoska, M. and Pearson, F. (1994) Developments in the global supply of arms: opportunity and motivation. The Annals of the American Academy of Political and Social Science, 535: $58-72$.

Buchli, V. and Lucas, G. (2001) The Archaeology of Alienation: A Late $20^{\text {th }}$ Century British Council House. London: Routledge.

Butzer, K. (1971) Recent History of an Ethiopian Delta: The Omo River and the level of Lake Rudolf. Chicago: Department of Geography.

Cappon, J. (2003) Why Do Communities Want Arms? Community Security, Small Arms and Governance in the Kerio Valley - Controlling the Demand for Small Arms: The Search for Strategies in the Horn of Africa and in the Balkans. The Hague: Pax Christi.

Carr, C. (2017) River Basin Development and Human Rights in Eastern Africa - A Policy Crossroads. Berkeley: Springer.

Carrier, N. and Quaintance, K. (2012) Frontier Photographs: northern Kenya and the Baxter collection. In R. Vokes (ed.) Photography in Africa, Ethnographic Perspectives.

Woodbridge: James Currey, 81-103.

Carrithers, M., Candea, M., Sykes, K., Holbraad, M. and Venkatesan, S. (2010) Ontology is just another word for culture. Critique of Anthropology, 30: 152-200.

Castells, M. (2000) End of Millennium. London: Blackwell.

Catley, A., Lind, J. and Scoones, I. Eds. (2013) Pastoralism and Development in Africa: Dynamic Change at the Margins. London: Routledge.

Chaliand, G. (1978) The Horn of Africa's dilemma. Foreign Policy, 30: 116-131.

Chanock, M. (1985) Law, Custom and Social Order: The Colonial Experience in Malawi and Zambia. Cambridge: Cambridge University Press.

Chapman, J. (1996) Enchainment, commodification, and gender in the Balkan Copper Age. Journal of European Archaeology 4: 203-242.

Chirikure, S. and Pwiti, G. (2008) Community involvement in archaeology and cultural heritage management: an assessment from case studies in Southern Africa and elsewhere. Current Anthropology, 49: 467-485.

Choge, S., Pasiecznik, N., Harvey, M., Wright, J., Awan, S. and Harris, P. (2007) Prosopis pods as human food, with special reference to Kenya. Water $S A$, 33: 419-424.

Clay, E. (1986) Rural public works and food-for-work: a survey. World Development, 14: 1237-1252. 
Clifford, J. (1991) Four northwest coast museums: travel reflections. In I. Karp and S. Lavine (eds.) The Poetics and Politics of Museum Display. Washington: Smithsonian Institution Press, 212-254.

Clifford, J. (1997) Museums as contact zones. In J. Clifford (ed.) Routes: Travel and Translation in the Late Twentieth Century. Cambridge: Harvard University Press, 188-219.

Clifford, J. and Marcus, G. (Eds.). (1986) Writing Culture: The Poetics and Politics of Ethnography. Berkeley: University of California Press.

Collier, J. and Collier, M. (1986) Visual Anthropology: Photography as a Research Method. Albuquerque: University of New Mexico Press.

Colwell-Chanthaphonh, C. (2012) Archaeology and indigenous collaboration. In I. Hodder (ed.) Archaeological Theory Today. Cambridge: Polity Press, 267-291.

Colwell-Chanthaphonh, C., Ferguson, T., Lippert, D., McGuire, R., Nicholas, G., Watkins, J. and Zimmerman, L. (2010) The premise and promise of indigenous archaeology. American Antiquity, 75: 228-238.

Comaroff, J. (1991) Missionaries and mechanical clocks: an essay on religion and history in South Africa. The Journal of Religion, 71: 1-17.

Coombes, A. (1994) Reinventing Africa: Museums, Material Culture and Popular Imagination in Late Victorian and Edwardian England. New Haven: Yale University Press.

Coupaye, L. and Douny, L. Dans la trajectoire des choses: comparaison des approaches francophones et anglophones contemporaines en anthropologie des techniques. Techniques et Culture, 52-3: 12-39.

Cronk, L. (2002) From true Dorobo to Mukogodo Maasai: Contested ethnicity in Kenya. Ethnology, 41: 27-49.

Crooke, E. (2008) Museums and the Community: Ideas, Issues and Challenges. London: Routledge.

Crowder, M. (1964) Indirect rule - French and British style. Africa, 34: 197-205.

Crumley, C. (1994) Historical ecology: a multidimensional ecological orientation. In C. Crumley (ed.) Historical Ecology: Cultural Knowledge and Changing Landscapes. Santa Fe: School of American Research Press, 1-16.

Cullis, A. and Pacey, A. (1992) A Development Dialogue: Rainwater Harvesting in Turkana. London: IT publications.

David, N. and Kramer, C. (2001) Ethnoarchaeology in Action. Cambridge: Cambridge University Press.

Davies, M. (2008) The irrigation system of the Pokot, northwest Kenya. Azania, 43: 50-76. 
Davies, M. (2010) A view from the east: an interdisciplinary 'historical ecology' approach to a contemporary agricultural landscape in northwest Kenya. African Studies, 69: 279-297.

Davies, M. (2012) Some thoughts on a "useable" African archaeology: settlement, population and intensive farming among the Pokot of northwest Kenya. African Archaeological Review, 29: 319-353.

Davies, M., Kipruto, T. and Moore, H. (2014) Revisiting the irrigated agricultural landscape of the Marakwet, Kenya: tracing local technology and knowledge over the recent past. Azania, 49: 486-523.

Davies, M. and Moore, H. (2016) Landscape, time and cultural resilience: a brief history of agriculture in Pokot and Marakwet, Kenya. Journal of Eastern African Studies, 10: 67-87.

Dawdy, S. (2009) Millennial archaeology. Locating the discipline in the age of insecurity. Archaeological Dialogues, 16 (2): 131-142.

De Castro, E. (1998) Cosmological deixis and Amerindian perspectivism. Journal of the Royal Anthropological Institute, 4: 469-488.

De Castro, E. (2014) Cannibal Metaphysics. Minneapolis: Univocal.

Deetz, J. (1977) In Small Things Forgotten: An Archaeology of Everyday Life in Early America. New York: Anchor/ Doubleday.

Deitler, M. and Herbich, I. (1993) Living on Luo time: reckoning sequence, duration, history and biography in a rural African society. World Archaeology, 25: 248-260.

Denbow, J., Mosothwane, M. and Ndobochani, N. (2009) Everybody here is all mixed up: postcolonial encounters with the past at Bosutswe, Botswana. In P. Schmidt (ed.)

Postcolonial Archaeologies in Africa. Santa Fe: School of American Research Press, 211230.

Derbyshire, S. (Forthcoming) Trade, development and destitution: a material culture history of fishing on the western shore of Lake Turkana, northern Kenya. African Studies, 77.

Derbyshire, S. and Lowasa, L. (Forthcoming) The ruins of Turkana: an archaeology of failed development in northern Kenya. In N. Berre, N. Hoyum, P. Geissler and J. Lagae (eds.) Forms of Freedom: Legacies of African Modernism. Bristol: Intellect.

Desai, G. (2010) Oceans connect: the Indian Ocean and African Identities. PMLA, 125 (3): 713-720.

Descola, P. (2005) Par-delà Nature et Culture. Paris: Éditions Gallimard.

Dietz, T. (1987) Pastoralists in Dire Straits: Survival Strategies and External Interventions in a Semiarid Region at the Kenya/Uganda Border: Western Pokot, 1900-1986. Amsterdam: University of Amsterdam Institute of Social Geography. 
Dietz, T. (1993) The state, the market and the decline of pastoralism: challenging some myths, with evidence from western Pokot in Kenya/ Uganda. In J. Markakis (ed.) Conflict and the Decline of Pastoralism in the Horn of Africa. London: Macmillan, 83-99.

Doornbos, M. (1993) Pasture and Polis: the roots of political marginalization of Somali pastoralism. In J. Markakis (ed.) Conflict and the Decline of Pastoralism in the Horn of Africa. London: Macmillan, 100-121.

Dowker, B. (1963) Sorghum and millet in Machakos District. East African Agricultural and Forestry Journal, 29: 52-57.

Dreyfus, H. (1991) Being-in-the-World: A Commentary on Heidegger's Being and Time, Division 1. Cambridge: MIT Press.

Durkheim, E. (1915) The Elementary Forms of Religious Life: A Study in Religious Sociology. London: Allen and Unwin.

Dyson-Hudson, N. (1966) Karimojong Politics. Oxford: Clarendon Press.

Dyson-Hudson, N. (1972) The study of nomads. Journal of Asian and African Studies, 7: 229.

Dyson-Hudson, R. (1999) Turkana in time perspective. In M. Little and P. Leslie (eds.) Turkana Herders of the Dry Savannah: Ecology and Biobehavioural Response of Nomads to an Uncertain Environment. Oxford: Oxford University Press, 25-42.

Dyson-Hudson, R. and Dyson-Hudson, N. (1980) Nomadic pastoralism. Annual Review of Anthropology, 9: 15-61.

Dyson-Hudson, R. and McCabe, J. (1983) Water resources and livestock movements in South Turkana, Kenya. Nomadic Peoples, 14: 41-46.

Dyson-Hudson, R. and McCabe, T. (1985) South Turkana Nomadism: Coping with an Unpredictably Varying Environment. New Haven: Human Relation Area Files.

Dyson-Hudson, R. and Meekers, D. (1996) The universality of African marriage reconsidered: evidence from Turkana males. Ethnology, 35: 301-320.

Dyson-Hudson, R., Meekers, D. and Dyson-Hudson, N. (1998) Children of the dancing ground, children of the house: costs and benefits of marriage rules (south Turkana, Kenya). Journal of Anthropological Research, 54: 19-47.

Eaton, D. (2010) The rise of the "trader": the commercialisation of raiding in Karamoja. Nomadic Peoples, 14: 106-122.

Edwards, E. (2001) Raw Histories: Photographs, Anthropology and Museums. Oxford: Berg.

Edwards, E. (2002) Material beings: objecthood and ethnographic photographs. Visual Studies, 17: 67-75. 
Edwards, E. (2003) Talking visual histories: introduction. In L. Peers and A. Brown (eds.) Museums and Source Communities. London: Routledge, 83-99.

Edwards, E. (2010) Imagined Time: Thesiger, photography and the past. In C. Morton and P. Grover (eds.) Wilfred Thesiger in Africa. London: Harper Press, 106-115.

Ehret, C. (2001) Bantu expansions: re-envisioning a central problem of early African history. International Journal of African Historical Studies, 34: 5-41.

Ehret, C. (2002) The Civilizations of Africa: A History to 1800. Charlottesville: University Press of Virginia.

Ehret, C. and Posnansky, M. (Eds.). (1982) The Archaeological and Linguistic Reconstruction of African History. Berkeley: University of California Press.

Ellis, J., Coughenour, M. and Swift, D. (1991) Climate variability, ecosystem stability, and the implications for range and livestock development. In R. Cincotta, C. Gay and G. Perrier (eds.) Proceedings of the 1991 International Rangeland Development Symposium, New Concepts in International Rangeland Development: Theories and Applications. Logan: Utah State University, Department of Range Science, 1-12.

Ellis, J., Coughenour, M. and Swift, D. (1993) Climate variability, ecosystem stability, and the implications for range and livestock development. In R. Behnke, I. Scoones and C. Kerven (eds.) Range Ecology at Disequilibrium: New Models of Natural Variability and Pastoral Adaptation in Africa Savannahs. London: Overseas Development Institute, 31-41.

Ellis, J., Galvin, K., McCabe, T. and Swift, D. (1987) Pastoralism and Drought in Turkana District, Kenya. Final Report to the Norwegian Agency for International Development. Oslo: NORAD.

Ellis, J. and Swift, D. (1988) Stability of African pastoral ecosystems: alternate paradigms and implications for development. Rangeland Ecology and Management, 41: 450-459.

Emley, E. (1927) The Turkana of Kolosia District. Journal of the Royal Anthropological Institute of Great Britain and Ireland, 57: 157-201.

Enns, C. and Bersaglio, B. (2016) Pastoralism in the time of oil: youth perspectives on the oil industry and the future of pastoralism in Turkana, Kenya. The Extractive Industries and Society, 3: 160-170.

Escobar, A. (1988) Power and visibility: development and the invention and management of the Third World. Cultural Anthropology, 3: 428-443.

Escobar, A. (1991) Anthropology and the development encounter: the making and marketing of development anthropology. American Ethnologist, 18: 658-682.

Escobar, A. (2011) Encountering Development: The Making and Unmaking of the Third World. Princeton: Princeton University Press.

Evans-Pritchard, E. (1939) Nuer time-reckoning. Africa, 12: 189-216. 
Evans-Pritchard, E. (1940) The Nuer: A Description of the Modes of Livelihood and Political Institutions of a Nilotic People. Oxford: Clarendon Press.

Fabian, J. (1983) Time and the Other: How Anthropology Makes its Object. New York: Columbia University Press.

Ferguson, J. (1994a) The Anti-Politics Machine: "Development", Depoliticization, and Bureaucratic Power in Lesotho. Minneapolis: University of Minnesota Press.

Ferguson, J. (1994b) Modernist narratives, conventional wisdoms, and colonial liberalism: reply to a straw man. Journal of Southern African Studies, 20: 633-640.

Ferguson, J. (2006) Global Shadows: Africa in the Neoliberal World Order. Durham: Duke University Press.

Fontein, J. (2015) Remaking Mutirikwi: Landscape, Water and Belonging in Southern Zimbabwe. Oxford: James Currey.

Fontein, J. (2017) Epilogue. In S. Jensen and O. Zenker (eds.) South African Homelands as Frontiers: Apartheid's Loose Ends in the Postcolonial Era. London: Routledge.

Food and Agriculture Organisation. (1986) Irrigation in Africa South of the Sahara - FAO Investment Centre Technical Paper no. 5. Rome: UN.

Fortier, J. (2009) Kings of the Forest: The Cultural Resilience of Himalayan HunterGatherers. Honolulu: University of Hawai'i Press.

Foucault, M. (1979) Discipline and Punish: The Birth of the Prison. New York: Vintage Books.

Fowler, C. (2010) From identity and material culture to personhood and materiality. In D. Hicks and M. Beudry (eds.) Oxford Handbook of Material Culture Studies. Oxford: Oxford University Press, 352-385.

Fratkin, E. (1986) Stability and resilience in East African pastoralism: the Rendille and the Ariaal of northern Kenya. Human Ecology, 14: 269-286.

Fratkin, E. (2001) East African pastoralism in transition: Maasai, Boran, and Rendille cases. African Studies Review, 44: 1-25.

Fredriksen, P. and Bandama, F. (2016) The mobility of memory: space/knowledge dynamics in rural potting workshops in Limpopo Province, South Africa. Azania, 51: 489-506.

Fukui, K. and Markakis, J. Eds. (1994a) Ethnicity and Conflict in the Horn of Africa. London: James Currey.

Fukui, K. and Markakis, J. (1994b) Introduction. In K. Fukui and J. Markakis (eds.) Ethnicity and Conflict in the Horn of Africa. London, James Currey, 1-11. 
Fukui, K. and Turton, D. (Eds.). (1979) Warfare Among East African herders. Osaka: National Museum of Ethnology.

Galaty, J. (2013) The indigenisation of pastoral modernity: territoriality, mobility and poverty in Dryland Africa. In M. Bollig, M. Schnegg and H. Wotzka (eds.) Pastoralism in Africa: Past Present and Future. New York: Berghahn, 473-510.

Galaty, J. and Bonte, P. (Eds.). (1991) Herders, Warriors, and Traders: Pastoralism in Africa. Boulder: Westview.

Galvin, K. (1985) Food Procurement, Diet, Activities and Nutrition of Ngisonyoka, Turkana Pastoralists in an Ecological and Social Context. Unpublished PhD thesis, State University of New York.

Gebre, Y. (2012) Environmental Change, Food Crises and Violence in Dassanech, Southern Ethiopia. Berlin: Freie Universität Berlin.

Gebresenbet, F. and Kefale, A. (2012) Traditional coping mechanisms for climate change of pastoralists in South Omo, Ethiopia. Indian Journal of Traditional Knowledge, 11: 573-579.

Geheb, K. (1995) Exploring people-environment relationships: The changing nature of the small-scale fishery in the Kenyan sector of Lake Victoria. In T. Binns (ed.) People and Environment in Africa. Chichester: John Wiley, 91-101.

Geheb, K. and Binns, T. (1997) "Fishing farmers" or "farming fishermen"? The quest for household income and nutritional security on the Kenyan shores of Lake Victoria. African Affairs, 96: 73-93.

Gell, A. (1992) The Anthropology of Time: Cultural Constructions of Temporal Maps and Images. Oxford: Berg.

Gell, A. (1998) Art and Agency: An Anthropological Theory. Oxford: Clarendon Press.

Giblin, J. (2010) Reconstructing the past in post-genocide Rwanda: an archaeological contribution. Azania, 45: 341.

Giblin, J. (2012) Decolonial challenges and post-genocide archaeological politics in Rwanda. Public Archaeology, 11: 123-143.

Giblin, J. (2014) Toward a politicised interpretation ethic in African archaeology. Azania, 49: 148-165.

Giddens, A. (1984) The Constitution of Society: Outline of the Theory of Structuration. Berkley: University of California Press.

Githui, F., Gitau, W., Mutua, F. and Bauwens, W. (2009) Climate change impact on SWAT stimulated streamflow in western Kenya. International Journal of Climatology, 29: 18231834. 
Glowacki, L. and Wrangham, R. (2015) Warfare and reproductive success in a tribal population. Proceedings of the National Academy of Sciences (USA), 112: 348-353.

González-Ruibal, A. (2006) The past is tomorrow: towards an archaeology of the vanishing present. Norwegian Archaeological Review, 39: 110-125.

González-Ruibal, A. (Ed.). (2013) Reclaiming Archaeology: Beyond the Tropes of Modernity. London: Routledge.

González-Ruibal, A., Edensor, T., Funari, P., Hall, M., Holtorf, C., Leone, M., Meskell, L., Oliver, L., Saunders, N., Schofield, J. and Zarankin, A. (2008) Time to destroy: an archaeology of supermodernity. Current Anthropology, 49: 247-279.

González-Ruibal, A., Hernando, A. and Politis, G. (2011) Ontology of the self and material culture: arrow-making among the Awá hunter-gatherers (Brazil). Journal of Anthropological Archaeology, 30: 1-16.

González-Ruibal, A., Sahle, Y. and Villa Ayán, X. (2011) A social archaeology of colonial war in Ethiopia. World Archaeology, 43: 40-65.

Gooch, P. (2009) Victims of conservation or rights as forest dwellers: Van Gujjar pastoralists between contesting codes of law. Conservation and Society, 7: 239-248.

Gosden, C. (1994) Social Being and Time. Oxford: Blackwell.

Gosden, C. (1999) Anthropology and Archaeology: A Changing Relationship. London: Routledge.

Gosden, C. (2001) Making sense: archaeology and aesthetics. World Archaeology, 33: 163167.

Gosden, C. (2012) Post-colonial archaeology. In I. Hodder (ed.) Archaeological Theory Today. Cambridge: Polity Press, 251-266.

Gosden, C. and Head, L. (1994) Landscape - a usefully ambiguous concept. Archaeology in Oceania, 29: 113-116.

Gosden, C. and Knowles, C. (2001) Collecting Colonialism: Material Culture and Colonial Change. Oxford: Berg.

Gosden, C. and Marshall, Y. (1999) The cultural biography of objects. World Archaeology, 31: 169-178.

Gould, R. and Watson, P. (1982) A dialogue on the meaning and use of analogy in ethnoarchaeological reasoning. Journal of Anthropological Archaeology, 1: 355-381.

Goulden, M., Conway, D. and Persechino, A. (2009) Adaptation to climate change in international river basins in Africa: a review. Hydrological Sciences Journal, 54: 805-828. 
Gownaris, N., Pilkitch, E., Aller, J., Kaufmen, L., Kolding, J., Lwiza, K., Obiero, K., Ojwang, W., Malala, J. and Rountos, K. (2016) Fisheries and water level fluctuations in the world's largest desert lake. Ecohydrology, 10: 1-16.

Gray, S., Sundal, M., Wiebusch, B., Little, M., Leslie, P., Pike, I., Borgerhoffmulder, M., Schlee, G. and Sellen, D. Cattle raiding, cultural survival, and adaptability of East African pastoralists. Current Anthropology, 44: 3-30.

Greer, S., Harrison, R. and Mcintyre-Tamwoy, S. (2002) Community-based archaeology in Australia. World Archaeology, 34: 265-278.

Guliver, P. (1951) A Preliminary Survey of the Turkana: A Report Compiled for the Government of Kenya. Cape Town: School of African Studies, University of Cape Town.

Gulliver, P. (1955) The Family Herds: A Study of Two Pastoral Tribes in East Africa. London: Routledge.

Guliver, P. (1958) Turkana age organization. American Anthropologist, 60: 900-922.

Hadler, J. (2008) Muslims and Matriarchs: Cultural Resilience in Indonesia Through Jihad and Colonialism. Ithaca: Cornell University Press.

Halliday, F. (1977) US policy in the Horn of Africa: aboulia or proxy intervention?. Review of African Political Economy, 4(10): 8-32.

Hannerz, U. (1987) The world in creolization. Africa, 57: 546-59.

Hannerz, U. (1992) Cultural Complexity: Studies in the Social Organization of Meaning. New York: Columbia University Press.

Hannerz, U. (1996) Transnational Connections: Culture, People, Places. New York: Routledge.

Hardin, G. (1968) The tragedy of the commons. Science, 162: 1243-1248.

Harlan, T. (1995) Creating a visual history: a question of ownership. In P. Roalf (ed.) Strong Hearts: Native American Visions and Voices. New York: Aperture, 20-32.

Harmand, S., Lewis, J., Feibel, S., Lepre, C., Prat, S., Lenoble, A. and Taylor, N. (2015) 3.3million-year-old stone tools from Lomekwi 3, West Turkana, Kenya. Nature, 521: 310-315.

Harris, O. (1989) The earth and the state: the sources and meanings of money in northern Potosi, Bolivia. In M. Bloch and J. Parry (eds.) Money and the Morality of Exchange. Cambridge: Cambridge University Press, 232-268.

Harrison, R. (2013) Scratching the surface: reassembling and archaeology in and of the present. In A. González-Ruibal (ed.) Reclaiming Archaeology: Beyond the Tropes of Modernity. London: Routledge, 44-55.

Harrison, R. and Williamson, C. (2004) After Captain Cook: The Archaeology of the Recent Indigenous Past in Australia. Walnut Creek: AltaMira Press. 
Headrick, D. (1981) The Tools of Empire: Technology and European Imperialism in the Nineteenth Century. Oxford: Oxford University Press.

Hegel, G. (1977) Hegel's Phenomenology of Spirit. Oxford: Oxford University Press.

Heidegger, M. (1962) Being and Time. New York: Harper and Row.

Heidegger, M. (1971) Poetry, Language, Thought. New York: Harper and Row.

Heidegger, M. (1977) The Question Concerning Technology and Other Essays. New York: Harper and Row.

Henare, A., Holbraad, M. and Wastell, S. (Eds.). (2007) Thinking Through Things:

Theorising Artefacts Ethnographically. London: Routledge.

Hendrickson, D., Mearns, R. and Armon, J. (1996) Livestock raiding among the pastoral Turkana of Kenya: redistribution, predation and the links to famine. IDS Bulletin, 27(3): 1730 .

Hendrickson, D., Armon, J. and Mearns, R. (1998a) The changing nature of conflict and famine vulnerability: the case of livestock raiding in Turkana District, Kenya. Disasters, 22: 185-199.

Hendrickson, D., Armon, J. and Mearns, R. (1998b) Conflict and Vulnerability to Famine: Livestock Raiding in Turkana, Kenya. London: International Institute for Environment and Development.

Henriksen, G. (1974) Economic growth and ecological balance, problems of development in Turkana. University of Bergen Occasional Papers 11.

Heyer, J., Roberts, P. and Williams, G. (Eds.). (1981) Rural Development in Tropical Africa. London: Macmillan Press.

Heywood, P. (2012) Anthropology and what there is: reflections on "ontology". Cambridge Anthropology, 30: 143-151.

Hicks, D. (2010) The material-cultural turn: event and effect. In D. Hicks and M. Beaudry (eds.) The Oxford Handbook of Material Culture Studies. Oxford: Oxford University Press, 25-98.

Hill, J. (Ed.). (1988) Rethinking History and Myth: Indigenous South American Perspectives on the Past. Urbana, Illinois: University of Illinois Press.

Hillman, F. (1980) Water Harvesting in Turkana District, Kenya. London: Overseas Development Institute.

Hodder, I. (1982) Symbols in Action: Ethnoarchaeological Studies of Material Culture. Cambridge: Cambridge University Press. 
Hodder, I. (1994) The interpretation of documents and material culture. In N. Denzin and Y. Lincoln (eds.) Handbook of Qualitative Research. Thousand Oaks: Sage, 110-129.

Hogg, R. (1982) Destitution and development: the Turkana of north-west Kenya. Disasters, 6: $164-168$.

Hogg, R. (1983) Irrigation agriculture and pastoral development: a lesson from Kenya. Development and Change, 14: 577-591.

Hogg, R. (1987) Development in Kenya: drought, desertification and food scarcity. African Affairs, 86: 47-58.

Holbraad, M. (2012) Truth in Motion. The Recursive Anthropology of Cuban Divination. Chicago: Chicago University Press.

Homewood, K. (2008) Ecology of African Pastoralist Societies. Oxford: James Currey.

Hopson, A. (1982) A Report on the Findings of the Lake Turkana Project, 1972-1975. Nairobi: Fisheries Department.

Hoskins, J. (2006) Agency, biography and objects. In C. Tilley, W. Keane, S. Küchler, M. Rowlands and P. Spyer (eds.) Handbook of Material Culture. London: Sage, 74-84.

Hughes, L. (2006) Moving the Maasai: A Colonial Misadventure. London: Macmillan.

Husserl, E. (1964) The Phenomenology of Internal Time Consciousness. Bloomington: Indiana University Press.

Hutchinson, S. (1996) Nuer Dilemmas: Coping with Money, War and the State. Berkeley: University of California Press.

Hutchison, R., Spooner, B. and Walsh, N. (Eds). (1991) Fighting for Survival: Insecurity, People and the Environment in the Horn of Africa. Gland: Osprey Publishing.

Ingold, T. (2007) Materials against materiality. Archaeological Dialogues, 14: 1-16.

Ingold, T. (1993) The temporality of the landscape. World Archaeology, 25: 152-174.

Ingold, T. (2000) The Perception of the Environment: Essays on Livelihood, Dwelling and Skill. London: Routledge.

Jabs, L. (2005) Collectivism and conflict: conflict response styles in Karamoja, Uganda. International Journal of Conflict Management, 16: 354.

Jacobs, A. (1979) Maasai inter-tribal relations: belligerent herdsmen or peaceable pastoralists? In K. Fukui and D. Turton (eds.) Warfare Among East African Herders. Osaka: National Museum of Ethnology, 33-52.

Johannes, E., Zulu, L. and Kalipeni, E. (2015) Oil discovery in Turkana County, Kenya: a source of conflict or development?. African Geographical Review, 34: 142-164. 
Johnson, D. (1982) Tribal boundaries and border wars: Nuer-Dinka relations in the Sobat and Zaraf Valleys, c. 1860-1976. Journal of African History, 23: 183-203.

Johnson, M. (2010) Archaeological Theory: an introduction. Oxford: Blackwell.

Jorgensen, K., Raa, J., Saetersdal, G., Williams, J., Broch-Due, V. and Storas, F. (1989) Aid to Fisheries at Lake Turkana - Evaluations and Recommendations: A Report by an Advisory Group Appointed by NORAD September 1980. Nairobi: NORAD.

Keane, W. (2005) Signs are not the garb of meaning: on the social analysis of material things. In D. Miller (ed.) Materiality. Durham: Duke University Press, 182-205.

Keane, W. (2006) Subjects and objects: introduction. In C. Tilley, W. Keane, S. Küchler, M. Rowlands and P. Spyer (eds.) Handbook of Material Culture. London: Sage, 197-202.

King, R., Arthur, C. and Mitchell, P. (2014) Ha Makoanyane: the archaeology and history of colonial transitions in Lesotho. Southern African Humanities, 26: 57-81.

Kipkorir, B. (1983) Historical perspectives of development in the Kerio Valley. In B. E. Kipkorir, R. C. Soper and J. W. Ssennyonga (eds.) Kerio Valley: Past Present and Future. Nairobi: University of Nairobi Press, 1-11.

Knappett, C. (2007). Materials with materiality?. Archaeological Dialogues, 14: 20-23.

Knappett, C. (2012) Materiality. In I. Hodder (ed.) Archaeological Theory Today. Cambridge: Polity Press, 188-207.

Knighton, B. (2003) The state as raider among the Karamojong: "where there are no guns, they use the threat of guns". Africa, 73: 427-455.

Kohn, E. (2013) How Forests Think: Toward an Anthropology Beyond the Human. Berkeley: University of California Press.

Kolding, J. (1989) The fish resources of Lake Turkana and their environment. Unpublished MA thesis, University of Bergen.

Kolding, J. (1992) A summary of Lake Turkana: an ever-changing mixed environment. Verhandlungen des Internationalen Verein Limnologie, 23: 25-35.

Kopytoff, I. (1986) The cultural biography of things: commoditization as process. In A. Appadurai (ed.) The Social Life of Things: Commodities in Cultural Perspective. Cambridge: Cambridge University Press, 64-91.

Krätli, S. (2015) Valuing Variability: New Perspectives on Climate Resilient Drylands Development. London: International Institute for Environment and Development.

Krätli, S., Huelsebusch, C., Brooks, S. and Kaufmann, B. (2013) Pastoralism: a critical asset for food security under global climate change. Animal Frontiers, 3: 42-50. 
Kratz, C. (2002) The Ones that are Wanted: Communication and the Politics of Representation in a Photographic Exhibition. Berkley: University of California Press.

Kundzewicz, Z., Mata, L., Arnell, N., Döll, P., Kabat, P., Jiménez, B., Miller, K., Oki, T., Sen, Z. and Shiklomanov, I. (2007) Freshwater resources and their management. In M. Parry, O. Canziani, J. Palutikof, P. van der Linden and C. Hanson (eds.) Climate Change 2007: Impacts, Adaptation and Vulnerability. Contribution of Working Group II to the Fourth Assessment Report of the Intergovernmental Panel on Climate Change. Cambridge: Cambridge University Press, 173-210.

Lamphear, J. (1976) Aspects of Turkana leadership during the era of primary resistance. Journal of African History, 17: 225-243.

Lamphear, J. (1988) The people of the grey bull: the origin and expansion of the Turkana. Journal of African History, 29: 27-39.

Lamphear, J. (1992) The Scattering Time: Turkana Responses to Colonial Rule. Oxford: Clarendon Press.

Lamphear, J. (1993) Aspects of becoming Turkana. In T. Spear and R. Waller (eds.) Being Maasai: Ethnicity and Identity in East Africa. London: James Currey, 87-104.

Lamprey, H. (1983) Pastoralism yesterday and today: the overgrazing problem. In F. Bourliere (ed.) Ecosystems of the World, Vol. 13, Tropical Savannahs. Amsterdam: Elsevier Scientific, 643-666.

Landau, P. (2002) Introduction: an amazing distance: pictures and people in Africa. In P. Landau and D. Kaspin (eds.) Images and Empires: Visuality in Colonial and Postcolonial Africa. Berkley: University of California Press, 1-40.

Lane, P. (2004) Re-constructing Tswana townscapes: toward a critical historical archaeology. In A. Reid and P. Lane (eds.) African Historical Archaeologies. New York: Springer, 269299.

Lane, P. (2005) Barbarous tribes and unrewarding gyrations? The changing role of ethnographic imagination in African archaeology. In A. Stahl (ed.) African Archaeology: A Critical Introduction. Oxford: Blackwell, 24-54.

Lane, P. (2010) Developing landscape historical ecologies in eastern Africa: an outline of current research and potential future directions. African Studies, 69: 299-322.

Lane, P. (2011) Possibilities for a postcolonial archaeology in sub-Saharan Africa: indigenous and useable pasts. World Archaeology, 43: 7-25.

Lane, P. (2015) Primordial conservationists, environmental sustainability, and the rhetoric of pastoralist cultural heritage in East Africa. In T. Rico and K. Lafrenz Samuels (eds.) Heritage Keywords: Rhetoric and Redescription in Cultural Heritage. Boulder: University Press of Colorado, 259-283. 
Lansing, S. (1991) Priests and Programmers: Technologies of Power in the Engineered Landscape of Bali. Princeton: Princeton University Press.

Latour, B. (2005) Reassembling the Social: An Introduction to Actor-Network-Theory. Oxford: Oxford University Press.

Leakey, R. and Lewin, R. (1979) People of the Lake: Mankind and its Beginnings. New York: Anchor Press/ Doubleday.

Le Maitre, D., Gush, M. and Dzikiti, S. (2015) Impacts of invading alien plant species on water flows at stand and catchment scales. AoB Plants, 7: 1-21.

Lévi-Strauss, C. (1972) Structuralism and ecology. Barnard Alumnae, Spring Issue: 6-14.

Little, P. (2013) Reflections on the future of pastoralism in the Horn of Africa. In A. Catley, J. Lind and I. Scoones (eds.) Pastoralism and Development in Africa: Dynamic Change at the Margins. London: Routledge, 243-249.

Lokuruka, M. (2006) Meat is the meal and status is by meat: recognition of rank, wealth, and respect through meat in Turkana culture. Food and Foodways, 14: 201-229.

Lorde, A. (1984) Sister Outsider: Essays and Speeches. Berkley: The Crossing Press.

Lucas, G. (2004) The Archaeology of Time. London: Routledge.

Lugard, F. (1923) The Dual Mandate in British Tropical Africa. Edinburgh: W. Blackwood.

Lynch, G. (2001) I Say to You: Ethnic Politics and the Kalenjin in Kenya. Chicago:

University of Chicago Press.

Lynch, G. (2006) Negotiating ethnicity: identity politics in contemporary Kenya. Review of African Political Economy, 33: 49-65.

Malkki, L. (2015) The Need to Help: The Domestic Arts of International Humanitarianism. Durham: Duke University Press.

Marchant, R. and Lane, P. (2013) Past perspectives for the future: foundations for sustainable development in East Africa. Journal of Archaeological Science, 51:12-21.

Mbembe, A. (2001) On the Postcolony. London: University of California Press.

MacDougall, D. (1997) The visual in anthropology. In M. Banks and H. Morphy (eds.) Rethinking Visual Anthropology. London: New Haven Press, 276-295.

Marstine, J. (Ed.). (2006) New Museum Theory and Practice: An Introduction. Oxford: Blackwell.

McCabe, T. (1987) Drought and recovery: livestock dynamics among the Ngisonyoka Turkana of Kenya. Human Ecology, 15: 371-389. 
McCabe, T. (1990) Turkana pastoralism: a case against the tragedy of the commons. Human Ecology, 18: 81-103.

McCabe, T. (2004) Cattle Bring us to our Enemies: Turkana Ecology, Politics, and Raiding in a Disequilibrium system. Ann Arbor: University of Michigan Press.

Médard, C. (2010) 'Indigenous' Land Claims in Kenya: A Case Study of Chebyuk, Mount Elgon District. Nairobi: Institut de recherche pour le développement \& Kenyatta University.

Meier, P., Bond, D. and Bond, J. (2007) Environmental influences on pastoral conflict in the Horn of Africa. Political Geography, 26: 716-735.

Meskell, L. (2009) The nature of culture in Kruger National Park. In L. Meskell (ed.) Cosmopolitan Archaeologies. Durham: Duke University Press, 89-112.

Miller, D. (1987) Material Culture and Mass Consumption. Oxford: Blackwell.

Miller, D. (Ed.). (2005) Materiality. Durham: Duke University Press.

Miller, D. (2010) Stuff. Cambridge: Polity Press.

Ministry of Agriculture, Animal Husbandry and Water Resources. (1962) African Land Development in Kenya, 1946-1962. Nairobi: Government Printer.

Ministry of Finance and Planning. Turkana District Development Plan, 1984-1988. Nairobi: Government Printer.

Mirzela, M. and Young, C. (2000) Pastoral politics in the northeast periphery in Uganda: AK-47 as change agent. Journal of Modern African Studies, 38: 407-429.

Mkutu, K. (2003) Small Arms and Security in the Great Lakes Region and the Horn of Africa; The Kenya-Uganda Border - Pastoral Conflict and Small Arms. London: Safer World.

Mkutu, K. (2007) Small arms amongst pastoralists on the Kenya-Uganda border area. African Affairs, 422: 47-70.

Mkutu, K. (2008) Guns and Governance: Pastoralism and Small Arms in the Rift Valley. Oxford: James Currey.

Monbiot, G. (1994) The tragedy of enclosure. Scientific American, 270: 159-160.

Moore, H. (1986) Space, Text and Gender: An Anthropological Study of the Marakwet of Kenya. Cambridge: Cambridge University Press.

Moore, H. (2011) Still Life: Hopes, Desires and Satisfactions. London: Polity Press.

Morgan, W. (1971) The South Turkana expedition: scientific papers IV: land units of the Lokori area. Geographical Journal, 137: 14-28. 
Morgan, W. (1974) The south Turkana expedition: scientific papers X. Sorghum gardens in south Turkana: cultivation among a nomadic pastoral people. The Geographical Journal, 140: 80-93.

Morton, C. (2002) Dwelling and Building in Ngamiland, Northern Botswana. Unpublished $\mathrm{PhD}$ thesis, University of Oxford.

Moyo, D. (2009) Dead Aid: Why Aid is Not Working and How There is a Better Way for Africa. London: Penguin.

Mudimbe, V. (1985) African gnosis philosophy and the order of knowledge: an introduction. African Studies Review, 28: 149-233.

Mudimbe, V. (1988) The Invention of Africa: Gnosis, Philosophy and the Order of Knowledge. Indiana: Indiana University Press.

Muhereza, E. (1997) Analysing the Nature of Agro-Pastoral Relationships in Karamoja: A Case Study from the Bokora of Moroto District. Kampala: Centre for Basic Research.

Muller, H. (1989) Changing Generations; Dynamics of Generation Sets in Southeastern Sudan (Toposa) and Northwestern Kenya (Turkana). Fort Lauderdale: Verlag Breitenbach.

Müller-Dempf, H. (2009) The Ngibokoi dilemma: generation sets and social system engineering in times of stress - an example from the Toposa of Southern Sudan. Zeitschrift für Ethnologie, 134: 189-211.

Munn, N. (1992) The cultural anthropology of time: a critical essay. Annual Review of Anthropology, 21: 93-123.

Munro, F. (1975) Colonial Rule and the Akamba. Oxford: Oxford University Press.

Muturi, G., Poorter, L., Mohren, G. and Kigomo, B. (2013) Ecological impact of Prosopis species invasion in Turkwel riverine forest, Kenya. Journal of Arid Environments, 92: 89-97.

Mwangi, E. and Swallow, B. (2005) Invasion of Prosopis juliflora and Local Livelihoods: Case Study from the Lake Baringo Area of Kenya. Nairobi: World Agroforestry Centre.

Nannyonjo, J. (2005) Conflicts, poverty and human development in northern Uganda. The Round Table, 94: 473-488.

Nicholas, G. (2010) Seeking the end to indigenous archaeology. In C. Phillips (ed.) Bridging the Divide: Indigenous Communities and Archaeology into the $21^{\text {st }}$ Century. Walnut Creek: Left Coast Press, 233-252.

Nicholas, G. (1997) Education and empowerment: Archaeology with, for, and by the Shuswap Nation. In G. Nicholas and T. Andrews (eds.) At a Crossroads: Archaeology and First Peoples in Canada. Burnaby: SFU Archaeology Press, 85-104.

Nicholas, G. and Andrews, T. (Eds). (1997) At a Crossroads: archaeology and first peoples in Canada. Burnaby, BC: SFU Archaeology Press. 
Niessen, S. (1991) More to it than meets the eye: photo-elicitation amongst the Batak of Sumatra. Visual Anthropology, 4: 415-430.

Nugent, P. (2008) Putting the history back into ethnicity: enslavement, religion, and cultural brokerage in the construction of Mandinka/Jola and Ewe/Agotime identities in West Africa, c. 1650-1930. Comparative Studies in Society and History, 50: 920-948.

Nusrat, R. (2011) Marginalization of Himalayan pastoralists and exclusion from their traditional habitat: a case study of Van Gujjars in India. International Journal of Human Development and Sustainability, 4: 93-102.

Nyamnjoh, F. (2012) Blinded by sight: diving the future of anthropology in Africa. Africa Spectrum, 47: 63-92.

Oba, G. (1992) Ecological Factors in Land use Conflicts, Land Administration and Food Insecurity in Turkana, Kenya. London: Overseas Development Institute.

ODI. (1985) Turkana District Development Strategy and Programme, 1985/86-1987/88. London: Oversees Development Institute.

Ong, A. (1999) Flexible Citizenship: The Cultural Logics of Transnationality. Durham: Duke University Press.

Ortner, S. (1990) Patterns of history: cultural schemas in the foundings of Sherpa religious institutions. In E. Ohnuki-Tierney (ed.) Culture Through Time: Anthropological Approaches. Stanford: Stanford University Press.

Oswaggo, O. (1971) Soils of Kaputir Agricultural Development Scheme. Nairobi: Ministry of Agriculture.

Ojeda, G., Rueff, H., Ur-Rahim, I. and Maselli, D. (2012) Sustaining mobile pastoralists in the mountains of northern Pakistan. In M. Arynova (ed.) Evidence For Policy Series Regional Edition Central Asia. Bishkek: NCCR North-South.

Olsen, B. (2001) The end of history? Archaeology and the politics of identity in a globalized world. In R. Layton, P. Stone and J. Thomas (eds.) Destruction and Conservation of Cultural Property. London: Routledge, 42-54.

Pallaver, K. (2008) A recognized currency in beads. Glass beads as money in $19^{\text {th }}$ century East Africa: the central caravan road. In C. Eagleton and H. Fuller (eds.) Money in Africa. London: British Museum Press, 20-29.

Pavitt, N. (2008) Kenya: A Country in the Making 1880-1940. New York: WW Norton and Company.

Pedersen, M. (2012) Common nonsense: a review of certain recent reviews of the “ontological turn”. Anthropology of This Century, 5: 59-65.

Peers, L. and Brown, A. Eds. (2003) Museums and Source Communities. London: Routledge. 
Petek, N. and Lane, P. (2017) Ethnogenesis and surplus food production: communities and identity building among nineteenth-and early twentieth-century Ilchamus, Lake Baringo, Kenya. World Archaeology, 49: 40-60.

Pikirayi, I. (2004) Less implicit historical archaeologies: oral traditions and later Karanga settlement in south-central Zimbabwe. In A. Reid and P. Lane (eds.) African Historical Archaeologies. New York: Springer, 243-267.

Plieninger, T. and Bieling, C. (Eds.). (2012) Resilience and the Cultural Landscape: Understanding and Managing Change in Human-Shaped Environments. Cambridge: Cambridge University Press.

Poignant, R. (1994) About friendship: about trade: about photographs. Voices: The Quarterly Journal of the National Library of Australia, 4: 55.

Poignant, R. (1996) Encounter at Nagalarramba. Canberra: Canberra University Press.

Polanyi, M. (1958) Personal Knowledge: Towards a Post-Critical Philosophy. Chicago: University of Chicago Press.

Polanyi, M. (1966) The logic of tacit inference. Philosophy, 41: 1-18.

Postel, S. (2000) Entering an era of water scarcity: the challenges ahead. Ecological Applications, 10: 941-948.

Prestholdt, J. (2004) On the global repercussions of East African consumerism. The American Historical Review, 109: 755-781.

Prestholdt, J. (2008) Domesticating the World: African Consumerism and the Genealogies of Globalization. Berkley: University of California Press.

Pringle, R. (2005) The Nile perch in Lake Victoria: local responses and adaptions. Africa, 75: 510-537.

Raikes, P. (1981) Livestock Development and Policy in East Africa. Uppsala: Scandinavian Institute for African Studies.

Ranger, T. and Hobsbawm, J. Eds. (1983) The Invention of Tradition. Cambridge: Cambridge University Press.

Rayne, H. (1923) The Ivory Raiders. London: Heinemann.

Reid, A. and Lane, P. Eds. (2004) African Historical Archaeologies. New York: Springer.

Republic of Kenya. (1984) Kenya's Experiences in Combatting Desertification: Kenya's Country Position Paper. Nairobi: National Environment and Human Settlements Secretariat.

Rika-Heke, M. (2010) Archaeology and Indigeneity in Aotearoa/ New Zealand: why do Maori not engage with archaeology?. In C. Phillips (ed.) Bridging the Divide: Indigenous 
Communities and Archaeology into the $21^{\text {st }}$ Century. Walnut Creek: West Coast Press, 197212.

Robb, J. (2002) Time and biography: osteobiography of the Italian Neolithic lifespan. In Y.Hamilakis, M. Pluciennik and S. Tarlow (eds.) Thinking Through the Body: Archaeologies of Corporeality. New York: Kluwer/Plenum, 23-7.

Robinson, L. and Berkes, F. (2010) Applying resilience thinking to questions of policy for pastoralist systems: lessons from the Gabra of northern Kenya. Human Ecology, 38: 335-350.

Robinson, P., Brown, R., Goddard, P. and Parry, K. (2005) War and media. Media, Culture and Society, 27: 951-959.

Rowlands, M. (2005) A materialist approach to materiality. In D. Miller (ed.) Materiality. Durham: Duke University Press, 72-87.

Sahlins, M. (1999) What is anthropological enlightenment? Some lessons of the twentieth century. Annual Review of Anthropology, 28: i-xxiii.

Saussure, F. (1959) A Course in General Linguistics. New York: McGraw-Hill.

Schiffer, M. (1991) The Portable Radio in American Life. Tucson: University of Arizona Press.

Schilling, J., Locham, R., Weinzierl, T., Vivekananda, J. and Scheffran, J. (2015) The nexus of oil, conflict and climate change: vulnerability of pastoral communities in northwest Kenya. Earth System Dynamics, 6: 703-717.

Schmidt, P. and Walz, J. (2007) Silences and mentions in history making. Historical Archaeology, 41: 129-146.

Schmidt, P. (2009) Variability in Eritrea and the archaeology of the northern Horn during the first millennium BC: subsistence, ritual and gold production. African Archaeological Review, 26: 305-325.

Schmidt, P. (2010) Social memory and trauma in northwestern Tanzania: organic, spontaneous community collaboration. Journal of Social Archaeology, 10: 255-279.

Schmidt, P. (2014) Rediscovering community archaeology in Africa and reframing its practice. Journal of Community Archaeology and Heritage, 1: 37-55.

Schmidt, P. and Pikirayi, I. Eds. (2016) Community Archaeology and Heritage in Africa: Decolonizing Practice. London: Routledge.

Schneider, H. (1988) Principles of development: a view from anthropology. In J. Bennet and J. Bowen (eds.) Production and Autonomy: Anthropological Studies and Critiques of Development. Lanham: University Press of America, 61-80.

Scoones, I. (1996) Introduction. In I. Scoones (ed.) Living with Uncertainty: New Directions in Pastoral Development in Africa. London: Intermediate Technology Publications, 1-36. 
Scott, J. (1998) Seeing Like a State: How Certain Schemes to Improve the Human Condition Have Failed. New Haven: Yale University Press.

Shanks, M. and Tilley, C. (1987) Social Theory and Archaeology. Cambridge: Polity Press.

Shell-Duncan, B. and Wimmer, M. (1999) Premarital childbearing in northwest Kenya: challenging the concept of illegitimacy. Social Biology, 46: 47-61.

Shepherd, N. and Haber, A. (2011) What's up with WAC? Archaeology and 'engagement' in a globalized world. Public Archaeology, 10: 96-115.

Silliman, S. (Ed.). (2008) Collaborating at the Trowel's Edge: Teaching and Learning in Indigenous Archaeology. Tucson: University of Arizona Press.

Sillitoe, P. (Ed.). (2007) Local Science versus Global Science: Approaches to Indigenous Knowledge in International Development. Oxford: Berghahn.

Skoggard, I. and Adem, T. (2012) From raiders to rustlers: the filial disaffection of a Turkana age-set. Ethnology: An International Journal of Cultural and Social Anthropology, 49: 249262.

Smith, N. (1997) The satanic geographies of globalization: uneven development in the 1990s. Public Culture, 10: 169-189.

Smith, C. and Wobst, H. Eds. (2005) Indigenous Archaeologies: Decolonizing Theory. London: Routledge.

Snyder, F. (1981) Colonialism and legal form: the creation of customary law in Senegal. The Journal of Legal Pluralism and Unofficial Law, 13: 49-90.

Sobania, N. (1980) The Historical Tradition of the Peoples of the Eastern Lake Turkana Basin c. 1840-1925. Unpublished PhD thesis, School of Oriental and African Studies.

Sobania, N. (1988) Fishermen herders: Subsistence, survival and cultural change in northern Kenya. Journal of African History, 29: 41-56.

Soper, R. (Ed.). (1985) Socio-Cultural Profile of Turkana District. Nairobi: University of Nairobi and Ministry of Finance and Planning.

Spear, T. (2003) Neo-traditionalism and the limits of invention in British colonial Africa. The Journal of African History, 44: 3-27.

Spencer, I. (1983) Pastoralism and colonial policy in Kenya, 1895-1929. In R. Rotberg (ed.) Imperialism, Colonialism and Hunger: East and Central Africa. Lexington, Massachusetts: Heath, 113-140.

Spivak, G. (1988) In Other Worlds: Essays in Cultural Politics. London: Routledge. 
Stahl, A. (2001) Making History in Banda: Anthropological Visions of Africa's Past. Cambridge: Cambridge University Press.

Straight, B., Lane, P., Hilton, C. and Letua, M. (2016) Dust people: Samburu perspectives on disaster, identity and landscape. Journal of Eastern African Studies, 10: 168-188.

Stump, D. (2010) "Ancient and backward or long-lived and sustainable?" The role of the past in debates concerning rural livelihoods and resource conservation in Eastern Africa. World Development, 38: 1251-1262.

Stump, D. (2013) On applied archaeology, indigenous knowledge, and the useable past. Current Anthropology, 54: 268-298.

Sullivan, S. and Rohde, R. (2002) On non-equilibrium in arid and semi-arid grazing systems. Journal of Biogeography, 29: 1595-1618.

Swift, J. (1977) Sahelian pastoralists: underdevelopment, desertification and famine. Annual Review of Anthropology, 6: 457-478.

Teka, T., Azeze, A. and Gebremariam, A. (1991) Cross-Border Livestock Trade and Food Security in the Southern and Southeastern Ethiopia Borderlands. Addis Ababa: Organisation for Social Science Research in Eastern and Southern Africa.

Tengö, M. and Hammer, M. (2003) Management practices for building adaptive capacity: a case study from northern Tanzania. In F. Berkes, J. Colding and C. Folke (eds.) Navigating Social-Ecological Systems: Building Resilience for Complexity and Change. Cambridge: Cambridge University Press, 132-162.

Thomas, L. (1999) Under the Canopy: Ritual Process and Spiritual Resilience in South Africa. Columbia: University of South Carolina Press.

Thomas, N. (1997) Partial texts: representation, colonialism and agency in Pacific history. In N. Thomas (ed.) In Oceania: Visions, Artifacts, Histories. Durham: Duke University Press, 139-158.

Thomas, N. (1999) The case of the misplaced ponchos: speculations concerning the history of cloth in Polynesia. Journal of Material Culture, 4: 5-20.

Tilley, C. (1990) On modernity and archaeological discourse. In I. Bapty and T. Yates (eds.) Archaeology After Structuralism: Post Structuralism and the Practice of Archaeology.

London: Routledge, 127-152.

Tilley, C. (2006) Objectification. In C. Tilley, W. Keane, S. Küchler, M. Rowlands and P. Spyer (eds.) Handbook of Material Culture. London: Sage, 60-73.

Tilley, C. (2007) Materiality in Materials. Archaeological Dialogues, 14: 16-20.

Tilley, C., Keane, W., Küchler, S., Rowlands, M. and Spyer, P. (Eds.) Handbook of Material Culture. London: Sage. 
Tornay, S. (1979) Armed conflicts in the Lower Omo Valley, 1970-1976: an analysis from within Nyangatom society. In K. Fukui and D. Turton (eds.) Warfare Among East African Herders. Osaka: National Museum of Ethnology, 97-117.

Turton, D. (1979) War, peace, and Mursi identity. In K. Fukui and D. Turton (eds.) Warfare Among East African Herders. Osaka: National Museum of Ethnology, 179-210.

Turton, D. (1994) Mursi political identity and warfare: the survival of an idea. In K. Fukui and J. Markakis (eds.) Ethnicity and Conflict in the Horn of Africa. London: James Currey, $15-31$.

Turton, D. (2003) The politician, the priest and the anthropologist: living beyond conflict in southwestern Ethiopia. Ethnos, 68: 5-26.

Van Zwanenberg, R. (1976) Dorobo hunting and gathering: A way of life or a mode of production?. African Economic History, 2: 12-21.

Vasquez, P. (2013) Kenya at a crossroads: hopes and fears concerning the development of oil and gas reserves. International Development Policy, 4. Online.

Velpuri, N. and Senay, G. (2012) Assessing the potential hydrological impact of the Gibe III dam on Lake Turkana water level using multi-source satellite data. Hydrology and Earth System Sciences, 16: 3561-3578.

Vetter, S. (2005) Rangelands at equilibrium and non-equilibrium: recent developments in the debate. Journal of Arid Environments, 62: 321-341.

Von Hohnel, L. (1894) Discovery by Count Teleki of Lakes Rudolf and Stefanie. London: Longmans.

Watkins, J. (2000) Indigenous Archaeology: American Indian Values and Scientific Practice. Walnut Creek: Altamira Press.

Watkins, J. (2003) Beyond the margin: American Indians, first nations, and archaeology in North America. American Antiquity, 68: 273-285.

Watkins, J. (2005) Through wary eyes: indigenous perspectives on archaeology. Annual Review of Anthropology, 34: 429-449.

Watson, E., Kochore, H. and Dabasso, B. (2016) Camels and climate resilience: adaptation in northern Kenya. Human Ecology, 44: 701-713.

Webmoor, T. and Witmore, C. (2008) Things are us! A commentary on human/things relations under the banner of a 'social' archaeology. Norwegian Archaeological Review, 14: $53-70$.

Westoby, M., Walker, B. and Noy-Meir, I. (1989) Opportunistic management of rangelands not at equilibrium. Journal of Range Management, 42: 266-74. 
White, G. (1971) Firearms in Africa: an introduction. Journal of African History, 12: 173184.

Widgren, M. (2012) Resilience thinking versus political ecology: understanding the dynamics of small-scale, labour intensive farming landscapes. In T. Plieninger and C. Bieling (eds.) Resilience and the Cultural Landscape: Understanding and Managing Change in Human-Shaped Environments. Cambridge: Cambridge University Press, 95-110.

Widgren, M. and Sutton, J. (2004) Islands of Intensive Agriculture in Eastern Africa: Past and Present. Oxford: James Currey.

Widlok, T., Aufgebauer, A., Bradtmöller, M., Dikau, R., Hoffmann, T., Kretschmer, I., Panagiotopoulos, K., Pastoors, A., Peters, R., Schäbitz, F. and Schlummer, M. (2012) Towards a theoretical framework for analyzing integrated socio-environmental systems. Quaternary International, 274: 259-272.

Williams, G. (1987) The World Bank in rural Nigeria, revisited: a review of the World Bank's Nigeria: agricultural sector review. Review of African Political Economy, 15: 42-67.

Wilmsen, E. (1989) Land Filled with Flies: A Political Economy of the Kalahari. Chicago: University of Chicago Press.

Wolf, E. (1982) Europe and the People without History. Berkley: University of California Press.

Wood, B. and Leakey, M. (2011) The Omo-Turkana Basin fossil hominins and their contribution to our understanding of human evolution in Africa. Evolutionary Anthropology, 20: 264-292.

World Bank. (1990) Sub-Saharan Africa: From Crisis to Sustainable Growth. Washington: World Bank.

Wylie, A. (1982) An analogy by any other name is just as analogical: a commentary on the Gould-Watson dialogue. Journal of Anthropological Archaeology, 1: 382-401.

Wynne-Jones, S. and Fleisher, J. (Eds.). (2015) Theory in Africa, Africa in Theory: Locating Meaning in Archaeology. London: Routledge.

Yeh, E. (2007) Tibetan Indigeneity: translations, resemblances, and uptake. In M. de la Cadena and O. Starn (eds.) Indigenous Experience Today. Oxford: Berg, 69-97.

Ying, L., Johnson, D. and Marzouk, A. Pauperizing the pastoral periphery: the marginalization of herding communities in the world's dry lands. Journal of Geographical Sciences, 12: 1-14.

Yongo, E., Abila, R. and Lwenya, C. (2010) Emerging resource use conflicts between Kenyan fishermen, pastoralists and tribesmen of Lake Turkana. Aquatic Ecosystem Health and Management, 13: 28-34. 
Yuretich, R. and Cerling, T. (1983) Hydrogeochemistry of Lake Turkana, Kenya: mass balance and mineral reactions in an alkaline lake. Geochimica et Cosmochimica Acta, 47: 1099-1109.

Zaal, F. and Dietz, T. (1999) Of markets, meat, maize and milk: pastoral commoditization in Kenya. In D. Anderson and V. Broch-Due (eds.) The Poor Are not Us: Poverty and Pastoralism in East Africa. Oxford: James Currey, 163-198. 
Appendix A. Timeline of early European explorations into the Lake Turkana region.

\begin{tabular}{|l|l|}
\hline Year & Explorer \\
\hline $\mathbf{1 8 8 6 - 1 8 8 8}$ & $\begin{array}{l}\text { Count Samuel Teleki } \\
\text { with von Höhnel }\end{array}$ \\
\hline $\mathbf{1 8 9 2 - 1 8 9 4}$ & $\begin{array}{l}\text { William Chanler } \\
\text { with von Höhnel }\end{array}$ \\
\hline $\mathbf{1 8 9 3 - 1 8 9 6}$ & Arthur Henry Neumann \\
\hline $\mathbf{1 8 9 4 - 1 8 9 5}$ & Arthur Donaldson Smith \\
\hline $\mathbf{1 8 9 5 - 1 8 9 7}$ & Vittorio Bottego \\
\hline $\mathbf{1 8 9 6 - 1 8 9 7}$ & Henry Cavendish \\
\hline $\mathbf{1 8 9 6 - 1 8 9 8}$ & $\begin{array}{l}\text { Hugh Cholmondeley } \\
\text { (3 } \text { rd Baron Delamere) }\end{array}$ \\
\hline $\mathbf{1 8 9 8 - 1 8 9 9}$ & Montague Sinclair Wellby \\
\hline $\mathbf{1 8 9 9 - 1 9 0 0}$ & Arthur Donaldson Smith (second expedition) \\
\hline $\mathbf{1 8 9 9 - 1 9 0 0}$ & James Harrison \\
\hline $\mathbf{1 9 0 1}$ & Herbert Austin \\
\hline $\mathbf{1 9 0 1}$ & Count Eduard Wickenburg \\
\hline $\mathbf{1 9 0 1 - 1 9 0 3}$ & Pierre Marie Robert de Bozas \\
\hline $\mathbf{1 9 0 9}$ & Chauncey Stigand \\
\hline
\end{tabular}


Appendix B. Supplementary shots of the remains of the NORAD scheme on the western shore of Lake Turkana.

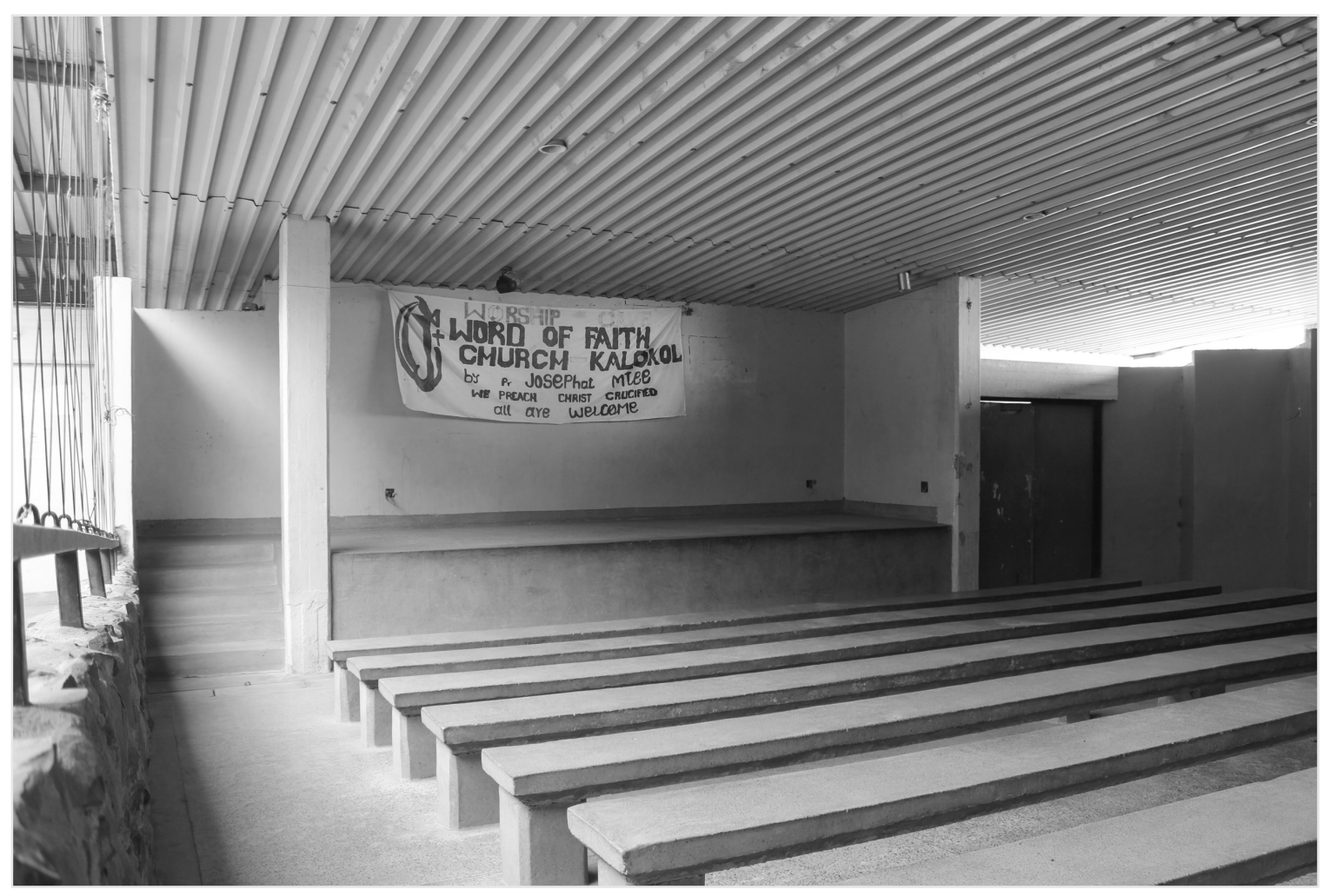

The Kalokol facility meeting room, which now serves as a makeshift church.

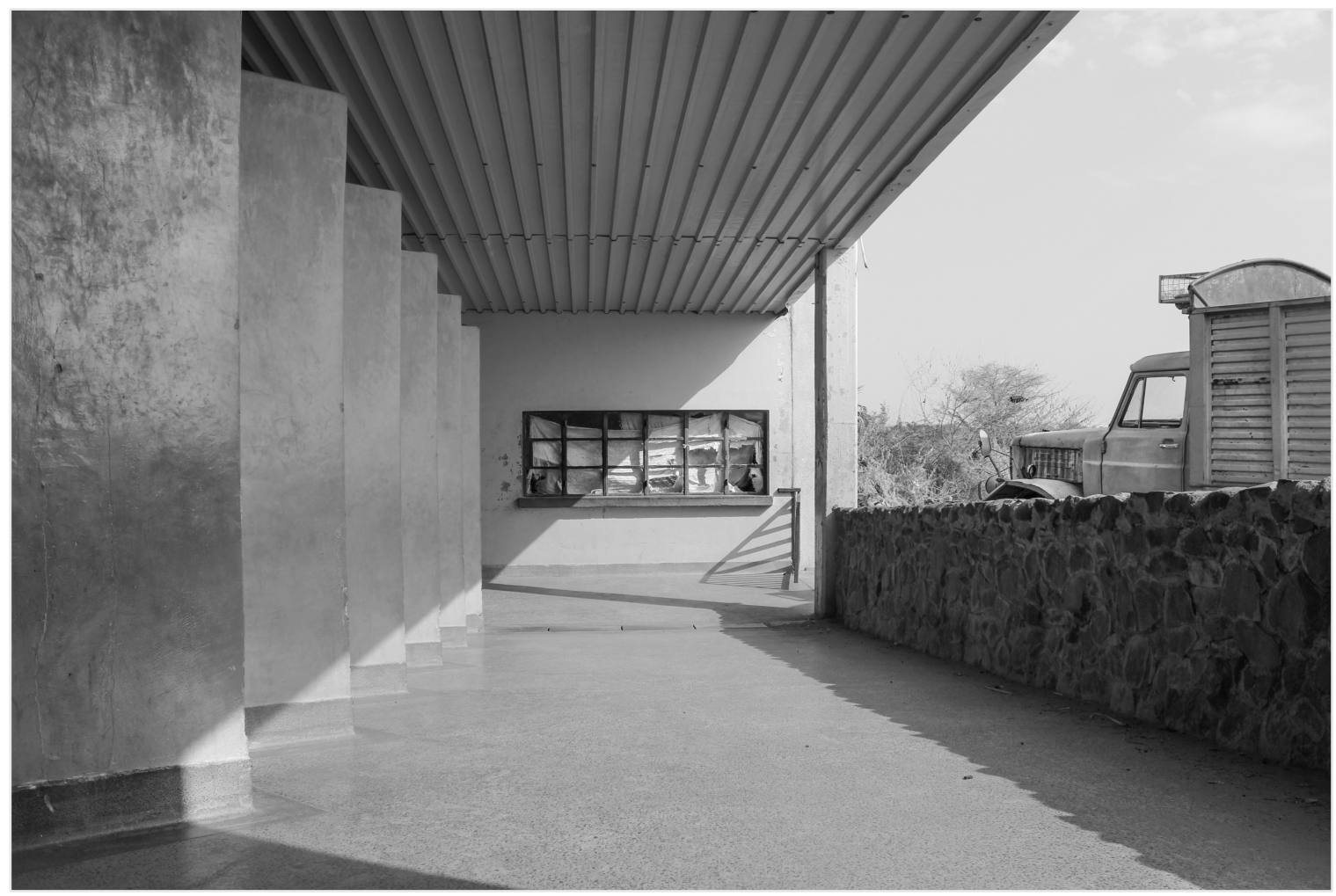

The Kalokol facility fish purchasing kiosk. 


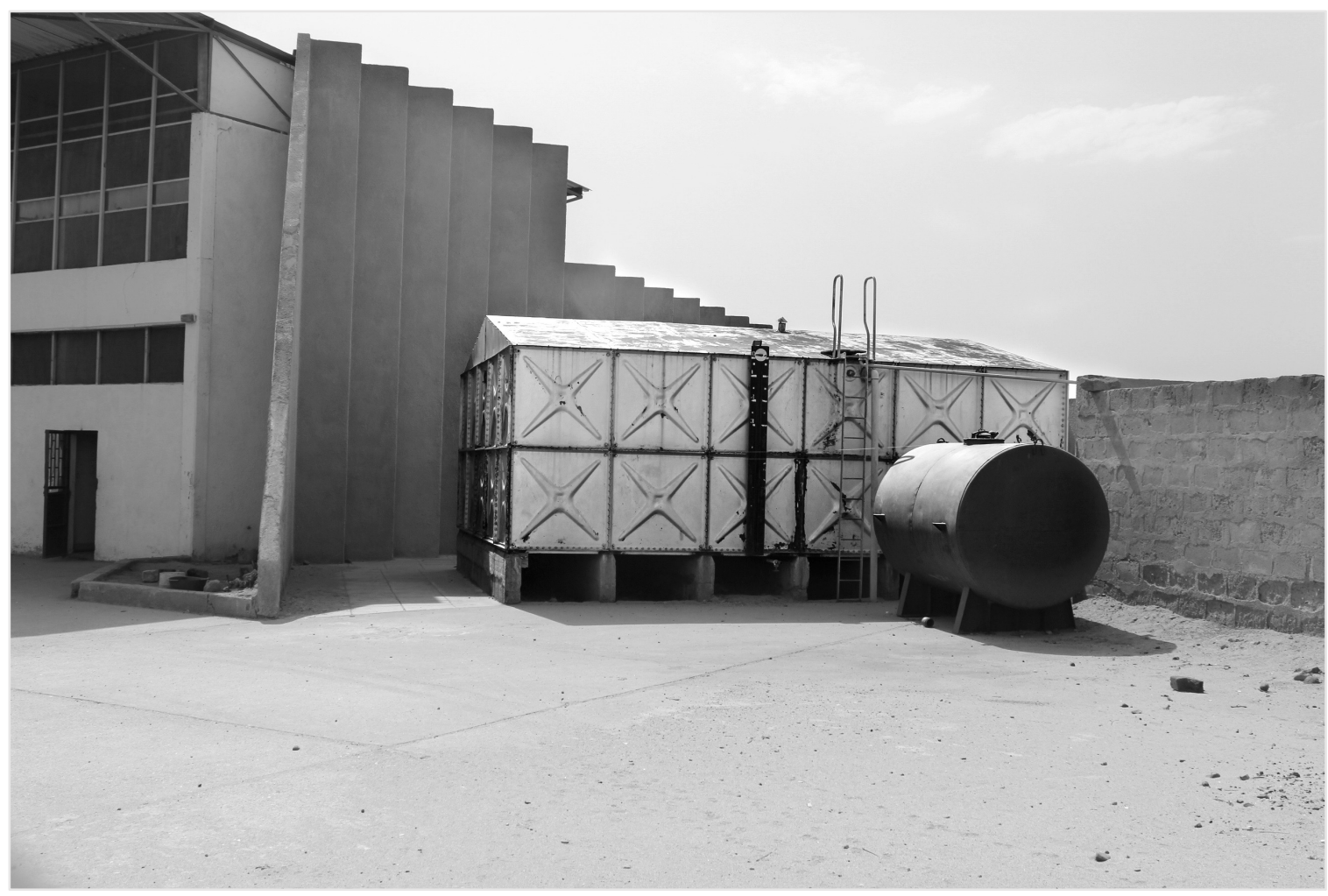

The Kalokol facility façade, with watchman on bench.

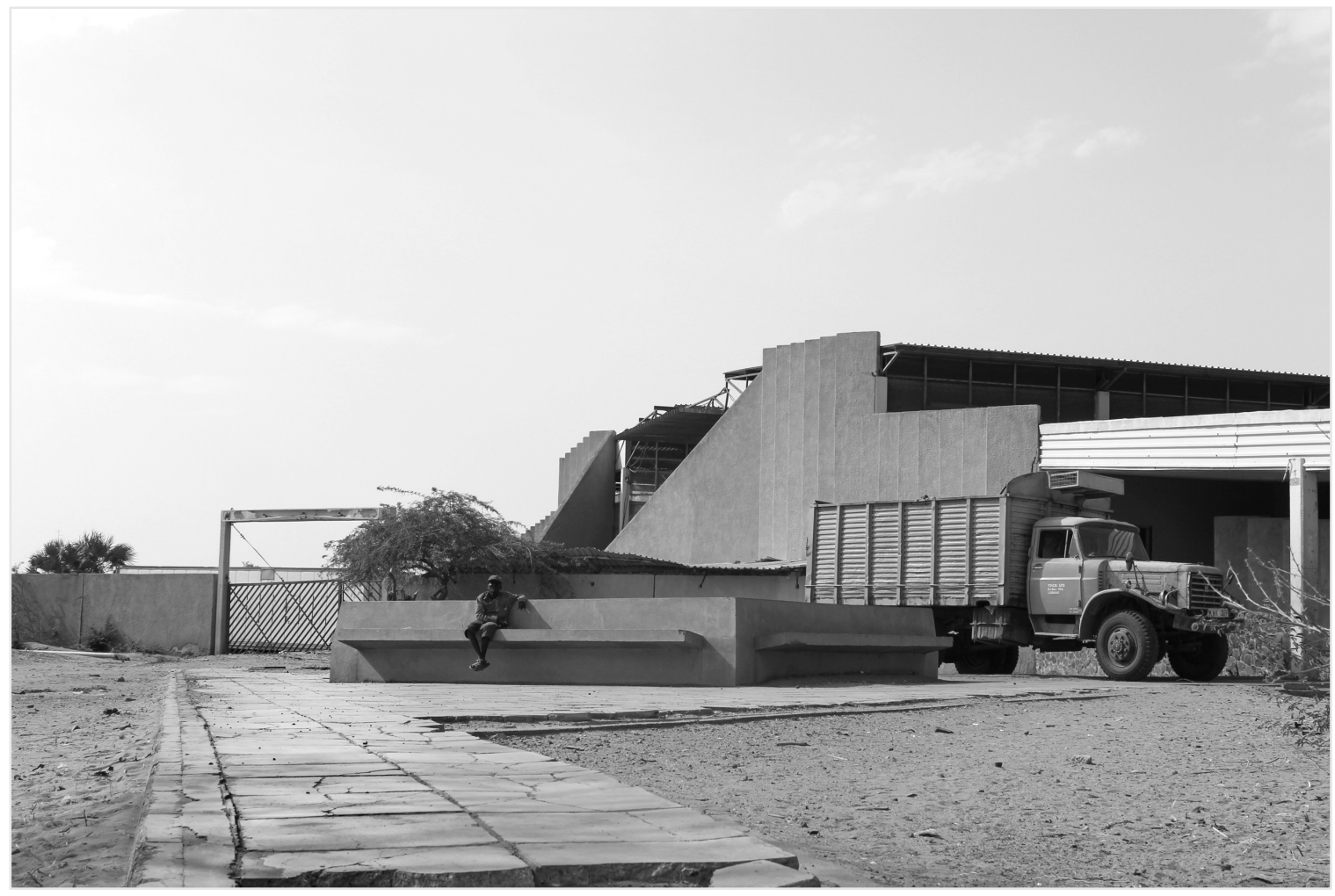

The Kalokol facility rear internal courtyard. 


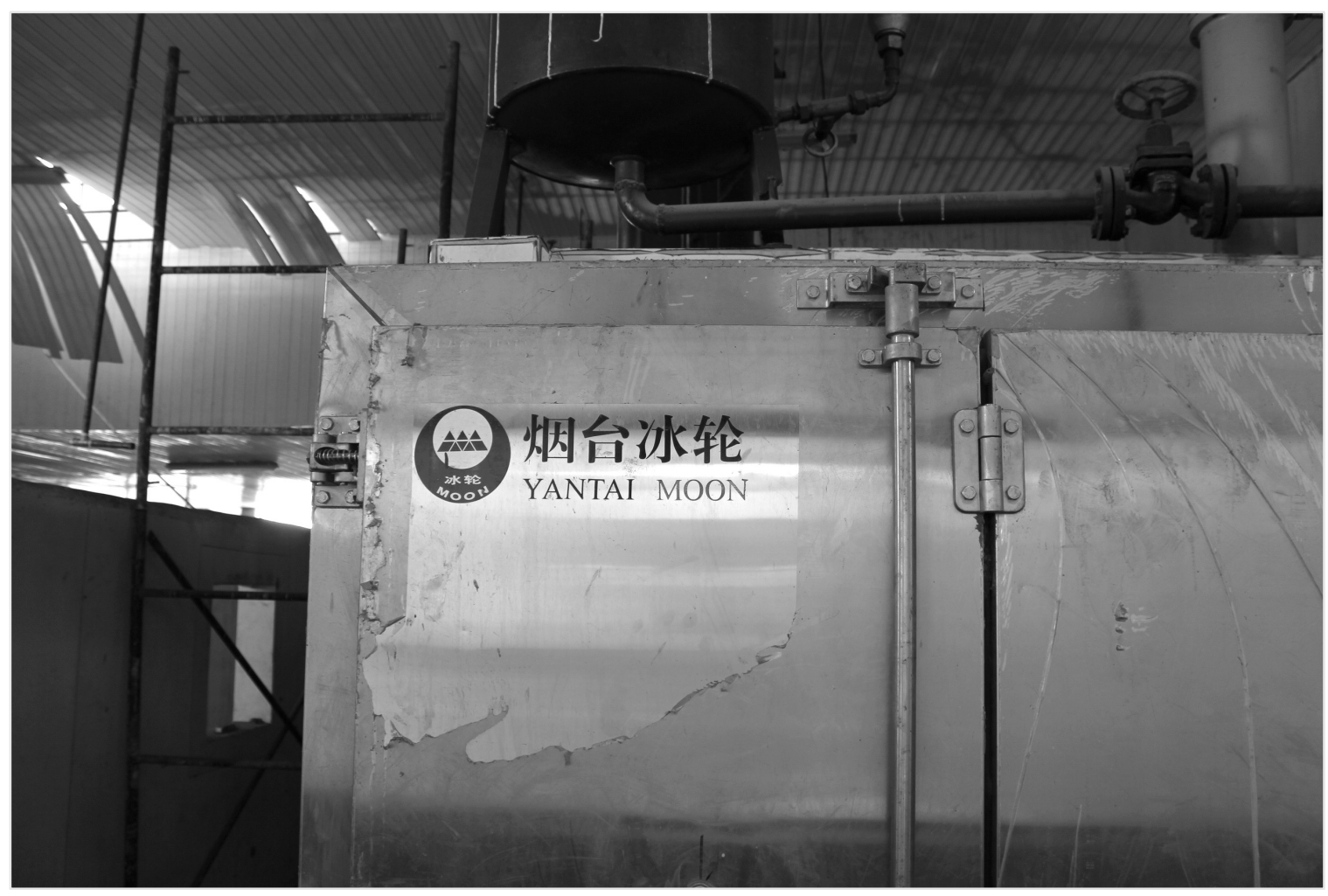

The Kalokol facility fish freezing room.

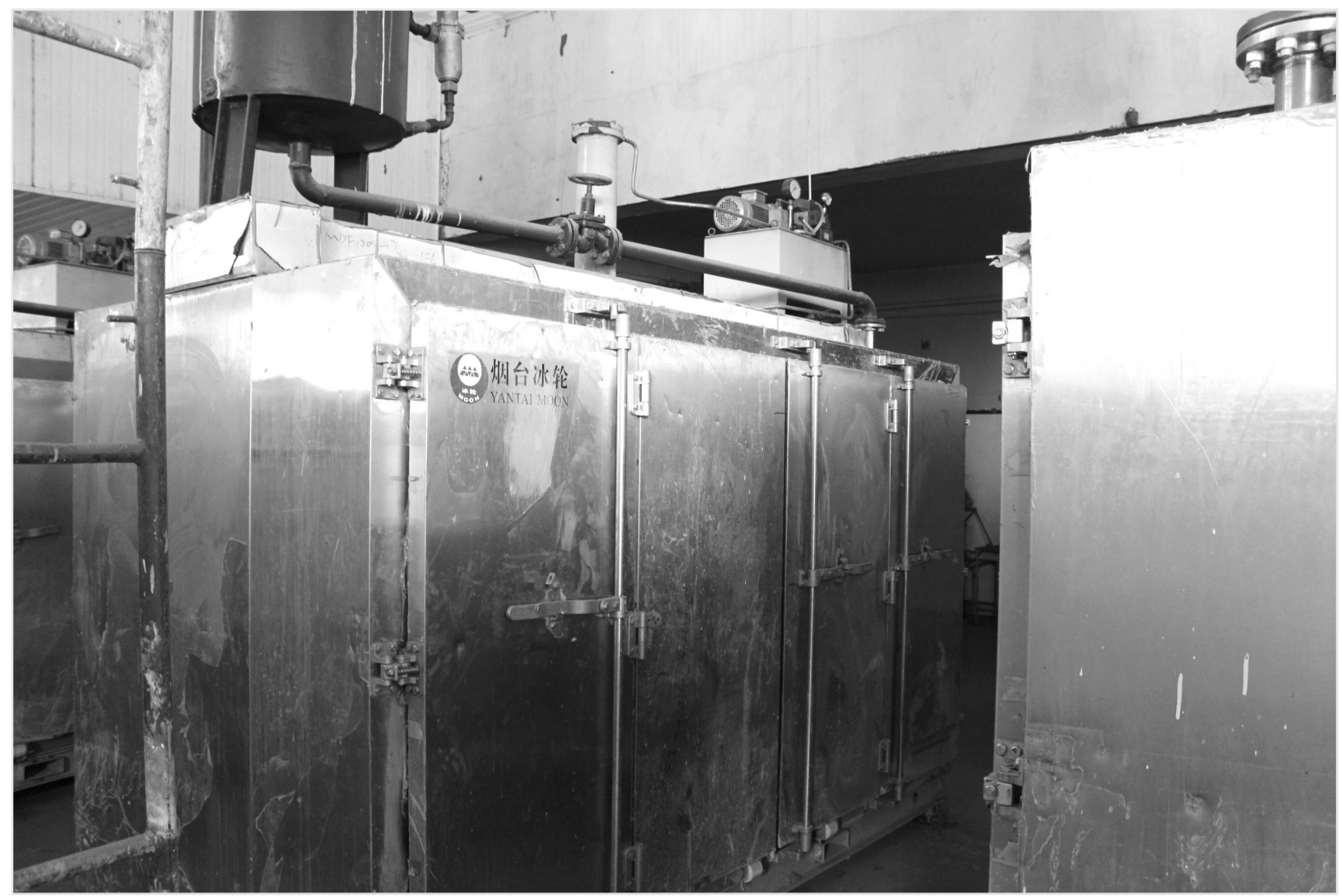

The Kalokol facility fish freezing room. 


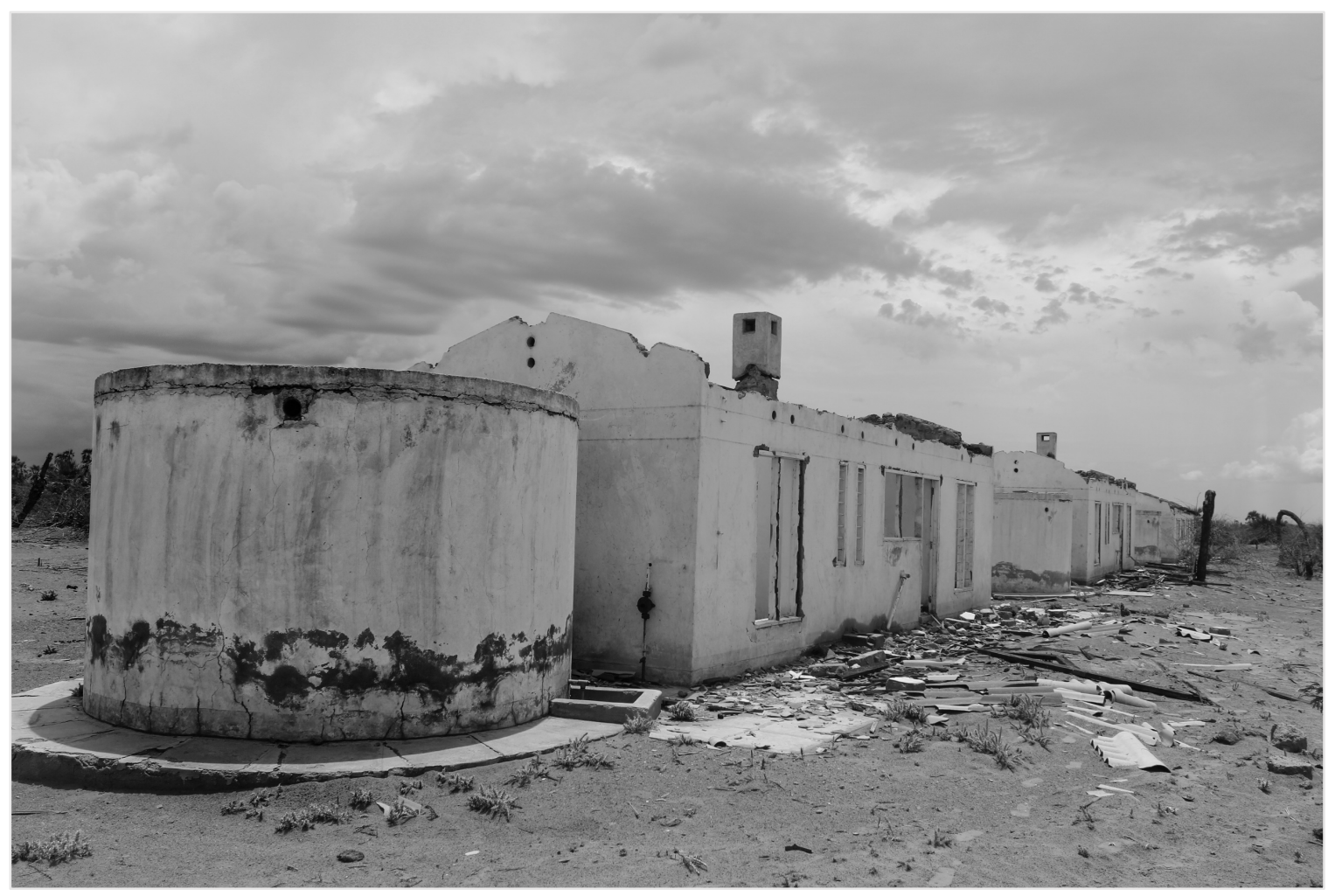

The remains of the dispensary close to the TFCS Kerio branch store.

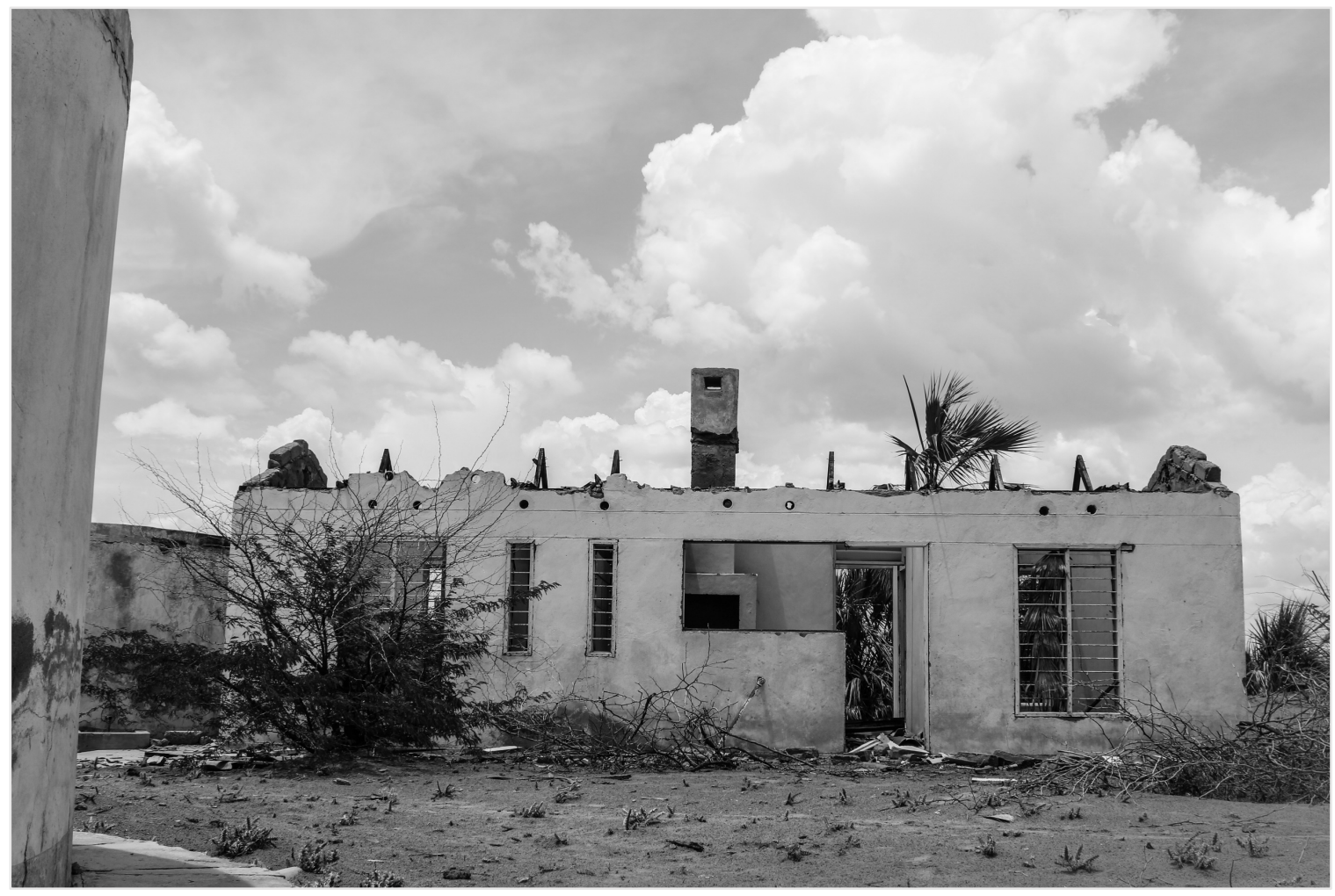

The remains of the dispensary close to the TFCS Kerio branch store. 


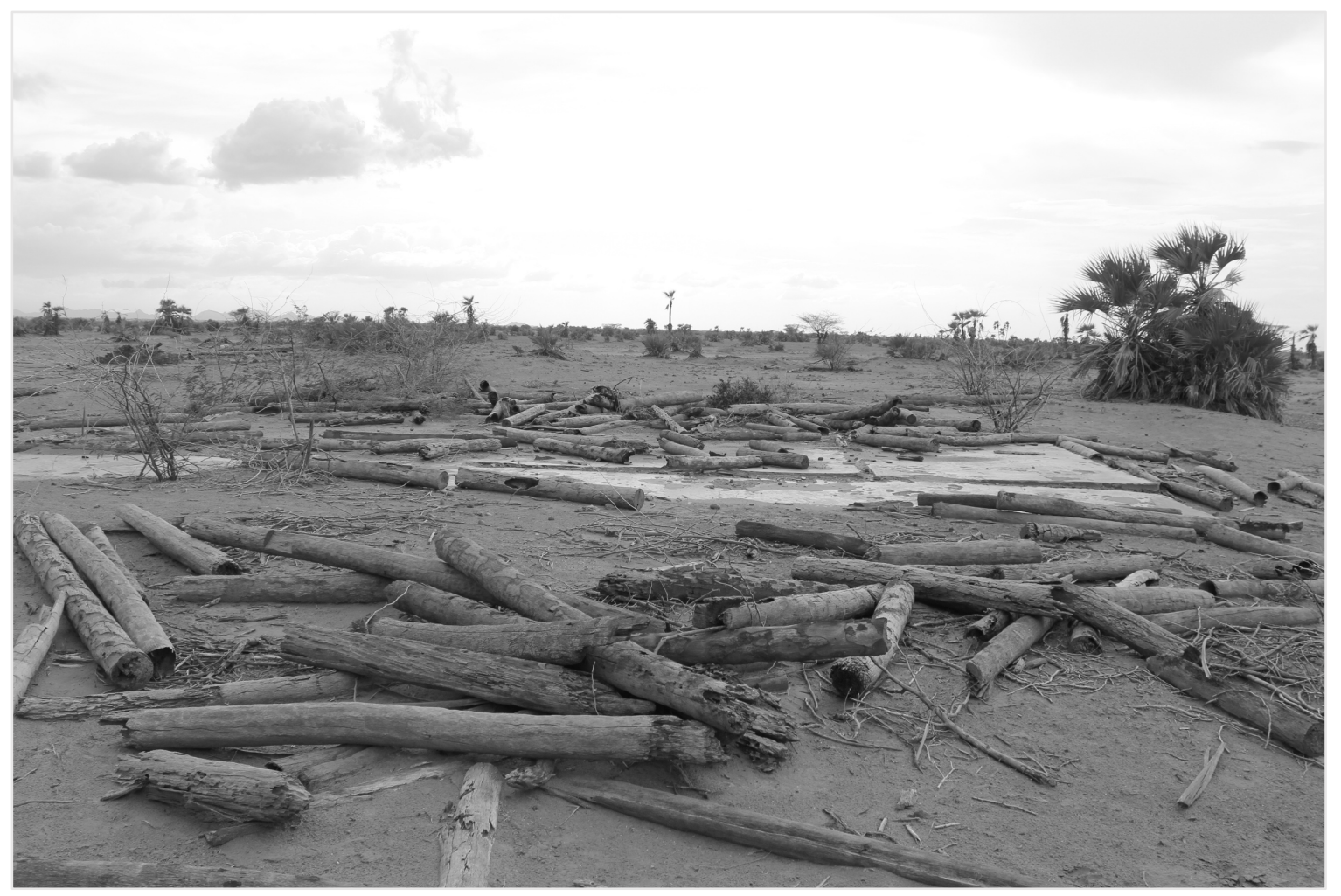

The remains of an unknown building beside the TFCS Kerio branch store.

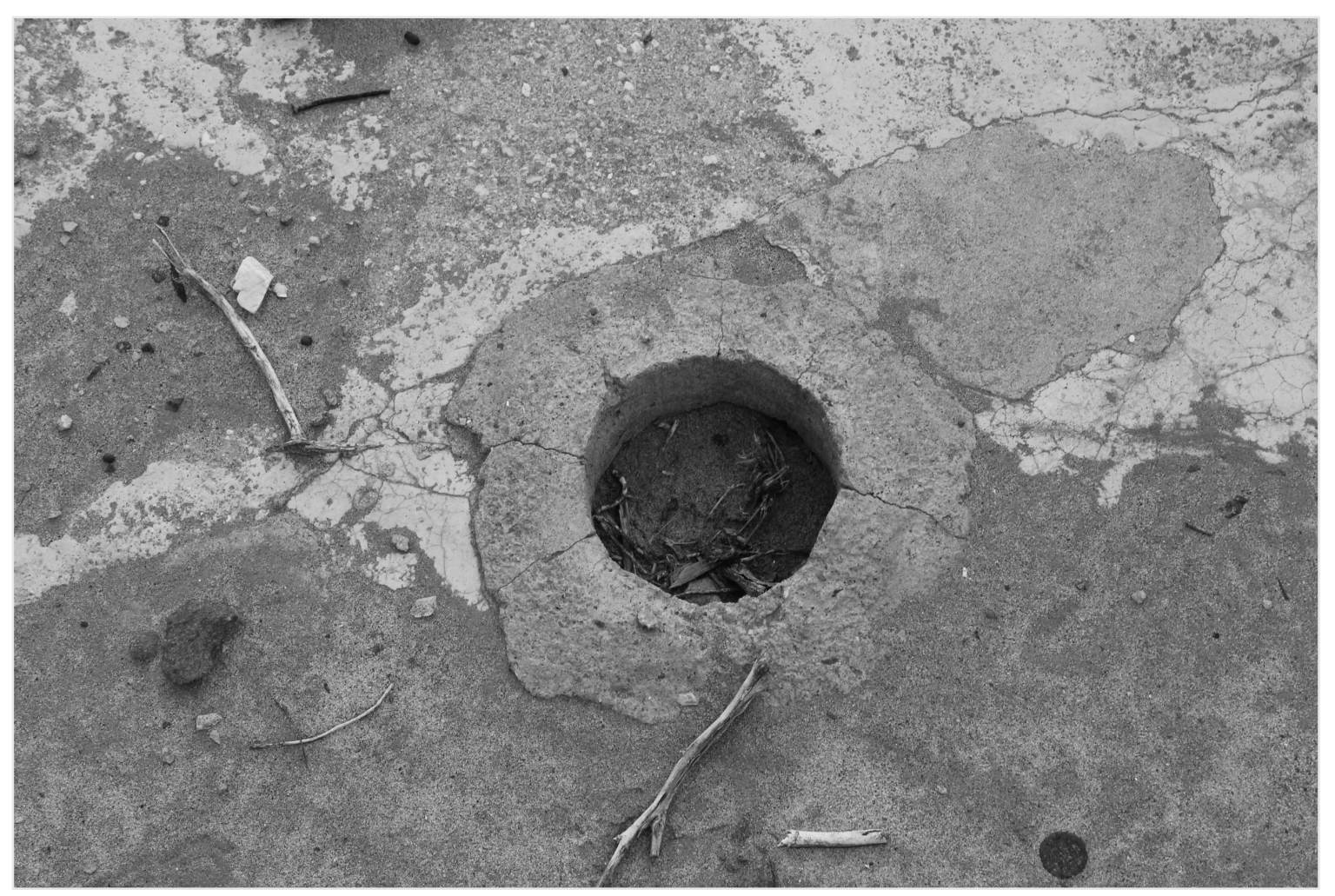

Posthole in the foundations of an unknown building beside the TFCS Kerio branch store. 


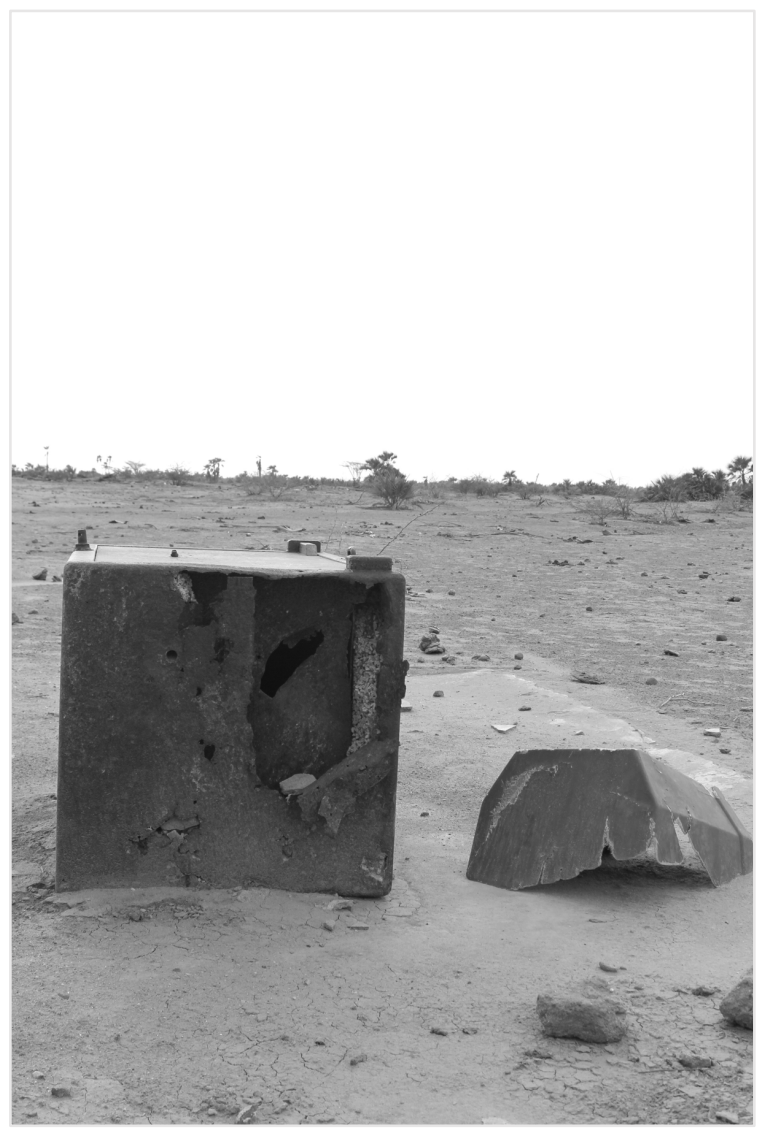

The safe of the TFCS Kerio branch store

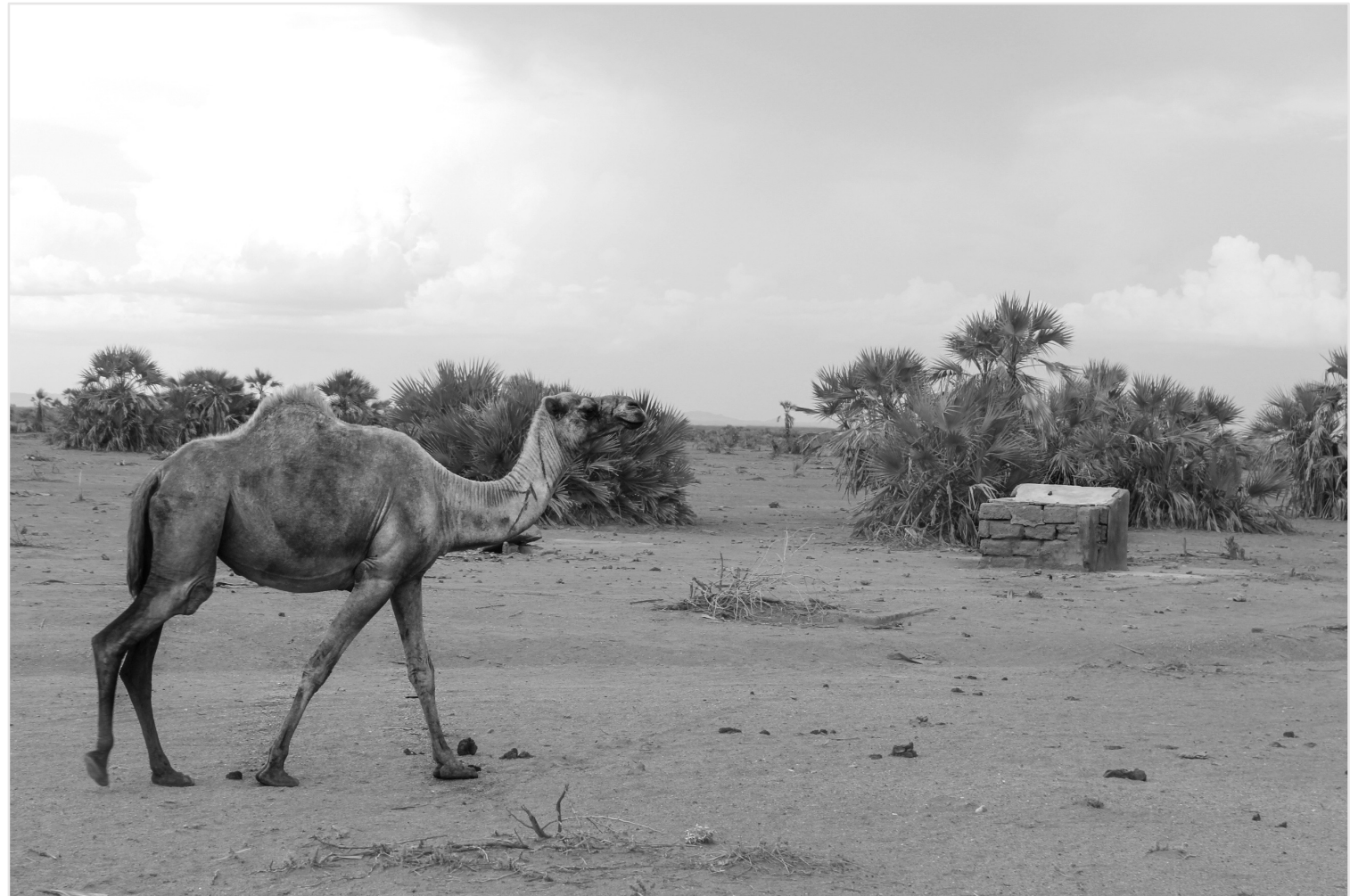

View of the remains of the TFCS Kerio branch store in the wider landscape. 
Appendix C. Supplementary shots of photo-elicitation sessions with the Pitt Rivers Museum collection.

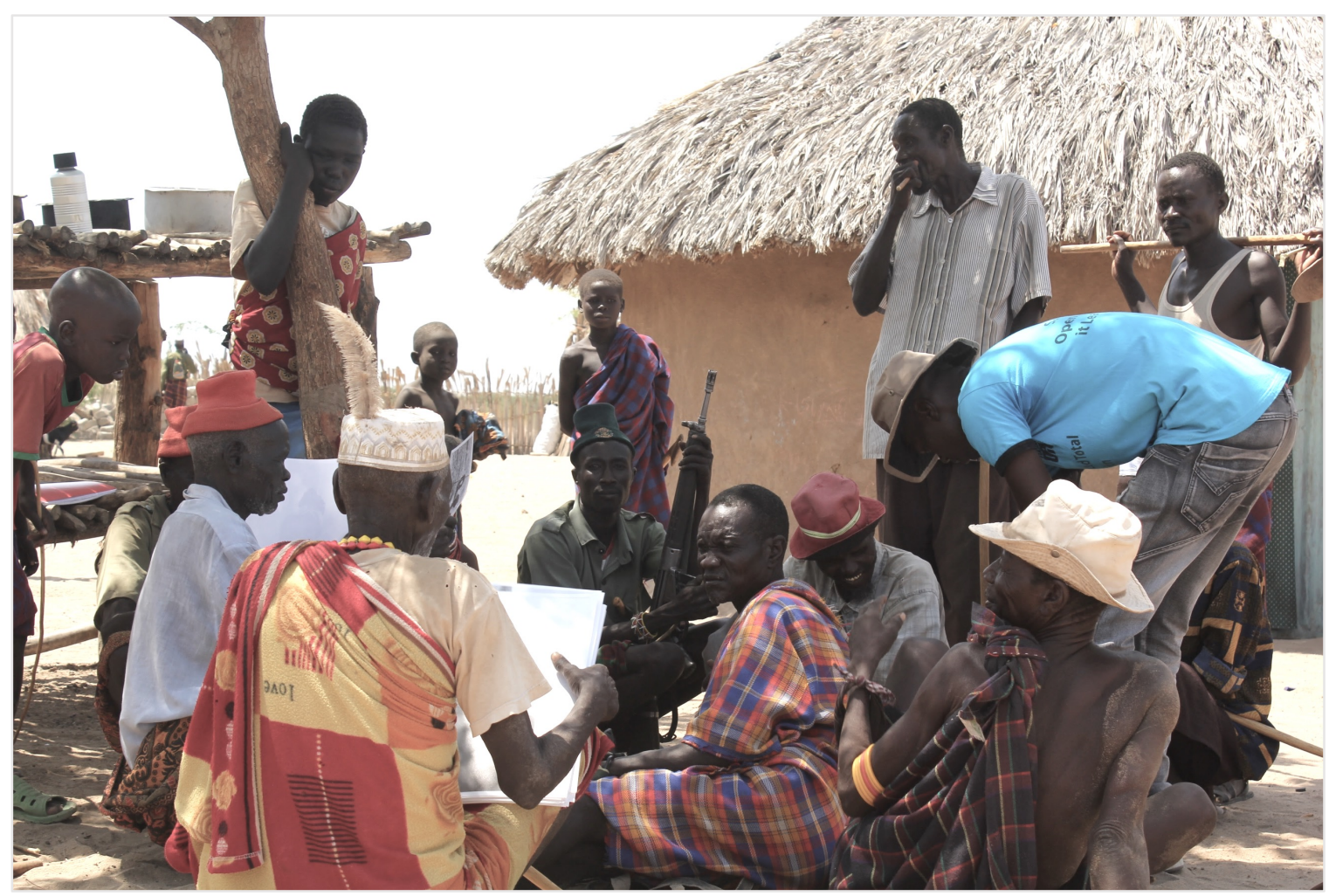

Nakurio, July 2014

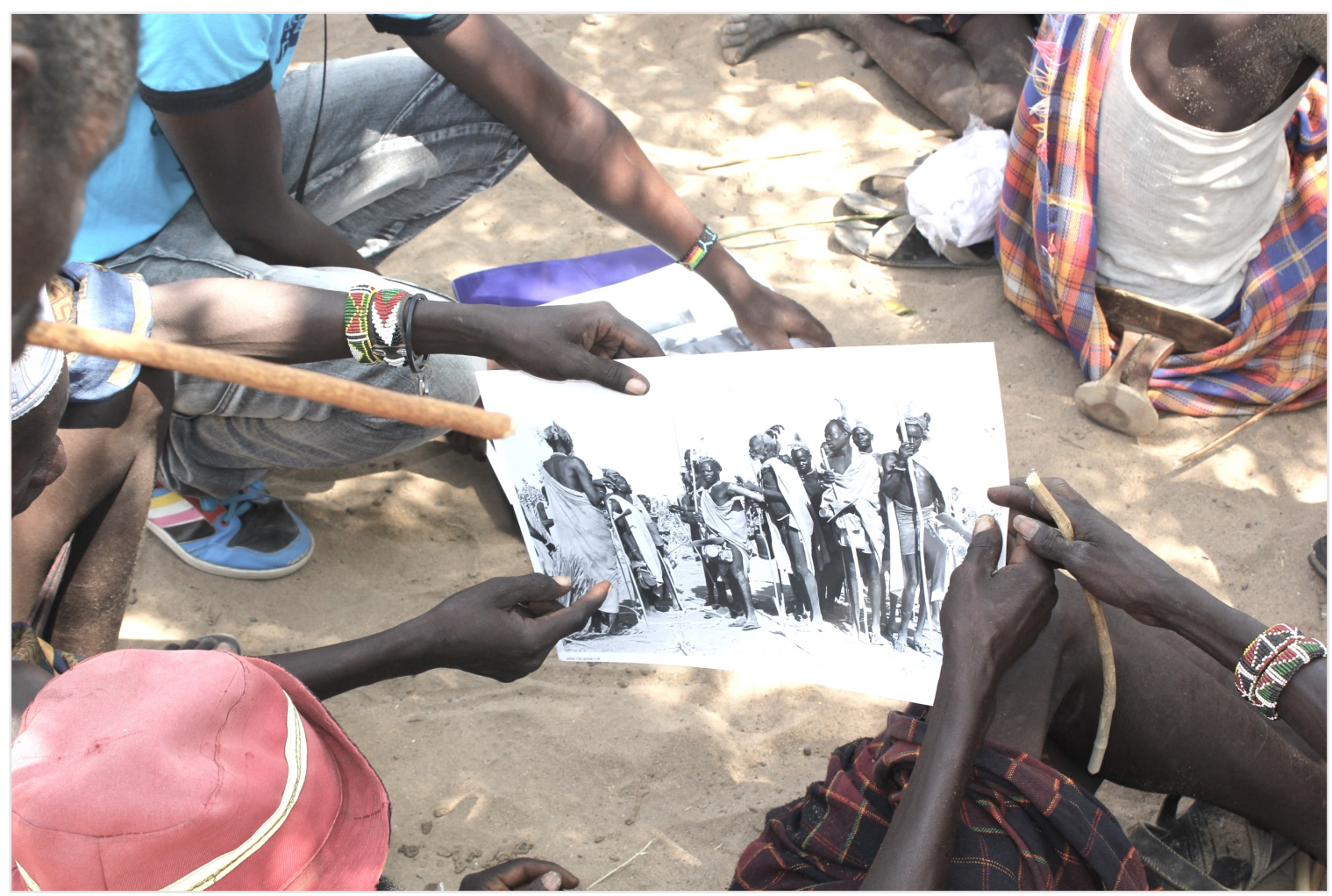

Nakurio, July 2014 


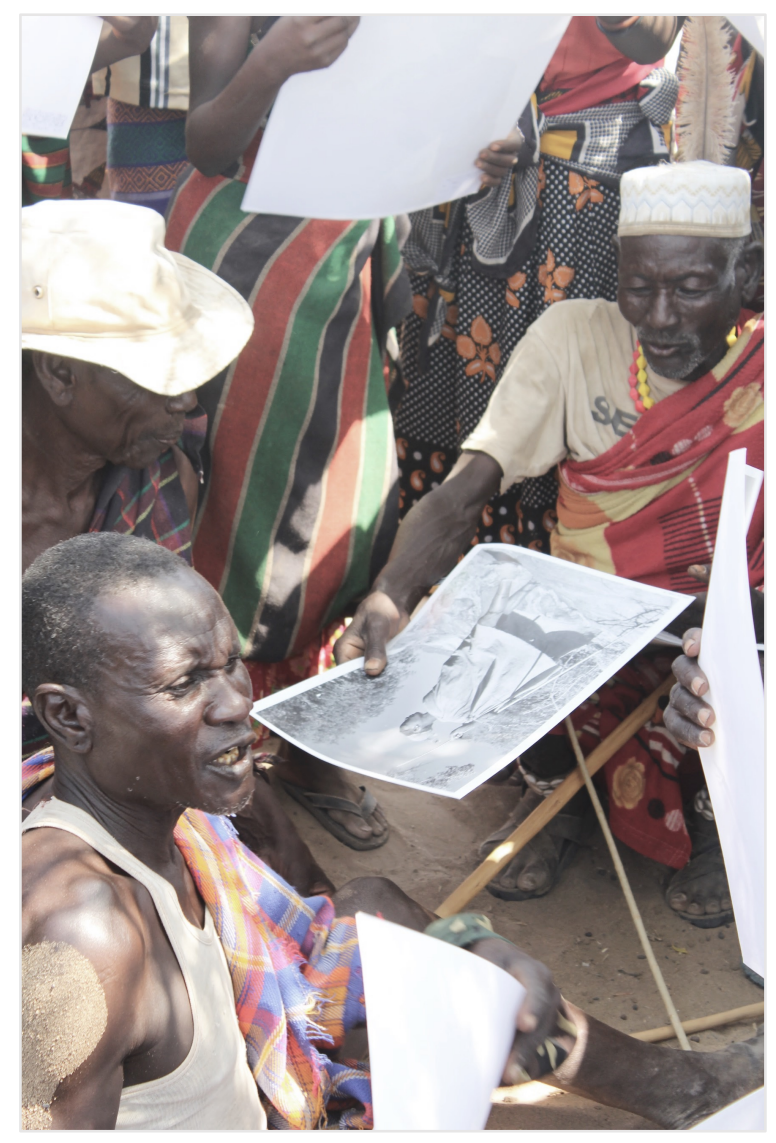

Nakurio, July 2014

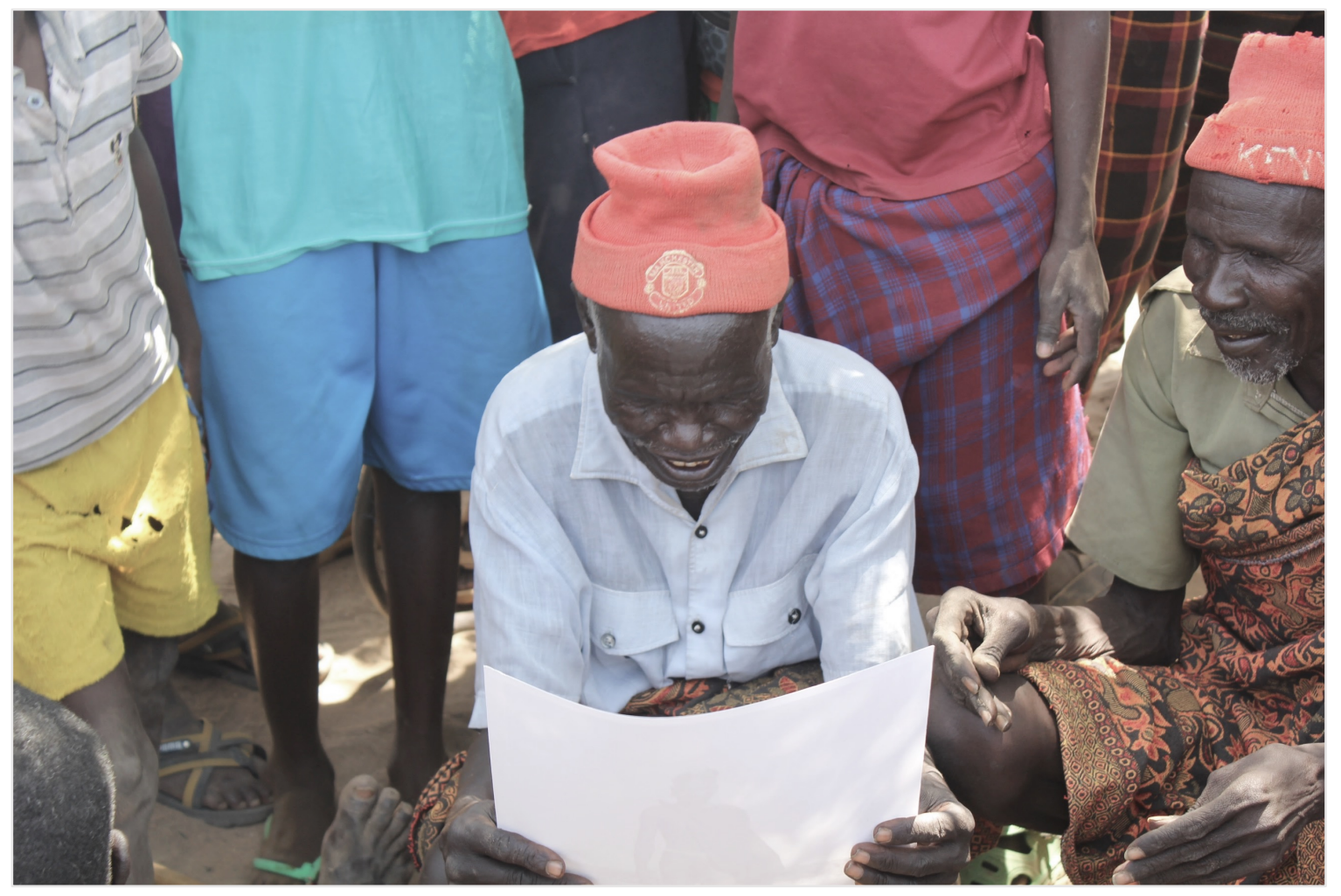

Nakurio, July 2014 


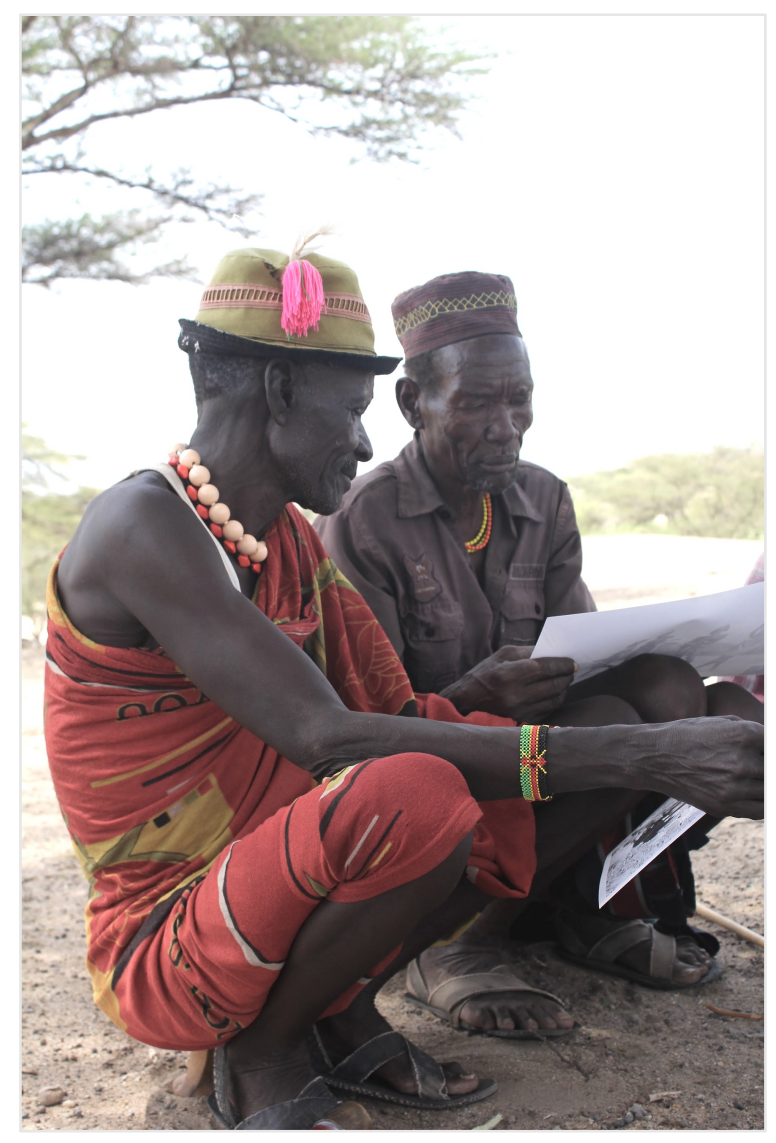

Nakoret, July 2014

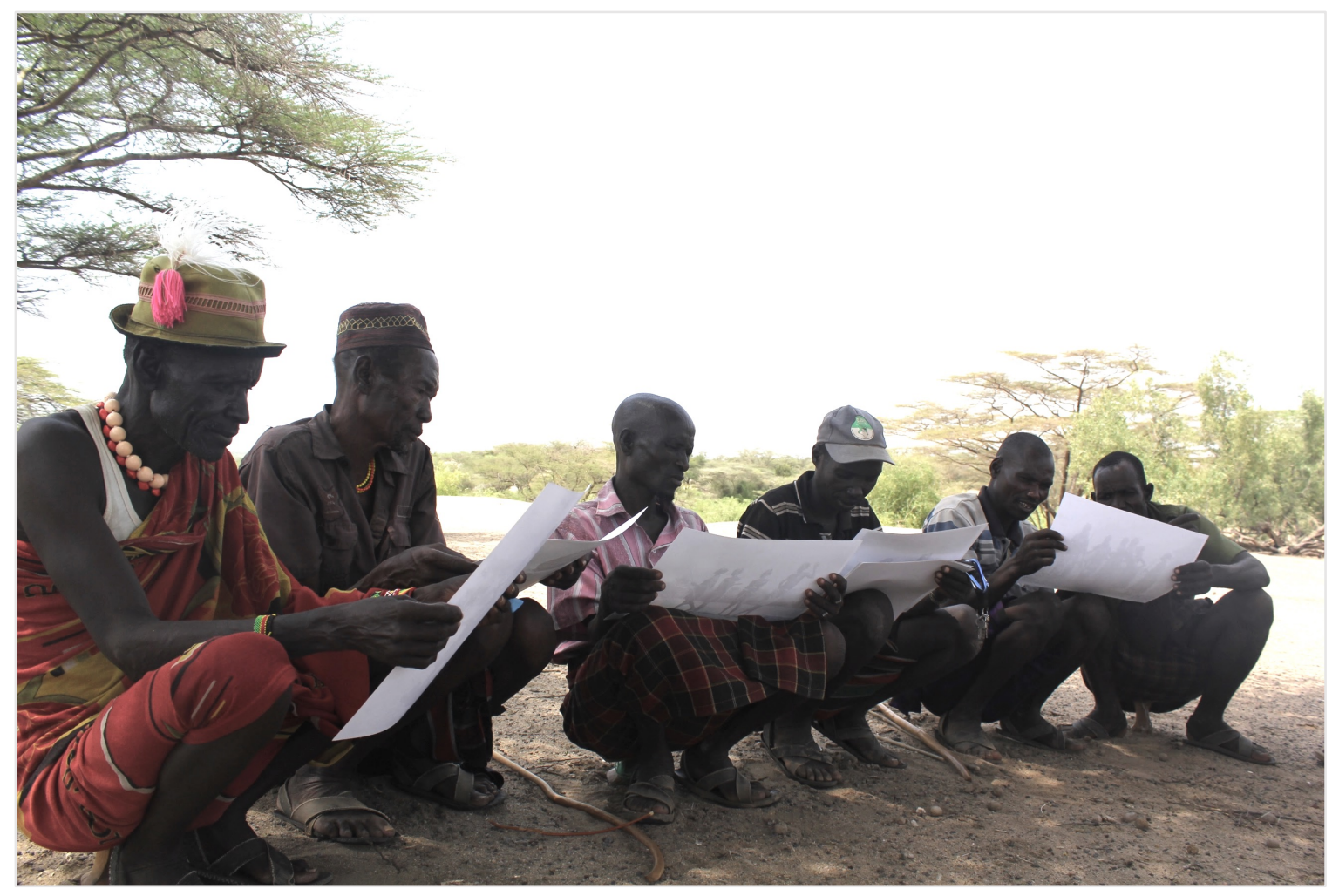

Nakoret, July 2014 


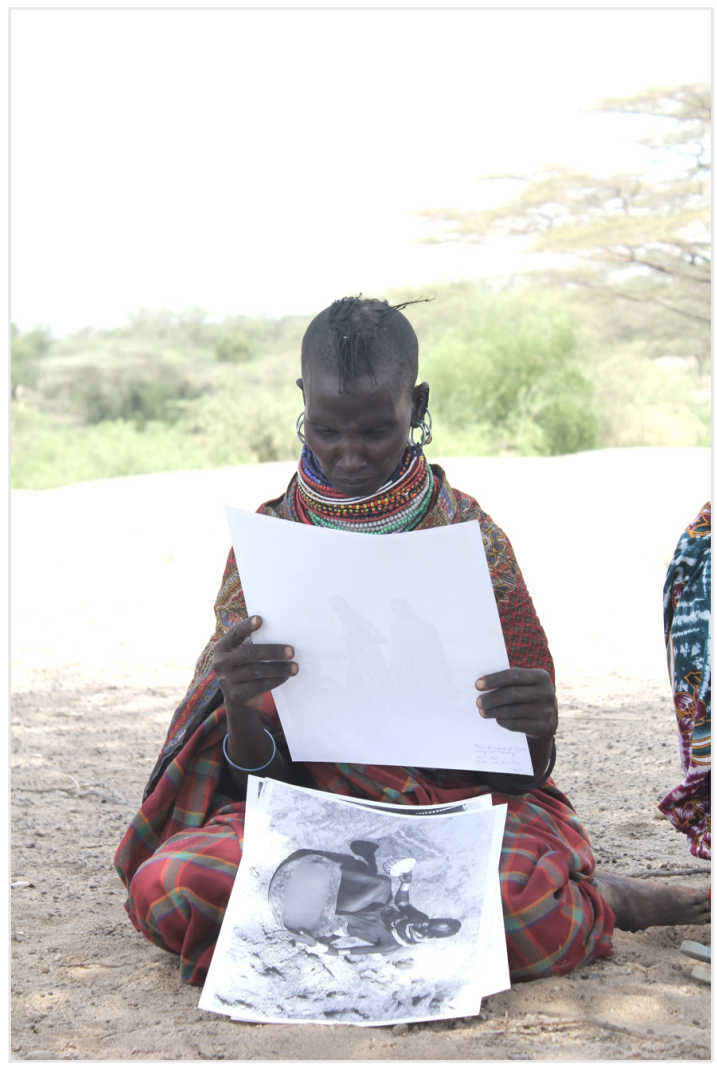

Nakoret, July 2014

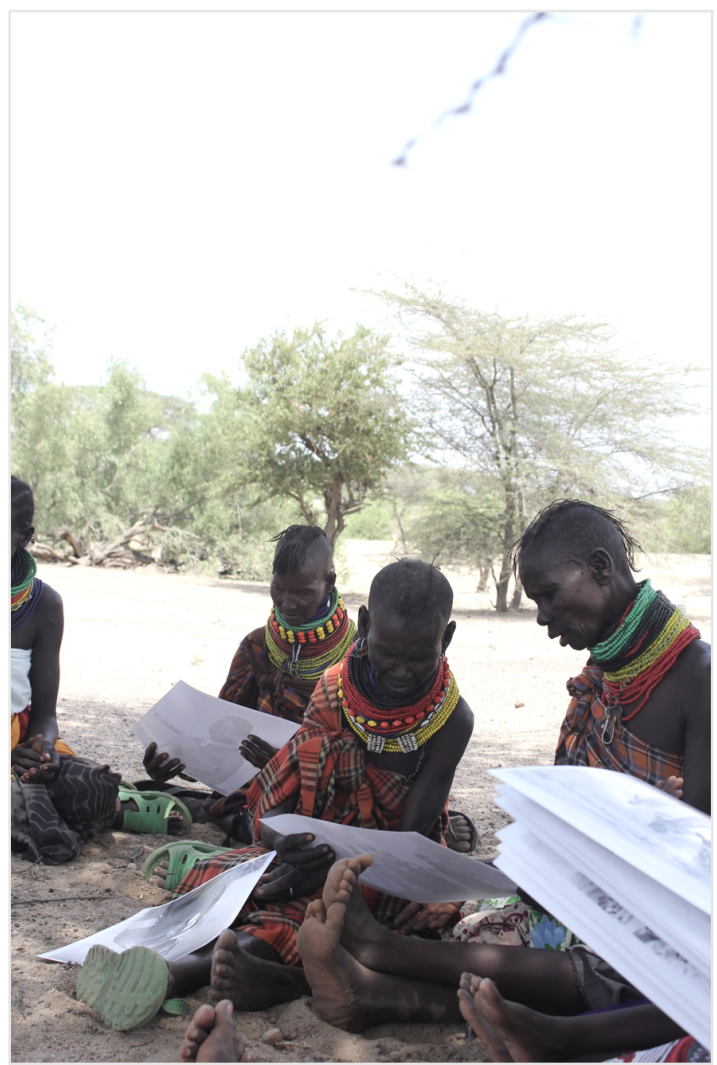

Nakoret, July 2014 


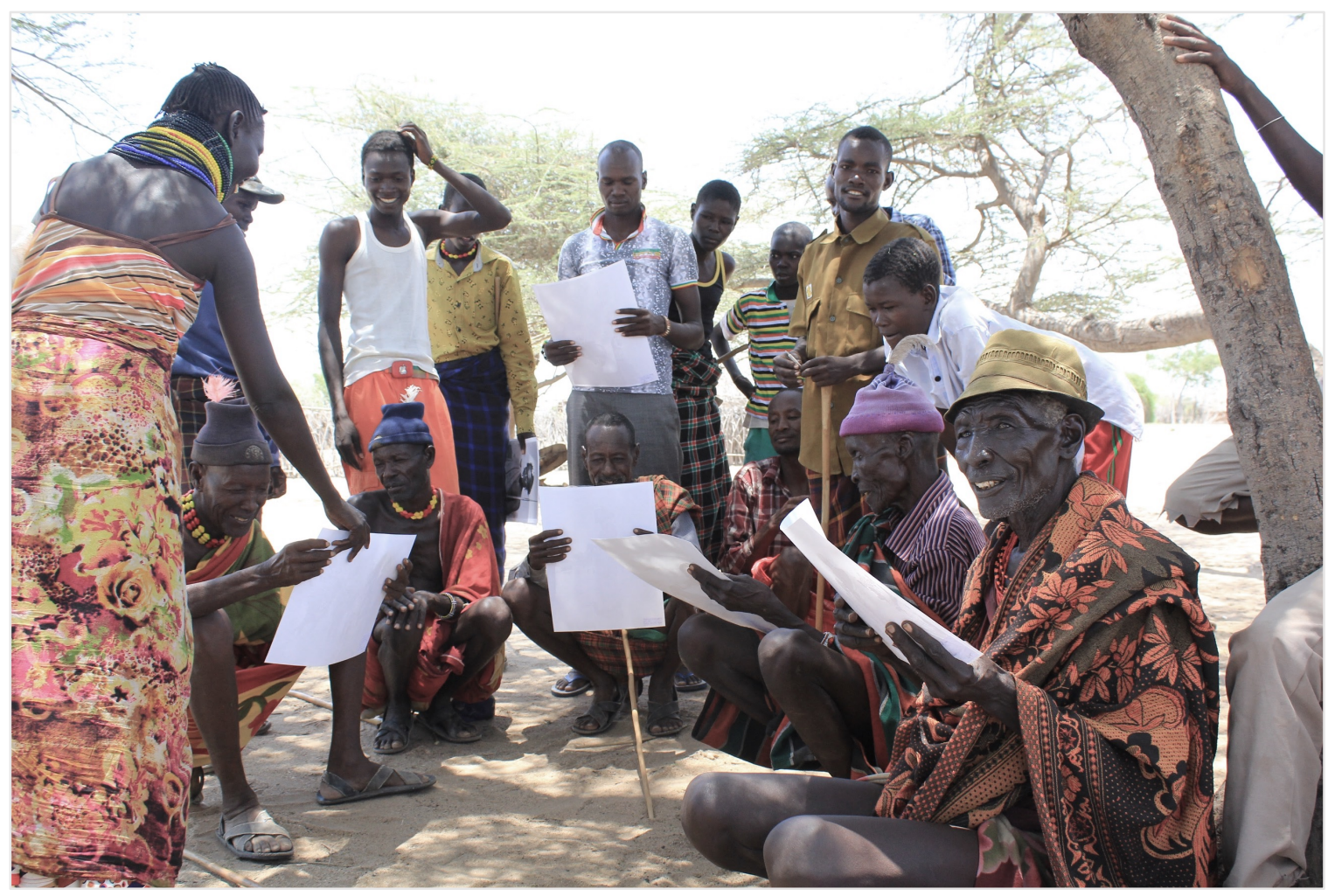

Kangarisae, September 2014

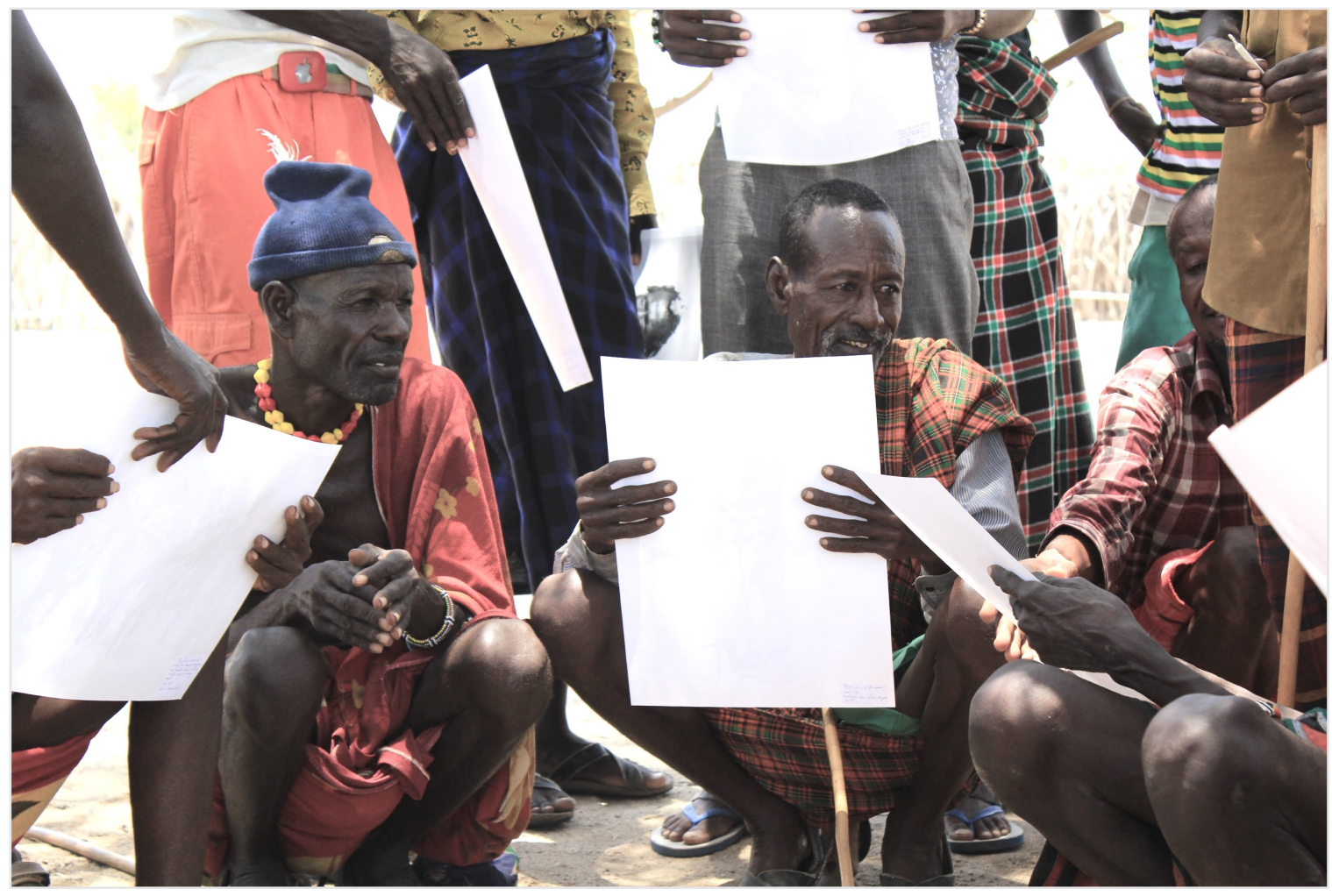

Kangarisae, September 2014 


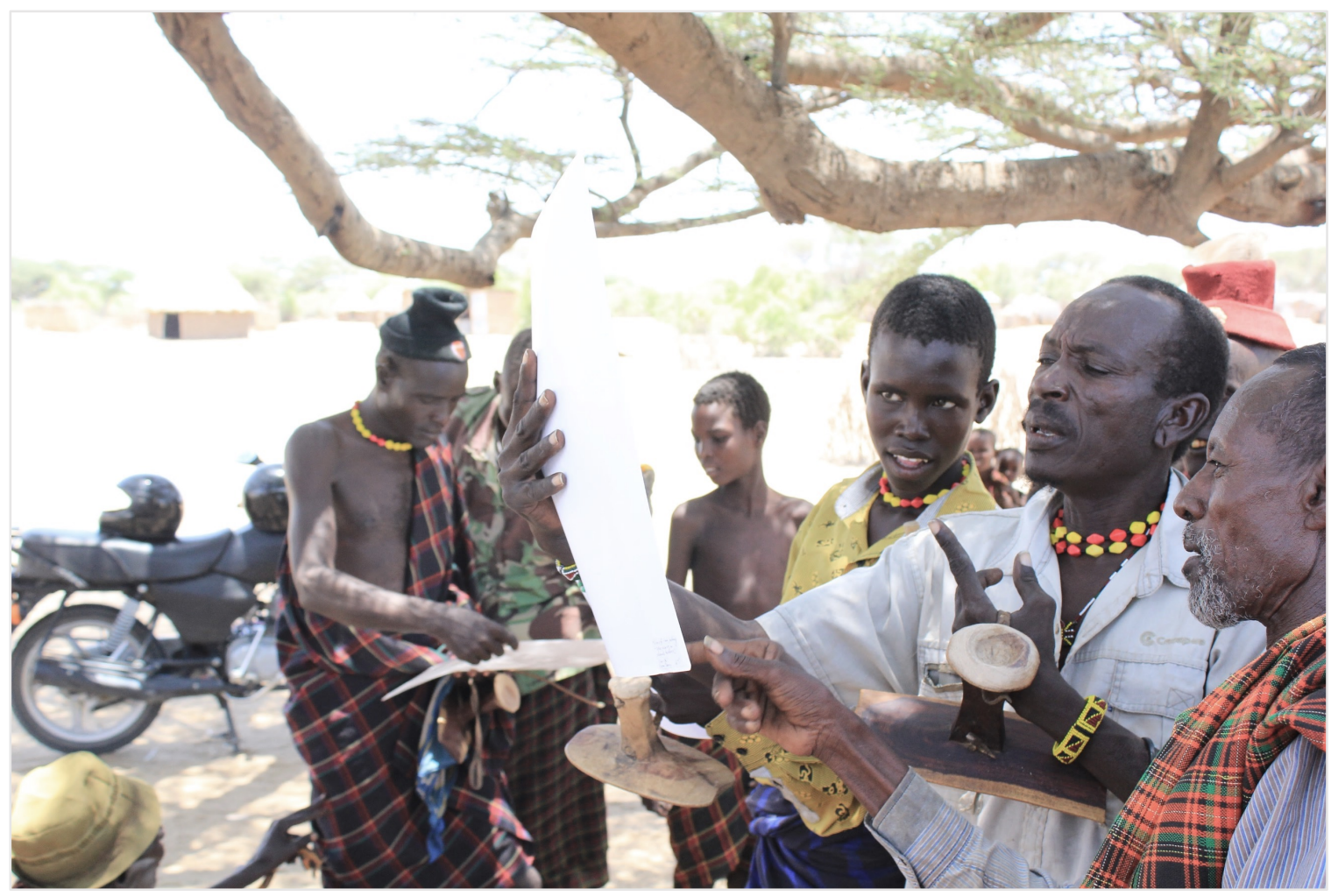

Kangarisae, September 2014

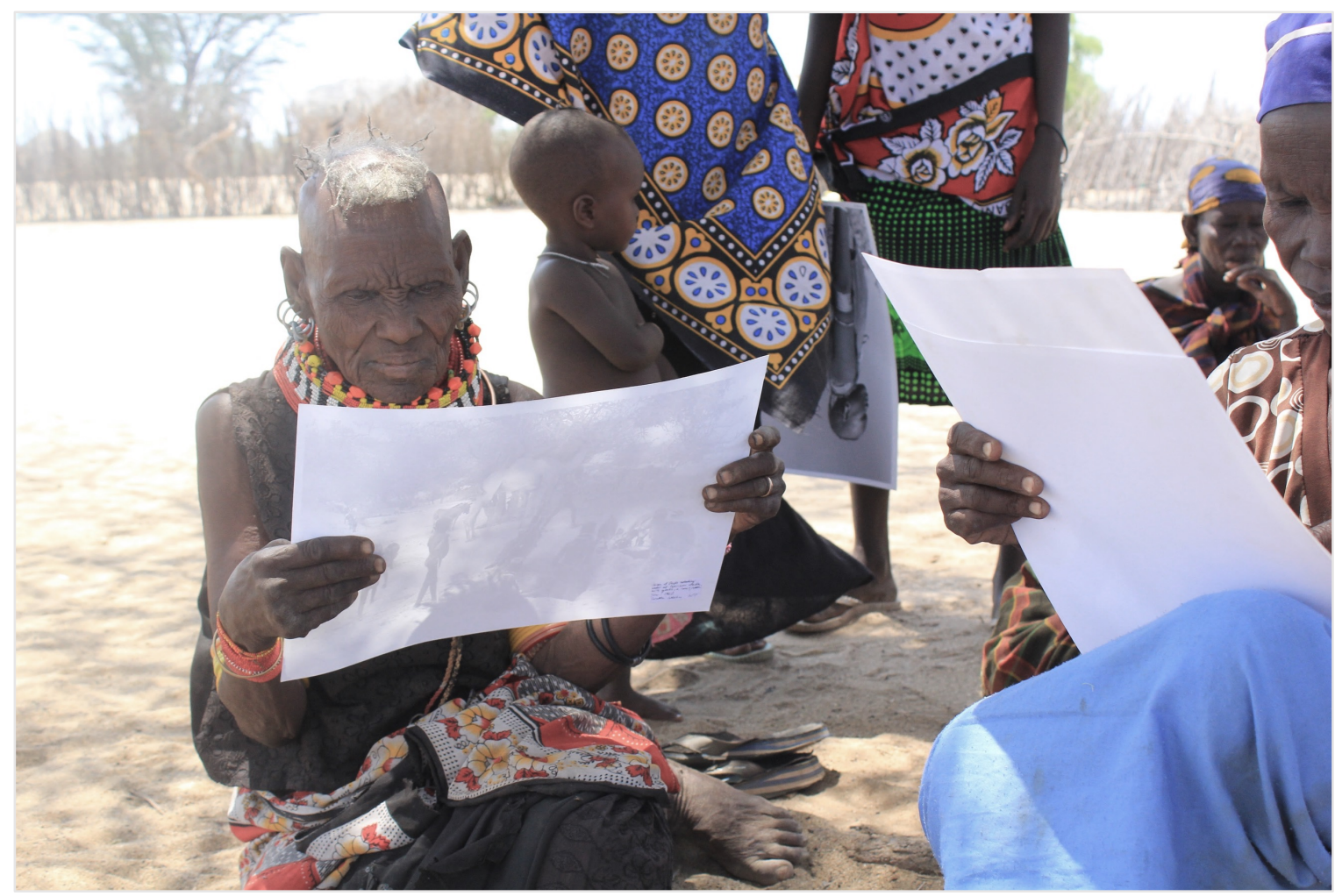

Kangarisae, September 2014. 